\title{
AS RELAÇÕES ENTRE A SATISFAÇÃO COM ASPECTOS PSICOSSOCIAIS NO TRABALHO E A SAÚDE DO TRABALHADOR
}

\section{MARIA CARMEN MARTINEZ}

Dissertação de Mestrado apresentada ao Departamento de Saúde Ambiental da Faculdade de Saúde Pública da Universidade de São Paulo para obtenção do Grau de Mestre

Área de concentração: Saúde Ambiental

Orientador: Profa. Dra. Ana Isabel Bruzzi Bezerra Paraguay

São Paulo 
Autorizo, exclusivamente para fins acadêmicos e científicos, a reprodução total ou parcial desta dissertação, por processos fotocopiadores.

Assinatura:

Data: 
... A gente não quer só comer

A gente quer prazer pra aliviar a dor

A gente não quer só dinheiro

A gente quer dinheiro e felicidade

A gente não quer só dinheiro

A gente quer inteiro e não pela metade ...

Arnaldo Antunes 


\section{AGRADECIMENTOS}

A primeira pessoa a quem devo agradecer é a Sergio Candio, não só por ter possibilitado a realização deste estudo gerenciando e liberando trâmites administrativos e burocráticos, mas por me incentivar e apoiar, ao longo destes anos, a estudar, criar e a buscar novos desafios e alternativas e, principalmente, pelo seu exemplo profissional competente e arrojado, e pela sua presença sempre íntegra, honesta, entusiasta e amiga.

Não posso deixar de lembrar de Maurício Machado Fonseca por ter me aberto as portas para o mundo da saúde do trabalhador e por, também ao longo destes anos, sempre cobrar, apoiar, incentivar, questionar e auxiliar na busca do desenvolvimento de um trabalho sério, ético e produtivo.

À Profa. Dra. Ana Isabel B. B. Paraguay quero agradecer por me auxiliar a entender os caminhos do método científico e a fazer crescer a motivação e a curiosidade para a pesquisa.

Quero agradecer à Profa. Dra. Maria do Rosário D. O. Latorre, não só pela preciosa assessoria na análise estatística dos dados deste estudo, mas por ter me introduzido no instigante conhecimento da bioestatística e da epidemiologia, demonstrando que os caminhos do ensino e aprendizagem são divertidos, desafiadores, exigentes e podem ser cheios de carinho e de vida.

Finalmente, e em especial, agradeço aos empregados da Fundação CESP que, de forma sempre gentil, disponível e solícita, colaboraram e participaram em todas etapas desta pesquisa fazendo com que ela pudesse existir.

Não vou citar mais nomes pois corro o risco de ser injusta esquecendo alguém, mas quero agradecer a todos que, de alguma forma, colaboraram, apoiaram e deram forças e condições para este trabalho chegar até seu final. 


\section{RESUMO}

Martinez MC. As relações entre a satisfação com aspectos psicossociais no trabalho e a saúde do trabalhador. São Paulo; 2002. [Dissertação de Mestrado Faculdade de Saúde Pública da USP].

Objetivo. Este estudo pretendeu colaborar com a análise das relações entre satisfação com aspectos psicossociais no trabalho e saúde do trabalhador. Método. Realizou-se estudo transversal junto aos empregados de uma empresa de auto-gestão em saúde e previdência privada em São Paulo. O estudo incluiu três etapas: (a) 42 entrevistas exploratórias para verificar a semelhança entre referências da literatura com percepções dos empregados quanto ao conceito e às fontes de satisfação no trabalho; (b) questionários auto-aplicados respondidos por 224 empregados para análise das associações entre satisfação no trabalho e saúde: a escala Satisfação no Trabalho do Occupational Stress Indicator, o SF-36, e o Índice de Capacidade para o Trabalho; e (c) análise ergonômica de 43 postos de trabalho por meio da técnica AET - Análise Ergonômica do Trabalho de Rohmert e Landau, visando identificar aspectos da organização do trabalho interferindo na satisfação no trabalho. Resultados. As percepções dos empregados quanto ao conceito e fontes de satisfação no trabalho foram semelhantes aos conhecimentos da literatura adotada como referencial teórico. Satisfação no trabalho esteve associada com aspectos da saúde mental e com capacidade para o trabalho e estas associações ocorrem independentes de aspectos sócio-demográficos e funcionais. As condições e a organização do trabalho apresentaram características que podem configurar elevada carga mental no trabalho. Conclusões. Foram discutidas as relações entre satisfação no trabalho e saúde do trabalhdor e feitas considerações referentes a mudanças visando melhorias quanto aos aspectos psicossociais no trabalho, favorecendo a satisfação no trabalho e a saúde do trabalhador.

Descritores: satisfação no trabalho, fatores psicossociais no trabalho, análise ergonômica do trabalho, saúde mental, capacidade para o trabalho, saúde do trabalhador 


\section{SUMMARY}

Martinez MC. The relationships among satisfaction with psychosocial factors at work and the worker's health. São Paulo; 2002. Master dissertation - Faculdade de Saúde Pública - USP].

Objetive. This study intends to collaborate with the analysis of the relationships among satisfaction with psychosocial factors at work and the worker's health. Methods. It took place a cross-sectional study close to the employees of a selfadministration company in health and providence private. The study included three stages: (a) 42 exploratory interviews to verify the similarity among references of the literature with the employees' perceptions about the concept and sources of job satisfaction; (b) self-applied questionnaires answered by 224 employees for analysis of the associations among job satisfaction and health: the Job Satisfaction scale of the Occupational Stress Indicator - OSI, the SF-36, and the Work Ability Index; and (c) ergonomic analysis of 43 workstations by AET technique - Job Ergonomics Analysis of Rohmert and Landau, looking for identify spectos of work organization interfering on the job satisfaction. Results. The employees' perceptions about the concept and sources of job satisfaction are similar to the knowledge of the literature adopted as theoretical framework. Job satisfaction was associated with aspects of the workers' mental health, and with work ability, and this associations happens independent of social-demographic and functional aspects. The job conditions and organization presented characteristics that can configure high mental load at the work. Conclusions: the relationships among job satisfaction and worker's health were discussed, and made considerations regarding changes seeking improvements of the psychosical aspects at work, favoring job satisfaction and worker's health.

Descriptors: job satisfaction, psychosocial factors at work, job ergonomic analysis, mental health, work ability, worker's health 


\section{ÍNDICE}

1 - INTRODUÇÃ̃O

1.1 - DELIMITAÇÃO DO PROBLEMA …………………………....... 1

1.2 - SATISFAÇÃO NO TRABALHO ………………………………....

1.2 .1 - Conceitos

1.2.2 - Teorias sobre satisfação no trabalho …............................... 11

1.2.3 - Determinantes da satisfação no trabalho $\quad$............................ 30

1.2.4 - Conseqüências da satisfação no trabalho .......................... 33

1.3 - FATORES PSICOSSOCIAIS NO TRABALHO $\quad$........................ 34

1.3.1-Conceito

1.3.2 - Transformações no mundo todo trabalho, fatores

psicossociais no trabalho e conseqüências para a saúde do

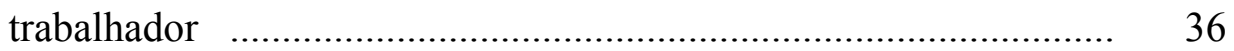

1.3.3 - Modelo teórico ................................................................. 40

1.4 - SAÚDE DO TRABALHADOR …............................................ 44

1.5 - RELAÇÕES ENTRE SATISFAÇÃO NO TRABALHO,

FATORES PSICOSSOCIAIS E SAÚDE DO TRABALHADOR .. 49

1.6 - REFERENCIAL TEÓRICO DO ESTUDO ................................. 52

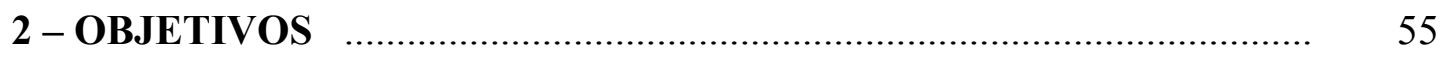

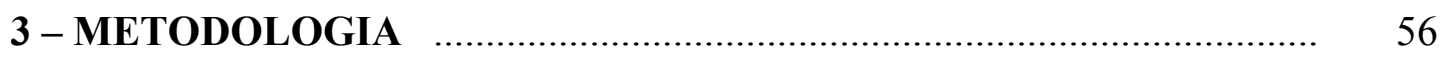

3.1 - HIPÓTESES ....................................................................... 56

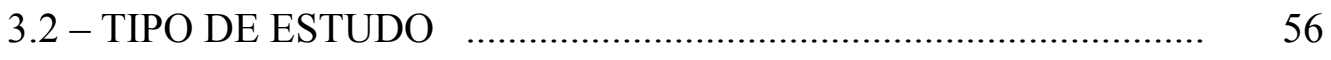

3.3 - ESTRATÉGIAS PARA COLETA E ANÁLISE DE DADOS ....... 57

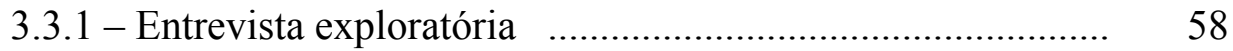

3.3.2 - Questionários auto-aplicados $\quad$........................................ 61

3.3.3 - Análise ergonômica do trabalho ….................................... 79

3.3.4 - Etapas da coleta de dados $\quad$................................................ $\quad 84$ 
4 - RESULTADOS

4.1 - ENTREVISTA EXPLORATÓRIA …........................................ 88

4.2 - QUESTIONÁRIOS AUTO-APLICADOS ….............................. 94

4.2.1 - Confiabilidade dos instrumentos ....................................... 94

4.2 .2 - Análise das perdas ......................................................... 96

4.2.3 - Caracterização da população de estudo ............................... 99

4.2.4 - Análise das associações .................................................... 105

4.2.5 - Análise de regressão $\quad$....................................................... 110

4.3 - ANÁLISE ERGONÔMICA DO TRABALHO $\quad$............................ 112

4.3.1 - Representatividade da amostra $\quad$........................................ 112

4.3.2 - Análise dos postos de trabalho ……............................... 114

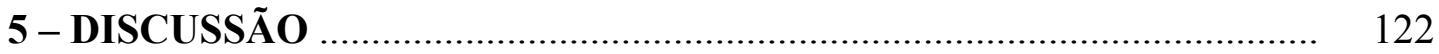

5.1 - TAXA DE RESPOSTA E REPRESENTATIVIDADE DA

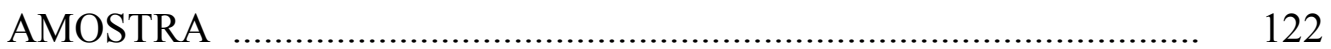

5.2 - ENTREVISTA EXPLORATÓRIA …......................................... 125

5.3 - CONFIABILIDADE DOS QUESTIONÁRIOS

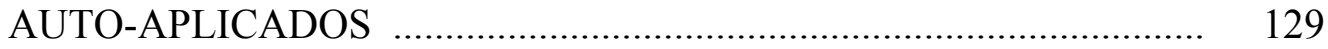

5.4 - PREVALÊNCIAS DE SATISFAÇÃO NO TRABALHO $\quad$............. 131

5.5 - RELAÇÕES ENTRE SATISFAÇÃO NO TRABALHO E

CARACTERÍSTICAS SÓCIO-DEMOGRÁFICAS E FUNCIONAIS ... 138

5.6 - RELAÇÕES ENTRE SATISFAÇÃO NO TRABALHO E

SAÚDE

5.6.1 - Satisfação no trabalho e componentes da saúde física e da saúde mental

5.6.2 - Satisfação no trabalho e capacidade para o trabalho

5.7 - SATISFAÇÃO NO TRABALHO E ORGANIZAÇÃO DO

TRABALHO 
9 - ANEXOS

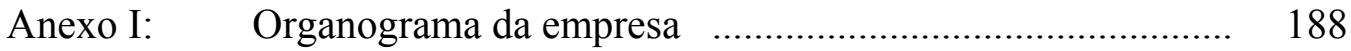

Anexo II: $\quad$ Competências das áreas de trabalho .................................. 189

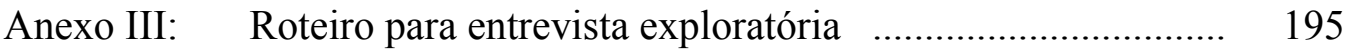

Anexo IV: $\quad$ Propriedades de medida de um questionário $\quad$..................... 196

Anexo V: $\quad$ Questionário 1 - Identificação .......................................... 200

Anexo VI: Questionário 2 - Escala Satisfação no Trabalho do OSI Occupational Stress Indicator ......................................... 201

Anexo VII: Questionário 3 - SF 36 - versão em português do Medical Outcomes Study 36-Item short form health survey ........ 203

Anexo VIII: Questionário 4 - ICT - Índice de Capacidade para o Trabalho

Anexo IX: Glossário de termos estatísticos

Anexo X: Roteiro para análise ergonômica do trabalho

Anexo XI: Termo de consentimento

Anexo XII: Cronograma de trabalho

Anexo XIII: Distribuição dos níveis de satisfação no trabalho

Anexo XIV: Teste de normalidade das variáveis

Anexo XV: Resumo da distribuição dos resultados da análise ergonômica do trabalho 


\section{LISTA DE TABELAS, GRÁFICOS, QUADROS E FIGURAS}

Tabela 1: Distribuição dos usuários dos serviços gerenciados pela Fundação CESP, segundo situação funcional e área geográfica, Fundação CESP, 2001

Figura 1: Interações entre fatores do ambiente psicossocial e saúde

Tabela 2: Resumo das possíveis interpretações dos resultados do SF-36 para cada uma de suas escalas

Tabela 3: Valores do Coeficiente Alfa de Cronbach do questionário "Satisfação no Trabalho" (Escala Satisfação no Trabalho do OSI), segundo item excluído e para o módulo completo, Fundação CESP, 2001

Tabela 4: Valores do Coeficiente Alfa de Cronbach do questionário SF-36, segundo componente (saúde física e saúde mental), item excluído, e escalas completas, Fundação CESP, 2001

Tabela 5: Valores do Coeficiente Alfa de Cronbach do questionário “Índice de Capacidade para o Trabalho" (ICT), segundo item excluído e para o módulo completo, Fundação CESP, 2001

Tabela 6: Análise das correlações entre população de estudo e perdas, segundo característica sócio-demográfica, Fundação CESP, 2001

Tabela 7: Análise das correlações entre população de estudo e perdas, segundo característica funcional, Fundação CESP, 2001

Tabela 8: Distribuição do número e porcentagem de empregados segundo característica sócio-demográfica, Fundação CESP, 2001

Tabela 9: Distribuição do número e porcentagem de empregados segundo característica funcional, Fundação CESP, 2001 
Gráfico 1: Distribuição (\%) dos empregados, segundo nível da satisfação e 103 aspecto do trabalho, Fundação CESP, 2001

Gráfico 2: Distribuição $\left(\mathrm{N}^{\circ}\right)$ dos empregados no escore de saúde, segundo componente da saúde, Fundação CESP, 2001

Tabela 10: Distribuição do número e porcentagem de empregados segundo componente da saúde e parâmetro populacional, Fundação CESP, 2001

Tabela 11: Distribuição do número e porcentagem de empregados segundo índice de capacidade para o trabalho, Fundação CESP, 2001 .....

Tabela 12: Correlação entre satisfação no trabalho e variáveis quantitativas sócio-demográficas e funcionais , Fundação CESP, 2001

Tabela 13: Média, desvio-padrão (DP), máxima e mínima, e associação entre satisfação no trabalho e variáveis qualitativas sóciodemográficas, Fundação CESP, 2001

Tabela 14: Média, desvio-padrão (DP), máxima e mínima e associação entre satisfação no trabalho e variáveis qualitativas funcionais, Fundação CESP, 2001

Tabela 15: Média, desvio-padrão (DP), máxima e mínima entre satisfação no trabalho e área de trabalho, Fundação CESP, 2001

Tabela 16: Correlação entre satisfação no trabalho e saúde, Fundação CESP, 2001

Tabela 17: Análise das correlações entre satisfação no trabalho (ST), saúde e variáveis sócio-demográficas e funcionais, Fundação CESP, 2001

Tabela 18: Análise das correlações entre participantes da análise ergonômica do trabalho e não participantes, segundo características sócio-demográficas, Fundação CESP, 2001

Tabela 19: Análise das correlações entre participantes da análise ergonômica do trabalho e não participantes, segundo características funcionais, Fundação CESP, 2001 
Gráfico 3: Distribuição do percentual de empregados em situação de exposição às principais fontes de estresse relacionadas ao sistema de trabalho, Fundaçào CESP, 2001

Gráfico 4: Distribução do percentual de epregados em situação de exposição ao estresse decorrente da magnitude da importância da tarefa, Fundação CESP, 2001

Gráfico 5: Distribuição do percentual de empregados em situação de exposição às principais fontes de estresse relacionadas às exigências do trabalho, Fundação CESP, 2001

Tabela 20: Prevalência de satisfação no trabalho em alguns estudos nacionais e internacionais 


\section{1 - INTRODUÇÃO}

\section{1 - DELIMITAÇÃO DO PROBLEMA}

O acentuado processo de globalização que vem ocorrendo nas últimas décadas é caracterizado pela revolução tecnológica (intensivo desenvolvimento das telecomunicações e da informática), pela desterritorialização (descentralização geográfica da produção), pelo domínio do conhecimento (domínio da tecnologia e do conhecimento científico pelos países industrializados), pela concentração e centralização do capital (entre os que detêm a informação tecnológica) e tem como uma de suas conseqüências a acentuação do processo de desigualdade social (RIGOTTO 1998; RAPÔSO e MATOS “sd”).

Na busca de adequação a esta nova ordem mundial, o Brasil estabeleceu uma diretriz de reforma do Estado onde a mudança que mais avançou foi o processo de privatização das empresas públicas com passagem do controle das mãos do Estado para a iniciativa privada (ALMEIDA 1999; RAPÔSO e MATOS “sd”).

Estudos (SELIGMANN-SILVA 1994a; RIGOTTO 1998; KANTORSKI 1997; LINO e DIAS “sd") apontam várias situações decorrentes da globalização e/ou privatização que têm impactos sobre a saúde dos trabalhadores. Algumas dessas situações são: exigências crescentes de trabalhadores com maior qualificação e escolaridade, difusão das novas tecnologias, desemprego e sub-emprego (empregos temporários, em tempo parcial ou terceirizados e a economia informal), retrocessos nos direitos e conquistas dos trabalhadores, relações de trabalho mais competitivas e conflituosas, aumento do tempo e/ou intensidade de exposição a agentes de risco ambientais, incluindo os riscos relacionados às doenças ósteo-articulares, aumento do ritmo e intensidade do trabalho em funcionários remanescentes após demissões, acúmulo e/ou desvio de funções, maior exigência de iniciativa, criatividade e comprometimento por parte do trabalhador, intensificação de formas de dominação, 
seja por métodos autoritários ou pela introdução de estratégias de gestão que levem à cooperação por parte dos trabalhadores. Uma outra situação que tem sido apontada é o medo da demissão, que pode gerar aumento da competitividade nas relações humanas e sentimentos de insegurança quanto ao futuro e de impotência, decorrente da submissão pelo temor de perda do emprego (RIGOTTO 1998; SELIGMANNSILVA 1994a).

Todas estas situações configuram fatores psicossociais do trabalho que podem gerar sobrecargas de trabalho físicas e mentais que trazem conseqüências para a satisfação, saúde e bem-estar dos trabalhadores.

Neste sentido, é importante ressaltar que a população de estudo desta pesquisa foi composta pelos 288 empregados da Fundação CESP. Esta é uma empresa que está em processo bastante avançado de reestruturação, mas que ainda não foi concluído, e este é um fator que tem sido sinalizado informalmente pelos empregados como fonte de preocupação e de insegurança quanto ao futuro.

A Fundação CESP é uma entidade privada que realiza a administração e gerenciamento dos planos de previdência privada e de saúde para os empregados (e seus dependentes) ativos e aposentados de 15 empresas do setor eletricitário do Estado de São Paulo e que tem como provedoras estas empresas.

Ela foi criada em 1969 como Fundação de Assistência aos Empregados da CESP Companhia Energética de São Paulo e, progressivamente, foi assumindo a gestão da assistência de saúde e dos planos previdenciários de outras empresas estatais do setor eletricitário. Atualmente os serviços gerenciados pela Fundação CESP atendem usuários que estão distribuídos no Estado de São Paulo (capital e interior) e nos demais estados do país, em um total de 157.252 vidas, entre empregados ativos e seus dependentes, empregados aposentados e seus dependentes e, ainda, dependentes designados (familiares até $3^{\circ}$ grau de parentesco com o titular do plano) ou aposentados (tabela 1). 
Tabela 1: Distribuição dos usuários dos serviços gerenciados pela Fundação CESP segundo situação funcional e área geográfica, Fundação CESP, 2001.

\begin{tabular}{|c|c|c|c|c|c|c|c|c|}
\hline \multirow{2}{*}{$\begin{array}{l}\text { Área geográfica } \\
\text { Situação funcional }\end{array}$} & \multicolumn{2}{|c|}{$\begin{array}{l}\text { São Paulo } \\
\text { Capital }\end{array}$} & \multicolumn{2}{|c|}{$\begin{array}{l}\text { São Paulo } \\
\text { Interior }\end{array}$} & \multicolumn{2}{|c|}{$\begin{array}{l}\text { Demais } \\
\text { Estados }\end{array}$} & \multicolumn{2}{|c|}{ Total } \\
\hline & $\mathrm{N}^{\mathrm{o}}$ & $\%$ & $\mathrm{~N}^{\mathrm{o}}$ & $\%$ & $\mathrm{~N}^{\mathrm{o}}$ & $\%$ & $\mathrm{~N}^{\mathrm{o}}$ & $\%$ \\
\hline $\begin{array}{l}\text { Empregados } \\
\text { ativos e seus } \\
\text { dependentes }\end{array}$ & 19.473 & 29,32 & 45.702 & 68,82 & 1.236 & 1,86 & 66.411 & 100,0 \\
\hline $\begin{array}{c}\text { e seus } \\
\text { dependentes }\end{array}$ & 18.878 & 29,32 & 42.322 & 65,74 & 3.178 & 4,94 & 64.378 & 100,0 \\
\hline aposentados & 10.188 & 38,50 & 15.515 & 58,63 & 760 & 2,87 & 26.463 & 100,0 \\
\hline Total & 48.539 & 30,87 & 103.539 & 65,84 & 5174 & 3,29 & 157.252 & 100,0 \\
\hline
\end{tabular}

Para gerenciar os planos de previdência privada e de saúde, os recursos financeiros dos quais a empresa dispõem provêm de 3 fontes: mensalidades e co-participações dos empregados ativos e aposentados, co-participações das empresas provedoras e rendimentos provenientes de um patrimônio próprio. Destas fontes, as empresas provedoras entram com um montante significativo de recursos.

Atualmente o quadro de pessoal da Fundação CESP tem seus empregados distribuídos nos níveis hierárquicos de diretoria, gerência, chefia, analistas, técnicos e auxiliares.

Para a gestão dos benefícios administrados pela Fundação CESP são desenvolvidas atividades que vão desde a identificação de necessidades (quantitativas e qualitativas) de alocação de recursos ou serviços, realização e manutenção de contratos com serviços de saúde, recebimento, conferência, processamento e pagamento dos gastos com os serviços de saúde e outros benefícios, auditoria de qualidade e financeira dos serviços prestados, até o acompanhamento e avaliação de qualidade e custos, revisão e remodelação dos planos oferecidos, passando por ações na área de comunicação, marketing e jurídica e desenvolvimento de programas na área de promoção da saúde. O Anexo I apresenta o organograma da empresa e o 
Anexo II apresenta uma síntese das competências das diversas áreas de trabalho da empresa.

No desenvolvimento dessas atividades, na Fundação CESP, alguns aspectos chamam a atenção:

- O relacionamento de empregados com os usuários de serviços e benefícios de saúde e previdência envolve, freqüentemente, um forte componente emocional por parte dos usuários. Isso ocorre porque, muitas vezes, esse contato se dá em situações de doença, óbito e/ou dificuldade financeira, onde os usuários e/ou familiares estão irritados, assustados, preocupados, tensos ou agressivos, podendo gerar dificuldades no relacionamento interpessoal.

- O relacionamento interpessoal dos empregados com prestadores de serviços também pode apresentar conflitos em decorrência de glosas de pagamentos, erros no processamento e efetivação de pagamentos de serviços prestados, descredenciamentos ou, ainda, dificuldades de entendimento de rotinas administrativas.

- A distribuição geográfica fragmentada de usuários e prestadores de serviços gera dificuldades de comunicação, de atendimento rápido de necessidades e de acompanhamento de situações de saúde, de qualidade ou administrativas.

- A existência de deficiências no sistema de informações (software atualmente em uso), a quantidade de atividades administrativas e a existência de fluxos de procedimentos e de rotinas conflitantes ou ainda indefinidos podem acarretar complexidades burocráticas, duplicidade de ações e situações imprevistas.

- A existência de 15 diferentes empresas patrocinadoras implica no atendimento de diferentes necessidades gerenciais, operacionais, administrativas, políticas e econômicas na gestão dos benefícios de saúde e previdência exigindo um processo de trabalho que atenda de forma rápida, personalizada e flexível as diferentes demandas.

Embora sendo uma entidade privada, a Fundação CESP sempre esteve vinculada ao contexto político, econômico, organizacional e cultural de empresas estatais e é 
importante apresentarmos o contexto deste setor, pois é nele que a Fundação CESP está inserida.

O setor eletricitário é dividido em 3 grandes áreas de atividade: (1) geração de eletricidade (é a transformação da matéria prima em eletricidade), (2) transmissão (transmissão da eletricidade das usinas geradoras até as estações e sub-estações nos municípios) e (3) distribuição (transformação do potencial de energia recebido das unidades geradoras e distribuição dessa energia das estações e sub-estações aos usuários finais).

SERRANO (1999), relata que o processo de globalização determinou o surgimento de pressões competitivas e de modificações na política de gerência dos negócios do setor elétrico fazendo com que as empresas redirecionassem seus critérios de administração econômico-financeira e focassem aspectos relacionados à competitividade.

Neste cenário se dá o início do processo de privatização das concessionárias de energia elétrica principalmente por meio da compra de ativos onde, em geral, as empresas internacionais buscam parceiros nacionais. No âmbito federal, em 1992 foi iniciado o Programa de Desestatização - PND que conduziu o processo de reestruturação do setor e, em 1997, foi criada a Agência Nacional de Energia Elétrica - ANEEL com a finalidade de regular e fiscalizar a produção, transmissão, distribuição e comercialização de energia elétrica e de prover licitações destinadas à contratação de concessionárias (SEADE 2001).

Em São Paulo o processo de reestruturação e privatização do setor elétrico foi iniciado em 1996 e tem sua conclusão prevista para 2002, sendo conduzido pelo Programa Estadual de Desestatização (SEADE 2001). Neste processo, as três empresas estatais de origem (CPFL - Companhia Paulista de Força e Luz, ELETROPAULO - Empresa Paulista de Transmissão de Energia Elétrica S.A., e CESP - Companhia Energética de São Paulo) são cindidas e passam a ter como controladoras empresas de diferentes nacionalidades. Atualmente o setor eletricitário 
no Estado de São Paulo conta com 15 empresas, com controladoras de origem nacional (estatal e privadas), norte-americana, e portuguesa. A Fundação CESP, por ter como patrocinadoras estas empresas, tem o seu quadro hierárquico de direção e gerenciamento por elas definido.

Como conseqüência das exigências de adequação a esta nova realidade, o processo que ocorreu na Fundação CESP não diferiu das demais empresas brasileiras na luta por se firmarem no cenário de globalização: ele foi caracterizado pela reestruturação dos processos de trabalho e do quadro de pessoal. Nesta reestruturação - com redução do quadro de pessoal e reorganização técnica e operacional - ocorreu uma configuração na qual os empregados que permaneceram na empresa apresentam:

- insegurança quanto ao seu futuro na empresa, uma vez que esta reestruturação ainda não está completamente concluída;

- maior pressão de prazos e/ou diversidade de soluções visando realizar trabalho flexibilizado para atender demandas específicas de cada empresa patrocinadora;

- maior volume de trabalho em decorrência da ampliação do escopo de atividades e responsabilidades e/ou da diminuição do número de pessoas disponíveis para executar as atividades;

- uma ampliação no seu escopo de atuação, já que os empregados deixaram de executar atividades isoladas e passaram a estar envolvidos em processos mais abrangentes, tanto devido à diminuição do número de empregados como à introdução de novos processos de trabalho;

- maior qualificação técnico-educacional, visto que um dos critérios de avaliação dos empregados foi o nível de escolaridade e a qualificação profissional.

Em revisão bibliográfica realizada em fevereiro e atualizada no segundo semestre de 2001 utilizando as bases de dados MEDLINE, SciELO, LILACS, ProBE e DEDALUS, não foram encontrados estudos sobre os efeitos da globalização e da privatização em empregados de empresas de auto-gestão em saúde (que é o caso da população de estudo), embora os efeitos sobre os trabalhadores em geral venham sendo estudados. 
A importância deste estudo se justificada pela relevância que satisfação no trabalho parece exercer sobre os trabalhadores e pela possibilidade de auxiliar na compreensão de como se dá a associação entre demandas do trabalho, satisfação no trabalho e saúde do trabalhador em um contexto onde um processo de privatização recente exerce novas demandas de trabalho. Este estudo se propõe a estudar as associações entre satisfação no trabalho e saúde do trabalhador, esperando que os resultados e análises sejam utilizados para adoção de medidas preventivas e corretivas no ambiente psicossocial do trabalho, visando a promoção da saúde dos trabalhadores.

\section{2 - SATISFAÇÃO NO TRABALHO}

\subsection{1 - Conceitos}

Os estudos sistemáticos sobre satisfação no trabalho iniciaram-se na década de 30 (KLIJN 1998), e desde então têm despertado o interesse de estudiosos das áreas sociais, da psicologia e de outros profissionais da saúde.

Este interesse decorre da influência que a satisfação no trabalho pode exercer sobre o trabalhador, podendo afetar sua saúde física e mental, interferir no seu comportamento profissional e/ou social, com repercussões para a vida pessoal e familiar do indivíduo e para as organizações (LOCKE 1976; PÉREZ-RAMOS 1980; CURA 1994; ZALEWSKA 1999a, 1999b).

Satisfação no trabalho é um fenômeno complexo e de difícil definição. Uma parte desta dificuldade decorre do fato de satisfação no trabalho ser "um estado subjetivo e pessoal percebido pelo indivíduo como ocorrendo em seu favor" (FRASER 1983, p.23), implicando que uma situação ou evento pode ser considerada importante para 
a satisfação de um trabalhador não o sendo para outro ou sendo em menor medida. Outro fator apontado por FRASER (1983, p.24) a ser considerado é que satisfação no trabalho "não é um estado estático e está sujeito a influências e modificações por forças internas e externas ao ambiente de trabalho imediato" podendo ser modificada constantemente.

Esta dificuldade pode ser apreendida quando se foca a satisfação no trabalho como: "parte de um contínuo indefinido, um estado pessoal, oposto a um estado grupal, e seus objetivos variam de pessoa a pessoa, de circunstância para circunstância e ao longo do tempo na mesma pessoa. Além do mais, está, ao final, em função tanto do indivíduo como do trabalho, com conotações de bem-estar positivo que são consistentes somente com a realidade e realização provável de, no máximo, algumas poucas pessoas" (FRASER 1983, p. 56).

Devido a sua complexidade, a satisfação no trabalho tem sido definida de diferentes maneiras, dependendo do referencial teórico adotado pelo autor. As conceituações mais freqüentes referem-se a satisfação no trabalho como sinônimo de motivação, como atitude ou como estado emocional positivo havendo, ainda, os que consideram satisfação como o extremo oposto de insatisfação no trabalho, e os que consideram satisfação e insatisfação como fenômenos distintos.

Essas diferentes definições têm sido apontadas como determinantes de dificuldades ou falhas metodológicas em estudos sobre o assunto (PÉREZ-RAMOS 1980; CURA 1994). A seguir, procuramos estabelecer as diferenças entre estas definições:

\section{- Satisfação no trabalho como sinônimo de motivação:}

PÉREZ-RAMOS (1980) analisa que a confusão entre os termos "motivação" e "satisfação" tem sido considerada como causa de falhas na formulação de hipóteses e na seleção de instrumentos de medida em pesquisas, em especial nas destinadas a correlacionar satisfação no trabalho com produtividade. 
STEUER (1989) diferencia motivação de satisfação, pontuando que motivação manifesta a tensão gerada por uma necessidade e satisfação expressa a sensação de atendimento da necessidade.

\section{- Satisfação no trabalho como atitude:}

Por atitude entende-se a "disposição para atuar e assumir posição perante determinadas situações" (PÉREZ-RAMOS 1980, p.22) ou como a combinação de conceitos, informações e emoções que resultam em uma resposta favorável ou desfavorável com respeito a uma pessoa em particular, grupo, idéia, evento ou objeto e que, por serem derivadas de crenças, são poderosas influências sobre o comportamento e a aprendizagem (CAMPBELL 1999). Portanto, se levarmos em conta que atitudes são disposições para agir decorrentes de conceitos, informações e emoções, podemos considerar que algumas atitudes podem ser decorrentes da satisfação no trabalho mas não a sua definição.

\section{- Satisfação X insatisfação no trabalho:}

Alguns autores consideram satisfação e insatisfação no trabalho como os dois extremos de um mesmo fenômeno, sendo freqüentes estudos, como os de BEGLEY e CZAJKA (1993); ZALEWSKA (1999a); WRIGHT e CROPANZANO (2000); O'DRISCOLL e BEEHR (2000); ELOVAINIO et. al. (2000), que adotam uma medida de satisfação por meio de escalas que vão de um extremo de "muito satisfeito" até o extremo oposto de "muito insatisfeito".

Outros autores, como ARAÚJO (1985); CODA (1986) e PAULA (1990), optam por adotar a distinção entre satisfação e insatisfação estabelecida na Teoria da Motivação-Higiene. Nesta teoria (descrita no item 1.2.2 - Teorias sobre satisfação no trabalho), satisfação e insatisfação no trabalho são consideradas 
fenômenos distintos, de natureza diversa, onde insatisfação é determinada pela carência dos fatores extrínsecos ao trabalho ou "fatores de higiene" (remuneração, supervisão, ambiente de trabalho) e a satisfação é determinada pelos fatores intrínsecos ao trabalho ou "fatores motivadores" (relacionados ao conteúdo do trabalho e desafios das atividades) (HERZBERG 1971).

\section{- Satisfação no trabalho como estado emocional:}

HARRIS (1989, p.13) define satisfação no trabalho como "um sentimento experienciado pelo trabalhador em resposta à situação total do trabalho".

Para LOCKE (1969, 1976), satisfação no trabalho é um estado emocional agradável resultante da avaliação que o indivíduo faz de seu trabalho e resulta da percepção da pessoa sobre como o trabalho satisfaz ou permite satisfação dos seus valores importantes em relação a este trabalho.

Nesta conceituação observam-se os dois aspectos considerados como componentes da satisfação no trabalho: (a) um componente cognitivo, que se refere ao pensamento do indivíduo e as suas opiniões sobre o trabalho e (b) um componente afetivo ou emocional, que se refere a quão bem uma pessoa sente-se sobre um trabalho, sugerindo que a satisfação no trabalho é baseada parcialmente no que o indivíduo pensa e parcialmente no que o indivíduo sente (ZALEWSKA 1999a; WRIGHT e CROPANZANO 2000).

Para PÉREZ-RAMOS (1980) o conceito de satisfação no trabalho tem sido relacionado com a idéia de felicidade em um contexto que tem mais o sentido vivencial do que conceitual. Felicidade pode ser entendida como "primariamente uma experiência afetiva ou emocional onde indivíduos felizes sentem-se bem no sentido que experimentam uma boa quantidade de emoções positivas e, relacionadamente, menos emoções negativas" (WRIGHT e CROPANZANO 2000). 


\subsection{2 - Teorias sobre satisfação no trabalho}

O primeiro estudo sobre satisfação no trabalho data de 1920 (STEUER 1989). Desde então, a satisfação no trabalho vem sendo amplamente estudada sob diferentes enfoques metodológicos, sendo essa diversidade decorrente da variedade de referenciais teóricos existentes relacionados aos assunto. Foi elaborado, e é apresentado a seguir, um sumário das principais abordagens teóricas de interesse para o tema. Este sumário não pretende introduzir uma discussão sobre as teorias relacionadas à satisfação no trabalho mas, tão somente, ilustrar como se deu a evolução desta teorização.

\section{- Escola da Administração Científica:}

Com a Revolução Industrial e o advento da produção em massa surgiu a necessidade de que máquinas e homens se tornassem mais produtivos e eficientes. Buscando esses objetivos, no início do século XX, Taylor publica os Princípios da Administração Científica que foi fundamentada em quatro princípios: (1) substituição do critério individual do operário por uma ciência; (2) seleção e aperfeiçoamento científico dos trabalhadores; (3) cooperação íntima da administração com os trabalhadores; (4) divisão equânime das tarefas onde a administração encarrega-se das atribuições para as quais está mais bem aparelhada e os operários das restantes (TAYLOR 1995).

O primeiro critério tem como base o estudo de tempos e movimentos: o trabalho passa a ser desenvolvido mediante um padrão rígido pré-determinado para execução de tarefas repetitivas, retirando do trabalhador a possibilidade de controlar os processos e ritmo de trabalho. O segundo princípio prevê a seleção e utilização de operários adequados ao trabalho. No terceiro princípio está a idéia de que o trabalho organizado cientificamente daria lugar a uma cooperação e atuação conjunta e sem conflitos entre administrados e trabalhadores. No último princípio fica estabelecida a 
divisão social do trabalho cabendo à administração as atividades de planejamento e controle, e aos operários a execução das tarefas, determinando a separação entre trabalho intelectual e trabalho braçal.

Nesta escola também se destacaram Fayol e Ford. FAYOL (1971) considera que os princípios mais relevantes no gerenciamento são a divisão do trabalho, autoridade, disciplina, unidade de comando, unidade de direção, subordinação dos interesses pessoais aos interesses gerais, remuneração, centralização, hierarquia, ordem, eqüidade, iniciativa e espírito de unidade.

Para FAYOL (1971, p.39), “conceber um plano e assegurar seu sucesso é uma das mais vivas satisfações que o homem inteligente pode experimentar", e que "este poder de pensar e executar é chamado iniciativa”. Mas, dentro de uma visão mecanicista do homem, Fayol considera que, ao mesmo tempo em que é essencial encorajar e desenvolver a capacidade de iniciativa, esta iniciativa deve ser mantida sob o controle das chefias, onde "muito tato e alguma integridade são exigidos para inspirar e manter a iniciativa de todos, dentro dos limites impostos em respeito à autoridade e à disciplina" (FAYOL 1971, pg.39).

KANTORSKI (1997) relata que Ford estende as inovações tayloristas introduzindo as linhas de montagem e o processo de produção em série caracterizado pela rigidez, controle do trabalho e homogeneização. ARAÚJO (1985) chama a atenção para o fato de que este sistema de montagem fez desaparecer a habilidade manual necessária ao operário especializado, sendo que para Ford isso não consistia em nenhum problema uma vez que as pessoas prefeririam agir mecanicamente:

“Para ele (Ford) somente uma pequena quantidade de pessoas estava disposta a pensar e a ver no trabalho uma fonte de satisfação profissional onde se pode dar vazão às potencialidade criativas. A grande maioria, contudo preferia agir mecanicamente motivada por fatores extrínsecos fornecidos pelo meioambiente" (ARAÚJO 1985, p.16). 
A Escola da Administração científica não considera a existência dos fatores psicossociais do ambiente de trabalho na determinação da satisfação no trabalho e esta é vista unicamente como decorrente de recompensas salariais.

\section{- Escola das Relações Humanas:}

Esta escola surgiu nos anos 20 como uma reação à Administração Científica representando uma evolução da concepção mecanicista do homem para uma concepção mais progressista do indivíduo (ARAÚJO 1985).

MAYO (1959), em 1927, chefiou uma pesquisa para estudar a fadiga, os acidentes, a rotatividade do pessoal e o efeito das condições físicas do trabalho sobre a produtividade. Com base nos resultados da pesquisa, MAYO (1959) concluiu que as pessoas não são motivadas apenas pelo salário ou condições de trabalho, mas também pelo reconhecimento e pelo sentimento de pertencer a um grupo, onde as atitudes em relação ao trabalho são fortemente influenciadas pelo grupo.

MAYO (1959) introduziu questões relacionadas aos fatores sociais e psicológicos no estudo do trabalho:

"A colaboração humana no trabalho depende, para sua perpetuação, de um código social que regula as relações entre as pessoas e suas atitudes recíprocas. A insistência em um lógica de produção meramente econômica interfere no desenvolvimento do código social e, por conseguinte, faz surgir dentro do grupo um sentido de frustração humana. Esta frustração resulta na formação de um código social de nível mais baixo, e que se opõe à lógica econômica, trazendo conseqüências para a indústria e para o indivíduo" (MAYO 1959, p.117).

Esta escola representa uma evolução na teorização em relação à satisfação no trabalho, ao constatar que, na abordagem do trabalho e da produtividade, o ambiente social do trabalho e as necessidades psicológicas dos trabalhadores devem estar 
contemplados. PRADO et. al. (1985, p. 34) chamam a atenção para que "a partir das teses defendidas por Mayo, abriu-se um novo campo de pesquisas onde as necessidades psicológicas e sociais deveriam ser estudadas e entendidas, devido a sua importância para a consecução dos objetivos empresariais”.

\section{- Teoria da Hierarquia das Necessidades Humanas}

Nos anos 40 Maslow (1970) estruturou esta teoria que considera que as pessoas têm necessidades que são passíveis de serem hierarquizadas em cinco níveis ascendentes:

- Necessidades fisiológicas: são relacionadas à sobrevivência e homeostase do organismo - alimento, água, oxigênio, sexo, eliminações e outras.

- Necessidades de segurança: são necessidades de segurança tanto física como emocional, familiar e social e estão relacionadas à estabilidade, dependência, proteção, ausência de medo e ansiedade, ordem e lei.

- Necessidades sociais: referem-se às necessidades de relacionamento, afeição e amor, representadas pelo desejo de interagir socialmente, sendo estimado e aceito, de pertencer a um grupo, de amizade e de amor.

- Necessidades de estima: diz respeito às necessidades do indivíduo em conseguir a auto-estima e a estima de outros, de desenvolver sentimentos de confiança, valor, capacidade, poder, de ser útil e necessário. São, também, as necessidades ligadas ao prestígio, reputação, posição social, poder, reconhecimento, atenção e dignidade.

- Necessidades de auto-realização: dizem respeito ao desejo de autodesenvolviment, e à tendência dos indivíduos em tornar reais os seus potenciais.

A medida que as primeiras necessidades vão sendo satisfeitas vão surgindo as necessidades dos níveis seguintes até chegar às mais elevadas. Porém esta hierarquia não é rígida: necessidades mais elevadas podem surgir antes das mais básicas terem sido completamente satisfeitas, podendo estes níveis estarem interdependentes e justapostos (MALSOW 1970). 
PÉREZ-RAMOS (1980, p.49) ressalta que “o modelo teórico de Maslow é importante para compreender e para explicar o comportamento das pessoas na situação de trabalho, especialmente em termos de satisfação, enfatizando a tendência humana de progredir e ultrapassar os respectivos níveis da escala hierárquica”.

De acordo com esta teoria, pode-se inferir que o trabalho tem papel importante para os indivíduos na medida em que os aspectos psicossociais do trabalho favoreçam ou dificultem a satisfação de suas necessidades.

\section{- Teoria X - Teoria Y:}

Nos anos 60 McGregor descreve os dois principais modelos teóricos que sustentavam as políticas e práticas utilizados na gestão de recursos humanos das empresas: a Teoria X e a Teoria Y.

A Teoria X considera que o ser humano não gosta de trabalhar e, devido a esta característica, as pessoas precisam ser coagidas, vigiadas ou ameaçadas com castigos a fim de fazer os esforços que a empresa espera (MCGREGOR “sd”).

Discutindo a Teoria X à luz da Teoria das Necessidades Humanas, o autor argumenta que:

“as pessoas privadas de oportunidade para satisfazer no trabalho as necessidades que lhes são importantes comportam-se exatamente como podemos prever - com indolência, passividade, relutância em aceitar responsabilidades, resistência à inovações, disposição para ouvir demagogos, exigências injustificadas de vantagens econômicas" (MCGREGOR "sd", p.66).

Observando a falta de consistência e a inadequação da Teoria X, McGregor passa a descrever a Teoria $\mathrm{Y}$, na qual as causas para a indolência e falta de responsabilidade 
dos empregados devem ser procuradas nos métodos da organização e controle do trabalho (MCGREGOR “sd"). A Teoria Y é fundamentada nas seguintes idéias: o homem não sente aversão inerente pelo trabalho, o controle exterior e ameaça de castigo não são os únicos meios para suscitar esforços, o empenho no alcance dos objetivos é função das recompensas pelo êxito da tarefa, o homem busca responsabilidades, as pessoas têm ampla capacidade de imaginação e espírito criador, e as empresas usam apenas parcialmente as potencialidades intelectuais do homem (MCGREGOR “sd”).

Na Teoria Y o princípio fundamental é a integração entre os objetivos individuais e organizacionais, e MCGREGOR (“sd”, p.73) considera que "dependendo de condições evitáveis, o trabalho pode ser fonte de satisfação (e será feito voluntariamente), ou fonte de castigo (e, se possível, será evitado)".

\section{- Teoria da Motivação-Higiene:}

Em 1959 Herzberg estrutura um modelo no qual satisfação e insatisfação são fenômenos de natureza diversa.

A insatisfação é determinada pela carência ou deficiência de "fatores de higiene" que são aqueles relacionados ao salário, supervisão, política e administração da empresa, relações interpessoais e condições de trabalho. Por serem externos ao indivíduo são chamados de fatores extrínsecos (HERZBERG 1971).

A satisfação é determinada pela existência de "fatores motivadores" considerados efetivos na motivação dos indivíduos para um esforço e desempenho superior, e compreendem realização, reconhecimento, conteúdo do trabalho, responsabilidade e crescimento profissional. Por estarem relacionados às necessidades de autorealização e de desenvolvimento pessoal são chamados fatores intrínsecos (HERZBERG 1971). 
Esta teoria recebeu críticas relacionadas à falta de consistência empírica para a divisão dos aspectos do trabalho como intrínsecos ou extrínsecos e para a separação de satisfação e insatisfação como eventos distintos (LOCKE 1969, 1976). LOCKE e WHITING (1974) e LOCKE (1976) relatam que alguns de seus estudos e de outros autores identificaram aspectos classificados por Herzberg como motivadores (relacionados ao conteúdo do trabalho) e outros classificados como de higiene (remuneração, condições de trabalho, políticas da empresa e relações interpessoais) sendo responsáveis tanto pela satisfação como pela insatisfação no trabalho, ou seja, a mesma classe de eventos é responsável tanto por satisfação como por insatisfação, não dando suporte à concepção de dois contínuos unipolares independentes (um pertencendo à satisfação e outro à insatisfação).

Um outro aspecto apontado por LOCKE (1976) é que Herzberg não considera a existência de diferenças entre empregados no relato de fontes de satisfação e insatisfação no trabalho. Segundo LOCKE (1976), embora seja possível defender que todos os homens têm as mesmas necessidades, não é possível defender que tenham os mesmos valores e - uma vez que os valores dos indivíduos são os principais determinantes de suas reações emocionais no trabalho - estes diferentes valores não podem ser desconsiderados na avaliação das fontes de satisfação e insatisfação.

Apesar das críticas, esta teoria tem sido amplamente utilizada no estudo da satisfação no trabalho, podendo ser encontrada em estudos como os de ARAÚJO (1985), CODA (1986) e PAULA (1990).

PÉREZ-RAMOS (1980, p.54) ressalta que a principal colaboração desta teoria se deu no campo dos

“.... programas de 'enriquecimento do trabalho', os quais se baseiam especialmente no aumento planejado de responsabilidades e no desafio do trabalho, a fim de desenvolver ao máximo as capacidades e motivações do indivíduo. Dessa forma, o empregado terá oportunidade de alcançar o nível mais alto de satisfação no seu trabalho". 


\section{- Teoria da expectância:}

Para VROOM (1967) a motivação é resultado de um comportamento decorrente de um campo de forças que têm direção e magnitude, onde uma força é a combinação de expectâncias e valências. Expectância é uma associação ação-resultado, é a probabilidade de que uma ação será seguida por um resultado, e valência é uma orientação afetiva em relação a um resultado específico, é a percepção da satisfação antecipada por um resultado (VROOM 1967). Este modelo também aborda o conceito de instrumentalidade que é uma associação resultado-resultado, é a crença de que um primeiro resultado obtido é condição necessária e suficiente para obter um segundo resultado (VROOM 1967).

Esta teoria sustenta que desejos e expectativas conscientes do indivíduo são mais importantes do que seus impulsos ou necessidades inconscientes. Há um processo cognitivo com raciocínio lógico para tomar decisões onde o indivíduo pondera a soma das valências e a probabilidade de êxito e é este processo que determina a motivação (PÉREZ-RAMOS 1980; STEUER 1989).

Para VROOM (1967), a valência de um trabalho é função do produto das valências de todos os outros resultados que possam ser obtidos, e da concepção de instrumentalidade que este trabalho tem para o alcance desses resultados. Assim, a extensão da satisfação no trabalho está diretamente relacionada com a extensão pela qual o trabalho é instrumental para o alcance de objetivos considerados atrativos para o indivíduo (VROOM 1967).

\section{- Teoria da Imaturidade-Maturidade:}

Esta teoria foi formulada por Argyris nos anos 60 e 70 e considera que as estruturas das organizações são fontes de bloqueio para a capacidade e realização dos empregados. A estrutura formal, os controles administrativos e a liderança impositiva 
estabelecem métodos para garantir a ordem e eficiência desejadas pelas organizações, buscando adaptar o homem ao trabalho e funcionando como fontes de bloqueios para o desenvolvimento das potencialidades e capacidades dos empregados, mantendo-os imaturos e frustrados quanto ao alcance de seus objetivos (ARGYRIS 1969).

ARGYRIS (1969) considera que a adaptação dos empregados à estrutura formal da empresa se manifesta por meio do crescimento da produção e da identificação do empregado com a organização e tem como conseqüências aumento do desgaste, enfermidade, desinteresse no trabalho e aumento da importância atribuída aos aspectos financeiros.

O autor propõe mudanças nas organizações que possibilitem o desenvolvimento de tarefas enriquecidas e motivadoras, favorecendo a participação, o desenvolvimento e o uso de potencialidades, possibilitando ao empregado partir de um estado de imaturidade para a maturidade (ARGYRIS 1969)

PÉREZ-RAMOS (1980, p.61) considera que nesta proposta de mudanças organizacionais "está implícita a idéia do homem valorizado e identificado com os objetivos da organização, possibilitando, desta maneira, alto grau de satisfação no trabalho e maior produtividade".

\section{- Psicodinâmica do Trabalho:}

Esta disciplina tem suas bases na teoria psicanalítica e na psicopatologia do trabalho, e se desenvolveu nas décadas de 80 e 90 a partir dos estudos de Dejours da análise psicodinâmica das situações de trabalho (SELIGMANN-SILVA 1994b).

Para DEJOURS (1987) o sofrimento começa quando a relação homem-organização do trabalho está bloqueada. Assim, a organização do trabalho é, por um lado a divisão do trabalho (divisão de tarefas, repartição, cadência, tempo prescrito) e, por 
outro lado a divisão dos homens (responsabilidade, hierarquia, comando, controle) (DEJOURS e ABDOUCHELI 1994), e a organização do trabalho define o conteúdo das tarefas e das relações humanas de trabalho, onde o trabalhador é forçado a agir conforme a vontade de outro (DEJOURS 1994). A divisão das tarefas modularia o sentido e o interesse do trabalho para o indivíduo, enquanto a divisão dos homens modularia as relações entre as pessoas e mobilizaria a afetividade e, desta forma, a organização do trabalho atuaria ao nível do funcionamento psíquico (DEJOURS e ABDOUCHELI 1994).

Segundo DEJOURS (1994) o trabalho torna-se perigoso para o aparelho psíquico quando ele se opõe à livre atividade, quando a liberdade para organização do trabalho é limitada opondo-se aos desejos do trabalhador, gerando aumento da carga psíquica e abrindo espaço para o sofrimento no trabalho. Dejours aborda o sofrimento no trabalho por meio da Psicodinâmica do Trabalho que parte da noção de carga psíquica para explicar este sofrimento. Carga psíquica do trabalho diz respeito aos elementos afetivos e relacionais da carga mental do trabalho, onde a carga mental compreende fenômenos de ordem neurofisiológica e psicológica (DEJOURS 1994).

Segundo este autor, quando o indivíduo vive situações de tensão ele dispõe de vias de descarga desta energia. Essas vias são de natureza psíquica, motora e visceral. Pela via psíquica o indivíduo tomado pela hostilidade pode produzir fantasias agressivas (fantasmas) suficientes para descarregar a tensão interior. Pela via motora o indivíduo tem descargas psicomotoras ou comportamentais onde utiliza a musculatura por meio de fuga, crise de raiva motora, atuação agressiva ou violência para obter alívio da tensão. Pela via visceral a energia pulsional é descarregada via sistema nervoso autônomo com processos de somatização (DEJOURS 1994).

Para este autor o bem-estar, em matéria de carga psíquica, é decorrente da existência de um sentido atribuído ao trabalho executado. Quando o trabalho não permite o uso suficiente das atividades psíquicas fantasmáticas ou psicomotoras, ele retém a tensão constituindo a carga psíquica de trabalho. Se um trabalho é livremente escolhido e 
organizado ele oferece vias de descarga da carga psíquica e é um trabalho equilibrante. Se ele não permite a descarga da energia psíquica acumulada, tornandose fonte de tensão e desprazer, a carga psíquica cresce até que surge a fadiga e, a partir daí, a patologia, é o trabalho fatigante (DEJOURS 1994).

Quando o trabalho permite o alívio da carga psíquica ele é um instrumento de equilíbrio e fonte de prazer para o trabalhador. Quando não permite, ele dá origem ao sofrimento e à patologia. $\mathrm{O}$ sofrimento é considerado uma vivência subjetiva intermediária entre a doença mental descompensada e o bem-estar psíquico., implicando em um estado de luta contra as forças que o empurram em direção a doença mental (DEJOURS e ABDOUCHELI 1994). DEJOURS (1994) salienta que, desta forma, a questão deve ser enunciada em termos de identificar quais os componentes do trabalho que se opõem à descarga de energia, que travam o livre jogo do sistema "motivação-satisfação" (ou desejo-prazer).

DEJOURS (1987) considera a insatisfação no trabalho como uma das formas fundamentais de sofrimento do trabalhador, onde esta insatisfação está relacionada ao conteúdo significativo da tarefa, podendo ser decorrente de sentimentos de indignidade pela obrigação de realizar uma tarefa desinteressante e sem significado, de inutilidade por desconhecer o que representa seu trabalho no conjunto das atividades na empresa, e de desqualificação tanto em função de questões salariais como de questões ligadas à valorização do seu trabalho no que diz respeito a aspectos como responsabilidade, risco ou conhecimentos necessários.

\section{- Teoria de Locke sobre Satisfação no Trabalho:}

Este modelo foi concebido e desenvolvido por Locke a partir dos anos 70. Segundo PÉREZ-RAMOS (1990), o modelo tem seu fundamento na concomitância dos "valores" (importância que a pessoa atribui à meta que deseja alcançar) e das "metas" (o objetivo desejado), que são os impulsores que levam o indivíduo a agir 
(desempenho), obtendo resultados (satisfação) que irão servir como feedback (reforço) para a atribuição dos valores.

Para LOCKE (1984) a satisfação é uma emoção resultante da realização de um valor, cuja seqüência causal é: objeto $\rightarrow$ cognição $\rightarrow$ avaliação do valor $\rightarrow$ emoção.

\section{- Objeto:}

Toda emoção é sobre alguma coisa. Qualquer coisa que possa ser percebida ou imaginada pode ser objeto de uma emoção: ações, atributos, situações, objetos, idéias, pessoas ou até emoções anteriores. Nem sempre o indivíduo consegue identificar o objeto atual de uma emoção e, às vezes, existe mais de um objeto envolvido (LOCKE 1984).

\section{- Cognição:}

Envolve dois processos: a percepção sensória e a identificação conceitual sobre o objeto. A percepção sensória é automaticamente associada ao conhecimento conceitual que o indivíduo tem sobre o objeto, bem como ao conhecimento do contexto no qual o objeto é percebido (LOCKE 1984). Assim, tão logo o indivíduo perceba o objeto por meio dos sentidos, essa percepção é associada ao conhecimento (o que ele sabe ou pensa) sobre o objeto, bem como ao conhecimento do contexto no qual o objeto é percebido (o que está favorecendo a existência do objeto, como ele pode afetar o indivíduo, quais os recursos para lidar com ele, e outros).

- Avaliação de valor:

Valor é o que uma pessoa considera que contribui para seu bem-estar; é o que uma pessoa consciente ou subconscientemente deseja, quer, procura conseguir (LOCKE 1976).

A avaliação de valores envolve uma estimativa da relação entre aquilo que o indivíduo percebe (objeto, condições, conteúdo) e a realização ou frustração de seu padrão de valores. "Se a situação é percebida como favorecendo ou 
facilitando o alcance dos valores da pessoa, então uma emoção positiva é experienciada. Se a situação é percebida como ameaçadora, bloqueadora ou destrutiva aos valores da pessoa, então uma emoção negativa é experienciada" (LOCKE 1984, p.98). Portanto, o resultado da avaliação de um valor, envolvendo os conhecimentos e crenças dos indivíduos, são as emoções.

LOCKE (1969) esclarece que todo valor tem dois atributos: conteúdo e intensidade, onde conteúdo diz respeito a o que a pessoa quer obter e/ou manter, e intensidade diz respeito a quanto a pessoa quer obter e/ou manter.

Para LOCKE (1969) é importante diferenciar valores de necessidades. Segundo o autor, necessidades são condições requeridas para a sobrevivência e bem-estar do organismo, são inatas e comuns a todos os indivíduos (LOCKE 1969, 1976). Valores dizem respeito a o que o indivíduo quer ou considera benefícios, são adquiridos e diferem de indivíduo para indivíduo.

\section{- Emoção:}

Segundo LOCKE $(1969,1976,1984)$, emoções são o resultado de uma avaliação de valores, são a forma pela qual o indivíduo experimenta o alcance ou negação dos valores. Para o autor, as noções básicas da maioria das pessoas são o prazer ou alegria (decorrentes do alcance percebido de seus valores) e o desprazer ou sofrimento (decorrentes da negação ou destruição de seus valores).

Para o autor (LOCKE 1976), a resposta emocional é um reflexo de um julgamento de valores dual: a discrepância entre o que o indivíduo quer e o que ele percebe como estando obtendo, e a importância do que ele quer (o quanto ele quer). Portanto, a intensidade da emoção vai depender do local em que os valores implicados na emoção ocupam da hierarquia de valores do indivíduo (LOCKE 1984). A obtenção de valores importantes está associada com alta satisfação, a obtenção de valores sem importância não está associada com satisfação, e a presença de características desvalorizadas é associada com insatisfação. 
Partindo deste referencial LOCKE $(1969,1976)$ considera a satisfação no trabalho como uma função da relação percebida entre o que um indivíduo quer de seu trabalho e o que ele percebe que está obtendo. Para ele (LOCKE 1969, 1976, 1984) a satisfação no trabalho é um estado emocional prazeroso resultante da avaliação do trabalho realizado em relação aos valores no trabalho do indivíduo, e insatisfação no trabalho é um estado emocional não prazeroso resultante da avaliação do trabalho como ignorando, frustrando ou negando os valores do indivíduo no trabalho. Para o autor, a satisfação e insatisfação no trabalho não são fenômenos distintos, mas situações opostas de um mesmo fenômeno, ou seja, um estado emocional que se manifesta na forma de alegria (satisfação) ou sofrimento (insatisfação) (LOCKE 1969, 1976, 1984).

LOCKE (1969) assinala que existem três elementos envolvidos neste processo de avaliação: (1) a percepção de algum aspecto do trabalho, (2) um padrão de valores implícito ou explícito, e (3) um julgamento consciente ou subconsciente da relação entre a(s) percepção(ões) e o(s) valor(es) do indivíduo.

Segundo LOCKE $(1969$, 1976), o trabalho não é uma entidade, mas uma interação complexa de tarefas, papéis, responsabilidades, relações, incentivos e recompensas, num dado contexto físico e social. E por isso, o entendimento da satisfação no trabalho requer que o trabalho seja analisado em termos de seus elementos constituintes e dinâmicos e onde satisfação global no trabalho é o resultado da satisfação com diversos elementos do trabalho (LOCKE 1969, 1976).

LOCKE (1984) relata que, embora existam diferenças individuais significativas em relação a o que os empregados querem de seus empregos, também existem grandes semelhanças entre os fatores causais da satisfação no trabalho. O autor (LOCKE 1976) classifica esses fatores causais em dois grandes grupos: (1) eventos e condições, e (2) agentes. Ele assinala que eles não devem ser analisados somente de forma isolada, mas também em suas inter-relações. LOCKE $(1976,1984)$ e HENNE e LOCKE (1985) apresentam estes fatores causais da seguinte forma: 


\section{- Eventos e condições:}

- Trabalho: diz respeito ao trabalho propriamente dito e ao conteúdo do trabalho e inclui: um trabalho que seja pessoalmente interessante e significativo, sucesso e sentimento de realização, possibilidade de uso de habilidades e capacidades, possibilidade de crescimento, variedade de tarefas, responsabilidade, autonomia na tomada de decisões, clareza de papéis e ausência de conflito de papéis, avaliação do seu desempenho no trabalho, harmonia e integração inter-pessoal, e ausência de fadiga física e de monotonia.

- Pagamento: compreende eqüidade (em comparação a o que outros estão recebendo), quantidade (suficiente para suas despesas no contexto de seu estilo de vida preferido), forma de pagamento e benefícios (assistência médica, aposentadoria, férias, seguro desemprego e outros). $\mathrm{O}$ autor também acrescenta que a segurança (estabilidade) no emprego como um fator importante no pagamento porque significa uma segurança de recebimento de pagamentos.

- Promoção: inclui oportunidades, justiça e clareza (no sistema de promoções) e disponibilidade (nem todos os empregados querem promoção).

- Reconhecimento: inclui receber créditos pelas realizações, elogios, um anúncio público na empresa ou mesmo comentários informais.

- Condições de trabalho e ambiente de trabalho: engloba recursos disponíveis (tempo, dinheiro, equipamentos, suporte) para realização do trabalho, jornada de trabalho, pausas, turnos de trabalho, condições físicas (ruído, ventilação, umidade, temperatura, arranjo físico e posto de trabalho), e segurança (ausência de riscos). 


\section{- Agentes:}

- Colegas e subordinados: envolve relações de confiança, competência, colaboração e amizade, bem como o compartilhamento de valores.

- Supervisão e gerenciamento: empregados esperam que seus supervisores sejam atenciosos (o que inclui facilitar o alcance de seus valores), justos, competentes, reconheçam e recompensem o bom desenvolvimento dos empregados, e permitam alguma participação no processo de tomada de decisões. Devem, também, demonstrar respeito aos empregados como seres humanos, incluindo comportamento honesto e boa comunicação de informações.

- Empresa / organização: diz respeito a como as empresas demonstram respeito pelos empregados e por seus valores, bem como à política de benefícios e pagamentos. Também diz respeito à competência da organização (sentido de direção, gerenciamento eficaz, e a geração de um bom produto).

Para LOCKE $(1976,1984)$ e HENNE e LOCKE (1985), a satisfação no trabalho tem efeitos que podem afetar aspectos comportamentais, a saúde física e a saúde dos indivíduos com conseqüências para os empregados e para a empresa:

\section{- Efeitos comportamentais:}

Segundo LOCKE $(1976,1984)$, existe uma ampla gama de tendências de ações que um indivíduo pode desenvolver em resposta às emoções, mas essas tendências não são necessariamente seguidas por alguma ação. Entre essas tendências as principais categorias de respostas são:

- Abordagens positivas:

- $\quad$ Aproximar-se, reter ou proteger o objeto, repetir uma ação. 
- Se insatisfeito ou antecipando futuros aborrecimentos ou fracassos: interromper atividades, estabelecer novo objetivo, escolher nova tarefa, buscar nova tentativa.

- Abordagens negativas:

- Não desenvolver nenhuma ação.

- Evitar o objeto, abandonar a situação, pensar sobre abandonar a situação, fazer planos para partir, gastar menos tempo na situação.

- Mudança ou ataque ao objeto: ataque físico (destruir, danificar, prejudicar ou punir o objeto ou pessoas), persuasão, reclamação, discussão, convencer o agente a modificar ações, barganhar, criticar, molestar, fazer greve, modificar as próprias ações ou desempenho.

- Mudança ou reação direta ao objeto: modificar conteúdo ou hierarquia dos próprios valores (por auto-persuasão, terapia ou aconselhamento); modificar a avaliação do relacionamento entre a situação ou objeto e seus próprios valores; usar mecanismos de defesa (ausência psicológica, drogas, repressão, fantasia, deslocamento para distorcer a percepção ou avaliação do objeto).

- Tolerar a situação (foco sobre aspectos valorizados da situação).

- Repetir ações anteriores (rigidez, compulsão, medo de mudanças).

A escolha da forma como um indivíduo vai reagir em resposta à emoção vai depender de seus valores, crenças, forma de pensamento, dificuldades e oportunidades oferecidas na situação e da forma como o aspecto é percebido, se como benéfico ou prejudicial (LOCKE 1976).

Os efeitos comportamentais conseqüentes a essas tendências de ações ou ações manifestam-se em várias condições, sendo que algumas delas são:

- Ausências: o trabalhador pode procurar formas de evitar a situação que provoca insatisfação e uma dessas formas é manter-se afastado do trabalho, o que se dá por meio de absenteísmo, rotatividade, atrasos ou pausas prolongadas e/ou não autorizadas. A ausência psicológica ocorre quando o 
trabalhador torna-se passivo e desinteressado de seu trabalho (LOCKE 1976, 1984; HENNE e LOCKE 1985).

- Produtividade: LOCKE (1976) e HENNE e LOCKE (1985) relatam que existe grande controvérsia no estudo das associações entre satisfação no trabalho e produtividade, onde a questão é se a insatisfação leva à queda de produtividade ou vice-versa, ou se existem elementos que podem afetar tanto a satisfação como a produtividade. LOCKE (1984) assinala que baixa produtividade e pouca qualidade de trabalho são respostas possíveis à insatisfação no trabalho, mas que seguramente não ocorrem em todos os empregados insatisfeitos. O autor (LOCKE 1984) também chama a atenção para a possibilidade que a insatisfação possa ter efeitos indiretos sobre a produtividade por meio de absenteísmo, rotatividade e greves.

- Protestos e greves: a insatisfação com a situação de trabalho pode dar origem a tentativas para modificar esta situação e que se manifestam na forma de protestos ou greves (LOCKE 1984; HENNE e LOCKE 1985).

- Satisfação com a vida: para LOCKE (1976) e HENNE e LOCKE (1985), os indivíduos podem ter efeitos sobre a satisfação com a vida como um resultado das alternativas de ação e dos ajustes psicológicos feitos em face à insatisfação no trabalho. Desde que o trabalho é um componente da vida do indivíduo, ele pode afetar sua atitude perante a vida como um todo, porém a forma como isso ocorre não é a mesma para todas as pessoas, e vai depender da importância do trabalho na hierarquia de valores do indivíduo.

\section{- Efeitos sobre a saúde física:}

LOCKE (1976) e HENNE e LOCKE (1985) em revisão de estudos sobre satisfação no trabalho observaram que estes estudos identificaram associações entre nível de satisfação e agravos físicos (fadiga, dificuldade respiratória, dor de cabeça, perda de apetite, aumento do colesterol, doença cardíaca aterosclerótica) e longevidade, onde 
indivíduos mais satisfeitos apresentaram menor incidência de problemas de saúde e maior longevidade.

HENNE e LOCKE (1985) consideram que há plausibilidade nestes estudos, uma vez que satisfação é um estado emocional e que todas emoções implicam em respostas físicas automáticas e onde o nível de satisfação pode atuar como fonte de estresse. Porém, ele alerta para que estes resultados devem ser observados com cuidado pois podem ser interpretados de outra maneira: o nível de satisfação no trabalho pode ser devido ao estresse (e não a sua causa), ou ainda que o nível de satisfação no trabalho e o estado de saúde podem estar sendo influenciados por algum outro fator em comum. Para os autores seria igualmente razoável considerar que condições físicas são covariáveis e não conseqüências do nível de satisfação no trabalho e concluem que a conecção entre saúde física e satisfação no trabalho pode ser difícil de ser estabelecida.

\section{- Efeitos sobre a saúde mental:}

Segundo LOCKE (1976) e HENNE e LOCKE (1985), a insatisfação no trabalho é um estado psicológico desagradável e a existência desse estado implica em conflito quando significa que o indivíduo está suportando um trabalho que preferiria evitar. Para os autores este conflito pode levar a problemas de saúde mental e a chave para isso está na relação entre o trabalho e os valores do indivíduo.

Segundo os autores (HENNE e LOCKE 1985) existem associações entre nível de satisfação e estresse no trabalho, mas estas associações devem ser melhor estudadas. A maior probabilidade é que exista uma relação recíproca entre os dois construtos: o nível de satisfação no trabalho, como um estado de conflito contínuo na mente do empregado, pode contribuir para o estresse; por outro lado, o estresse percebido pode representar uma causa do sentimento de insatisfação no trabalho, sendo que o estresse pode ter conseqüências psicológicas como nervosismo e depressão (HENNE e LOCKE 1985). 
Entre as teorias apresentadas, que são originadas na psicologia, na psicopatologia ou na administração, nem todas são específicas sobre satisfação no trabalho e algumas oferecem enfoques que contemplam a satisfação em suas relações com motivação, identificação com o trabalho, produtividade e/ou qualidade de vida. Segundo SILVA (1998), algumas teorias se detêm na experiência do indivíduo, outras na avaliação da probabilidade de conseqüências, outras nas características subjetivas e necessidades individuais, outras no meio social circundante, e outras na situação de trabalho, sendo que todas elas contribuem para uma melhor compreensão da satisfação no trabalho, porém como satisfação no trabalho está situada no campo das intersubjetividades, é muito difícil, se não impossível, encontrar padrões explicativos universais para este fenômeno.

\subsection{3 - Determinantes da satisfação no trabalho:}

CAVANAGH (1992) informa que existem três grupos de aspectos que influenciam na satisfação no trabalho: diferenças na personalidade, diferenças no trabalho e diferenças nos valores atribuídos ao trabalho.

\section{- Diferenças na personalidade:}

Para alguns autores "a perspectiva das diferenças de personalidade vê a satisfação no trabalho como um fenômeno que pode ser explicado predominantemente em termos da personalidade dos indivíduos" (CAVANAGH 1992, p.704). Outros autores buscam analisar conjuntamente aspectos individuais com aspectos organizacionais.

ELOVAINIO et. al. (2000), em estudo objetivando construir e testar um modelo multinível para verificar os efeitos da interação entre aspectos específicos do ambiente psicossocial (controle do trabalho) e aspectos de personalidade (hostilidade e ansiedade) demonstraram a significância estatística de 
características individuais e de efeitos organizacionais sobre resultados referentes à saúde mental e à satisfação no trabalho.

JUDGE et. al. (2000) também identificaram influência, tanto de características de personalidade como de características do trabalho, sobre a satisfação. Esses autores, em estudo buscando identificar as relações entre auto-avaliação da caráter (itens de características de personalidade), características de trabalho (complexidade do trabalho) e satisfação no trabalho, identificaram que, tanto a complexidade do trabalho explica a relação entre auto-avaliação de caráter e satisfação no trabalho, como a auto-avaliação de caráter apresenta relação significativa com complexidade do trabalho e satisfação no trabalho.

As características de personalidade que têm sido mais apontadas influenciando a satisfação no trabalho são o locus de controle (locus of control), o comportamento do tipo A (CHAN et. al. 2000) e a capacidade de enfrentamento (HARRIS 1989). Locus de controle é a "extensão na qual o indivíduo acredita que resultados são determinados por esforços e habilidades pessoais mais do que por eventos externos, tais como sorte, oportunidades ou outras influências" (PARKES 1994, p.114). Comportamento tipo A é "caracterizado por impaciência, hostilidade, irritabilidade, envolvimento como o trabalho, competitividade e esforço para realizações; é usualmente conceituado como um complexo emoção-ação provocado por demandas ambientais desafiadoras" (PARKES 1994, p.115). Capacidade de enfrentamento refere-se aos esforços (incluindo estratégias defensivas), tanto intra-psíquicos como orientados para a ação, direcionados para lidar (controlar, tolerar, reduzir, minimizar) com as demandas ambientais e internas do indivíduo e com os conflitos (COHEN 1987).

LINO (1999) assinala que atributos pessoais e sócio-demográficos, tais como idade, tempo de experiência no trabalho, estado conjugal e nível de educação, também podem influenciar nas diferenças na personalidade. 


\section{- Diferenças no ambiente de trabalho:}

As variações na satisfação no trabalho são resultados de diferenças na natureza do trabalho (CAVANAGH 1992). Aqui podem ser considerados todos os aspectos psicossociais do trabalho, tais como demandas físicas e da tarefa, papel do indivíduo na organização, relacionamentos interpessoais, possibilidades de desenvolvimento de carreira, clima e estrutura organizacional. A importância dos fatores psicossociais do ambiente de trabalho em relação à satisfação no trabalho está comentada no item 1.5 - Relações entre satisfação no trabalho, fatores psicossociais, e saúde do trabalhador.

\section{- Variações nos valores atribuídos ao trabalho:}

Pessoas avaliam seu trabalho de maneiras diferentes: para alguns ele é uma parte muito importante da vida, para outros ele é apenas um aspecto da vida que existe para prover outras necessidades (CAVANAGH 1992). A satisfação no trabalho, sendo decorrente da avaliação que o indivíduo faz de seu trabalho, pode ser influenciada pela medida na qual seu trabalho é compatível com seus valores pessoais (LOCKE 1969, 1976).

No conceito de satisfação no trabalho enunciado por LOCKE $(1969,1976)$ podem ser identificados os três aspectos referidos acima: (1) diferenças de personalidade (“.... estado emocional .... resulta da percepção da pessoa....”); (2) diferenças no ambiente de trabalho (“.... avaliação de um trabalho ou experiência de trabalho....”) e (3) diferenças nos valores atribuídos ao trabalho (“.... seus valores importantes....”). Em função disso, para o estudo da satisfação no trabalho, os três aspectos devem ser considerados, porém, de acordo com os objetivos, referenciais teóricos e métodos selecionados pelo pesquisador, pode ser dada maior ênfase a um aspecto específico. 


\subsection{4 - Conseqüências da satisfação no trabalho}

O nível da satisfação no trabalho tem sido apontado como exercendo influências sobre o trabalhador que podem se manifestar sobre sua saúde, qualidade de vida e comportamento, com conseqüências para os indivíduos e para as organizações:

- Saúde: satisfação no trabalho tem sido identificada associada à saúde dos trabalhadores, onde indivíduos mais satisfeitos com seu trabalho apresentam melhor qualidade de saúde e menor ocorrência de doenças, tanto no que se refere à saúde física como mental (LOCKE 1976; ROCHA 1996; ZALEWSKA 1999a, 1999b). A satisfação no trabalho também tem sido apontada como um fator associado à longevidade (LOCKE 1976; FRASER 1983, MINISTÉRIO DA SAÚDE 1999a).

- Qualidade de vida: Desde que satisfação no trabalho é parte da vida do indivíduo, ela vai influenciar a satisfação com a vida por meio da generalização das emoções do trabalho para a vida fora do trabalho, e atitudes decorrentes também podem afetar a família do indivíduo (LOCKE 1976). Segundo ZALEWSKA (1999a, 1999b), satisfação global no trabalho é um dos principais componentes da satisfação geral com a vida, ou uma avaliação cognitiva de bemestar subjetivo.

- Efeitos sobre o comportamento: o nível de satisfação no trabalho pode afetar o comportamento do indivíduo, traduzindo-se na forma de absenteísmo, rotatividade, queda da produtividade, greves, acidentes de trabalho ou consumo de álcool ou drogas (LOCKE 1976; PÉREZ-RAMOS 1980; ZALEWSKA 1999a, 1999b). 


\section{3 - FATORES PSICOSSOCIAIS NO TRABALHO}

\subsection{1 - Conceito}

As doenças ocupacionais (como saturnismo, silicose ou dermatoses ocupacionais) são mais simples de serem abordadas na medida em que existe um agente etiológico identificado e medidas de controle, diagnóstico e tratamento conhecidas e definidas. Já outros problemas ou agravos relacionados ao trabalho (como as doenças ósteoarticulares relacionadas ao trabalho e o estresse) são multicausais, de diagnóstico e estabelecimento de nexo causal mais complexo e nem sempre claro, necessitando de tratamento para sintomas, distúrbios ou doenças inespecíficos, múltiplos ou que se sobrepõem e exigem a adoção de medidas corretivas que interferem não só nos aspectos ambientais mas também na organização e nas relações no trabalho. Neste sentido, KALIMO (1987) e SPURGEON et. al. (1996) referem que especial atenção tem sido dada aos fatores psicossociais no trabalho.

Em 1984 a OIT - International Labour Office (Organização Internacional do Trabalho) definiu fatores psicossociais no trabalho como aqueles que "referem-se à interação entre e no meio ambiente de trabalho, conteúdo do trabalho, condições organizacionais e habilidades do trabalhador, necessidades, cultura, causas extratrabalho pessoais que podem, por meio de percepções e experiência, influenciar a saúde, o desempenho no trabalho e a satisfação no trabalho" (ILO 1984) e salientou que este conceito é difícil de abarcar, já que ele representa experiências e percepções do trabalhador e reflete aspectos relacionados ao trabalhador individual, às condições de trabalho, ao ambiente de trabalho e à influências econômicas e sociais que estão fora do local de trabalho mas, que nele têm repercussões.

Para o NIOSH - National Institute for Occupational Safety and Health (Instituto Nacional de Saúde e Segurança Ocupacional), o conceito de fatores psicossociais inclui uma vasta variedade de condições e um grande número de fatores, sendo que a 
ação da interação desses fatores constitui o que tem sido chamado de "processo de estresse" cujos resultados são considerados como exercendo impactos sobre a condição de saúde e o desempenho no trabalho (NIOSH 1997).

Segundo SUTHERLAND e COOPER (1988) e o NIOSH (1997), esses fatores psicossociais, também chamados como fontes de estresse (ou estressores), são agrupados em três amplos domínios:

\section{1 - Fatores associados ao ambiente e organização do trabalho:}

- Demandas físicas (ou agentes físicos): ruído, vibração, temperatura, ventilação, umidade, iluminação, condições de higiene e clima.

- Conteúdo do trabalho: carga de trabalho, repetitividade, controle do trabalho, demandas mentais.

- Aspectos temporais do trabalho: trabalho em turnos, trabalho noturno, ciclo de tempo.

- Papel do indivíduo na organização: conflito de papéis, ambigüidade de papéis, responsabilidade.

- Relacionamentos e demandas interpessoais: relacionamentos no trabalho (relacionamentos sociais suportivos com pares, superiores e subordinados) e demandas interpessoais (incongruência de posição social, personalidades abrasivas, estilo de liderança e pressão do grupo).

- Desenvolvimento da carreira: insegurança (instabilidade) no emprego, possibilidades de promoção.

- Remuneração: pagamento, benefícios, questões de eqüidade.

- Clima e estrutura organizacional: autonomia, tipo de estrutura, recompensas, respeito, participação no processo de tomada de decisão, comunicação e consulta efetiva, restrições injustificadas de comportamento, políticas oficiais.

\section{2 - Fatores extra-organizacionais:}

- Inclui os elementos concernentes à vida da pessoa que podem interagir com eventos do trabalho e com a organização e, desse modo, exercer pressão sobre o indivíduo. 


\section{3 - Fatores relacionados ao indivíduo:}

- Fatores genéticos: como sexo, etnia, condições de saúde ou inteligência.

- Aspectos adquiridos: classe social, cultura, nível educacional, habilidades e experiências.

- Fatores dispositivos: traços de personalidade, necessidades e valores, estilo de comportamento, em especial comportamento tipo A e locus de controle (locus of control).

Os fatores referentes ao ambiente de trabalho, em especial os relacionados ao desenho, organização e gerenciamento do trabalho e ao contexto organizacional das empresas, têm sido considerados como demandas ou fatores de risco com potencial para causar dano físico ou mental ao trabalhador (COX e GRIFFITHS 1995; NIOSH 1997).

Neste sentido, no estudo dos fatores psicossociais no trabalho, a forma como o trabalho está organizado adquire importância ao configurar riscos que podem impactar sobre a saúde dos trabalhadores. Organização no trabalho é entendida como sendo por um lado a divisão do trabalho (divisão de tarefas, repartição, cadência, tempo prescrito) e, por outro lado, a divisão dos homens (responsabilidade, hierarquia, comando, controle) (DEJOURS e ABDOUCHELI 1994). A organização do trabalho define o conteúdo das tarefas e das relações de trabalho, onde o trabalhador é forçado a agir conforme a vontade de outro (DEJOURS 1994).

\subsection{2 - Transformações no mundo do trabalho, fatores psicossociais no trabalho e conseqüências para a saúde do trabalhador}

Nas últimas décadas a emergência da globalização, acompanhada de uma transição do modelo taylorista de organização do trabalho (organização do trabalho hierarquizada, com centralização do controle e rígida divisão do trabalho) para o atual modelo flexibilizado (com novas formas de regulação e controle do trabalho, 
exigindo trabalhadores mais qualificados e polivalentes), acarretou profunda reestruturação produtiva gerando significativas conseqüências para a vida e saúde dos trabalhadores.

Para KANTORSKI (1997) o contexto de crise das taxas de crescimento mundial somado ao desenvolvimento da microeletrônica e da biotecnologia deu origem a uma forma de reprodução do capital que passa a exigir novas formas de produção e de relações sociais apoiadas na necessidade do trabalhador conservar seu emprego e no desgaste das organizações representantes dos interesses dos trabalhadores.

RIGOTTO (1998) e LINO e DIAS ("sd") apontam os reflexos que essas novas formas de produção e de relações sociais têm sobre o mundo do trabalho:

- Exigência de um novo perfil de trabalhador caracterizado pela aquisição permanente de novos conhecimentos, polivalente, com maior iniciativa e criatividade;

- aumento da produtividade conseguido por meio de uma combinação do aumento do ritmo de trabalho, diminuição das pausas para descanso e aumento da carga de responsabilidade dos trabalhadores;

- controle exercido por chefias sobre os trabalhadores é substituído por estratégias de gestão que levam à cooperação por parte dos trabalhadores;

- flexibilização de horários com diminuição da jornada de trabalho e/ou exigência de horas-extras;

- medo da demissão e a insegurança quanto ao futuro gerando a competitividade e a permanente preocupação com a perda de emprego, e provocando a deterioração das relações humanas no trabalho;

- tendência de controle dos riscos ocupacionais mais agressivos, com persistência de exposições a riscos em baixas dosagens, levando a efeitos crônicos.

Esse processo tem condicionado mudanças no perfil de morbimortalidade dos trabalhadores com aumento de doenças mentais, psicossomáticas, cardiovasculares, 
doenças ósteo-articulares, doenças malignas severas e suicídios (LINO e DIAS "sd"; LEVI 1998; RIGOTTO 1998).

Segundo LEVI (1998), a mudança no padrão de morbidade e mortalidade em quase todas as sociedades pós-industriais no Mundo Ocidental é a primeira razão para mudanças de prioridades nos investimentos para a saúde, e enfatiza que os fatores sócio-econômicos e psicossociais têm um grande e crescente papel na etiologia e/ou patogênese de muitas das doenças mais freqüentes.

Para VINGÅRD e THEORELL (1998) e THEORELL (1999), a tendência deste aumento da atenção que vem sendo dada nos últimos anos às relações entre ambiente psicossocial de trabalho e saúde tem lógica, uma vez que o aumento da complexidade da sociedade moderna determina fortes impactos dos fatores psicossociais e sociais com conseqüências para os indivíduos, grupos de empregados, famílias e sociedades.

Esses impactos podem ser de ordem física, psicológica ou comportamental:

\section{- Efeitos físicos:}

As reações iniciais que o indivíduo pode apresentar são sinais e sintomas inespecíficos que desaparecem com a remoção do estressor ou com o reestabelecimento do equilíbrio entre o indivíduo e ambiente. Entre estes sinais e sintomas estão: dores musculares, palpitações, aceleração da respiração, midríase, diminuição da resposta inflamatória, diminuição da produção de anticorpos, vasoconstrição, diarréia, episódios de ansiedade, de agitação ou de depressão (VANDER et. al. 1981; LEVI 1984; SILVA et. al. 1994; MCEWEN 1998).

Se as fontes de estresse não são removidas e/ou se o indivíduo não consegue lutar eficazmente com estas fontes, ocorre a constante estimulação dos mecanismos de adaptação, podendo gerar um desgaste nas funções e estruturas de órgãos (LEVI 1998). Secundariamente, podem se instalar doenças como úlcera gástrica e 
duodenal, hipertensão arterial, doença coronariana e diminuição da produção de anticorpos com queda da resistência do organismo (VANDER et. al. 1981; ILO 1984; LEVI 1984; SILVA et. al. 1994).

\section{- Efeitos psicológicos:}

Os primeiros indicadores de efeitos psicológicos negativos são sentimentos como irritação, preocupação, tensão e depressão, e também distúrbios cognitivos como dificuldades na concentração, memorização e tomada de decisões, afetando o bem-estar psicológico dos indivíduos (ILO 1984). Pode ocorrer ansiedade, hipocondria, insegurança, desesperança e desamparo (LEVI 1997). Caso os estressores não tenham sua ação interrompida, o indivíduo pode evoluir para o estresse crônico que é definido por sentimentos de fadiga, falta de energia, irritabilidade, desmoralização e hostilidade (MCEWEN 1998).

\section{- Efeitos no comportamento:}

O desempenho no trabalho pode ser prejudicado em decorrência de reações cognitivas onde ocorre diminuição do escopo da percepção, dificuldades na concentração e aprendizado, distúrbio da função da memória, hesitação na tomada de decisões e perda da criatividade (LEVI 1997).

Podem ocorrer atrasos, greves, aumento do absenteísmo e da rotatividade (EMPLOYMENT E SOCIAL AFFAIRS 1999). Também pode ocorrer o uso e abuso de álcool e tabaco, alterações de hábitos alimentares e de exercícios físicos, acidentes de trânsito, suicídios, agressão e violência (LEVI 1997; EMPLOYMENT E SOCIAL AFFAIRS 1999).

No que se refere às doenças relacionadas ao trabalho no Brasil, WÜNSCH FILHO (2001) aponta que nas últimas duas décadas ocorreram mudanças significativas no padrão de morbidade por doenças relacionadas ao trabalho, e exemplifica a partir da prevalência destas doenças no Estado de São Paulo, entre os anos de 1960 a 2000: 
nos anos 60 e 70 as principais causas de doenças relacionadas ao trabalho eram as dermatoses profissionais, o saturnismo e outras intoxicações; nos anos 70 as hipoacusias tinham prevalência importante, tornando-se a primeira causa de morbidade relacionada ao trabalho nos anos 80; nesta mesma década as lesões por esforços repetitivos passam a ganhar visibilidade, tornando-se a principal causa de morbidade nos anos 90 e no ano 2000, sendo que nestes dois últimos períodos começaram a ganhar importância as prevalências de asma ocupacional e os transtornos mentais relacionados ao trabalho, onde as tendências temporais de incidência destes dois últimos agravos indicam a importância que deverão assumir nas próximas décadas (WÜNSCH FILHO 2001).

O impacto dessas mudanças nas condições de trabalho sobre a saúde dos trabalhadores leva o MINISTÉRIO DA SAÚDE (1999b) a elaborar o documento "Doenças Ocupacionais e Acidentes de Trabalho" que inclui as lesões por esforços repetitivos / doenças osteomusculares relacionadas ao trabalho e os distúrbios mentais relacionados ao trabalho nas prioridades para notificação e investigação epidemiológica e reconhece o trabalho como importante fator de adoecimento, de desencadeamento e de crescente aumento de distúrbios psíquicos. O mesmo Ministério cria a Portaria $n^{0} 1.339$ que institui a lista de doenças relacionadas ao trabalho e que inclui os transtornos mentais e comportamentais que teriam como agente etiológico ou fator de risco as "condições difíceis de trabalho", as "circunstâncias relativas às condições de trabalho", "ritmo de trabalho penoso", a "má adaptação à organização do trabalho (trabalho em turnos ou noturno)" e "outras dificuldades físicas e mentais relacionadas ao trabalho" (MINISTÉRIO DA SAÚDE 1999C).

\subsection{3 - Modelo teórico}

LEVI $(1987,1998)$ considera que os fatores psicossociais surgem de arranjos sociais e são mediados pela percepção e experiência do indivíduo. O autor propõe o modelo 
teórico de "Interação entre fatores do ambiente psicossocial e saúde" (Figura 1), onde denominadores comuns na gênese de saúde/doença induzida psicossocialmente são: a discrepância entre necessidades humanas e possibilidades ambientais para sua satisfação, a discrepância entre capacidade humana e demandas ambientais e a discrepância entre expectativas humanas e como a situação é percebida.

Figura 1: Interações entre fatores do ambiente psicossocial e saúde

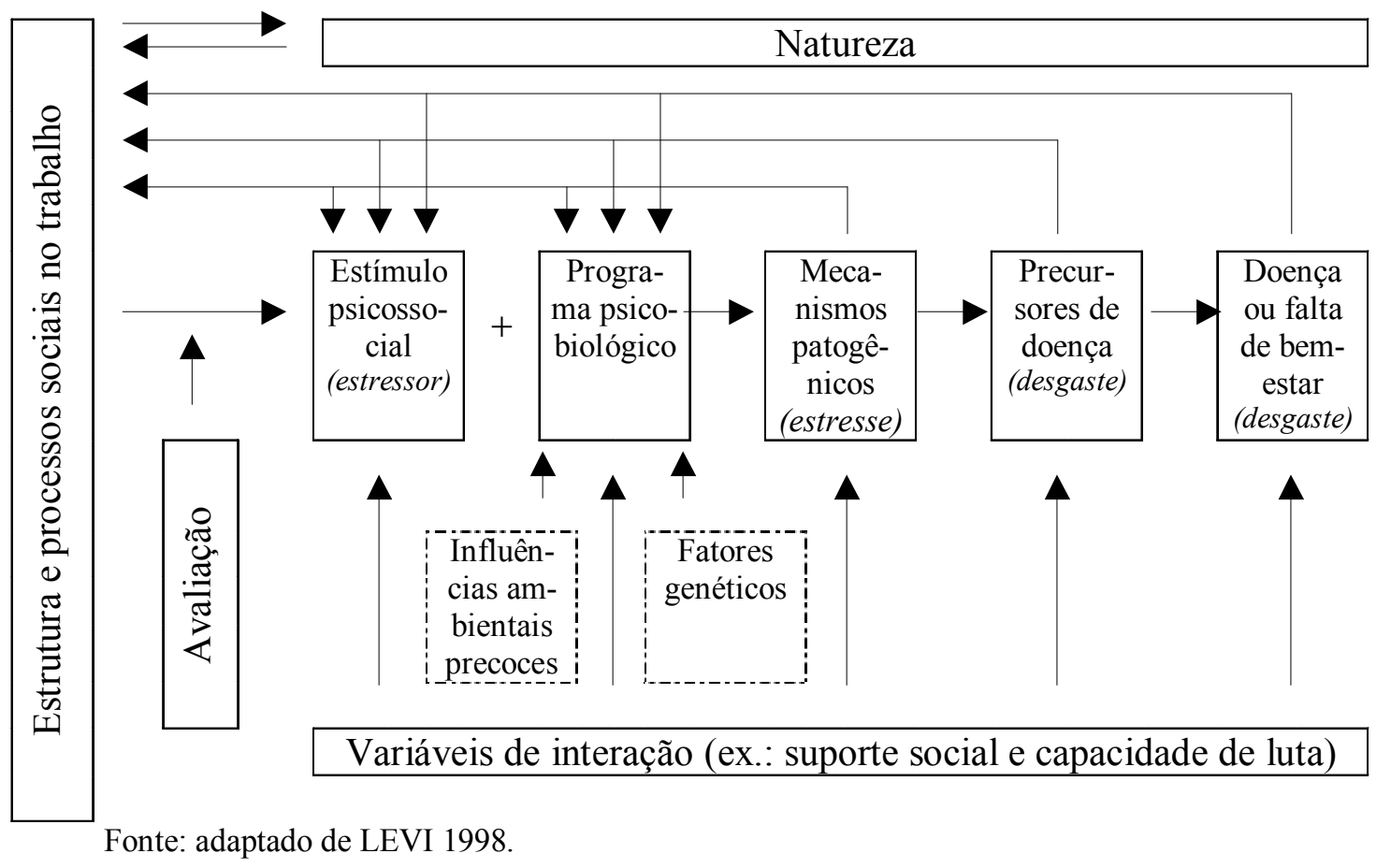

De acordo com este modelo (LEVI 1987, 1997, 1998), o ambiente, os processos, o conteúdo e a organização do trabalho constituem o que o autor classifica como estruturas e processos sociais, que são circundados e interagem com a natureza. Daí podem surgir demandas que vão atuar como estressores psicossociais (ou estímulos psicossociais) sobre os trabalhadores (LEVI e LUNDE-JENSEN 1996; LEVI 1987, 1997, 1998). 
Para LEVI e LUNDE-JENSEN (1996) e LEVI (1987, 1997, 1998), os indivíduos são caracterizados por um programa psicobiológico condicionado por fatores genéticos e por influências ambientais anteriores (como experiências no trabalho, exposições a agentes de risco, conhecimentos e treinamento) que vão influenciar a maneira pela qual o indivíduo vai avaliar sua situação de trabalho.

A interação entre estímulos psicossociais e o programa psicobiológico do trabalhador pode provocar mecanismos patogênicos, onde os efeitos da exposição aos estressores vão depender tanto da intensidade, duração e freqüência da exposição, como da avaliação que o trabalhador exposto faz sobre a situação do trabalho (LEVI e LUNDE-JENSEN 1996; LEVI 1987, 1997, 1998).

Alguns desses mecanismos de reação são específicos, no sentido em que são relacionados a um agente específico ou a certas características individuais ou levam a tipos específicos de doença. Outros são inespecíficos, no sentido em que são disparados por várias condições, em vários tipos de indivíduos ou relacionam-se a vários tipos de morbidade e mortalidade. Este último grupo de reações tem sido chamado de estresse (LEVI 1987, 1997, 1998). Estresse é a experiência subjetiva que o indivíduo apresenta em relação à situação (PRATT e BARLING 1988).

Segundo LEVI e LUNDE-JENSEN (1996), a relação entre estímulo psicossocial e estresse pode ser descrita como uma curva em forma de $U$, onde maiores níveis de estresse são encontrados nos dois extremos de um continuum de estimulação (altos níveis de estresse podem ser induzidos tanto pela super como pela sub-estimulação), e o melhor funcionamento do organismo humano ocorre quando um certo nível de estimulação (nem muito alto, nem muito baixo) está presente.

Essas reações podem ser cognitivas, emocionais, comportamentais e/ou fisiológicas dependendo das características do estressor e da forma como a situação é avaliada pelo indivíduo, e podem levar a precursores de doenças (LEVI 1997). Precursores de doenças são condições de mal funcionamento de sistemas físicos e mentais que podem evoluir para doença ou falta de bem-estar (LEVI 1997). Estas conseqüências 
são chamadas de desgaste (strain), que é a resposta fisiológica e/ou psicológica mal ajustada ao estresse (PRATT e BARLING 1988).

Esse fluxo de eventos pode ser modificado pela presença de variáveis de interação onde as mais importantes são a presença ou ausência de suporte social e a capacidade de enfrentamento do indivíduo (LEVI 1987, 1997, 1998).

Suporte social no trabalho refere-se aos níveis gerais de interação social de ajuda disponíveis no trabalho, tanto por parte de colegas como de supervisores (KARASEK e THEORELL 1990).

Capacidade de enfrentamento refere-se aos esforços que o indivíduo desenvolve, tanto intra-psíquicos como por meio da ação, direcionados para lidar (controlar, tolerar, reduzir, minimizar) com as demandas ambientais e internas do indivíduo e com os conflitos existentes (COHEN 1987). Segundo o mesmo autor, existem 5 modos de enfrentamento: busca de informação (aprender mais sobre a situação e como lidar com ela), ação direta (adoção de um comportamento concreto), inibição da ação (não fazer algo deliberadamente), processos intrapsíquicos (envolve meios de reavaliar uma situação) e busca de suporte em outras pessoas .

LEVI $(1987,1997,1998)$ salienta que o processo de interação entre fatores do ambiente psicossocial e saúde não caminha em mão única, de maneira simples ou linear, mas caracteriza-se pela interação e retroalimentação contínua entre os vários componentes do processo.

Este modelo possibilita uma abordagem dinâmica da interação entre demandas no trabalho, indivíduos e outras variáveis (como suporte social e capacidade de enfrentamento), onde os aspectos psicossociais representam um papel fundamental na determinação do processo saúde/doença.

Mesmo sendo uma simplificação da complexidade das interações entre os elementos que compõe o processo, este modelo auxilia no conhecimento e intervenção em uma 
situação do trabalho. Isso é possível na medida em que permite identificar elementos do processo, suas características e principais interações, possibilitando direcionar o planejamento, execução e avaliação de ações direcionadas para a eliminação e/ou controle de problemas relacionados à saúde e bem-estar dos trabalhadores.

\section{4 - SAÚDE DO TRABALHADOR}

As relações entre o trabalho e o processo saúde/doença vêm sendo estudadas desde a Antigüidade mas foi a partir da Revolução Industrial que passaram a receber maior atenção (MINAYO-GOMEZ e THEDIM-COSTA 1997; MENDES 1999; BRAGA et. al. 2001).

A Revolução Industrial, surgida na primeira metade do século XIX, trouxe grandes mudanças no processo de produção, passando o trabalhador a ser submetido a extensas jornadas de trabalho, com salários baixos, sob condições penosas e perigosas e sem higiene ou conforto. Neste ambiente proliferaram os acidentes graves e fatais, o envelhecimento precoce, as alterações de comportamento e as doenças infecto-contagiosas, elevando as taxas de morbidade e mortalidade (MENDES e DIAS 1991; MINAYO-GOMEZ e THEDIM-COSTA 1997; MENDES 1999; BRAGA et. al. 2001).

Neste contexto a atuação do médico é introduzida no interior das fábricas com os objetivos de identificar os processos danosos à saúde e auxiliar na recuperação do trabalhador visando seu retorno ao trabalho (MINAYO-GOMEZ e THEDIMCOSTA 1997). Assim surge a Medicina do Trabalho, que centra sua atuação na figura do médico e é orientada pela teoria da unicausalidade considerando que para cada doença existe um agente etiológico (MENDES e DIAS 1991; MINAYOGOMEZ e THEDIM-COSTA 1997). Como conseqüência, a relação saúde/trabalho é vista como uma questão essencialmente ambiental, com abordagem puramente 
técnica direcionada para a identificação e controle de um risco e para o tratamento de sinais e sintomas (MINAYO-GOMEZ e THEDIM-COSTA 1997).

A II Guerra Mundial impôs a necessidade de um esforço industrial traduzido em novos produtos, equipamentos e processos de trabalho, o que vai determinar novo aumento da morbimortalidade por acidentes e doenças do trabalho (MENDES e DIAS 1991; BRAGA et. al. 2001).

Como a Medicina do Trabalho não consegue lidar com estes problemas, surge a Saúde Ocupacional no interior das grandes empresas (MENDES e DIAS 1991). A Saúde Ocupacional significa um avanço em relação à Medicina do Trabalho na medida em que incorpora a teoria da multicausalidade (onde a doença é resultado da interação entre agente, hospedeiro e ambiente) e passa a atuar por meio de equipes multi e interdisciplinares, com base nos conhecimentos e técnicas da Higiene Industrial e passando a ser considerada um ramo da saúde ambiental (MENDES e DIAS 1991; MINAYO-GOMEZ e THEDIM-COSTA 1997, MENDES 1999; BRAGA et. al. 2001).

Apesar desses avanços, a Saúde Ocupacional centra sua atenção nos agentes de risco sem contextualização em suas causas originais e com ênfase no controle por meio do uso de equipamentos de proteção ambiental e de normas de segurança (MINAYOGOMEZ e THEDIM-COSTA 1997; BRAGA et. al. 2001).

A partir do final dos anos 60 iniciam-se movimentos sociais e políticos nos países industrializados, caracterizados por questionamentos dos valores, sentido da vida, liberdade e significado do trabalho, com repercussões na legislação trabalhista refletindo em aumento da participação e direitos dos trabalhadores (MENDES e DIAS 1991).

Neste contexto surge a Saúde do Trabalhador que tem foco na teoria da determinação social do processo saúde/doença e com centralidade colocada no trabalho (MENDES e DIAS 1991). A Saúde do Trabalhador abandona a concepção de risco ou fatores de 
risco como únicos causadores da doença na medida em que vê o processo saúde/doença como dinâmico e determinado por um momento social, político e histórico, e contando com a participação dos trabalhadores nas questões relacionadas à saúde.

A Saúde do Trabalhador chegou ao Brasil nos anos 80 como uma prática interdisciplinar e multiprofissional, tendo seu campo de conhecimento ancorado na Medicina Social e na Saúde Coletiva (MENDES e DIAS 1991; LACAZ 1997).

Como o objeto da saúde do trabalhador é o processo saúde/doença em sua relação com o trabalho, passam a receber atenção prioritária o contexto geral do trabalho e a organização do trabalho (MENDES e DIAS 1991; MINAYO-GOMEZ e THEDIMCOSTA 1997). Além dos riscos decorrentes dos objetos e meios de trabalho, também passam a ser analisadas as cargas e exigências decorrentes da organização do trabalho e os efeitos de caráter psicossocial passam a aparecer com maior significância (MINAYO-GOMEZ e THEDIM-COSTA 1997).

O trabalhador deixa de ser visto apenas com um ser biológico e sua saúde passa a ser considerada como o resultado de interações dinâmicas e complexas determinadas pelos domínios sociais, mentais, históricos e políticos, onde o trabalho tem caráter central.

Para a OMS - Organização Mundial da Saúde, saúde é o estado de completo bemestar físico, mental e social, e não somente a ausência de doença (OMS 1998).

Este conceito de saúde é centrado no princípio do bem-estar. Bem-estar é definido como o estado de satisfação em relação a aquilo que a vida oferece em um dado contexto, e resulta da avaliação que reflete a diferença entre o que o indivíduo aspira e o que ele percebe que está obtendo (SPINI et. al. 1999). 
Para o Health Canada - Departamento Federal de Saúde do Canadá, tornar saúde um sinônimo de bem-estar, desenvolvimento ou qualidade de vida confunde a saúde com os seus determinantes e torna impossível falar da contribuição da saúde para o bemestar social e qualidade de vida, ainda que esta relação deva ser vista como recíproca e mutuamente fortalecedora (HEALTH CANADA 2001). Este mesmo Departamento considera que, mais adequado do que reconhecer como um estado, é reconhecer a saúde como sendo uma capacidade ou um recurso do qual o indivíduo dispõe para perseguir seus objetivos, para adquirir habilidades e educação e para crescer. Esta é uma noção ampla de saúde que reconhece a extensão dos fatores ambientais e sociais, econômicos e físicos que contribuem para ela (HEALTH CANADA 2001).

A Academia para Pesquisa de Serviços de Saúde e Políticas de Saúde nos Estados Unidos da América (ACADEMY 2002) também reconhece saúde como tendo várias dimensões e sendo definida culturalmente, onde a importância da limitação das habilidades que o indivíduo possa apresentar vai diferir dependendo do papel e valores deste indivíduo em uma dada cultura.

Essa concepção de saúde, tida como uma condição concreta e determinada em um dado contexto histórico, é reconhecida no Brasil desde os anos 80 por meio da $8^{\text {a }}$ Conferência Nacional de Saúde que considerou a saúde como sendo resultante das condições de alimentação, habitação, educação, renda, meio-ambiente, trabalho, transporte, emprego, lazer, liberdade, acesso e posse da terra e acesso a serviços de saúde definidas pelas formas de organização social da produção (MINISTÉRIO DA SAÚDE 1987).

Ver a saúde sob estes aspectos expressa o entendimento de saúde como sendo um recurso que indivíduo tem para enfrentar a vida e que é um resultado do processo de interação de fatores sociais, físicos, culturais e econômicos e, portanto, definida em um contexto político e histórico, sendo ao mesmo tempo causa e conseqüência do bem-estar e qualidade de vida. 
Dejours (1986), discutindo o conceito de saúde, considera que o trabalho possui um caráter central. Para ele "a saúde para cada homem, mulher ou criança, é ter meios de traçar um caminho pessoal e original, em direção ao bem-estar físico, psíquico e social" (DEJOURS 1986). O autor entende que para o bem-estar físico é necessária a liberdade para regular as variações que aparecem no estado do organismo, ou seja, ter o direito a atender às necessidades físicas como dormir, repousar, comer ou cuidar da doença quando ela surge. Para o bem-estar psíquico, Dejours considera que é necessária a liberdade para organizar a própria vida segundo o desejo de cada indivíduo. E para o bem-estar social, o autor entende como necessária a liberdade para agir individual e coletivamente sobre a organização do trabalho, ou seja, sobre o conteúdo do trabalho, a divisão das tarefas, a divisão dos homens e as relações que mantêm entre si (DEJOURS 1986).

Para DEJOURS (1999) nenhuma relação de trabalho é neutra no que diz respeito à saúde: ou o trabalhador consegue subverter os efeitos das pressões de trabalho e utilizá-lo em favor da auto-realização, ou o trabalho perde seu sentido subjetivo e não permite subverter o sofrimento que causa, tornando-se patogênico e podendo levar à doença mental ou somática. Desta forma, para DEJOURS (1999), a saúde não é um estado natural, mas uma construção intencional, na qual as relações no trabalho desempenham papel central.

Considerando os conceitos abordados e coerente com o campo de atuação da Saúde do Trabalhador, quando se pensa a concepção de saúde em termos da saúde do trabalhador, o trabalho adquire caráter central tanto por exigir do trabalhador habilidades para o desempenho deste trabalho, como pelos impactos que as condições físicas, as relações e a organização do trabalho exercem sobre o trabalhador. Portanto, a saúde do trabalhador pode ser entendida como uma condição concreta e dinâmica da qual o trabalhador dispõe para traçar e perseguir seus objetivos em direção ao bem-estar físico, psíquico e social, e que é influenciada pelas condições e organização do trabalho e pelo contexto no qual ele está inserido. 


\section{5 - RELAÇÕES ENTRE SATISFAÇÃO NO TRABALHO, FATORES PSICOSSOCIAIS NO TRABALHO E SAÚDE DO TRABALHADOR}

A satisfação no trabalho, que é fortemente determinada pelos aspectos psicossociais do trabalho, tem sido apontada como fator importante na condição de saúde, surgimento de doenças e longevidade (LOCKE 1976; ZALEWSKA 1999a, 1999b; MINISTÉRIO DA SAÚDE 1999a).

Revendo a literatura sobre o assunto, verifica-se que existe uma grande quantidade de estudos investigando e explicando a importância e os efeitos dos fatores psicossociais do trabalho sobre a saúde do trabalhador e/ou sobre a satisfação no trabalho. Porém, existe uma quantidade menor de estudos investigando as associações entre satisfação no trabalho e saúde do trabalhador.

Entre estes estudos podem ser citados os de RAHMAN e SEN (1987), O'DRISCOLL e BEEHR (1994), ROCHA (1996), ZALEWSKA (1996), RAMIREZ et. al. (1996) e PETERSON e DUNNAGAN (1998) que encontraram associações significativas entre satisfação no trabalho e saúde mental, onde um aumento do nível de satisfação no trabalho é acompanhado de melhoria da condição de saúde mental e/ou da diminuição de queixas ou de manifestações de desordens psiquiátricas. ROCHA (1996), ZALEWSKA (1996) e PETERSON e DUNNAGAN (1998), também encontraram associações significativas entre satisfação no trabalho e saúde física, onde aumento do nível de satisfação é acompanhado da diminuição de queixas e/ou de agravos relacionados à saúde física.

Estes estudos evidenciam as associações entre satisfação no trabalho e saúde do trabalhador e apontam para os fatores psicossociais no trabalho como determinantes importantes dos níveis de satisfação. Porém, não preenchem uma lacuna que é a indefinição do sentido em que se dá a relação causal entre satisfação no trabalho e 
saúde. HENNE e LOCKE (1985) e PETERSON e DUNNAGAN (1998) apontam que esta direção não é clara e questionam se a saúde influencia a satisfação no trabalho, se a satisfação no trabalho influencia a saúde, ou se ambas são influenciadas por algum outro fator em comum. Conforme assinalam PETERSON e DUNNAGAN (1998), as relações entre os três fenômenos - fatores psicossociais do trabalho, satisfação no trabalho e saúde - não estão suficientemente claras e necessitam de estudos mais aprofundados.

Em revisão bibliográfica realizada no segundo semestre de 2000 e atualizada no segundo semestre de 2001, utilizando as bases de dados MEDLINE, SciELO, LILACS, ProBE e DEDALUS, identificou-se que alguns dos aspectos psicossociais do trabalhos que têm sido estudados em suas associações com satisfação no trabalho são:

- Estabilidade no emprego (BRAGA 1978; ARAÚJO 1985; PAULA 1990; KORUNKA e VITOUCH 1999; ZALEWSKA 1999a, 1999b; O’DRISCOLL e BEEHR 1994, 2000; ELOVAINIO et. al. 2000).

- Salários, pagamentos, recompensas financeiras e beneficios (BRAGA 1978; ARAÚJO 1985; CODA 1986; BRIEF e ROBERSON 1989; PAULA 1990; LICHT 1990; SNEED e HERMAN 1990; CAVANAGH 1992; LINO 1999; KORUNKA e VITOUCH 1999; ZALEWSKA 1999a, 1999b; O’DRISCOLL e BEEHR 1994, 2000; ELOVAINIO et. al. 2000).

- Relações sociais no trabalho (colegas, clientes, fornecedores, etc.) (ARAÚJO 1985; BRIEF e ROBERSON 1989; PAULA 1990; LICHT 1990; SNEED e HERMAN 1990; JUDGE e LOCKE 1993; LINO 1999; ZALEWSKA 1999a, 1999b; KORUNKA e VITOUCH 1999; ELOVAINIO et. al. 2000; O’DRISCOLL e BEEHR 1994, 2000; SAN MARTÍN et. al. 2000; WRIGHT e CROPANZANO 2000; CHAN et. al. 2000).

- Supervisão, relação com chefias, suporte de chefias, competência técnica e administrativa das chefias, estilo de liderança (ARAÚJO 1985; BRIEF e ROBERSON 1989; LICHT 1990; SNEED e HERMAN 1990; JUDGE e LOCKE 1993; ZALEWSKA 1996, 1999a, 1999b; KORUNKA e VITOUCH 1999; 
ELOVAINIO et. al. 2000; O'DRISCOLL e BEEHR 2000; WRIGHT e CROPANZANO 2000).

- Carga de trabalho (física e mental) (O’DRISCOLL e BEEHR 1994, 2000; SAN MARTÍN et. al. 2000).

- Promoção / perspectivas de carreira (BRIEF e ROBERSON 1989; SNEED e HERMAN 1990; CAVANAGH 1992; JUDGE e LOCKE 1993; KORUNKA e VITOUCH 1999; O’DRISCOLL e BEEHR 2000; SAN MARTÍN et. al. 2000; CHAN et. al. 2000).

- Ambiente físico de trabalho (relacionado aos agentes físicos, químicos, biológicos e ergonômicos) (LICHT 1990; KORUNKA e VITOUCH 1999; O’DRISCOLL e BEEHR 1994, 2000).

- Variedade / monotonia (CAVANAGH 1992; ROCHA 1996; O’DRISCOLL e BEEHR 1994, 2000; SAN MARTÍN et. al. 2000).

- Conteúdo do trabalho (ZALEWSKA 1999a, 1999b).

- Desafios no trabalho (O’DRISCOLL e BEEHR 1994, 2000).

- Autonomia (O’DRISCOLL e BEEHR 1994, 2000; LINO 1999).

- Prazos (KORUNKA e VITOUCH 1999).

- Oportunidade de desenvolvimento profissional (acesso e troca de informações com outros profissionais, educação e treinamento) (LICHT 1990; CAVANAGH 1992; ROCHA 1996; ZALEWSKA 1999a, 1999b; O’DRISCOLL e BEEHR 1994, 2000; ELOVAINIO et. al. 2000).

- Participação (na tomada de decisão) (CAVANAGH 1999).

- Pressão para o desempenho (CHAN et. al. 2000).

- Uso de habilidades e possibilidade de criação (ZALEWSKA 1996, 1999a, 1999b; ROCHA 1996).

- Equipamentos / tecnologia (ROCHA 1996).

- Reconhecimento / valorização profissional (LICHT 1990; ROCHA 1996).

- Importância do trabalho (ROCHA 1996).

- Posição social (“status”) (LINO 1999). 
A dinâmica entre fatores psicossociais do trabalho e os indivíduos é determinada pela interação de múltiplos fatores, onde a organização do trabalho exerce um papel importante porque define o conteúdo das tarefas e as relações no trabalho.

Como conseqüência, as relações entre fatores psicossociais, satisfação no trabalho e saúde são complexas, multidirecionais e, às vezes, difíceis de serem identificadas. Esta complexidade pode ser explicada pelo fato de que "trabalho, estresse e satisfação no trabalho, são vastos no seu escopo, intangíveis em maior ou menor grau na sua definição, e transdisciplinares no conhecimento requerido" (FRASER 1983, p.3).

Como a satisfação no trabalho é influenciada por diferenças na personalidade e pelos valores atribuídos ao trabalho, então esta satisfação é intermediada pela percepção e avaliação que os indivíduos têm quanto aos diversos aspectos do trabalho. Assim, a avaliação dos efeitos do ambiente psicossocial na saúde do coletivo de trabalho passa pela avaliação da percepção dos indivíduos quanto à satisfação com o ambiente compartilhado por um determinado grupo de trabalhadores.

\section{6 - REFERENCIAL TEÓRICO DO ESTUDO}

Conforme dito anteriormente, as relações ente satisfação com fatores psicossociais no trabalho e saúde são complexas, multidirecionais e difíceis de serem identificadas. Além disso, as teorias sobre satisfação no trabalho não oferecem evidências conclusivas sobre as relações entre satisfação no trabalho e saúde do trabalhador.

Essa situação definiu a necessidade de buscar referenciais teóricos em diferentes áreas do conhecimento (como a psicologia, a medicina, a ergonomia e a epidemiologia) que possibilitassem o estudo das associações entre esses fenômenos dentro de uma abordagem multidisciplinar. 
Assim, para compreensão do fenômeno satisfação no trabalho foi adotada a Teoria de Locke que está apresentada no item 1.2.2 - Teorias sobre satisfação no trabalho.

Esta teoria apresenta um conceito de satisfação no trabalho que é compatível com a concepção de satisfação como fenômeno caracterizado pela subjetividade e valores do indivíduo e sujeita às influências do ambiente de trabalho. Em sua conceituação LOCKE $(1969,1976,1984)$ considera que a satisfação e a insatisfação no trabalho não são fenômenos distintos, mas situações opostas de um mesmo fenômeno. Este conceito está apresentado nos itens 1.2.1 - Conceitos e definições, e no item 1.2.2 Teorias sobre satisfação no trabalho.

A Teoria de Locke apresenta uma abordagem abrangente que contempla a importância dos aspectos psicossociais no trabalho agindo sobre os trabalhadores, considera aspectos da subjetividade dos indivíduos, e apresenta alguma teorização sobre os efeitos da satisfação no trabalho sobre a saúde dos trabalhadores. Além disso, esta teoria considera que a satisfação global com o trabalho pode ser avaliada a partir do conjunto, da soma da avaliação com os diversos aspectos do trabalho, possibilitando a obtenção de um indicador válido de satisfação global no trabalho (LOCKE 1969).

É importante lembrar que, embora as respostas sejam individuais, existe uma semelhança entre o que o conjunto dos trabalhadores quer (HENNE e LOCKE 1985), o que permite que esta teoria seja utilizada como referencial tanto para estudos com abordagem qualitativa e subjetiva focada em indivíduos, como em estudos com abordagem quantitativa e epidemiológica focada em populações de trabalhadores, que é o caso desta pesquisa.

Para compreensão dos fatores psicossociais no trabalho foi adotado o Modelo de interação entre fatores do ambiente psicossocial e saúde proposto por LEVI (1987, 1997, 1998), apresentado no item 1.3.3 - Modelo teórico. 
Este modelo apresenta uma abordagem da determinação do estresse que leva em conta, não só os aspectos fisiológicos, mas, principalmente, questões psicossociais representando um papel fundamental na determinação da satisfação no trabalho e do processo saúde-doença.

No escopo da abordagem dos fatores psicossociais no trabalho, a organização do trabalho desempenha papel importante porque é ela que define tanto o sentido e o interesse do trabalho como as relações humanas no trabalho (DEJOURS 1987; DEJOURS e ABDOUCHELI 1994). Neste estudo foi adotado o conceito de DEJOURS (1987) que considera a organização do trabalho como sendo a divisão do trabalho e a divisão dos homens. Este conceito está expresso no item 1.2.2 - Teorias sobre satisfação no trabalho em seu sub-item "Psicodinâmica do Trabalho". Os principais aspectos que são considerados na organização do trabalho estão citados no item 1.3.1 - Conceito em seu sub-item "Fatores associados ao ambiente e organização do trabalho".

Para entendimento do conceito de saúde do trabalhador são utilizadas as abordagens apresentadas no item 1.4 - Saúde do Trabalhador, e que consideram este fenômeno como uma condição dinâmica e definida em um dado contexto histórico e social.

Também foram usados, como embasamento teórico, os estudos de RAHMAN e SEN (1987), O’DRISCOLL e BEEHR (1994), RAMIREZ et. al. (1996), ZALEWSKA (1996), ROCHA (1996), e PETERSON e DUNNAGAN (1998) que encontraram associações significativas entre satisfação no trabalho e saúde, onde maiores níveis de satisfação estão relacionados à melhor condição de saúde e à diminuição de queixas ou agravos à saúde. 


\section{2 - OBJETIVOS}

Este estudo pretende colaborar com a análise das relações entre satisfação com aspectos psicossociais do trabalho e saúde do trabalhador, definida em termos de saúde física, saúde mental e capacidade para o trabalho.

Para tal, tem como objetivos:

- Reconhecer qual o conceito que os trabalhadores que compõem a população de estudo têm de satisfação no trabalho e quais os aspectos psicossociais do trabalho que consideram que influenciam na satisfação no trabalho.

- Verificar se o conceito de satisfação no trabalho e se os aspectos psicossociais do trabalho citados pelos trabalhadores que compõem a população de estudo coincidem com os da literatura.

- Identificar os níveis de satisfação no trabalho dos trabalhadores que compõem a população de estudo em relação ao seu trabalho.

- Identificar quais as características sócio-demográficas e funcionais que estão associadas à satisfação no trabalho.

- Verificar se satisfação no trabalho está relacionada à saúde dos trabalhadores que compõem a população de estudo.

- Verificar quais aspectos da organização do trabalho podem estar influenciando a satisfação no trabalho dos trabalhadores que compõem a população de estudo. 


\section{3 - METODOLOGIA}

\section{1 - HIPÓTESES}

Foram levantadas duas hipóteses para investigação neste estudo:

- Hipótese 1: a satisfação com aspectos psicossociais no trabalho está relacionada à saúde dos trabalhadores da população de estudo.

- Hipótese 2: níveis mais elevados de satisfação com aspectos psicossociais do trabalho estão relacionados a uma melhor condição de saúde entre os trabalhadores da população de estudo.

\section{2 - TIPO DE ESTUDO}

Este estudo é caracterizado como epidemiológico com modelo transversal, que consiste em um corte no fluxo histórico do evento, no qual exposição e efeito são observados simultaneamente. Segundo ALMEIDA FILHO e ROUQUAYROL (1992), a análise dos dados baseia-se na comparação de prevalências de indivíduos "acometidos" entre os expostos e os não expostos e utiliza teste de hipóteses para verificar relações de associação.

Devido a exposição e efeito serem observadas no mesmo lapso de tempo, os resultados desse tipo de estudo não são indicativos de seqüência temporal, não podendo determinar causalidade (ALMEIDA FILHO e ROUQUAYROL 1992). 
Portanto, este tipo de estudo informa o que está acontecendo no momento, indicando se há associação entre exposição e evento, mas não identificando qual a relação de causalidade.

Para verificar a relação de causalidade, o estudo transversal deve ser complementado por outras estratégias (como abordagens qualitativas ou a partir de conhecimentos científicos já estabelecidos) ou, se possível, dar origem a um estudo longitudinal, que possibilite acompanhar os indivíduos ao longo de um período e, então, estabelecer relações causais.

Complementarmente, foram realizadas entrevistas exploratórias para verificar a semelhança entre referências encontradas em literatura com as percepções dos empregados da população de estudo quanto ao conceito e à fontes de satisfação no trabalho. Também foram realizadas análises ergonômicas do trabalho buscando caracterizar aspectos da organização do trabalho destes empregados.

\section{3 - ESTRATÉGIAS PARA COLETA E ANÁLISE DE DADOS}

$\mathrm{Na}$ avaliação que o indivíduo faz sobre a satisfação que sente em relação ao seu trabalho estão envolvidos aspectos subjetivos relacionados a valores, sentimentos e expectativas, uma vez que satisfação no trabalho é um estado emocional que envolve um componente cognitivo e um emocional. Esta complexidade faz com que este seja um fenômeno difícil de ser mensurado e avaliado.

Por isso, considerou-se a necessidade de utilização de diferentes técnicas e instrumentos e, para tanto, optou-se por 3 estratégias para obtenção de dados: 
- Entrevista exploratória: para identificação da percepção dos empregados da população de estudo quanto ao fenômeno satisfação no trabalho no seu próprio contexto de trabalho;

- Questionário auto-aplicado: possibilitando mensuração dos níveis de satisfação no trabalho e da condição de saúde, para identificação dos aspectos psicossociais do trabalho que influenciam nos níveis de satisfação e para verificação das associações entre os fenômenos satisfação e saúde;

- Análise ergonômica do trabalho: buscando caracterizar a organização do trabalho e a manifestação de aspectos psicossociais do trabalho sobre os empregados da população de estudo e verificar quais destas características ou aspectos interferem na satisfação no trabalho.

\subsection{1 - Entrevista exploratória}

\subsubsection{1 - Justificativa da escolha do instrumento:}

SELLTIZ et. al. (1967) esclarecem que os estudos exploratórios têm como funções, entre outras, aumentar o conhecimento do pesquisador acerca do fenômeno que deseja investigar ou da situação em que pretende realizar tal estudo; o esclarecimento de conceitos; o estabelecimento de prioridades para futuras pesquisas e a obtenção de informações sobre possibilidades práticas de realização de pesquisas em situação de vida real. MORENO (1993) complementa que o principal objetivo de uma pesquisa exploratória é evitar que vieses profissionais do pesquisador interfiram na percepção do que está sendo observado.

Como satisfação no trabalho pode variar em decorrência de aspectos subjetivos, sociais e culturais, a entrevista exploratória foi realizada para identificar a percepção dos empregados da população de estudo em relação ao conceito de satisfação no 
trabalho e à percepção de quais aspectos psicossociais do trabalho são considerados como influentes (positiva ou negativamente) sobre a satisfação e insatisfação no trabalho, bem como verificar se há discrepância entre estes achados e os identificados na literatura.

Percepção é o ato pelo qual o indivíduo toma conhecimento de um objeto ou situação do meio exterior por meio dos sentidos, e dá a ele um significado baseado em elementos da memória, do raciocínio, do juízo e do afeto; é um processo pelo qual o indivíduo acopla elementos subjetivos e próprios de cada pessoa às qualidades objetivas do mundo exterior; a percepção confere originalidade pessoal à realidade apreendida (BALLONE 1999).

\subsubsection{2 - Instrumento:}

Foi realizada entrevista semi-estruturada baseada em três questões (Anexo III Roteiro para entrevista exploratória). A entrevista semi-estruturada baseia-se em apenas uma ou poucas questões-guia, quase sempre abertas, onde nem todas as questões elaboradas são utilizadas durante a realização da entrevista, e onde podem ser introduzidas outras questões que venham a surgir no processo da entrevista (TANAKA e MELO 2001).

\subsubsection{3 - Amostra:}

Não foi definido a priori um número de entrevistas a serem realizadas. Segundo SELLTIZ et. al. (1967), em um estudo exploratório, quando as respostas começam a se repetir e caem em um padrão que já se conhece, outras entrevistas se tornam cada vez menos compensadoras.

Considerou-se que, estando a empresa ainda em fase de reestruturação, a escolha de empregados para participação na entrevista por sorteio ou indicação poderia gerar 
algum potencial medo ou insegurança, e as pessoas poderiam sentir-se ameaçadas e/ou omitir ou mascarar informações relevantes. Também considerou-se que, voluntários, além de serem pessoas que estariam interessadas em participar da pesquisa, estariam mais à vontade para responder as questões. Uma outra consideração foi que, em função do medo e insegurança já citados, poderiam haver poucos voluntários.

Levando em conta estas considerações, optou-se por utilizar amostra com ao menos um representante de cada área de trabalho e, caso continuassem a surgir novas informações, aumentar o número de participantes.

\subsubsection{4 - Análise dos dados:}

Foi utilizada a análise de conteúdo por meio da análise categorial. Análise de conteúdo é um "conjunto de técnicas de análise das comunicações, que utiliza procedimentos sistemáticos e objetivos de descrição do conteúdo das mensagens" (BARDIN 1977). A análise categorial é um dos métodos da análise de conteúdo, que classifica os elementos de significação da mensagem em categorias (BARDIN 1977).

A técnica de análise categorial fornece uma representação simplificada dos dados brutos e consiste em desmembrar o texto em diferentes elementos, reagrupando-o segundo critérios susceptíveis de fazer surgir um sentido que dê ordenação na confusão inicial do discurso e onde os critérios de classificação dependem daquilo que se procura ou que se espera encontrar (BARDIN 1977).

Para esta análise foram realizadas as seguintes etapas:

- Transcrição da gravação das entrevistas

- Identificação, no texto do discurso, dos elementos relacionados a cada um dos itens de interesse (conceito de satisfação no trabalho, aspectos relacionados à satisfação e aspectos relacionados à insatisfação no trabalho). 
- Reagrupamento dos elementos em categorias. O critério utilizado foi $\mathrm{o}$ semântico, ou seja, as categorias foram estabelecidas segundo temas, considerando o que há de comum entre os diversos elementos.

- A proposta foi identificar e categorizar a maior quantidade possível de elementos, sem preocupação em verificar a freqüência com que cada elemento apareceu no discurso.

\subsection{2 - Questionários auto-aplicados}

\subsubsection{1 - Justificativa da escolha dos instrumentos:}

A avaliação de dados qualitativos, em especial, dados subjetivos, por meio de abordagem quantitativa requer utilização de estratégias definidas e validadas para mensuração e análise das variáveis, sendo que estratégias adequadas para uma situação ou contexto podem não ser para outro.

No estudo dos fatores psicossociais no trabalho que atuam como fontes de estresse, o questionário é o instrumento mais freqüentemente utilizado (ILO 1984). Para sua utilização, são necessárias grandes amostras (mínimo de 100 sujeitos) para oferecer resultados estáveis e que tenham relevância teórica e prática (HOLLMANN et. al. 1999).

Este tipo de questionário permite a análise conjunta de múltiplas variáveis, inclusive características de personalidade e avaliação de aspectos psicossociais do trabalho, segundo a percepção dos trabalhadores. Permite, também, cruzar estas variáveis com outras de medida objetiva.

Segundo PEREIRA (1999), atributos de natureza qualitativa podem receber tratamento quantitativo desde que o pesquisador possa assumir algumas premissas de natureza ontológica e semântica para a concepção de seus dados. Assim, desde que 
se possa estabelecer premissas na relação entre as palavras e o pensamento referente ao objeto de estudo, e se possa assumir premissas relacionadas ao conhecimento geral e abstrato a cerca do objeto de estudo, o pesquisador pode desenvolver uma abordagem quantitativa para estudar eventos qualitativos.

Os questionários possibilitam a obtenção de um indicador quantitativo dos fenômenos qualitativos estudados. Um indicador é uma característica de um indivíduo, população ou entorno susceptível de medição (direta ou indireta) e que pode ser utilizado para descrever um ou mais aspectos de um indivíduo ou população em termos de qualidade, quantidade ou tempo (OMS 1998). Um indicador também pode ser considerado como uma variável composta a partir da mensuração dos diversos elementos considerados integrantes do objeto de estudo (PEREIRA 1999) e tem como característica principal a capacidade de sintetizar aquilo que se quer mostrar.

Para que um questionário seja considerado adequado para a mensuração de eventos qualitativos subjetivos, duas condições devem ser observadas: este instrumento deve apresentar confiabilidade e validade. Além disso, se o questionário for traduzido de uma língua para outra, ele deve passar pelo processo de adaptação transcultural. $\mathrm{O}$ Anexo IV (Propriedades de medida de um questionário) apresenta um resumo sobre alguns dos principais aspectos referentes à confiabilidade, validade e adaptação transcultural.

Existe uma grande quantidade e variedade de instrumentos disponíveis para avaliação de saúde e de satisfação no trabalho, tanto em língua portuguesa como estrangeira, porém estes instrumentos nem sempre são elaborados ou traduzidos com o rigor exigido em um processo de validação e/ou adaptação transcultural. Neste estudo buscou-se instrumentos que procuram obedecer estes critérios.

Para avaliar satisfação buscou-se um instrumento que medisse a satisfação do indivíduo a partir de sua percepção com diversos aspectos psicossociais do trabalho e que, a partir dessa mensuração oferecesse um indicador de satisfação global no 
trabalho. Para tanto foi escolhida a escala Satisfação no Trabalho do Occupational Stress Indicator - OSI de Cooper, Sloan e Williams (ROBERTSON et. al. 1990).

Para avaliar a saúde buscou-se um instrumento que considerasse a percepção dos indivíduos quanto aos seu próprio estado de saúde e que contemplasse os aspectos mais representativos da saúde. Para tanto optou-se pela versão em português do Medical Outcomes Study 36 - Item short form health survey (SF-36) (CICONELLI 1997), que oferece uma avaliação genérica da saúde.

Como este estudo é focado na saúde do trabalhador, considerou-se que a possibilidade de trabalhar é fundamental para determinar tanto a condição social como a condição de saúde dos indivíduos. Segundo TUOMI et. al. (1997), a capacidade para o trabalho é a base do bem-estar para todos e pode ser entendida como a condição que o trabalhador apresenta para executar seu trabalho em função das demandas deste trabalho, de seu estado de saúde e de suas capacidades físicas e mentais. Este é um conceito que compreende saúde, capacidade funcional física e psicológica, competência ocupacional e motivação para o trabalho (PEURALA 1999).

A capacidade para o trabalho é, portanto, uma forma de manifestação da condição de saúde do trabalhador e foi utilizada neste estudo como uma medida indireta da saúde do trabalhador. Para avaliar a capacidade para o trabalho optou-se pelo Índice de Capacidade para o Trabalho (TUOMI et. al. 1997).

\subsubsection{2 - Instrumentos:}

O instrumento para avaliação da satisfação no trabalho e da saúde utilizado nesta pesquisa foi composto por 4 questionários: 
- Questionário 1: Identificação

- Questionário 2: escala Satisfação no Trabalho do Occupational Stress Indicator OSI

- Questionário 3: SF 36 - Pesquisa em Saúde (versão em português do Medical Outcomes Study 36 - Item short form health survey)

- Questionário 4: ICT - Índice de Capacidade para o Trabalho

Estes instrumentos são discutidos a seguir.

\section{- Questionário 1: Identificação (Anexo V)}

Esta parte do instrumento contém uma breve explicação sobre a finalidade do mesmo e questões com alternativas fechadas referentes a dados sócio-demográficos e funcionais (setor de trabalho, cargo, tempo de empresa, idade, escolaridade e estado civil).

- Questionário 2: Escala Satisfação no Trabalho do OSI - Occupational Stress Incidator (Anexo VI)

Em revisão bibliográfica realizada nos segundo semestre de 2000 nas bases de dados MEDLINE, SciELO, LILACS, ProBE e DEDALUS, identificou-se que há uma série de instrumentos para avaliação da satisfação no trabalho disponíveis em literatura estrangeira.

Poucos desses instrumentos estão traduzidos, adaptados e/ou validados para o português. Um deles é o Job Satisfaction Scale de BRAYFIELD e ROTHE (1951) utilizado por BRAGA (1978), porém não foram encontradas informações sobre a metodologia utilizada para tradução, adaptação e/ou validação deste questionário para o português. Outro questionário é o Index of Work Satisfaction, com adaptação 
transcultural realizada por LINO (1999), mas trata-se de um instrumento especificamente estruturado para avaliação de satisfação profissional em enfermeiras.

Foram encontrados também outros questionários elaborados por pesquisadores brasileiros (BRAGA 1978; ARAÚJO 1985; CODA 1986; LICHT 1990; PAULA 1990; GIUZI 1993; FRANCA 1996; ROCHA 1996) mas que não foram considerados passíveis de serem utilizados neste estudo uma vez que a metodologia adotada pelos autores é diferente da adotada neste estudo. Por exemplo: questionários construídos para um contexto ou grupo profissional específico, referenciais teóricos diferentes, objetivos diferentes, inserção da satisfação no contexto de qualidade de vida ou de motivação para o trabalho ou uso de abordagem qualitativa por meio de entrevistas.

Uma opção encontrada foi a utilização da escala "Satisfação no Trabalho" do OSI Occupational Stress Indicator de Cooper, Sloan e Williams (ROBERTSON et. al. 1990).

O OSI é um instrumento construído para mensurar fontes de estresse no trabalho e suas conseqüências para o trabalhador a partir de uma abordagem do indivíduo e da situação. Para isso o instrumento é composto por 6 escalas independentes que mensuram fontes de estresse, comportamento tipo A, locus de controle, estratégias de enfrentamento, saúde (física e mental) e satisfação no trabalho (ROBERTSON et. al. 1990). Segundo MORAES et. al. (1998), o OSI não é um instrumento pronto e acabado, mas um modelo que vai sendo construído à medida em que toma contato com a realidade e a cada nova realidade ele pode ser modificado para atender as necessidades situacionais.

Este instrumento foi traduzido e validado para o português por SWAN et. al. (1993), onde a escala satisfação no trabalho apresentou confiabilidade satisfatória, com alfa de Cronbach $=0,92$ (para comentários sobre o coeficiente alfa de Cronbach, ver Anexo IX - Glossário de termos estatísticos). Para validação desta escala foi 
verificada sua validade de construto por meio de análise estatística correlacional e multivariada (SWAN et. al. 1993).

$\mathrm{Na}$ versão original em inglês, a escala é dividida em sub-escalas com base em uma análise estatística fatorial. Os autores do processo de validação deste instrumento consideraram que diferenças culturais entre os países, com diferenças entre os valores dos indivíduos, poderiam ter implicações na construção das sub-escalas e, por isso, optaram por não considerá-las na versão em português, trabalhando com a escala única (SWAN et. al. 1993). A versão em português desta escala do OSI é encontrada em COUTO (2000).

A escala satisfação no trabalho compõe uma variável que mede os sentimentos do indivíduo em relação a diferentes aspectos do seu trabalho (MORAES et. al. 1998). Essa escala possibilita a mensuração da satisfação no trabalho com 22 diferentes aspectos psicossociais do trabalho por meio de escalas de Likert de 6 pontos, classificando o nível de satisfação como: (1) enorme insatisfação, (2) muita insatisfação, (3) alguma insatisfação, (4) alguma satisfação, (5) muita satisfação, e (6) enorme satisfação. A soma dessas medidas fornece um indicador de satisfação no trabalho global dado por um escore que varia de 22 a 132 pontos. Não há um ponto de corte definido neste escore. Alguns autores optam por usar escores médios e atribuem um ponto de corte aleatório (MORAES et. al. 1998), outros optam por utilizar o escore bruto sem atribuição de ponto de corte (LU et. al. 1997).

As escalas de Likert podem ser encontradas em grande número de estudos sobre satisfação no trabalho (BRAYFIELD e ROTHE 1951; HARTMAN et. al. 1986; SNEED e HERMAN 1990; GROENEWEGEN e HUTTEN 1991; SIEFERT et. al. 1991; JUDGE e LOCKE 1993; BEGLEY e CZAJKA 1993; PETERSON e DUNNAGAN 1998; ZALEWSKA 1999a, 1999b; JUDGE et. al. 2000; ELOVAINIO et. al. 2000; O’DRISCOLL e BEEHR 2000; WRIGHT e CROPANZANO 2000).

PEREIRA (1999) atribui a grande utilização deste tipo de escala ao fato de ter sensibilidade para reconhecer a oposição entre os contrários, reconhecer gradiente e 
apresentar uma relação adequada entre a precisão e acurácia da mensuração. Segundo o mesmo autor, precisão diz respeito à fineza com que se realiza a medida e acurácia diz respeito à validade ou capacidade da medida em representar bem o objeto medido.

Segundo PEREIRA (1999, p.55), “a criação de uma escala envolve o estabelecimento de premissas de relação entre atributos de um objeto e uma representação simbólica desses atributos. A escala atribui rótulos numéricos aos atributos e é arbitrada, definida pelos pesquisador." Assim, o pesquisador define os atributos de um objeto e atribui a eles um número que permita representar estes atributos de forma quantitativa.

No uso destas escalas, o indivíduo usa o julgamento para relacionar representações psicológicas latentes à respostas manifestas, e estas são assinaladas sobre uma escala de avaliação gráfica (RUSSEL e BOBKO 1992). Neste sentido, "o dado qualitativo é uma forma de quantificação do evento qualitativo que normatiza e confere caráter à sua observação" (PEREIRA 1999, p.21), ou seja, o dado qualitativo expressa de forma quantitativa a percepção dos indivíduos a respeito de um fenômeno.

- Questionário 3: SF 36 - Pesquisa em Saúde (versão em português do Medical Outcomes Study 36 - Item short form health survey) (Anexo VII)

A opção por uma avaliação de saúde auto-referida se deu porque ela contempla as percepções do indivíduo e, conforme relatam LUNDBERG e MANDERBACKA (1996), a medida de saúde auto-avaliada tem demonstrado ser uma estratégia válida como representativa da saúde global havendo, inclusive, evidências de um poder preditivo da saúde auto-referida sobre a mortalidade, o indivíduo e a população geral.

Para tanto, optou-se pela utilização da versão brasileira do SF-36 - Medical Outcomes Study 36 - item short form health survey, questionário traduzido e validado para o português por CICONELLI (1997). 
O SF-36 foi criado com a finalidade de ser um questionário genérico de avaliação de saúde e, portanto, seus conceitos não são específicos para uma determinada idade, doença ou grupo de tratamento (CICONELLI 1997; WARE 2000). O SF-36 é formado por 36 itens, englobados em 8 escalas ou componentes (CICONELLI 1997). Estes 8 componentes da saúde foram escolhidos por representar os conceitos mais freqüentemente mensurados nos inquéritos de saúde (WARE 2000) e são:

- Capacidade funcional: avalia presença e extensão de limitações relacionadas à capacidade física.

- Aspectos físicos: avalia as limitações no tipo e na quantidade do trabalho e das atividades de vida diária em conseqüência de problemas físicos.

- Dor: avalia a extensão da dor e a interferência nas atividades de vida diária.

- Estado geral de saúde: avalia as percepções referentes ao estado de saúde geral.

- Vitalidade: considera o nível de energia e de fadiga.

- Aspectos sociais: avalia a limitação da participação do indivíduo em atividades sociais, decorrente de problemas com a saúde.

- Aspecto emocional: avalia as limitações no tipo e na quantidade do trabalho e das atividades de vida diária em conseqüência de problemas emocionais.

- Saúde mental: avalia as percepções em relação a 4 principais dimensões da saúde mental: ansiedade, depressão, alterações do comportamento e bem-estar psicológico.

Para avaliação dos resultados é dado um escore para cada questão que, posteriormente, são transformados em uma escala de 0 a 100 onde 0 (zero) corresponde a um pior estado de saúde e 100 a um melhor estado de saúde, sendo que cada dimensão é analisada em separado (CICONELLI 1997). A pontuação das questões e instruções para cálculo dos escores é encontrada em CICONELLI (1997). A Tabela 2 apresenta um resumo de como podem ser interpretados os resultados. 
Tabela 2: Resumo das possíveis interpretações dos resultados do SF-36 para cada uma de suas escalas.

\begin{tabular}{|c|c|c|}
\hline Escala & Interpretação no pior escore & $\begin{array}{c}\text { Interpretação no melhor } \\
\text { escore }\end{array}$ \\
\hline $\begin{array}{l}\text { Capacidade } \\
\text { funcional }\end{array}$ & $\begin{array}{l}\text { Grande limitação no } \\
\text { desempenho de todas atividades } \\
\text { físicas, incluindo tomar banho e } \\
\text { vestir-se }\end{array}$ & $\begin{array}{l}\text { Desempenha todo tipo de } \\
\text { atividades físicas incluindo as } \\
\text { mais vigorosas, sem limitações } \\
\text { induzidas pela saúde }\end{array}$ \\
\hline $\begin{array}{l}\text { Aspectos } \\
\text { físicos }\end{array}$ & $\begin{array}{l}\text { Problemas com o trabalho ou } \\
\text { outras atividades diárias como } \\
\text { resultado da saúde física }\end{array}$ & $\begin{array}{l}\text { Sem problemas com o trabalho } \\
\text { ou outras atividades diárias. }\end{array}$ \\
\hline Dor & $\begin{array}{l}\text { Dor muito severa e } \\
\text { extremamente limitante }\end{array}$ & $\begin{array}{l}\text { Sem dor ou limitações induzidas } \\
\text { por dor }\end{array}$ \\
\hline $\begin{array}{l}\text { Estado geral } \\
\text { de saúde }\end{array}$ & $\begin{array}{l}\text { Avaliação pessoal da saúde } \\
\text { como pobre, e crença de que irá } \\
\text { piorar }\end{array}$ & $\begin{array}{l}\text { Avaliação pessoal da saúde } \\
\text { como excelente }\end{array}$ \\
\hline Vitalidade & $\begin{array}{lll}\text { Sensação de cansaço } & \text { e } \\
\text { esgotamento durante todo } & \text { o } \\
\text { tempo } & & \end{array}$ & $\begin{array}{l}\text { Sensação de dinamismo } \\
\text { energia durante todo o tempo }\end{array}$ \\
\hline $\begin{array}{l}\text { Aspectos } \\
\text { sociais }\end{array}$ & $\begin{array}{lcr}\text { Interferência } & \text { extrema } & \text { e } \\
\text { freqüente } & \text { induzida } & \text { por } \\
\text { problemas } & \text { físicos } & \text { ou } \\
\text { emocionais } & \text { nas atividades } \\
\text { sociais } & & \end{array}$ & $\begin{array}{lrr}\text { Desempenho das atividades } \\
\text { sociais normais } & \text { sem } \\
\text { interferência induzida por } & \text { problemas físicos ou emocionais }\end{array}$ \\
\hline $\begin{array}{l}\text { Aspecto } \\
\text { emocional }\end{array}$ & $\begin{array}{l}\text { Problemas com o trabalho ou } \\
\text { outras atividades diárias como } \\
\text { resultado da saúde emocional }\end{array}$ & $\begin{array}{l}\text { Sem problemas com o trabalho } \\
\text { ou outras atividades diárias. }\end{array}$ \\
\hline $\begin{array}{l}\text { Saúde } \\
\text { mental }\end{array}$ & $\begin{array}{l}\text { Sentimentos de nervosismo e } \\
\text { depressão durante todo o tempo }\end{array}$ & $\begin{array}{l}\text { Sentimentos de tranqüilidade, } \\
\text { felicidade e calma durante todo } \\
\text { o tempo }\end{array}$ \\
\hline
\end{tabular}

Adaptado de WARE 2000

Segundo CICONELLI (1997) não é utilizado um único valor que resuma toda a avaliação visando evitar o erro de não se identificar ou subestimar problemas relacionados à saúde do indivíduo. 
$\mathrm{Na}$ versão em inglês, a análise de componentes demonstrou que existem dois conceitos distintos medidos pelo SF-36: uma dimensão física e uma dimensão mental, sendo que as 8 escalas podem ser agrupadas em 2 medidas sintéticas chamadas componente físico e componente mental (HOPMAN et. al. 2000; WARE e KOSINSKI 2001). O componente físico é composto pelas escalas capacidade funcional, aspectos físicos, dor e estado geral de saúde; o componente mental é composto pelas escalas vitalidade, aspectos sociais, aspecto emocional e saúde mental (WARE 2000; WARE e KOSINSKI 2001).

Como este procedimento não está validado para a versão brasileira, considerou-se, neste estudo, que as 4 primeiras escalas são representativas da saúde física, e as 4 últimas da saúde mental, porém cada uma das 8 escalas foi avaliada em separado, sem configuração de uma medida síntese para a saúde física e outra para a saúde mental.

Por se tratar de um instrumento que oferece uma avaliação genérica de saúde contemplando aspectos diversos representando a saúde física e a saúde mental, este instrumento possibilita uma avaliação que contempla saúde em um sentido amplo procurando abarcar não só aspectos relacionados à presença ou ausência de sintomas de disfunções ou agravos, mas também aspectos relacionados à comprometimentos que possam estar interferindo no bem-estar ou dificultando as atividades de vida do indivíduo.

Neste sentido, a avaliação da saúde física obtida por meio deste instrumento considera saúde física como sendo não apenas uma condição física livre de doença, mas também a possibilidade de desempenhar atividades físicas (atividades de vida diária, de trabalho, lazer ou sociais) sem limitações devidas à dor ou à intercorrências no funcionamento do organismo. Da mesma forma, a saúde mental é avaliada como sendo não apenas a ausência de sintomas ou doenças de ordem mental, mas também uma condição na qual o indivíduo desfrute sentimentos de bem-estar psicológico e tenha a possibilidade de desempenhar suas atividades de vida diária, sociais e de trabalho sem interferências decorrentes de problemas com saúde. 
O SF-36 apresenta, também, as vantagens de ser de fácil administração e compreensão e de rápida aplicação. CICONELLI (1997) informa que o SF-36 foi estruturado para ser auto-administrável. Como a população junto à qual foi realizado o estudo para validação do instrumento em língua portuguesa apresentava baixo nível sócio-econômico, cultural e de escolaridade, a autora do processo de adaptação transcultural indicou a aplicação do questionário por meio de entrevistas (CICONELLI 1997). Como a população deste atual estudo apresenta nível de escolaridade diferenciado ( $2^{\circ}$ e $3^{\circ}$ graus), optou-se pela forma auto-administrada.

\section{- Questionário 4: ICT - Índice de Capacidade para o trabalho (Anexo VIII)}

O ICT - Índice de Capacidade para o Trabalho é um instrumento elaborado e validado pelo Instituto de Saúde Ocupacional da Finlândia com base em estudos conduzidos no período de 1981 a 1992 (TUOMI et. al. 1997). O instrumento foi traduzido para o português e testado por um grupo composto por pesquisadores da Faculdade de Saúde Pública da Universidade de São Paulo e profissionais de outras universidades e instituições (públicas e privadas) do Brasil (TUOMI et. al. 1997).

É um instrumento que considera a percepção do próprio trabalhador para os seguintes aspectos: (a) capacidade para o trabalho atual e comparada com a melhor de toda a vida, (b) capacidade para o trabalho em relação às exigências do trabalho, (c) número atual de doenças auto-percebidas e diagnosticadas por médico, (d) perda estimada para o trabalho devido à doenças, (e) falta ao trabalho por doenças, (f) prognóstico próprio sobre a capacidade para o trabalho, e (g) recursos mentais.

Os itens recebem pontuações e fornecem um escore que varia de 7 a 49 pontos, com pontos de corte classificando a capacidade para o trabalho de cada indivíduo como baixa (7-27 pontos); moderada (28-36 pontos), boa (37-43 pontos) ou ótima (44-49 pontos) (TUOMI et. al. 1997). A pontuação das questões e instruções para cálculo dos escores é encontrada em TUOMI et. al. (1997). 
É um instrumento auto-aplicável, de aplicação rápida e fácil e com baixo custo. Os resultados podem ser utilizados no nível individual e coletivo. Individual porque permite identificar trabalhadores com comprometimento da capacidade funcional e adotar medidas de apoio. Coletivo porque permite a identificação de um perfil geral da capacidade para o trabalho, da capacidade funcional e dos fatores que os afetam, possibilitando adoção de medidas corretivas direcionadas para estes fatores (TUOMI et. al. 1997).

\subsubsection{3 - Amostra:}

Foi solicitada a participação de todos os empregados que estivessem trabalhando na época da coleta de dados. Assim, ficaram excluídos os empregados em férias, afastados por motivo de doença, participantes do pré-teste e a própria pesquisadora que é empregada da empresa.

\subsubsection{4 - Análise dos dados:}

\section{- Registro de dados:}

Foi elaborado um banco de dados utilizando o programa Microsoft Excell versão 97 (MICROSOFT 1998b). Posteriormente os dados foram exportados para os programas EPI INFO6 do CDC - Centers for Disease Control \& Prevention - Centro de Controle e Prevenção de Doenças (CDC 1996) e SPSS versão 10.0 (SPSS 1999). A digitação dos dados foi realizada pela própria pesquisadora.

\section{- Variáveis de estudo:}

Para análise estatística dos dados foram utilizadas as seguintes variáveis:

- Sexo: variável categorizada em feminino e masculino. 
- Idade: para categorização das faixas etárias considerou-se a curva de distribuição dos empregados segundo idade:

- Até 29 anos

- 30 a 39 anos

- 40 a 49 anos

- 50 anos ou mais.

- Escolaridade: os empregados foram categorizados em:

- $1^{\circ}$ grau completo

- $\quad 2^{\circ}$ grau completo

- $\quad 3^{\circ}$ grau completo

- Estado civil: os empregados foram categorizados como:

- Casados: casados(as) ou com companheiro(a)

- Não casados: solteiros(as), separados(as)/divorciados(as) e viúvos(as)

- Cargo: esta variável foi categorizada tendo como base a classificação de cargos adotada pela empresa, e foi composta formando as seguintes categorias:

- Analistas: empregados com escolaridade de nível universitário. Categoria composta por analistas de ações, acompanhamento financeiro, administração atendimento, cadastro, comunicação, controle de investimentos, custos, estudos atuariais, gestão de saúde, gestão odontológica, operacionalização de saúde, organização e métodos, previdência, projetos, recursos de saúde, risco, seguros, sistema de saúde, financeiro e contábil.

- Técnicos: empregados sem escolaridade universitária (o empregado pode ter nível universitário, mas seu cargo não exige esta qualificação). Categoria composta auxiliares de previdência, de operacionalização de saúde, de seguros e financeiro e por técnicos de administração, acompanhamento financeiro, cadastro, controle de investimentos, custos, operacionalização de saúde, previdência, recursos humanos, seguros, sistemas de saúde, financeiro e contábil. 
- Atendimento: empregados com cargo técnico que atuam no atendimento ao cliente, estando em contato com o cliente por meio pessoal direto ou telefônico. É composto por técnicos de atendimento e de tele-atendimento.

- Especialistas: empregados com escolaridade de nível universitário exercendo atividades técnicas e que não estão enquadrados na categoria analista. É composto por advogados, assistentes sociais, auditores, atuários, enfermeiros, jornalistas e secretárias.

- Direção: profissionais que têm cargos de liderança. É composta por chefes de setor, gerenciadores de projetos, gerentes de divisão e diretores.

- Area de trabalho: na empresa estudada existem 4 Diretorias, 10 Divisões e 16 Setores, alguns com pequeno número de empregados e com chefias em comum. Visando otimizar a análise dos dados foi realizado agrupamento em 18 áreas considerando semelhanças nas atribuições e liderança sob a mesma chefia. Este agrupamento consistiu na variável que foi denominada "área de trabalho". As competências das diversas áreas estão apresentadas no Anexo II.

- Tempo de empresa: esta variável foi categorizada da seguinte maneira:

- Menos de 3 anos: empregados admitidos após início do processo de privatização das mantenedoras.

- 3 a 5 anos: empregados admitidos no período que antecedeu a privatização das mantenedoras, e durante o qual esta privatização estava sendo definida.

- 6 a 10 anos: empregados admitidos no período em que a empresa tinha como mantenedoras apenas empresas estatais.

- 11 a 14: idem ao anterior, porém neste período haviam benefícios mais diferenciados.

- Renda: como a informação sobre rendimentos do empregado é sigilosa, esta variável foi composta a partir de informação sobre faixas de rendimento fornecida pelo Setor de Recursos Humanos da empresa. As categorias são dadas em número de salários mínimos (salário mínimo na ocasião da informação era de $\mathrm{R} \$ 152,00)$ : 
- Menos de 4 salários mínimos

- 4 a 6 salários mínimos

- 7 a 10 salários mínimos

- $\quad 11$ a 15 salários mínimos

- 16 a 20 salários mínimos

- $\quad 21$ a 25 salários mínimos

- $\quad$ acima de 25 salários mínimos

- Satisfação com aspectos específicos do trabalho: são 22 variáveis, cada uma referente a um aspecto do ambiente psicossocial do trabalho. Cada variável foi categorizada em:

- Insatisfação: enorme insatisfação e muita insatisfação

- Intermediário: alguma insatisfação e alguma satisfação

- Satisfação: muita satisfação e enorme satisfação

As variáveis analisadas foram:

- Comunicação: comunicação e forma do fluxo de informações na empresa

- Relacionamento: relacionamento com outras pessoas na empresa

- Avaliação: sentimento que tem em relação a como os esforços são avaliados

- Conteúdo: conteúdo do trabalho que realiza

- Motivação: grau em que se sente motivado para o trabalho

- Carreira: oportunidades pessoais na carreira

- Segurança: grau de segurança (estabilidade) no emprego

- Imagem: extensão em que se identifica com a imagem externa ou realizações da empresa

- Supervisão: estilo de supervisão dos superiores

- Mudança: forma pela qual as mudanças e inovações são implementadas

- Tarefa: tipo de tarefa e trabalho em que é cobrado

- Crescimento: grau em que sente que pode crescer e se desenvolver no trabalho

- Conflito: forma pela qual os conflitos são resolvidos

- Aspirações: oportunidades que o trabalho oferece para atingir aspirações e ambições 
- Decisão: grau de participação em decisões importantes

- Potencial: grau em que a empresa absorve as potencialidades que julga ter

- Liberdade: grau de liberdade e flexibilidade que julga ter no trabalho

- Clima: clima psicológico que predomina na empresa

- Salário: salário em relação à experiência e à responsabilidade

- Estrutura: estrutura organizacional da empresa

- Volume: volume de trabalho que tem para desenvolver

- Desenvolvimento: grau em que julga estar desenvolvendo suas potencialidades

- Satisfação no trabalho: é um indicador da satisfação global no trabalho, foi obtido pela soma dos resultados das respostas às 22 variáveis referentes à satisfação com aspectos específicos do trabalho. Este indicador fornece um escore com variação de 22 a 132 pontos contínuos, sem divisão em categorias.

- Saúde: a saúde foi avaliada com o uso de dois instrumentos: (1) SF-36 que oferece uma avaliação genérica de saúde por meio de 8 variáveis e (2) ICT que oferece uma avaliação da capacidade para o trabalho a partir da capacidade física e mental do trabalhador.

- Avaliação genérica de saúde: a saúde física foi representada pelas variáveis capacidade funcional, aspectos físicos, dor e estado geral de saúde. A saúde mental foi representada pelas variáveis vitalidade, aspectos sociais, aspecto emocional e saúde mental. Os resultados enquadraram-se em um escore com variação de 0 a 100, sem divisão em categorias.

- Índice de capacidade para o trabalho (ICT): os resultados enquadraram-se em um escore com variação de 7 a 49 pontos que é classificado como:

- Baixa capacidade para o trabalho: 7 a 27 pontos

- Moderada capacidade para o trabalho: 28 a 36 pontos

- Boa capacidade para o trabalho: 37 a 43 pontos

- Ótima capacidade para o trabalho: 44 a 49 pontos 


\section{- Análise estatística:}

A análise estatística dos dados obedeceu as etapas descritas abaixo. No Anexo IX Glossário de termos estatísticos, está apresentada uma breve explicação referente a termos estatísticos utilizados e aos testes estatísticos realizados.

\section{- Verificação da confiabilidade dos instrumentos:}

Considerando a possibilidade de erro inerente a questionários com componentes psicossociais e considerando que os instrumentos utilizados não haviam sido aplicados anteriormente nesta população de estudo, procedeu-se à análise de confiabilidade dos instrumentos por meio do Coeficiente alfa de Cronbach.

Além da confiabilidade dos instrumentos como um todo, foi verificado o papel de cada item de cada instrumento. Para isso foi analisado o alfa de Cronbach do instrumento se o item é desprezado, onde um aumento do valor do alfa indica que este item pode não ser adequado para compor o instrumento (PEREIRA 1999).

\section{- Análise das perdas:}

Foi feita a comparação entre população de estudo e perdas (empregados que não participaram do estudo) segundo características sócio-demográficas e funcionais, utilizando o teste de associação pelo Qui-quadrado.

\section{- Caracterização da população de estudo:}

Foi feita a análise descritiva dos dados por meio de médias, desvios padrão, valores mínimos, valores máximos e proporções. 


\section{- Análise das associações:}

Inicialmente foi feito o teste de Kolmogorov-Smirnov para verificar se as variáveis quantitativas contínuas apresentavam distribuição normal. Essa informação foi utilizada para determinar o tipo de teste estatístico adequado a cada variável.

Em seguida foi realizada a análise das correlações entre Satisfação no Trabalho e cada uma das demais variáveis independentes. Nesta análise satisfação no trabalho foi considerada como variável dependente e as demais variáveis como independentes.

Para análise da correlação da Satisfação no Trabalho com as variáveis quantitativas com distribuição não normal foi usado o Coeficiente de Correlação de Spearman.

Para análise da correlação da Satisfação no Trabalho com as variáveis qualitativas dicotômicas sem variância constante foi utilizado o teste Mann-Whitney. Para análise das correlações com as outras variáveis qualitativas (com 3 ou mais categorias) foi utilizado o teste de Kruskal-Wallis.

Havendo diferença estatisticamente significativa entre as médias foi realizado o teste post hoc para múltiplas comparações, para determinar quais as categorias da variável que determinam as diferenças.

\section{- Análise de regressão:}

A análise de regressão múltipla permite identificar como uma variável dependente é influenciada por outras variáveis chamadas independentes, bem como identificar o efeito de uma determinada variável independente sobre a variável dependente ajustado pelas demais variáveis independentes (DORIA FILHO 1999).

Foram elaborados modelos de regressão linear múltipla para verificar se a relação da satisfação no trabalho com cada aspecto da saúde permanece mesmo após ajuste por 
outras variáveis. Nesses modelos, a variável considerada como dependente foi o aspecto da saúde em estudo e as variáveis independentes foram satisfação no trabalho e demais características sócio-demográficas e funcionais.

Em todas as análises realizadas foi utilizado o nível de significância (p) de 5\%, que oferece uma probabilidade de 5\% de rejeitar incorretamente a hipótese nula quando ela é verdadeira (DAWSON-SAUNDERS e TRAPP 1994; BERQUÓ et. al. 1987).

\subsection{3 - Análise ergonômica do trabalho}

\subsubsection{1 - Justificativa da escolha do instrumento:}

Conforme discutido anteriormente, no estudo do fatores psicossociais no trabalho a organização do trabalho representa um papel importante porque é ela que define a divisão das tarefas e dos homens, o modo como o trabalho é estruturado.

Em outras palavras, a organização do trabalho define quem faz o que e de que maneira, portanto, exercendo impacto sobre a saúde e a satisfação no trabalho.

Para avaliar os diversos aspectos envolvidos na organização do trabalho optou-se pela realização da análise ergonômica do trabalho.

A ergonomia pode ser definida como o conjunto de conhecimentos aplicados à situação de trabalho na perspectiva de uma melhor adequação do trabalho ao homem, dos diversos pontos de vista: saúde, segurança e organização do trabalho (PARAGUAY 1987). A análise ergonômica do trabalho compreende a análise dos diversos aspectos organizacionais, das tarefas, das condições de trabalho e dos equipamentos de trabalho como elementos que integram a situação de trabalho (FISCHER e PARAGUAY 1989). 
Esta análise foi realizada buscando verificar quais destes aspectos podem estar interferindo na satisfação no trabalho.

Para realização da análise ergonômica do trabalho foi utilizado o método AET Análise Ergonômica do Trabalho de ROHMERT e LANDAU (1983). Este método contempla não só aspectos da biomecânica e do ambiente físico do trabalho, mas considera a organização do trabalho em seu escopo, contando com a participação do trabalhador como elemento necessário nesta análise.

\subsubsection{2 - Instrumento:}

O método AET - Análise Ergonômica do Trabalho de ROHMERT e LANDAU (1983) auxilia na sistematização da investigação das cargas e exigências do trabalho, e possibilita identificar demandas físicas e mentais do trabalho que estejam atuando como fontes de estresse.

Para tanto, o método AET propõe um roteiro de investigação do trabalho que incorpora a observação do trabalho e entrevistas com o trabalhador e sua chefia, se necessário (ILMARINEN et. al. 1991; LANDAU et. al. 1996). Este roteiro é composto por 216 questões distribuídas em 3 partes (ROHMERT e LANDAU 1983; LANDAU et. al. 1996; BELLUSCI 1998):

- Parte A - Análise do sistema de trabalho: composta por 143 questões que avaliam os tipos e propriedades de objetos de trabalho, o equipamento usado, o ambiente físico, social e organizacional.

- Parte B - Análise da tarefa: composta por 31 questões que avaliam as tarefas relacionadas a objetos materiais de trabalho, ao processamento de informações e planejamento, às outras pessoas e à freqüência de repetição de tarefas.

- Parte C - Análise das demandas: composta por 42 itens que avaliam as demandas referentes à recepção de informações, decisões, posturas e movimentações. 
As respostas às questões são classificadas por meio de códigos em escalas multinível representando os fatores fonte de estresse no trabalho; esses códigos representam o nível (significância), a duração e a freqüência (ou distribuição temporal) do estresse (ROHMERT e LANDAU 1983; ILMARINEN et. al. 1991) (Ver Anexo X - Roteiro para análise ergonômica do trabalho).

O método AET é baseado nos conceitos de estresse e desgaste e no sistema homemao-trabalho (ILMARINEN et. al. 1991). O sistema homem-ao-trabalho considera que, ao trabalhar, o homem estabelece relações sistemáticas (métodos) com os objetos de trabalho (materiais, energia, informações) para obter um resultado, em uma situação em que homem e objetos estão situados em um ambiente. As relações que se estabelecem entre homem, objetos de trabalho, métodos de trabalho e ambiente são dinâmicas, onde os diversos elementos envolvidos estão influenciando e recebendo influência dos demais (ROHMERT e LANDAU 1983). Um breve exemplo dessas influências pode ser o seguinte: ao soldar metais o homem os transforma em uma peça única para uma dada finalidade. Ao fazer isso, são eliminadas partículas de metal no ambiente. Em função das condições do ambiente (ventilação e exaustão) e do uso de equipamentos de proteção (máscara) estas partículas podem ser aspiradas pelo homem. Dependendo da freqüência, intensidade e duração do contato com estas partículas, o homem pode vir a desenvolver uma patologia.

Por trás do modelo do sistema homem-ao-trabalho, os conceitos de estresse e desgaste são outro requisito para a avaliação do trabalho. $\mathrm{O}$ desempenho do trabalho por meio da atividade humana pode ser caracterizado por tarefas de trabalho que determinam exigências. Essas exigências podem ser por meio de demandas físicas e do uso de informações, juntamente com condições do ambiente físico e organizacional, configurando fontes de estresse. Dependendo da freqüência, intensidade e duração da exposição do homem às fontes de estresse pode surgir o desgaste (ROHMERT e LANDAU 1983). Segundo os autores do método AET, o estresse determinado pelas tarefas e ambiente de trabalho relaciona-se à 
características, capacidades e habilidades do homem, onde o desgaste subjetivo resulta do estresse em função de características individuais.

Para ROHMERT e LANDAU (1983), o conceito de estresse/desgaste possibilita uma abordagem abrangente do sistema homem-ao-trabalho, dentro de várias dimensões quantitativas e qualitativas, que podem ser avaliadas por meio da análise do trabalho.

\subsubsection{3 - Amostra:}

Foi utilizada amostra não probabilística por conveniência (ver Anexo IX - Glossário de termos estatísticos). Observando-se as mesmas considerações da entrevista exploratória quanto à escolha de empregados para participação desta etapa da coleta de dados, optou-se por solicitar voluntários para participar na análise ergonômica do trabalho (ver item 3.3.1.3 - amostra da entrevista exploratória).

\subsubsection{4 - Análise dos dados:}

Para avaliar a representatividade da amostra, foi feita a comparação entre grupo de empregados participantes da análise ergonômica e grupo de não participantes da análise ergonômica segundo características sócio-demográficas e funcionais, utilizando o teste de associação pelo Qui-quadrado (para variáveis qualitativas) e o teste $\mathrm{t}$ (para variáveis quantitativas com distribuição normal).

A partir da amostra de voluntários foram compostos dois grupos de empregados para análise dos resultados:

a) um grupo formado pelos indivíduos com maiores níveis de satisfação, localizados no tercil superior do escore de satisfação global no trabalho (ver "variáveis de estudo" no item 3.3.2.4 - análise dos dados do questionário auto-aplicado), e 
b) um grupo formado pelos indivíduos com maior nível de insatisfação, localizados no tercil inferior do escore de satisfação global no trabalho (ver "variáveis de estudo" no item 3.3.2.4 - análise dos dados do questionário auto-aplicado).

Observou-se a distribuição do percentual de empregados de cada grupo (satisfeitos e insatisfeitos) em situações de maior exposição às fontes de estresse. Em seguida foi feito a comparação entre os dois grupos (satisfeitos e insatisfeitos) segundo exposição às fontes de estresse utilizando o teste de associação pelo Qui-quadrado e o teste exato de Fischer.

Maior exposição foi considerada como sendo a exposição mais intensa, freqüente ou significativa aos estressores em cada um dos itens avaliados pelo método AET, tomando como base as escala multinível do roteiro do AET (ver Anexo X - Roteiro para análise ergonômica do trabalho:

\section{- Freqüência:}

- Menor exposição: não se aplica, muito pouco freqüente, pouco freqüente, médio

- Maior exposição: freqüente, muito freqüente

- Significância:

- Menor exposição: não se aplica, muito pouca, pouca, média

- Pior exposição: alta, muito alta

- Duração:

- Menor exposição: não se aplica, menos de $10 \%$, menos de $30 \%$, entre 30 e $60 \%$

- $\quad$ Pior exposição: mais do que $60 \%$, contínuo

Por fim, realizou-se uma caracterização das condições do trabalho e organizacionais destes empregados. 


\subsection{4 - Etapas da coleta de dados}

Para realização da coleta de dados foi obedecida a seguinte seqüência:

a) Apresentação do projeto de pesquisa à Gerência da Divisão Saúde da Empresa e obtenção, neste nível hierárquico, de autorização para realização da pesquisa.

b) Apresentação do projeto de pesquisa, por parte da Gerência da Divisão Saúde, à Diretoria da Empresa e obtenção de autorização para realização da pesquisa. Neste momento, houve manifestação da Diretoria em utilizar os resultados da pesquisa como subsídio para implementação de futuras ações direcionadas à promoção de saúde dos empregados.

c) Apresentação do projeto de pesquisa às chefias, por meio de reuniões com cada uma destas chefias, com a presença da pesquisadora e da Gerência da Divisão Saúde. Nestas reuniões foi solicitada colaboração no sentido de facilitar o acesso aos subordinados para a operacionalização da pesquisa e foi agendado um horário para uma reunião com todos os empregados da área.

Em cada uma destas três etapas foram apresentados os objetivos da pesquisa e os métodos para coleta de dados, foram fornecidas informações sobre a necessidade de assinatura de termo de consentimento de participação na pesquisa e sobre a confidencialidade dos resultados individuais.

d) Apresentação do projeto de pesquisa à Comissão de Ética da Faculdade de Saúde Pública e obtenção da aprovação desta Comissão para realização da pesquisa.

e) Apresentação do projeto de pesquisa à Banca de Exame de Qualificação na Faculdade de Saúde Pública e obtenção da aprovação desta Banca para realização da pesquisa. 
f) Realização dos pré-testes: foram realizados pré-testes da entrevista, questionário e análise ergonômica do trabalho com empregados convidados para tal, e informados quanto aos objetivos do pré-teste e da pesquisa. Esses empregados foram orientados quanto à confidencialidade dos dados obtidos, e também assinaram termo de consentimento de participação na pesquisa (Anexo XI).

g) Apresentação do projeto de pesquisa para os empregados presentes no local de trabalho e entrega dos questionários: foi realizada reunião em cada uma das 18 área de trabalho com a presença da pesquisadora, de todos os empregados da área, e da chefia da área. Nestas reuniões foram fornecidas informações referentes à confidencialidade dos dados individuais, aos diversos instrumentos para coleta de dados, à não obrigatoriedade de participação (participação opcional e voluntária), à forma de preenchimento do questionário (ressaltando a importância de não deixar questões em branco), à assinatura do termo de consentimento.

Foram entregues os questionários com o termo de consentimento em envelope timbrado da Faculdade de Saúde Pública, individualizado e fechado. Foi combinada, com os empregados, uma data para a devolução dos questionários. Aproveitou-se esta ocasião para solicitar ao menos um voluntário em cada área para participar da entrevista exploratória e/ou da análise ergonômica do trabalho. Também nesta ocasião, a pesquisadora reiterou o compromisso de dar devolutiva dos resultados individuais a cada empregado e a realizar divulgação dos resultados coletivos.

h) Entrega dos questionários preenchidos: a pesquisadora retornou a cada área, na data combinada, para recolher os questionários preenchidos. Evitou-se o uso de malote interno ou outra forma de envio para assegurar que não houvessem extravios e para que os empregados se sentissem seguros no sentido de que suas respostas não estariam circulando por outras pessoas que não o pesquisador. 
Logo em seguida ao recebimento dos questionários, foi feita uma verificação quanto ao preenchimento de todas as questões. Havendo questões em branco, a pesquisadora procurava o empregado para verificar com ele se a questão havia sido deixada em branco deliberadamente, por não entendimento ou por esquecimento. Nos poucos casos em que não houve entendimento ou houve esquecimento, o empregado era orientado quanto à questão e convidado a respondê-la nesta ocasião.

i) Agendamento das entrevistas: por telefone, foi agendado com cada um dos voluntários, um horário para realização da entrevista. Este agendamento atendeu às disponibilidades de horário dos empregados.

j) Realização das entrevistas: foram realizadas em sala reservada e fechada, fora da área de trabalho do empregado. Os empregados foram novamente orientados quanto aos objetivos e confidencialidade. Foi solicitada e obtida autorização para gravação da entrevista.

k) Agendamento da análise ergonômica do trabalho: por telefone, foi agendado com cada um dos voluntários, um horário para realização da análise. Este agendamento atendeu às disponibilidades de horário dos empregados.

1) Realização das análises ergonômicas do trabalho: foram realizadas no próprio local de trabalho dos empregados. Estes foram novamente orientados quanto aos objetivos e confidencialidade. Antes de iniciar a fase de observação da análise ergonômica propriamente dita, foi feita entrevista e solicitado ao empregado que fizesse uma descrição de seu cargo e atividades. Essa entrevista teve a dupla função de possibilitar um melhor conhecimento do posto e da organização do trabalho e de familiarizar o empregado com a pesquisadora deixando-o mais à vontade para responder as questões e fornecer as informações referentes à análise ergonômica. 
m) Registro dos dados:

- Entrevista: as entrevistas foram gravadas com gravador portátil, e posteriormente foram processadas em texto utilizando o software Microsoft Word versão 97 (MICROSOFT 1998a).

- Questionários: os resultados foram registrados em banco de dados do programa Microsoft Excel versão 97 (MICROSOFT 1998b).

- Análises ergonômicas: os dados foram registradas manualmente e, posteriormente, digitados em banco de dados do programa Microsoft Excel versão 97 (MICROSOFT 1998b).

A coleta de dados ocorreu no período de julho a novembro de 2001. No Anexo XII encontra-se o cronograma de desenvolvimento de todas as etapas da pesquisa. 


\section{4 - RESULTADOS}

\section{1 - ENTREVISTA EXPLORATÓRIA}

Atendendo à solicitação de 1 voluntário em cada uma das 18 áreas de trabalho para participar da entrevista exploratória, apresentaram-se 42 pessoas interessadas em colaborar (14,6\% dos empregados), sendo que em apenas 1 área não houve voluntários (para definição de área de trabalho ver o item 3.3.2.4 - Variáveis de estudo do questionário).

A proposta inicial foi realizar a entrevista com 1 representante de cada área e, caso continuassem a surgir novas informações, solicitar novos voluntários até que começasse a ocorrer repetição no padrão de respostas. Com a realização da entrevista com os 42 voluntários, não foi necessária esta nova solicitação.

Após terem sido identificados, no texto do discurso dos empregados, os diversos elementos relacionados a cada item de interesse (conceito de satisfação no trabalho, aspectos relacionados à satisfação e aspectos relacionados à insatisfação no trabalho), estes elementos foram reagrupados por temas.

Observando os elementos referidos no conceito de satisfação no trabalho, identificou-se que estes dizem respeito a sentimentos que os empregados esperam ter em relação ao seu trabalho, bem como às condições que esperam que o trabalho lhes proporcione. Verificou-se, então, que estes elementos são compatíveis com o conceito de Locke (ver item 1.2.1 - Conceitos) adotado neste estudo e que considera satisfação no trabalho como um estado emocional resultante da avaliação do trabalho 
realizado em relação aos valores importantes do indivíduo. Esses elementos identificados foram agrupados nas categorias estado emocional e valores:

- Estado emocional: diz respeito aos sentimentos que os empregados esperam ter em relação ao seu trabalho: ter prazer no que faz, em trabalhar, estar alegre, estar contente, fazer o que gosta, gostar do trabalho, bem-estar, estar bem, sentir-se bem, sentir vontade de trabalhar, sentir-se disposto para trabalhar, não sentir peso ao trabalhar, sentir-se leve, estar com o ânimo alto, não ficar estressado, vir "legal" para o trabalho, fazer o que faz com "tesão" de trabalhar, fazer (trabalhar) com carinho, trabalhar "numa boa".

- Valores: diz respeito às condições que os empregados esperam que o trabalho lhes proporcione: contribuir para o crescimento pessoal e coletivo, agregar valores, fazer parte da Organização de maneira positiva, não ser só um número dentro da empresa, ser uma relação de troca, salário condizente para poder viver bem e fazer as coisas que se quer fazer, ser reconhecido pelo que faz, não ser somente uma obrigação, trabalhar naquilo para o qual foi contratado, atualização profissional, poder desenvolver um trabalho do início ao fim, conseguir resultados, estar produzindo, ser útil, contribuir para o aprimoramento de algo, poder ajudar, estar trabalhando (ter emprego), ter coisas interessantes para fazer, estar aprendendo, fazer coisas novas, ser respeitado pessoalmente, ser respeitado profissionalmente, ter autonomia, receber retorno (feedback), sentir-se importante, sentir que seu trabalho é importante, ter condições e estrutura apropriadas para trabalhar, ter um ambiente tranqüilo e saudável, ter bom relacionamento com os colegas, ter bom relacionamento com chefias, ter bom grupo de trabalho.

Observando-se os elementos referentes aos aspectos considerados como causadores tanto da satisfação como da insatisfação no trabalho, identificou-se que estes elementos podem ser categorizados segundo a classificação usada na Teoria de 
Locke sobre Satisfação no Trabalho (ver item 1.2.2 - Teorias sobre satisfação no trabalho). Estas categorias são: trabalho (diz respeito ao trabalho propriamente dito e ao conteúdo do trabalho), pagamento (tipo, quantidade, eqüidade, segurança e estabilidade de pagamentos e recompensas), promoção (oportunidades, justiça e clareza), reconhecimento (reconhecimento e valorização do trabalho realizado), condições e ambiente de trabalho (recursos disponíveis, organização do trabalho e ambiente trabalho), colegas e subordinados (relações de amizade, colaboração, competência e compartilhamento de valores), supervisão e gerenciamento (comportamento, caráter, qualificação e competência das chefias), e empresa/organização (política e posicionamento da empresa em relação aos empregados, competência da empresa).

Os elementos identificados como causadores de satisfação no trabalho em cada uma das categorias foram:

- Trabalho: desenvolver um trabalho do início ao fim, ver os resultados do trabalho, possibilidade de realizar um trabalho, renovação (novos projetos, novas atividades, fazer coisas novas), atuar na sua área de formação profissional, variedade no trabalho, possibilidade de desenvolvimento profissional, possibilidade de aprendizado, possibilidade de desenvolvimento de um trabalho, possibilidade de descobrir o próprio potencial, contato com o público/usuário, contato com pessoas, poder ajudar pessoas, resolver um problema, propiciar uma situação melhor para alguém, identificação com o trabalho, gostar do que faz, ter autonomia, cumprir as metas, identificar-se com o trabalho, identificar-se com a empresa, gostar do trabalho, desafios, o trabalho é importante, o trabalho é estimulante, poder ajudar a empresa a ser competitiva, participar nas tomadas de decisão.

- Pagamento: salário compatível ou melhor que o do mercado, bom salário, benefícios, recebimento do salário em dia 
- Promoção: recebimento de promoções, possibilidade de promoções.

- Reconhecimento: reconhecimento e valorização do trabalho realizado, reconhecimento por parte da chefia, reconhecimento por parte da empresa, recebimento de retorno (feedback), atividades desenvolvidas são prestigiadas, ter sua qualificação profissional valorizada.

- Condições e ambiente de trabalho: localização geográfica, flexibilidade de horários, mais agilidade, mais ferramentas de trabalho disponíveis, novas atividades, carga de trabalho adequada, tempo adequado para analisar e desenvolver as tarefas.

- Colegas e subordinados: possibilidade de troca, respeito profissional, responsabilidade, comprometimento, colaboração, contribuição, aprendizado com colegas mais experientes ou com maior nível de conhecimento, amizade, consideração, ajuda, apoio, espírito de grupo, interesse, chefia que "não fica no pé”.

- Supervisão e gerenciamento: diz respeito ao comportamento, caráter, qualificação e competência das chefias: respeito profissional, bom relacionamento, possibilidade de diálogo, possibilidade de conversar sobre assuntos pessoais, confiança, organização, ausência de cobranças, suporte, tolerância.

- Empresa / organização: preocupação da diretoria com os empregados, modernização, solução de problemas mais respaldo no futuro, qualidade do produto da empresa, imagem / nome da empresa no mercado, correção de situações erradas, desenvolvimento focado em uma direção. 
Os elementos identificados como causadores de insatisfação no trabalho em cada uma das categorias foram:

- Trabalho: falta de identificação com o trabalho, trabalho só operacional, falta de autonomia, impossibilidade de criar e de raciocinar, impossibilidade de crescimento, impossibilidade de aprendizado, falta de diversificação de atividades (rotina), restrição da atuação, impossibilidade de produzir mais, falta de oportunidade para assumir novas responsabilidades, aprisionamento do talento e da capacidade para o trabalho, falta de realização profissional, aumento da responsabilidade, indefinição das responsabilidades, falta de clareza da função, indefinição de papéis, desperdício de qualificação do pessoal, não utilização de capacidades e qualificações, impossibilidade de uso dos conhecimentos e da formação profissional, perda do controle, ausência ou perda da autonomia, não conclusão de trabalhos.

- Pagamento: medo de perder o emprego, medo de cortes, insegurança (instabilidade) no emprego, incerteza com o futuro, salário insuficiente, salário muito alto (fora da faixa), injustiça na distribuição de salários, política salarial, salário não condizente com as responsabilidades, salário não condizente com a carga de trabalho.

- Promoção: falta de reclassificação salarial, falta de reclassificação de cargos, privilegiamento de empregados novos em detrimento dos antigos, falta de perspectivas de carreira, injustiça no processo de promoção, privilegiamento de empregados com nível superior, não atendimento das expectativas de promoção.

- Reconhecimento: não valorização de idéias, não valorização do trabalho, falta de reconhecimento pela chefia, falta de reconhecimento por outros setores, injustiça na forma de avaliação do desempenho, não reconhecimento da importância do trabalho desenvolvido, não valorização dos cargos inferiores, não agradecimento. 
- Condições e ambiente de trabalho: mobiliário, equipamentos, sistema de informática, lay out do ambiente, excesso de burocracia, interrupções no trabalho, falta de flexibilidade nos horários, impossibilidade de executar um trabalho até o final, falta de treinamento e atualização, insuficiência de recursos humanos, distribuição inadequada dos recursos humanos, insuficiência de recursos financeiros, falta de suporte, informação e colaboração de outras áreas, volume de trabalho, prazos insuficientes, pouco tempo para pensar e analisar.

- Colegas e subordinados: falta de envolvimento e de comprometimento, falta de confiança, falta de educação, falta de respeito pessoal e profissional, falta de identificação com a cultura e com valores dos colegas, pessimismo.

- Supervisão e gerenciamento: centralização, autoritarismo, falta de transparência, falta de possibilidade de abordar questões pessoais, impossibilidade de participação nas decisões, falta de diálogo, injustiça, pressão, qualificação, competência e conhecimento, tratamento com desconfiança e fiscalizatório, chefia rancorosa, "pegação no pé”.

- Empresa / organização: falta de apoio ou auxílio para estudos e/ou qualificação, política da empresa, falta de valorização das pessoas e sentimento de uso, falta de política de recursos humanos, falta de preocupação com recursos humanos, falta de comunicação e informação com os empregados, falta de clareza e de transparência, distanciamento dos empregados, desvalorização dos empregados mais antigos, desvalorização dos empregados sem nível de escolaridade superior, forma de condução do processo de reestruturação da empresa e de demissões, clima psicológico, boatos, favorecimento de algumas áreas em detrimento de outras, favorecimento de algumas pessoas, critérios para manutenção e promoção do quadro de pessoal, falta de investimento nos jovens, falta de perspectiva de crescimento da empresa, indefinição dos rumos da empresa, mudanças constantes, estrutura empresarial restringindo o desenvolvimento pessoal e profissional das pessoas. 


\section{2 - QUESTIONÁRIOS AUTO-APLICADOS}

\subsection{1 - Confiabilidade dos instrumentos}

\subsubsection{1 - Escala Satisfação no Trabalho do OSI - Occupational Stress Indicator:}

O instrumento demonstrou confiabilidade satisfatória (alfa de Cronbach $=0,93$ ), e todos seus itens são adequados ao instrumento, uma vez que a exclusão do item não melhora o valor do Alfa (Tabela 3).

Tabela 3: Valores do Coeficiente alfa de Cronbach do questionário "Satisfação no Trabalho" (escala Satisfação no trabalho do OSI), segundo item excluído e para o questionário completo, Fundação CESP, 2001.

\begin{tabular}{|c|c|c|}
\hline Item & Questão & $\begin{array}{l}\text { Alfa de Cronbach obtido } \\
\text { com a exclusão do item }\end{array}$ \\
\hline Comunicação e forma do fluxo de informações & 1 & 0,93 \\
\hline Relacionamento com outras pessoas na empresa & 2 & 0,93 \\
\hline Avaliação dos esforços & 3 & 0,92 \\
\hline Conteúdo do trabalho & 4 & 0,93 \\
\hline Sentimento de motivação para o trabalho & 5 & 0,92 \\
\hline Oportunidades na carreira & 6 & 0,92 \\
\hline Segurança no emprego & 7 & 0,92 \\
\hline $\begin{array}{l}\text { Identificação com a imagem externa ou com } \\
\text { realizações da empresa }\end{array}$ & 8 & 0,93 \\
\hline Estilo de supervisão & 9 & 0,92 \\
\hline Implementação de mudanças e inovações & 10 & 0,92 \\
\hline Tipo de tarefas e trabalho & 11 & 0,92 \\
\hline Possibilidade de crescimento e desenvolvimento & 12 & 0,92 \\
\hline Resolução de conflitos & 13 & 0,93 \\
\hline Oportunidade para atingir aspirações e ambições & 14 & 0,92 \\
\hline Participação em decisões importantes & 15 & 0,93 \\
\hline Uso das potencialidades & 16 & 0,92 \\
\hline Flexibilidade e liberdade no trabalho & 17 & 0,93 \\
\hline Clima psicológico na empresa & 18 & 0,92 \\
\hline $\begin{array}{l}\text { Salário em relação à experiência e } \\
\text { responsabilidade }\end{array}$ & 19 & 0,93 \\
\hline Estrutura organizacional & 20 & 0,92 \\
\hline Volume de trabalho & 21 & 0,93 \\
\hline Desenvolvimento das potencialidades & 22 & 0,92 \\
\hline
\end{tabular}




\subsubsection{2 - SF-36 - Medical Outcomes Study 36 - item short-form health survey:}

Das 8 escalas do SF-36, 7 demonstraram confiabilidade satisfatória, com valor do alfa de Cronbach igual ou maior que 0,70. A exceção apareceu na escala "aspectos sociais" onde o valor do alfa foi 0,67 (Tabela 4).

Tabela 4: Valores do Coeficiente alfa de Cronbach do questionário SF-36, segundo componente (saúde física e saúde mental), item excluído e escalas completas,

Fundação CESP, 2001.

\begin{tabular}{|c|c|c|c|c|c|}
\hline $\begin{array}{l}\text { Componente } \\
\text { Saúde Física }\end{array}$ & Item & Alfa & $\begin{array}{l}\text { Componente } \\
\text { Saúde Mental }\end{array}$ & Item & Alfa \\
\hline \multirow[t]{10}{*}{ Capacidade Funcional } & $3 a$ & 0,80 & \multirow{6}{*}{ Vitalidade } & & \\
\hline & $3 b$ & 0,80 & & & \\
\hline & $3 c$ & 0,79 & & $9 \mathrm{a}$ & 0,80 \\
\hline & $3 d$ & 0,79 & & $9 \mathrm{e}$ & 0,80 \\
\hline & $3 e$ & 0,80 & & $9 g$ & 0,81 \\
\hline & $3 f$ & 0.80 & & $9 \mathrm{i}$ & 0,81 \\
\hline & $3 g$ & 0,79 & \multicolumn{2}{|c|}{ Alfa do total da escala } & 0,85 \\
\hline & $3 \mathrm{~h}$ & 0,79 & & & \\
\hline & $3 \mathrm{i}$ & 0,81 & & & \\
\hline & $3 \mathrm{j}$ & 0,82 & & & \\
\hline \multicolumn{2}{|c|}{ Alfa do total da escala } & 0,82 & & & \\
\hline \multirow[t]{4}{*}{ Aspecto físico } & $4 a$ & 0,65 & Aspecto emocional & $5 a$ & 0,59 \\
\hline & $4 \mathrm{~b}$ & 0,61 & & $5 b$ & 0,56 \\
\hline & $4 \mathrm{c}$ & 0,59 & & $5 c$ & 0,65 \\
\hline & $4 d$ & 0,69 & \multirow{2}{*}{\multicolumn{2}{|c|}{ Alfa do total da escala }} & 0,70 \\
\hline \multicolumn{2}{|c|}{ Alfa do total da escala } & & & & \\
\hline Dor & & & \multirow{2}{*}{\multicolumn{2}{|c|}{$\begin{array}{c}\text { Aspectos sociais } 6 \text { e } 10 \\
\text { Alfa do total da escala }\end{array}$}} & \\
\hline \multicolumn{2}{|c|}{ Alfa do total da escala } & 0,86 & & & 0,67 \\
\hline \multirow[t]{5}{*}{ Estado geral } & 1 & 0,71 & \multirow[t]{5}{*}{ Saúde Mental } & $9 \mathrm{~b}$ & 0,79 \\
\hline & $11 \mathrm{a}$ & 0,69 & & $9 \mathrm{c}$ & 0,80 \\
\hline & $11 \mathrm{~b}$ & 0,73 & & $9 d$ & 0,79 \\
\hline & $11 \mathrm{c}$ & 0,72 & & 9f & 0,77 \\
\hline & $11 d$ & 0,64 & & $9 \mathrm{~h}$ & 0,81 \\
\hline \multicolumn{2}{|c|}{ Alfa do total da escala } & 0,74 & Alfa do total da & & 0,83 \\
\hline
\end{tabular}

\subsubsection{3 - ICT - Índice de Capacidade para o Trabalho:}

$\mathrm{O}$ instrumento demonstrou confiabilidade satisfatória (alfa de Cronbach $=0,73$ ). A exclusão dos itens "número de doenças referidas como confirmadas pelo médico" e "capacidade para o trabalho daqui a dois anos" pode levar a um incremento do valor 
do alfa para 0,75 e 0,74 respectivamente (Tabela 5). A exclusão conjunta dos dois itens aumentaria o valor para 0,77 .

Considerando que a exclusão desses itens não acarretaria incremento importante e descaracterizaria o instrumento, inviabilizando seu uso, optou-se por sua permanência na análise dos dados.

Tabela 5: Valores do Coeficiente alfa de Cronbach do questionário "Índice de Capacidade para o Trabalho" (ICT), segundo item excluído e para o questionário completo, Fundação CESP, 2001.

\begin{tabular}{l|c}
\hline \multicolumn{1}{c|}{ Item } & $\begin{array}{c}\text { Alfa de Cronbach obtido } \\
\text { com a exclusão do item }\end{array}$ \\
\hline Melhor capacidade para o trabalho & 0,68 \\
Capacidade em relação às exigências físicas & 0,76 \\
Capacidade em relação às exigências mentais & 0,71 \\
Número de doenças referidas como confirmadas por médico & 0,75 \\
Impedimento para o trabalho atual & 0,71 \\
Dias de ausência no trabalho por problemas de saúde & 0,73 \\
Capacidade para o trabalho daqui a 2 anos & 0,74 \\
Apreciação das atividades diárias & 0,71 \\
Sentir-se ativo e alerta & 0,69 \\
Esperança para o futuro & 0,70 \\
\hline
\end{tabular}

Alfa do módulo completo: 0,73

\subsection{2 - Análise das perdas}

Dos 288 empregados da Fundação CESP, 16 (5,6\%) foram excluídos da amostra por estarem enquadrados em uma das seguintes situações: afastamento por motivo de doença, estar em férias no período da coleta de dados, ter participado do pré-teste, ser a própria pesquisadora.

Foram distribuídos questionários para os 272 empregados restantes. Destes, 45 pessoas $(16,54 \%)$ não responderam. Houve a participação de 227 pessoas que entregaram o questionário respondido, sendo que destas foram excluídas 3 por 
estarem com respostas incompletas. Restaram 224 pessoas correspondendo a 77,8\% do total de empregados da Fundação CESP.

- Características sócio-demográficas (Tabela 6): não existe associação estatisticamente significativa entre as perdas e a população de estudo.

- Características funcionais (Tabela 7): não foi feita a análise das perdas quanto à área de trabalho porque observa-se grande variação entre os grupos (tanto na população de estudo como nas perdas) devida ao tamanho de algumas áreas que é pequeno inviabilizando esta análise. Outro fator observado foi que, em algumas áreas onde houve menor número de respostas, foram alegadas razões de falta de tempo ou de interesse na participação. Não existe associação estatisticamente significativa entre as perdas e a população de estudo quanto ao tempo de empresa e cargo.

Assim, fica demonstrado que não houve diferenças entre as perdas e a população de estudo.

Tabela 6: Análise das correlações entre população de estudo e perdas, segundo características sócio-demográficas, Fundação CESP, 2001.

\begin{tabular}{|c|c|c|c|c|c|c|}
\hline \multirow[t]{2}{*}{ Variável } & \multirow[t]{2}{*}{ Categoria } & \multicolumn{2}{|c|}{ Pop. de estudo } & \multicolumn{2}{|c|}{ Perdas } & \multirow[t]{2}{*}{ p* } \\
\hline & & $\mathbf{N}^{\mathbf{O}}$ & $\%$ & $\mathbf{N}^{\mathbf{o}}$ & $\%$ & \\
\hline \multirow[t]{2}{*}{ Sexo } & Feminino & 115 & 79,9 & 29 & 20,1 & \multirow[t]{2}{*}{0,395} \\
\hline & Masculino & 109 & 75,7 & 35 & 24,3 & \\
\hline \multirow{4}{*}{$\begin{array}{c}\text { Idade } \\
\text { (em anos) }\end{array}$} & Menor que 30 & 64 & 83,1 & 13 & 16,9 & \multirow[t]{4}{*}{0,555} \\
\hline & 30 a 39 & 94 & 76,4 & 29 & 23,6 & \\
\hline & 40 a 49 & 57 & 76,0 & 18 & 24,0 & \\
\hline & 50 e mais & 9 & 69,2 & 4 & 30,8 & \\
\hline \multirow{6}{*}{$\begin{array}{c}\text { Renda } \\
\text { (em faixas de } \\
\text { salários mínimos) }\end{array}$} & 4 a 6 & 49 & 86,0 & 8 & 14,0 & \multirow[t]{6}{*}{0,113} \\
\hline & 7 a 10 & 51 & 76,1 & 16 & 23,9 & \\
\hline & 11 a 15 & 37 & 82,2 & 8 & 17,8 & \\
\hline & 16 a 20 & 23 & 74,2 & 8 & 25,8 & \\
\hline & 21 a 25 & 25 & 86,2 & 4 & 13,8 & \\
\hline & 26 ou mais & 39 & 66,1 & 20 & 33,9 & \\
\hline \multicolumn{2}{|l|}{ Total } & 224 & 77,8 & 64 & 22,2 & \\
\hline
\end{tabular}

* Teste de associação pelo $\chi^{2}$ 
Tabela 7: Análise das correlações entre população de estudo e perdas, segundo característica funcional, Fundação CESP, 2001.

\begin{tabular}{|c|c|c|c|c|c|c|}
\hline \multirow[t]{2}{*}{ Variável } & \multirow[t]{2}{*}{ Categoria } & \multicolumn{2}{|c|}{ Pop. de estudo } & \multicolumn{2}{|c|}{ Perdas } & \multirow[b]{2}{*}{ p* } \\
\hline & & $\mathbf{N}^{\mathbf{o}}$ & $\%$ & $\mathbf{N}^{\mathbf{0}}$ & $\%$ & \\
\hline \multirow{4}{*}{$\begin{array}{l}\text { Tempo de } \\
\text { empresa } \\
\text { (em anos) }\end{array}$} & Menor que 3 & 41 & 74,5 & 14 & 25,5 & 0,507 \\
\hline & 3 a 5 & 41 & 85,4 & 7 & 14,6 & \\
\hline & 6 a 10 & 42 & 79,2 & 11 & 20,8 & \\
\hline & 11 ou mais & 100 & 75,8 & 32 & 24,2 & \\
\hline \multirow[t]{5}{*}{ Cargo } & Analistas & 77 & 74,8 & 26 & 25,2 & 0,449 \\
\hline & Técnicos & 69 & 78,4 & 19 & 21,6 & \\
\hline & Atendimento & 35 & 87,5 & 5 & 12,5 & \\
\hline & Especialistas & 24 & 80,0 & 6 & 20,0 & \\
\hline & Direção & 19 & 70,4 & 8 & 29,6 & \\
\hline \multirow[t]{18}{*}{ Área } & Atendimento ao cliente & 42 & 89,4 & 5 & 10,6 & \\
\hline & $\begin{array}{l}\text { Operacionalização e } \\
\text { controle de sistemas de } \\
\text { saúde }\end{array}$ & 26 & 70,3 & 11 & 29,7 & \\
\hline & Atuarial & 22 & 73,3 & 8 & 26,7 & \\
\hline & Informática & 20 & 62,5 & 12 & 37,5 & \\
\hline & Finanças e orçamento & 16 & 88,9 & 2 & 11,1 & \\
\hline & $\begin{array}{l}\text { Gestão de sistemas de } \\
\text { saúde }\end{array}$ & 12 & 80,0 & 3 & 20,0 & \\
\hline & $\begin{array}{l}\text { Pagamentos } \\
\text { previdenciários, } \\
\text { pecúlios e seguros }\end{array}$ & 11 & 84,6 & 2 & 15,4 & \\
\hline & Contabilidade e custos & 10 & 71,4 & 4 & 28,6 & \\
\hline & Jurídico & 10 & 100,0 & - & - & \\
\hline & $\begin{array}{l}\text { Processamento e } \\
\text { controle de } \\
\text { investimentos }\end{array}$ & 9 & 100,0 & - & - & \\
\hline & Administração geral & 8 & 100,0 & - & - & \\
\hline & $\begin{array}{l}\text { Relações contratuais } \\
\text { em serviços de saúde }\end{array}$ & 8 & 72,7 & 3 & 27,3 & \\
\hline & Recursos humanos & 7 & 87,5 & 1 & 12,5 & \\
\hline & Diretoria & 6 & 100,0 & - & - & \\
\hline & $\begin{array}{l}\text { Cadastro de } \\
\text { beneficiários }\end{array}$ & 6 & 100,0 & - & - & \\
\hline & $\begin{array}{l}\text { Investimentos e } \\
\text { patrimônio }\end{array}$ & 4 & 26,7 & 11 & 73,3 & \\
\hline & Auditoria interna & 4 & 80,0 & 1 & 20,0 & \\
\hline & $\begin{array}{l}\text { Comunicação } \\
\text { institucional }\end{array}$ & 3 & 75,0 & 1 & 25,0 & \\
\hline Total & & 224 & 77,8 & 64 & 22,2 & \\
\hline
\end{tabular}

* Teste de associação pelo $\chi^{2}$ 


\subsection{3 - Caracterização da população de estudo}

\subsubsection{1 - Características sócio-demográficas e funcionais:}

A distribuição dos empregados (em número e porcentagem) segundo característica sócio-demográfica está apresentada na Tabela 8 , onde observa-se que:

- Sexo: $52,3 \%$ da população é do sexo feminino e $48,7 \%$ é do sexo masculino.

- Idade: a população de estudo apresenta idade com média de 34,7 anos, valor mínimo de 16,0 anos, valor máximo de 57,0 anos e desvio padrão de 8,36 anos. A maior parte dos empregados (42,0\%) têm idade entre 30 e 39 anos e apenas $4 \%$ têm acima de 49 anos.

- Renda: 44,7\% dos empregados contam com rendimentos nas faixas de 4 a 10 salários mínimos. Não há empregados com renda inferior a 4 salários mínimos.

- Escolaridade: os empregados apresentam alto nível de escolaridade, sendo que $63,4 \%$ têm nível universitário e apenas $2,2 \%$ contam com o $1^{\circ}$ grau completo.

- Estado civil: 55,4\% dos empregados são casados(as) ou com companheira(o).

A distribuição dos empregados (em número e porcentagem) segundo característica funcional está apresentada na Tabela 9, onde observa-se que:

- Tempo de empresa: a população de estudo apresenta tempo de empresa com média de 8,4 anos, tempo mínimo de 0,0 (zero) anos, tempo máximo de 14,0 anos e desvio padrão de 4,8 anos. A maior parte dos empregados (44,6\%) está na empresa há 11 anos ou mais. Os demais empregados estão distribuídos de forma homogênea nas demais faixas de tempo. 
- Cargo: as maiores proporções de empregados são compostas por analistas $(34,4 \%)$ e técnicos $(30,8 \%)$.

- Área de trabalho: as áreas de trabalho são compostas de forma numericamente distinta. As áreas com maiores proporções de empregados são o Atendimento ao Cliente (18,8\%), Operacionalização e Controle de Sistemas de Saúde (11,6\%), Atuarial $(9,8 \%)$ e Informática $(8,9 \%)$. As áreas com menores proporções de empregados são a Comunicação Institucional (1,3\%), Auditoria Interna $(1,8 \%)$ e Investimentos e Patrimônio (1,8\%).

Tabela 8: Distribuição do número e porcentagem de empregados segundo característica sócio-demográfica, Fundação CESP, 2001.

\begin{tabular}{|c|c|c|c|}
\hline Variável & Categoria & $\mathrm{N}^{\mathbf{0}}$ & $\%$ \\
\hline Sexo & $\begin{array}{l}\text { Feminino } \\
\text { Masculino }\end{array}$ & $\begin{array}{l}115 \\
109 \\
\end{array}$ & $\begin{array}{l}51,3 \\
48,7 \\
\end{array}$ \\
\hline $\begin{array}{c}\text { Idade } \\
\text { (em anos) }\end{array}$ & $\begin{array}{l}\text { Menor que } 30 \\
30 \text { a } 39 \\
40 \text { a } 49 \\
50 \text { e mais }\end{array}$ & $\begin{array}{c}64 \\
94 \\
57 \\
9 \\
\end{array}$ & $\begin{array}{c}28,6 \\
42,0 \\
25,4 \\
4,0 \\
\end{array}$ \\
\hline $\begin{array}{c}\text { Renda } \\
\text { (em faixas de } \\
\text { salários mínimos) }\end{array}$ & $\begin{array}{l}4 \text { a } 6 \\
7 \text { a } 10 \\
11 \text { a } 15 \\
16 \text { a } 20 \\
21 \text { a } 25 \\
26 \text { ou mais }\end{array}$ & $\begin{array}{l}49 \\
51 \\
37 \\
23 \\
25 \\
39\end{array}$ & $\begin{array}{l}21,9 \\
22,8 \\
16,5 \\
10,3 \\
11,2 \\
17,4\end{array}$ \\
\hline Escolaridade & $\begin{array}{l}1^{\circ} \text { grau completo } \\
2^{\mathrm{o}} \text { grau completo } \\
3^{\mathrm{o}} \text { grau completo }\end{array}$ & $\begin{array}{c}5 \\
77 \\
142 \\
\end{array}$ & $\begin{array}{c}2,2 \\
34,4 \\
63,4\end{array}$ \\
\hline Estado civil & $\begin{array}{l}\text { Casado / companheiro } \\
\text { Solteiro } \\
\text { Separado / divorciado } \\
\text { Viúvo }\end{array}$ & $\begin{array}{c}124 \\
85 \\
14 \\
1 \\
\end{array}$ & $\begin{array}{c}55,4 \\
37,9 \\
6,3 \\
0,4 \\
\end{array}$ \\
\hline Total & & 224 & 100,0 \\
\hline
\end{tabular}


Tabela 9: Distribuição do número e porcentagem de empregados segundo característica funcional, Fundação CESP, 2001.

\begin{tabular}{|c|c|c|c|}
\hline Variável & Categoria & $\mathbf{N}^{\mathbf{0}}$ & $\%$ \\
\hline $\begin{array}{c}\text { Tempo de empresa } \\
\text { (em anos) }\end{array}$ & $\begin{array}{l}\text { Menor que } 3 \\
3 \text { a } 5 \\
6 \text { a } 10 \\
11 \text { ou mais }\end{array}$ & $\begin{array}{c}41 \\
41 \\
42 \\
100\end{array}$ & $\begin{array}{l}18,3 \\
18,3 \\
18,8 \\
44,6\end{array}$ \\
\hline Cargo & $\begin{array}{l}\text { Analistas } \\
\text { Técnicos } \\
\text { Atendimento } \\
\text { Especialistas } \\
\text { Direção }\end{array}$ & $\begin{array}{l}77 \\
69 \\
35 \\
24 \\
19\end{array}$ & $\begin{array}{c}34,4 \\
30,8 \\
15,6 \\
10,7 \\
8,5\end{array}$ \\
\hline Área & $\begin{array}{l}\text { Atendimento ao cliente } \\
\text { Operacionalização e controle } \\
\text { de sistemas de saúde } \\
\text { Atuarial } \\
\text { Informática } \\
\text { Finanças e orçamento } \\
\text { Gestão de sistemas de saúde } \\
\text { Pagamentos previdenciários, } \\
\text { pecúlios e seguros } \\
\text { Contabilidade e custos } \\
\text { Jurídico } \\
\text { Processamento e controle de } \\
\text { investimentos } \\
\text { Administração geral } \\
\text { Relações contratuais em } \\
\text { serviços de saúde } \\
\text { Recursos humanos } \\
\text { Diretoria } \\
\text { Cadastro de beneficiários } \\
\text { Investimentos e patrimônio } \\
\text { Auditoria interna } \\
\text { Comunicação institucional } \\
\end{array}$ & $\begin{array}{l}42 \\
26 \\
22 \\
20 \\
16 \\
12 \\
11 \\
\\
10 \\
10 \\
9 \\
\\
8 \\
8 \\
7 \\
6 \\
6 \\
4 \\
4 \\
3 \\
\end{array}$ & $\begin{array}{l}18,8 \\
11,6 \\
9,8 \\
8,9 \\
7,1 \\
5,4 \\
4,9 \\
\\
4,5 \\
4,5 \\
4,0 \\
\\
3,6 \\
3,6 \\
\\
3,1 \\
2,7 \\
2,7 \\
1,8 \\
1,8 \\
1,3 \\
\end{array}$ \\
\hline Total & & 224 & 100,0 \\
\hline
\end{tabular}




\subsubsection{2 - Satisfação no trabalho:}

O nível de satisfação no trabalho dos empregados em relação aos aspectos do ambiente psicossocial de trabalho estão apresentadas no Gráfico 1 (para mais detalhes, ver o Anexo XIII - Distribuição no nível de satisfação no trabalho).

Observa-se que os aspectos do ambiente de trabalho nos quais os empregados referem maiores níveis de satisfação são "relacionamento com outras pessoas na empresa" (74,0\%), “conteúdo do trabalho que realiza" (64,3\%) e "grau de liberdade e flexibilidade que julga ter no trabalho" (50,9\%).

Os aspectos nos quais os empregados referem menores níveis de satisfação são "salário em relação à experiência e à responsabilidade" (20,5\%), "oportunidades pessoais na carreira" (17,0\%), "clima psicológico que predomina na empresa" $(17,0 \%)$ e "oportunidades que o trabalho oferece no sentido de atingir aspirações e ambições" (14,3\%).

Os aspectos que apresentam maiores percentuais na categoria intermediária são “comunicação e forma do fluxo de informações" (76,3\%); "forma pela qual as mudanças e inovações são implementadas" (73,6\%) e "forma pela qual os conflitos são resolvidos" (73,2\%).

A variável Satisfação no Trabalho, que representa um indicador geral da satisfação no trabalho e é composta pela soma dos resultados da satisfação com cada aspecto do trabalho, tem como possibilidade resultados num escore que varia de 22 a 132. Esta variável apresentou média de 88,4, valor mínimo de 47,0, valor máximo de 132,0 e desvio padrão de 14,3 . 


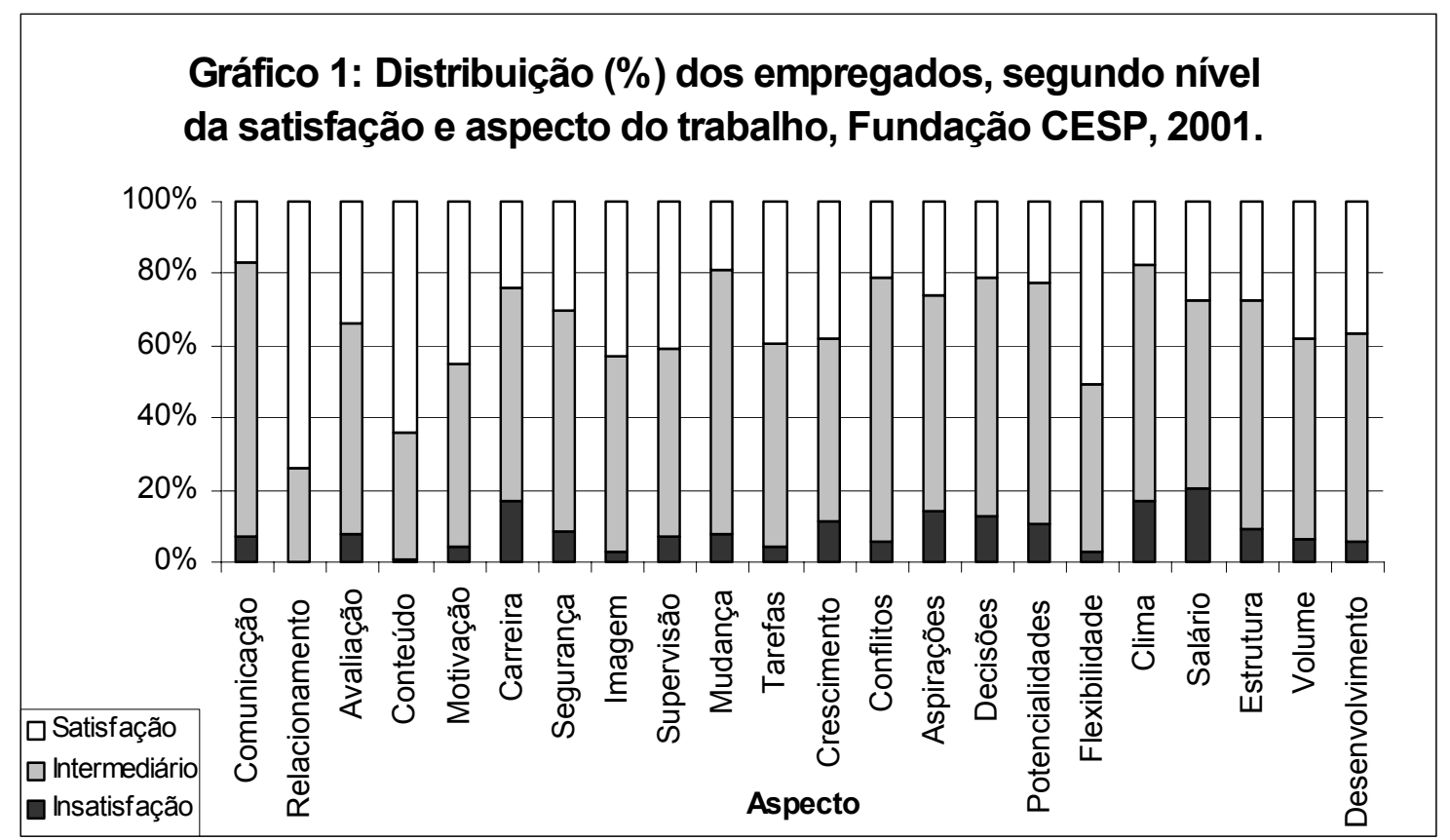

\subsubsection{3 - Saúde:}

- Avaliação genérica: O resultado da condição de saúde em cada um dos aspectos (capacidade funcional, aspectos físicos, dor, estado geral de saúde, vitalidade, aspectos sociais, aspectos emocionais e saúde mental) é dado em um escore que varia de 0 a 100. A distribuição dos empregados no escore de cada componente está apresentada no Gráfico 2, e a média, valor mínimo, valor máximo e DP de cada componente estão apresentados na Tabela 10. 
Gráfico 2: Distribuição $\left(\mathrm{N}^{0}\right)$ dos empregados no escore de saúde, segundo componente da saúde, Fundação CESP, 2001.
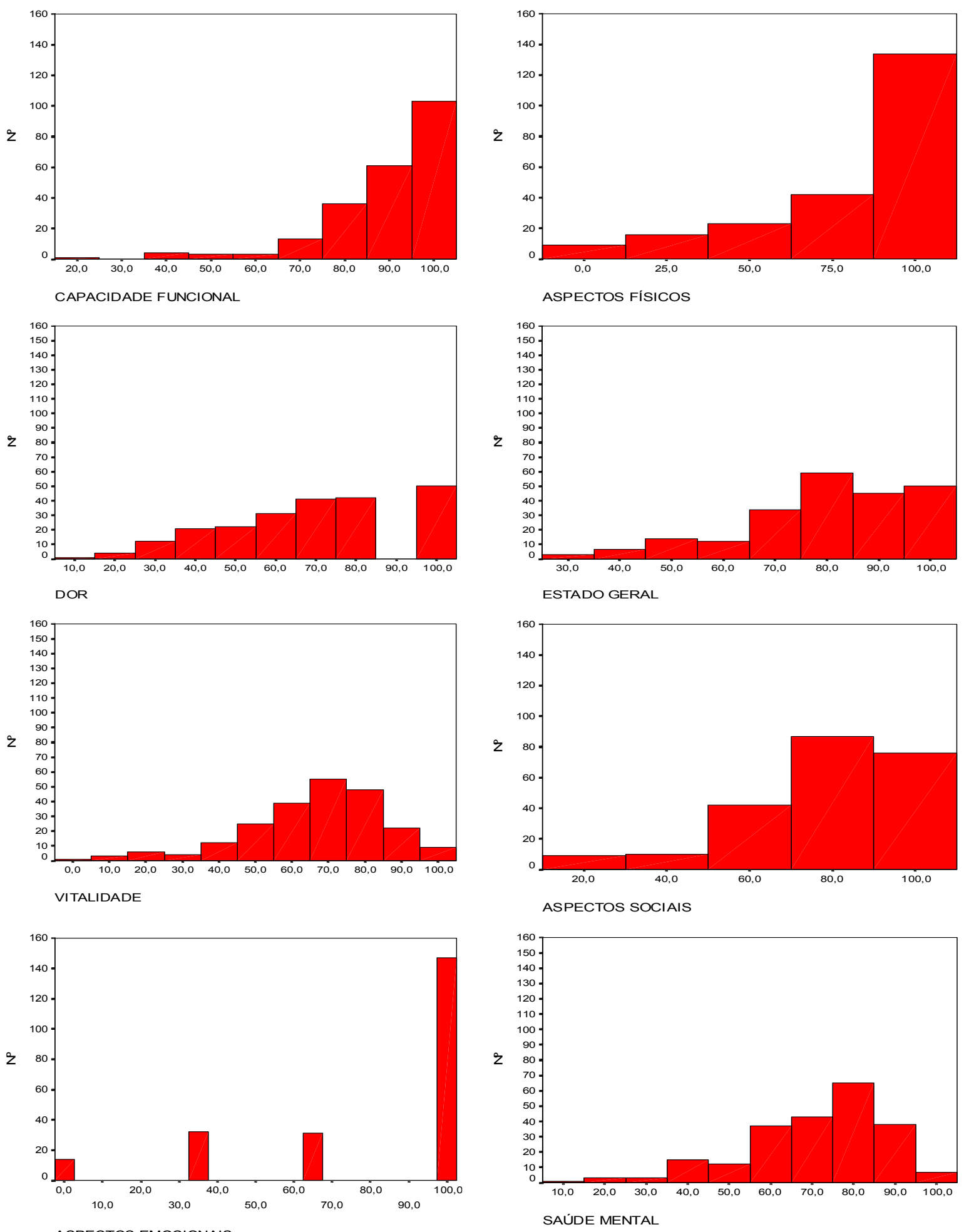

ASPECTOS EMOCIONAIS 
Tabela 10: Distribuição do número e porcentagem de empregados segundo componente da saúde e parâmetro populacional, Fundação CESP, 2001.

\begin{tabular}{l|cccc}
\hline \multicolumn{1}{c|}{ Componente } & Média & $\begin{array}{c}\text { Valor } \\
\text { mínimo }\end{array}$ & $\begin{array}{c}\text { Valor } \\
\text { máximo }\end{array}$ & $\begin{array}{c}\text { Desvio } \\
\text { padrão }\end{array}$ \\
\hline \hline $\begin{array}{c}\text { Saúde física } \\
\text { Capacidade funcional }\end{array}$ & 87,9 & 20,0 & 100,0 & 13,8 \\
Aspectos físicos & 80,0 & 0,0 & 100,0 & 28,5 \\
Dor & 71,0 & 10,0 & 100,0 & 22,3 \\
Estado geral de saúde & 79,4 & 32,0 & 100,0 & 16,4 \\
\hline \multicolumn{1}{c}{ Saúde mental } & & & & \\
Vitalidade & & & & \\
Aspectos sociais & 64,8 & 0,0 & 100,0 & 18,8 \\
Aspectos emocionais & 78,8 & 12,5 & 100,0 & 21,8 \\
Saúde mental & 79,6 & 0,0 & 100,0 & 31,7 \\
\hline
\end{tabular}

- Índice de Capacidade para o Trabalho: observa-se que 84,8\% dos empregados foram categorizados com apresentando capacidade para o trabalho boa ou ótima, e $15,2 \%$ estão com capacidade moderada (Tabela 11 ).

Tabela 11: Distribuição do número e porcentagem de empregados segundo índice de capacidade para 0 trabalho, Fundação CESP, 2001.

\begin{tabular}{l|cc}
\hline \multicolumn{1}{c|}{$\begin{array}{c}\text { Capacidade para o } \\
\text { trabalho }\end{array}$} & $\mathbf{N}^{\mathbf{0}}$ & $\mathbf{\%}$ \\
\hline \hline Baixa & - & - \\
Moderada & 34 & 15,2 \\
Boa & 88 & 39,3 \\
Ótima & 102 & 45,5 \\
\hline \hline Total & $\mathbf{2 2 4}$ & $\mathbf{1 0 0 , 0}$ \\
\hline \hline
\end{tabular}

\subsection{4 - Análise das associações}

O teste de Kolmogorov-Smirnov, demonstrou que satisfação no trabalho foi a única variável que apresentou distribuição normal $(p>0,05)$. As 8 variáveis referentes à avaliação genérica de saúde (capacidade funcional, aspectos físicos, dor, estado de saúde geral, vitalidade, aspectos sociais, aspectos emocionais, saúde mental), a 
variável referente à capacidade para o trabalho, e a variável idade não apresentaram distribuição normal (Anexo XIV - Teste de normalidade das variáveis).

\subsubsection{1 - Análise das associações de satisfação no trabalho com as variáveis sócio-demográficas e funcionais:}

- Idade (Tabela 12): não existe associação estatisticamente significativa entre satisfação no trabalho e idade $(\mathrm{p}=0,871)$.

- Sexo (Tabela 13): não existe associação estatisticamente significativa entre satisfação no trabalho e sexo $(p=0,736)$.

- Renda (Tabela 13): não existe associação estatisticamente significativa entre satisfação no trabalho e renda $(p=0,118)$.

- Escolaridade (Tabela 13): não existe associação estatisticamente significativa entre satisfação no trabalho e nível de escolaridade $(\mathrm{p}=0,144)$.

- Estado civil (Tabela 13): não existe associação estatisticamente significativa entre satisfação no trabalho e estado civil $(p=0,131)$.

- Cargo (Tabela 14): existe associação estatisticamente significativa entre satisfação no trabalho e cargo $(\mathrm{p}=0,003)$, sendo que os empregados do cargo "direção" apresentam maior nível de satisfação no trabalho que os empregados dos demais cargos (demonstrado pelo teste post hoc).

- Tempo de empresa: existe associação estatisticamente significativa inversa entre satisfação no trabalho e tempo de empresa $(r=-0,185 ; \mathrm{p}=0,006)$ (Tabela 12), indicando que quanto menor o tempo de empresa maior o nível de satisfação no trabalho. Quando a variável é transformada em categórica observa-se que a significância estatística se mantém $(p<0,001)$ (Tabela 14), sendo que os 
empregados com até 3 anos de casa apresentam maior nível de satisfação no trabalho que os empregados nos demais tempos de empresa (demonstrado pelo teste post hoc).

- Área de trabalho (Tabela 15): não foi feita a análise das relações quanto à área de trabalho porque observa-se grande variação entre os grupos, sendo que esta variação é devida ao tamanho de algumas áreas que é pequeno inviabilizando esta análise.

Tabela 12: Correlação entre satisfação no trabalho e variáveis quantitativas sócio-demográficas e funcionais , Fundação CESP, 2001.

\begin{tabular}{l|cc}
\hline \hline \multicolumn{1}{c|}{ Variável } & $\mathbf{r}$ & $\mathbf{p}$ \\
\hline \hline Idade & $0,011^{(\mathrm{S})}$ & 0,871 \\
Tempo de empresa & $-0,185^{(\mathrm{S})}$ & 0,006 \\
\hline \hline
\end{tabular}

${ }^{(\mathrm{S})}=$ Coeficiente de correlação de Spearman

Tabela 13: Média, desvio-padrão (DP), máxima e mínima, e associação entre satisfação no trabalho e variáveis qualitativas sócio-demográficas, Fundação CESP, 2001.

\begin{tabular}{|c|c|c|c|c|}
\hline Variável & Categoria & Média (DP) & Máx. / mín. & $\mathbf{p}$ \\
\hline Sexo & $\begin{array}{l}\text { Feminino } \\
\text { Masculino }\end{array}$ & $\begin{array}{l}88,56(14,13) \\
88,18(14,51)\end{array}$ & $\begin{array}{l}58,00-121,00 \\
47,00-132,00\end{array}$ & $0,736^{(\mathrm{M})}$ \\
\hline $\begin{array}{l}\text { Renda } \\
\text { (em faixas de } \\
\text { Salários mínimos) }\end{array}$ & $\begin{array}{l}4 \text { a } 6 \\
7 \text { a } 10 \\
11 \text { a } 15 \\
16 \text { a } 20 \\
21 \text { a } 25 \\
25 \text { e mais }\end{array}$ & $\begin{array}{l}90,86(16,39) \\
87,45(13,19) \\
82,95(15,75) \\
87,96(10,74) \\
88,52(13,17) \\
91,77(12,98)\end{array}$ & $\begin{array}{l}47,00-122,00 \\
63,00-132,00 \\
51,00-112,00 \\
69,00-111,00 \\
66,00-119,00 \\
62,00-119,00\end{array}$ & $0,118^{(\mathrm{K})}$ \\
\hline Escolaridade & $\begin{array}{l}1^{\circ} \text { grau completo } \\
2^{\circ} \text { grau completo } \\
3^{\circ} \text { grau completo }\end{array}$ & $\begin{array}{l}97,80(18,41) \\
90,04(15,24) \\
87,14(13,49)\end{array}$ & $\begin{array}{l}74,00-122,00 \\
47,00-132,00 \\
51,00-119,00\end{array}$ & $0,144^{(\mathrm{K})}$ \\
\hline Estado civil & $\begin{array}{l}\text { Casados } \\
\text { Não casados }\end{array}$ & $\begin{array}{l}89,44(12,80) \\
87,05(15,90)\end{array}$ & $\begin{array}{l}58,00-132,00 \\
47,00-122,00\end{array}$ & $0,131^{(\mathrm{K})}$ \\
\hline Total & & $88,38(14,29)$ & $47,00 / 132,00$ & \\
\hline
\end{tabular}


Tabela 14: Média, desvio-padrão (DP), máxima e mínima e associação entre satisfação no trabalho e variáveis qualitativas funcionais, Fundação CESP, 2001.

\begin{tabular}{ll|ccc}
\hline \hline Variável & \multicolumn{1}{c|}{ Categoria } & Média (DP) & Máx. / mín. & P \\
\hline \hline Cargo & Analistas & $85,43(13,30)$ & $51,00 / 112,00$ & $0,003^{(\mathrm{K})}$ \\
& Técnicos & $87,88(16,25)$ & $47,00 / 132,00$ & \\
& Atendimento & $91,23(12,00)$ & $67,00 / 121,00$ & \\
& Especialistas & $86,87(12,95)$ & $59,00 / 119,00$ & \\
& Direção & $98,74(11,34)$ & $74,00 / 119,00$ & \\
\hline Tempo & Menos de 3 anos & $100,15(12,16)$ & $75,00-122,00$ & $<0,0001^{(\mathrm{K})}$ \\
& 3 a 5 anos & $83,85(12,21)$ & $59,00-112,00$ & \\
& 6 a 10 anos & $84,50(14,08)$ & $47,00-115,00$ & \\
& 11 a 14 anos & $87,03(14,29)$ & $51,00-132,00$ & \\
\hline \hline Total & $\mathbf{8 8 , 3 8 ( 1 4 , 2 9 )}$ & $\mathbf{4 7 , 0 0 / 1 3 2 , 0 0}$ & \\
\hline (K)=Kruskal-Wallis & & &
\end{tabular}

Tabela 15: Média, desvio-padrão (DP), máxima e mínima entre satisfação no trabalho e área de trabalho, Fundação CESP, 2001.

\begin{tabular}{l|cc}
\hline \multicolumn{1}{c|}{ Área } & Média (DP) & Máx. / mín. \\
\hline \hline Atendimento ao cliente & $91,90(11,77)$ & $67,00 / 121,00$ \\
Administração geral & $92,12(11,65)$ & $72,00 / 112,00$ \\
Auditoria interna & $93,00(19,34)$ & $74,00 / 119,00$ \\
Atuarial & $87,68(11,52)$ & $68,00 / 115,00$ \\
Cadastro de beneficiários & $64,83(11,11)$ & $47,00 / 78,00$ \\
Comunicação institucional & $80,00(13,45)$ & $69,00 / 95,00$ \\
Contabilidade e custos & $82,50(21,57)$ & $51,00 / 132,00$ \\
Diretoria & $103,17(12,32)$ & $85,00 / 118,00$ \\
Finanças e orçamento & $87,06(11,24)$ & $72,00 / 107,00$ \\
Gestão de sistemas de saúde & $86,83(14,60)$ & $59,00 / 111,00$ \\
Investimentos e patrimônio & $82,00(11,34)$ & $70,00 / 94,00$ \\
Informática & $87,90(12,70)$ & $62,00 / 119,00$ \\
Jurídico & $91,70(12,96)$ & $66,00 / 112,00$ \\
Operacionalização e controle de sist. de & $88,73(15,74)$ & $63,00 / 122,00$ \\
saúde & & \\
Processamento e controle de investimentos & $85,33(15,43)$ & $59,00 / 102,00$ \\
Pagamentos previdenc., pecúlio e seguros & $88,09(15,33)$ & $59,00 / 107,00$ \\
Relações contratuais & $83,75(15,90)$ & $60,00 / 101,00$ \\
Recursos humanos & $96,14(10,79)$ & $78,00 / 111,00$ \\
\hline \hline Total & $\mathbf{8 8 , 3 8 ( 1 4 , 2 9 )}$ & $\mathbf{4 7 , 0 0 / 1 3 2 , 0 0}$ \\
\hline \hline
\end{tabular}


4.2.4.2 - Análise das correlações de satisfação no trabalho com as variáveis referentes à saúde (avaliação genérica de saúde e de capacidade para o trabalho):

- Domínio saúde física (Tabela 16): não existe associação estatisticamente significativa entre satisfação no trabalho e quaisquer das variáveis representativas da saúde física (capacidade funcional, aspecto físico, dor, estado geral).

- Domínio saúde mental (Tabela 16): existe associação estatisticamente significativa entre satisfação no trabalho e todas as variáveis representativas da saúde mental (vitalidade, aspectos sociais, aspectos emocionais, saúde mental).

- Capacidade para o trabalho (Tabela 16): existe associação estatisticamente significativa entre satisfação no trabalho e a capacidade para o trabalho .

Tabela 16: Correlação entre satisfação no trabalho e saúde, Fundação CESP, 2001.

\begin{tabular}{|c|c|c|}
\hline Saúde & $\mathbf{r}^{(\mathbf{S})}$ & $\mathbf{p}$ \\
\hline "Saúde física & & \\
\hline Capacidade funcional & 0,030 & 0,656 \\
\hline Aspecto físico & 0,082 & 0,222 \\
\hline Dor & 0,047 & 0,488 \\
\hline Estado geral & 0,068 & 0,313 \\
\hline Saúde mental & & \\
\hline Vitalidade & 0,338 & $<0,0001$ \\
\hline Aspectos sociais & 0,153 & 0,022 \\
\hline Aspecto emocional & 0,145 & 0,031 \\
\hline Saúde mental & 0,276 & $<0,0001$ \\
\hline $\begin{array}{l}\text { Capacidade para o trabalho } \\
\end{array}$ & 0,247 & $<0,0001$ \\
\hline
\end{tabular}




\subsection{5 - Análise de regressão}

A análise de regressão múltipla (Tabela 17) demonstra que o efeito da satisfação no trabalho sobre os aspectos da saúde permanece mesmo após ajuste pelas demais variáveis, não sendo influenciado por elas.

- Vitalidade: satisfação no trabalho apresenta correlação com a vitalidade $(\mathrm{p}<0,001)$, mas explica apenas $10 \%$ da variabilidade da amostra. O ajuste pelas demais variáveis não melhorou o modelo.

- Aspectos sociais: satisfação no trabalho apresenta correlação com a aspectos sociais $(\mathrm{p}=0,005)$, mas explica apenas $3 \%$ da variabilidade da amostra. $\mathrm{O}$ ajuste pelas demais variáveis diminuiu o nível de significância estatística do modelo.

- Aspecto emocional: satisfação no trabalho apresenta correlação com o aspecto emocional $(\mathrm{p}=0,013)$, mas explica apenas $2 \%$ da variabilidade da amostra. O ajuste pelas demais variáveis tirou a significância estatística do modelo.

- Saúde mental: satisfação no trabalho apresenta correlação com a saúde mental $(\mathrm{p}<0,001)$, mas explica apenas $10 \%$ da variabilidade da amostra. $\mathrm{O}$ ajuste pelas demais variáveis não alterou o modelo.

- Capacidade para o trabalho: satisfação no trabalho apresenta correlação com a capacidade para o trabalho $(\mathrm{p}<0,001)$, mas explica apenas $6 \%$ da variabilidade da amostra. $\mathrm{O}$ ajuste pelas demais variáveis alterou pouco o valor do $\beta_{1}$, o intervalo de confiança e o valor do $\mathrm{R}^{2} \mathrm{~A}$, sem alteração representativa para o modelo

A satisfação no trabalho apresenta correlação com cada um dos aspectos da saúde mental e com a capacidade para o trabalho independente de outras variáveis 
analisadas. Porém, apesar da alta significância estatística, satisfação no trabalho tem reduzido poder em explicar a variabilidade dos aspectos da saúde, indicando que existem outros fatores interferindo nestes aspectos da saúde que não foram contemplados nesta análise.

Tabela 17: Análise das correlações entre satisfação do trabalho (ST), saúde e variáveis sócio-demográficas e funcionais, Fundação CESP, 2001.

\begin{tabular}{|c|c|c|c|c|c|}
\hline $\begin{array}{l}\text { Aspecto da } \\
\text { saúde }\end{array}$ & Variáveis & $\beta$ & IC $_{95 \%}$ & $\mathbf{p}$ & $\mathbf{R}^{2} \mathbf{A}$ \\
\hline Vitalidade & $\begin{array}{l}\text { ST } \\
\text { ST ajustada por sexo, tempo de } \\
\text { empresa, idade, estado civil, } \\
\text { escolaridade, renda e cargo }\end{array}$ & $\begin{array}{l}0,428 \\
0,437\end{array}$ & $\begin{array}{l}0,264-0,593 \\
0,265-0,608\end{array}$ & $\begin{array}{l}<<0,0001 \\
<0,0001\end{array}$ & $\begin{array}{l}0,102 \\
0,129\end{array}$ \\
\hline $\begin{array}{l}\text { Aspectos } \\
\text { sociais }\end{array}$ & $\begin{array}{l}\text { ST } \\
\text { ST ajustada por sexo, tempo de } \\
\text { empresa, idade, estado civil, } \\
\text { escolaridade, renda e cargo }\end{array}$ & $\begin{array}{l}0,289 \\
0,275\end{array}$ & $\begin{array}{l}0,090-0,488 \\
0,065-0,485\end{array}$ & $\begin{array}{l}0,005 \\
0,055\end{array}$ & $\begin{array}{l}0,031 \\
0,033\end{array}$ \\
\hline $\begin{array}{c}\text { Aspecto } \\
\text { Emocional }\end{array}$ & $\begin{array}{l}\text { ST } \\
\text { ST ajustada por sexo, tempo de } \\
\text { empresa, idade, estado civil, } \\
\text { escolaridade, renda e cargo }\end{array}$ & $\begin{array}{l}0,368 \\
0,370\end{array}$ & $\begin{array}{l}0,079-0,657 \\
0,066-0,675\end{array}$ & $\begin{array}{l}0,013 \\
0,074\end{array}$ & $\begin{array}{l}0,023 \\
0,029\end{array}$ \\
\hline Saúde mental & $\begin{array}{l}\text { ST } \\
\text { ST ajustada por sexo, tempo de } \\
\text { empresa, idade, estado civil, } \\
\text { escolaridade, renda e cargo }\end{array}$ & $\begin{array}{l}0,378 \\
0,378\end{array}$ & $\begin{array}{l}0,231-0,526 \\
0,223-0,533\end{array}$ & $\begin{array}{l}<0,0001 \\
<0,0001\end{array}$ & $\begin{array}{l}0,100 \\
0,103\end{array}$ \\
\hline $\begin{array}{c}\text { Capacidade } \\
\text { para o trabalho }\end{array}$ & $\begin{array}{l}\text { ST } \\
\text { ST ajustada por sexo, tempo de } \\
\text { empresa, idade, estado civil, } \\
\text { escolaridade, renda e cargo }\end{array}$ & $\begin{array}{l}0,080 \\
0,075\end{array}$ & $\begin{array}{l}0,040-0,122 \\
0,032-0,118\end{array}$ & $\begin{array}{c}<0,0001 \\
0,001\end{array}$ & $\begin{array}{l}0,059 \\
0,080\end{array}$ \\
\hline
\end{tabular}




\section{3 - ANÁLISE ERGONÔMICA DO TRABALHO}

\subsection{1 - Representatividade da amostra}

Foi feita solicitação de 01 voluntário em cada uma das 18 áreas de trabalho existentes, para participar da análise ergonômica do trabalho. Apresentaram-se 43 pessoas interessadas em colaborar (14,9\% do total de empregados da empresa), sendo que em apenas 01 área não houve voluntários (para definição de área de trabalho ver o item 3.3.2.4 - Análise de dados do questionário). Foi feita análise ergonômica dos 43 postos de trabalho, mas uma análise foi excluída porque $\mathrm{o}$ empregado não respondeu ao questionário auto-aplicado, restando uma amostra composta por $18,8 \%$ dos empregados participantes do estudo.

- Características sócio-demográficas (tabela 18): não existe associação estatisticamente significativa entre o grupo de empregados que participou das análises ergonômicas e o grupo que não participou, porém nas variáveis idade e renda existem caselas com menos de 5 indivíduos indicando que estes resultados podem ser devidos ao acaso.

- Características funcionais (tabela 19): não existe associação estatisticamente significativa entre o grupo de empregados que participou das análises ergonômicas e o grupo que não participou, porém a variável cargo apresenta casela com menos de 5 indivíduos indicando que estes resultados podem ser devidos ao acaso.

Não foram encontradas diferenças entre o grupo empregados participantes da análise ergonômica e o grupo de não participantes, porém estes resultados devem considerados com cautela uma vez que a amostra é não probabilística, e existem algumas variáveis com categorias com pequeno número de empregados, indicando que estes resultados podem ser devidos ao acaso. 
Tabela 18: Análise das correlações entre participantes da análise ergonômica do trabalho e não participantes, segundo característica sócio-demográfica, Fundação CESP, 2001.

\begin{tabular}{|c|c|c|c|c|c|c|}
\hline \multirow[t]{2}{*}{ Variável } & \multirow[t]{2}{*}{ Categoria } & \multicolumn{2}{|c|}{ Não particip. } & \multicolumn{2}{|c|}{ Participantes } & \multirow[t]{2}{*}{$\bar{p}$} \\
\hline & & $\mathbf{N}^{\mathbf{o}}$ & $\%$ & $\mathbf{N}^{\mathbf{o}}$ & $\%$ & \\
\hline \multirow[t]{2}{*}{ Sexo } & Feminino & 91 & 79,8 & 23 & 20,2 & $0,578^{x}$ \\
\hline & Masculino & 91 & 82,7 & 19 & 17,3 & \\
\hline \multirow{4}{*}{$\begin{array}{c}\text { Idade } \\
\text { (em anos) }\end{array}$} & Menor que 30 & 52 & 81,3 & 12 & 18,8 & $0,837^{x}$ \\
\hline & 30 a 39 & 77 & 83,7 & 15 & 16,3 & \\
\hline & 40 a 49 & 46 & 78,0 & 13 & 22,0 & \\
\hline & 50 e mais & 7 & 77,8 & 2 & 22,2 & \\
\hline \multirow[t]{2}{*}{ Escolaridade } & Não universitário & 65 & 81,3 & 15 & 18,8 & $1,000^{\chi}$ \\
\hline & Universitário & 117 & 81,3 & 27 & 18,8 & \\
\hline \multirow[t]{2}{*}{ Estado civil } & Casado & 102 & 82,3 & 22 & 17,7 & $0,667^{x}$ \\
\hline & Não casado & 80 & 80,0 & 20 & 20,0 & \\
\hline \multirow{6}{*}{$\begin{array}{c}\text { Renda } \\
\text { (em faixas de } \\
\text { salários mínimos) }\end{array}$} & 4 a 6 & 41 & 85,4 & 7 & 14,6 & $0,158^{x}$ \\
\hline & 7 a 10 & 39 & 75,0 & 13 & 25,0 & \\
\hline & 11 a 15 & 32 & 91,4 & 3 & 8,6 & \\
\hline & 16 a 20 & 17 & 68,0 & 8 & 32,0 & \\
\hline & 21 a 25 & 22 & 88,0 & 3 & 12,0 & \\
\hline & 26 ou mais & 31 & 79,5 & 8 & 20,5 & \\
\hline Total & & 182 & 81,3 & 42 & 18,8 & \\
\hline
\end{tabular}

Tabela 19: Análise das correlações entre participantes da análise ergonômica do trabalho e não participantes, segundo característica funcional, Fundação CESP, 2001.

\begin{tabular}{|c|c|c|c|c|c|c|}
\hline \multirow[t]{2}{*}{ Variável } & \multirow[t]{2}{*}{ Categoria } & \multicolumn{2}{|c|}{ Não particip. } & \multicolumn{2}{|c|}{ Participantes } & \multirow[t]{2}{*}{$\bar{p}$} \\
\hline & & $\mathbf{N}^{\mathbf{o}}$ & $\%$ & $\mathbf{N}^{\mathbf{o}}$ & $\%$ & \\
\hline \multirow{4}{*}{$\begin{array}{c}\text { Tempo de } \\
\text { empresa } \\
\text { (em anos) }\end{array}$} & Menor que 3 & 32 & $\overline{78,0}$ & 9 & 22,0 & \multirow[t]{4}{*}{$0,809^{7}$} \\
\hline & 3 a 5 & 35 & 85,4 & 6 & 14,6 & \\
\hline & 6 a 10 & 33 & 78,6 & 9 & 21,4 & \\
\hline & 11 ou mais & 82 & 82,0 & 18 & 18,0 & \\
\hline \multirow[t]{5}{*}{ Cargo } & Analistas & 66 & 85,7 & 11 & 14,3 & \multirow[t]{5}{*}{$0,257^{\gamma}$} \\
\hline & Técnicos & 54 & 78,3 & 15 & 21,7 & \\
\hline & Atendimento & 31 & 88,6 & 4 & 11,4 & \\
\hline & Especialistas & 18 & 75,0 & 6 & 25,0 & \\
\hline & Direção & 13 & 68,4 & 6 & 31,6 & \\
\hline $\begin{array}{c}\text { Satisfação } \\
\text { no trabalho }\end{array}$ & & & -- & & -- & $0,812^{\mathrm{t}}$ \\
\hline Total & & 182 & 81,3 & 42 & 18,8 & \\
\hline
\end{tabular}




\subsection{2 - Análise dos postos de trabalho}

Foi efetuada a análise ergonômica do trabalho junto aos 43 voluntários. Destas, foram selecionadas aquelas referentes aos postos de trabalho de empregados que apresentaram maiores níveis de satisfação no trabalho (17 empregados), e aquelas referentes aos postos de trabalho de empregados que apresentaram maiores níveis de insatisfação no trabalho (18 empregados), compondo uma amostra de 35 análises ergonômicas.

Dos 216 itens que compõem o roteiro de investigação do método AET, foram utilizados 70 itens, sendo que os demais não se aplicam às situações de trabalho dos empregados analisados.

No Anexo XV estão apresentados os percentuais de indivíduos em cada um dos grupos de empregados (satisfeitos e insatisfeitos) e o nível de significância estatística das análises de associação para cada item analisado.

A análise das associações demonstrou que não existem diferenças significativas na exposição às fontes de estresse entre os dois grupos de empregados, sugerindo que as condições de trabalho e organizacionais são semelhantes entre os postos de trabalho analisados. O único item que apresentou diferença estatisticamente significativa foi "freqüência de estresse que pode ter origem em conflitos com padrões sociais", onde o grupo de empregados mais satisfeitos apresenta menor exposição a esta fonte de estresse do que o grupo de empregados mais insatisfeitos.

Considerando essa ausência de diferenças entre os dois grupos analisados, e considerando que para todos os empregados trata-se de trabalho essencialmente administrativo, optou-se por não realizar uma caracterização dos dois grupos em separado, mas por proceder a uma caracterização geral das condições e da organização do trabalho do conjunto dos postos de trabalho analisados. 
Nos itens 4.3.2.1, 4.3.2.2 e 4.3.2.3 a seguir, os números que aparecem entre parêntesis referem-se ao percentual de indivíduos na situação em referência.

\subsubsection{1 - Análise do sistema de trabalho:}

\section{- Objetos de trabalho:}

Por se tratar de trabalho administrativo, os objetos materiais de trabalho foram aqueles característicos destas atividades (computador, telefone, papéis, caneta e outros). Objetos de trabalho abstrato apareceram com grande importância, envolvendo utilização de habilidades mentais (organização, planejamento, aprendizado, desenvolvimento de estratégias, avaliação e outras) por grande parte do tempo de trabalho para a maior parte dos empregados $(83,3 \%)$.

\section{- Equipamentos de trabalho:}

- Os instrumentos mais utilizados foram os relacionados ao armazenamento, transmissão ou manipulação/transformação de informações, como computador $(97,2 \%)$, calculadoras, telefone e outros $(71,5 \%)$, com uma parcela de empregados com alta freqüência no uso de teclados $(71,4 \%)$.

- As cadeiras de trabalho eram ajustáveis $(97,1 \%)$, porém ocorreram relatos freqüentes de desconforto relacionado ao tamanho dos assentos e ao estado de manutenção.

- As mesas de trabalho não tinham altura ajustável (94,3\%). Foram freqüentes as queixas de espaço insuficiente e inadequação à finalidade a que se destina. Nem todos os empregados dispunham de mesa auxiliar para o computador e para acomodação de outros objetos, tendo sido freqüente a colocação de objetos pessoais e de trabalho sob a mesa.

- Poucos empregados dispunham de descanso para os pés (embora fossem poucos os que apresentassem ou referissem necessidade deste equipamento) ou de apóia-braços $(62,9 \%)$.

- Os tetos e paredes eram de cor clara, e as áreas separadas por divisórias de fórmica ou por armários de madeira, muitas vezes com grande número de 
pessoas trabalhando no mesmo espaço físico $(77,1 \%)$. As mesas estavam dispostas lado a lado ou uma em frente a outra, muitas vezes encostadas entre si. Os pisos, em geral, eram recobertos por carpete escuro. Em vários locais observou-se acúmulo de armários, arquivos ou caixas.

\section{- Ambiente de trabalho (físico, organizacional e de remuneração):}

- Iluminação: a mensuração dos níveis de iluminação realizada no PPRA Programa de Prevenção de Riscos Ambientais da empresa (FUNDAÇÃO CESP 2001) identificou que, de uma maneira geral, estes níveis encontravam-se dentro dos parâmetros previstos pela Norma Regulamentadora 17 - Ergonomia do Ministério do Trabalho e do Emprego (1978), porém com existência de alguns postos de trabalho abaixo destes limites. $28,6 \%$ dos empregados relataram algum tipo de desconforto relacionado à presença de reflexos das janelas ou luminárias nas telas dos computadores, fontes de ofuscamento dependendo da incidência da luz do sol, ou sensação de iluminação insuficiente.

- Temperatura: a mensuração dos níveis de temperatura realizada no PPRA Programa de Prevenção de Riscos Ambientais da empresa (FUNDAÇÃO CESP 2001) identificou que estes níveis estão dentro dos parâmetros previstos pela Norma Regulamentadora 15 - Atividades e Operações Insalubres do Ministério do Trabalho e do Emprego (1978). Não estavam disponíveis informações sobre níveis de temperatura efetiva, velocidade do ar e umidade relativa do ar para avaliação do conforto térmico de acordo com a Norma Regulamentadora 17 - Ergonomia do Ministério do Trabalho e do Emprego (1978). 42,8\% dos empregados relataram algum tipo de desconforto térmico relacionado à temperatura e ao fluxo de ar, em especial nos postos de trabalho localizados próximos às saídas de ar condicionado.

- Ruído: a mensuração dos níveis de ruído realizada no PPRA - Programa de Prevenção de Riscos Ambientais da empresa (FUNDAÇÃO CESP 2001) identificou que, de uma maneira geral, estes níveis estão dentro dos parâmetros previstos pela Norma Regulamentadora 15 - Atividades e Operações Insalubres do Ministério do Trabalho e do Emprego (1978), 
porém com existência de alguns postos de trabalho com níveis de ruído acima destes limites. 22,9\% dos empregados apresentaram queixas relacionadas ao ruído das conversas no ambiente de trabalho ou do trânsito que chega pelas janelas quando abertas.

- Havia um único turno de trabalho em horário administrativo (das $8 \mathrm{~h} 00 \mathrm{ou}$ 9 h00 até $17 \mathrm{~h} 00$ ou 18h00), com carga horária normal de 40 horas semanais, 60 a 90 minutos de almoço e a possibilidade de, ao menos, duas pausas de 5 minutos ou mais por dia. Era freqüente realização de 6 ou mais horas-extras por semana $(34,3 \%)$.

- De uma maneira geral os empregados relataram dispor de autonomia para organizar a estruturação e forma de desenvolvimento de seu trabalho (88,6\%), sendo que o tipo de instruções/orientações recebidas para execução das tarefas era genérico $(77,1 \%)$. Também de uma forma geral, a percepção dos entrevistados era de que não existia controle de qualidade formal sobre o trabalho executado $(77,2 \%)$.

- De uma maneira geral poucos empregados relataram responsabilidades significativas sobre acidentes $(5,7 \%)$ ou danos materiais (5,7\%). Muitos relataram responsabilidade alta ou muito alta em relação a perda de tempo $(54,3 \%)$, e a maioria considerou que tinha responsabilidade alta ou extrema em relação a valores abstratos (como imagem da empresa, ética, informações confidenciais e outros) $(74,3 \%)$.

- Ocorreram relatos de existência de potencial de conflitos na interação do empregado com outras pessoas da empresa $(17,1 \%)$ e/ou com terceiros, pessoas não empregadas da empresa (25,7\%).

- A forma de contrato era por CLT (Consolidação das Leis Trabalhistas). Os critérios para classificação de cargos e remuneração eram por nível educacional $(82,9 \%)$ e por mérito (avaliação de desempenho anual) $(100,0 \%)$. O salário era pago em duas parcelas no mês (adiantamento e salário). 
O Gráfico 3 apresenta um resumo da distribuição de empregados em situação de exposição às principais fontes de estresse decorrente de aspectos do sistema de trabalho.

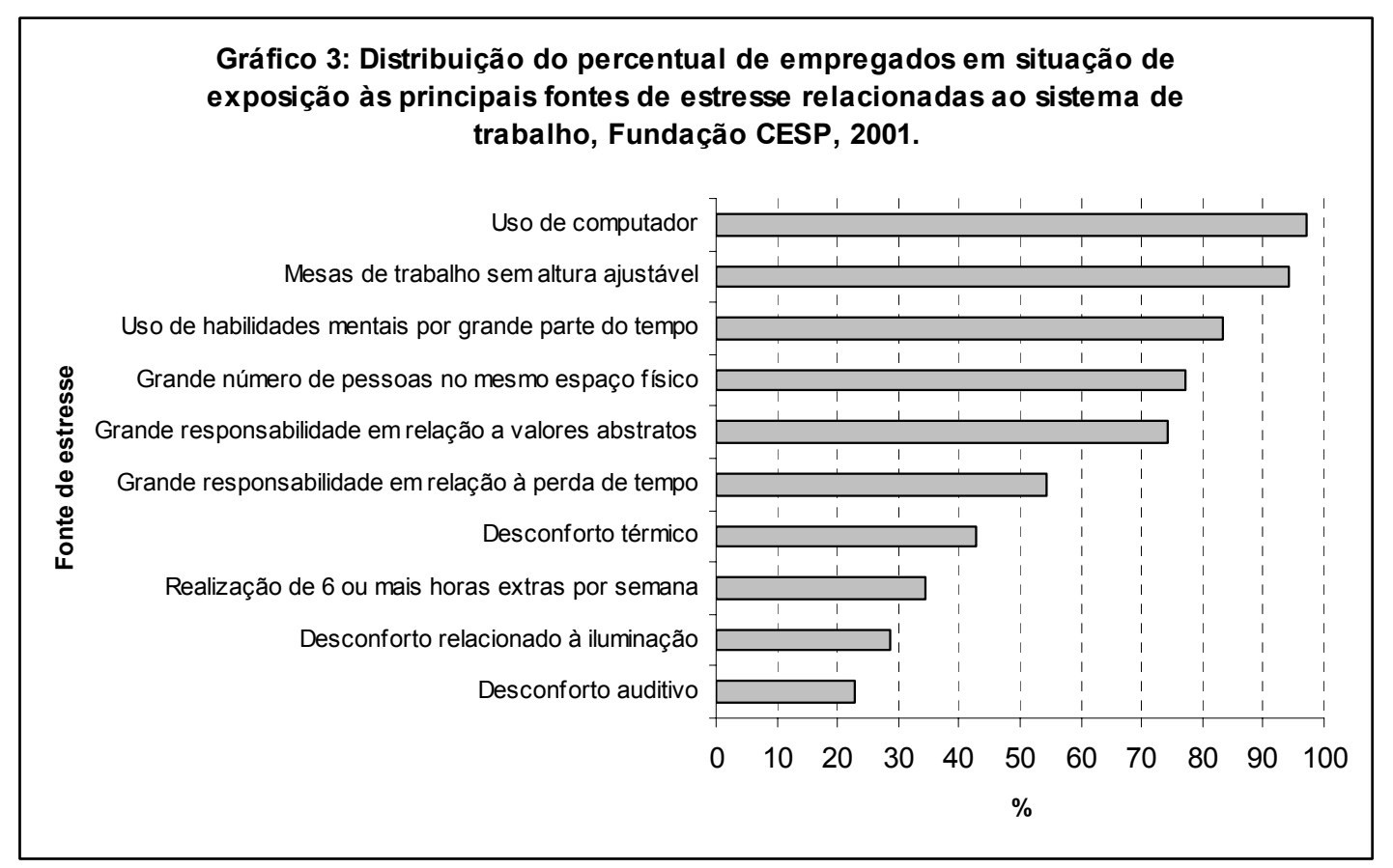

\subsubsection{2 - Análise da tarefa:}

\section{- Objetos de trabalho material:}

Por se tratar de trabalho administrativo, os objetos materiais de trabalho estiveram restritos ao computador e outros equipamentos para escritórios (máquina fotocopiadora, caneta, telefone, e outros).

\section{- Objetos de trabalho abstrato (planejamento e processamento de informações):}

De uma maneira geral os empregados consideraram que as atividades relacionadas ao planejamento e organização das atividades/tarefas $(88,5 \%)$, ao registro de dados $(77,1 \%)$, codificação de informações $(48,6 \%)$, organização e classificação de informações $(68,6 \%)$, síntese de informações $(74,3 \%)$, análise de informações $(77,2 \%)$, uso de matemática simples $(60,0 \%)$ e/ou avançada $(37,1 \%)$ tinham importância alta ou muito alta para o desempenho de seu trabalho. 


\section{- Tarefas relacionadas às pessoas:}

Foi freqüente o relato de empregados que consideraram que atividades relacionadas à apresentações em público $(25,7 \%)$, avaliação de comportamento humano $(37,2 \%)$, atendimento $(14,3 \%)$, aconselhamento $(28,5 \%)$, negociação $(45,7 \%)$, treinamento $(17,2 \%)$ e entrevistas $(11,5 \%)$ têm importância alta ou muito alta para o desempenho de seu trabalho.

\section{- Repetitividade de tarefas:}

De uma maneira geral, existe diversificação na quantidade e tipo de tarefas. Os relatos de queixas existentes são direcionados para a falta de possibilidade de aprendizado e de execução de novas atividades.

O Gráfico 4 apresenta um resumo da distribuição de empregados em situação de exposição ao estresse decorrente da magnitude da importância que as tarefas têm para o desempenho de seu trabalho.

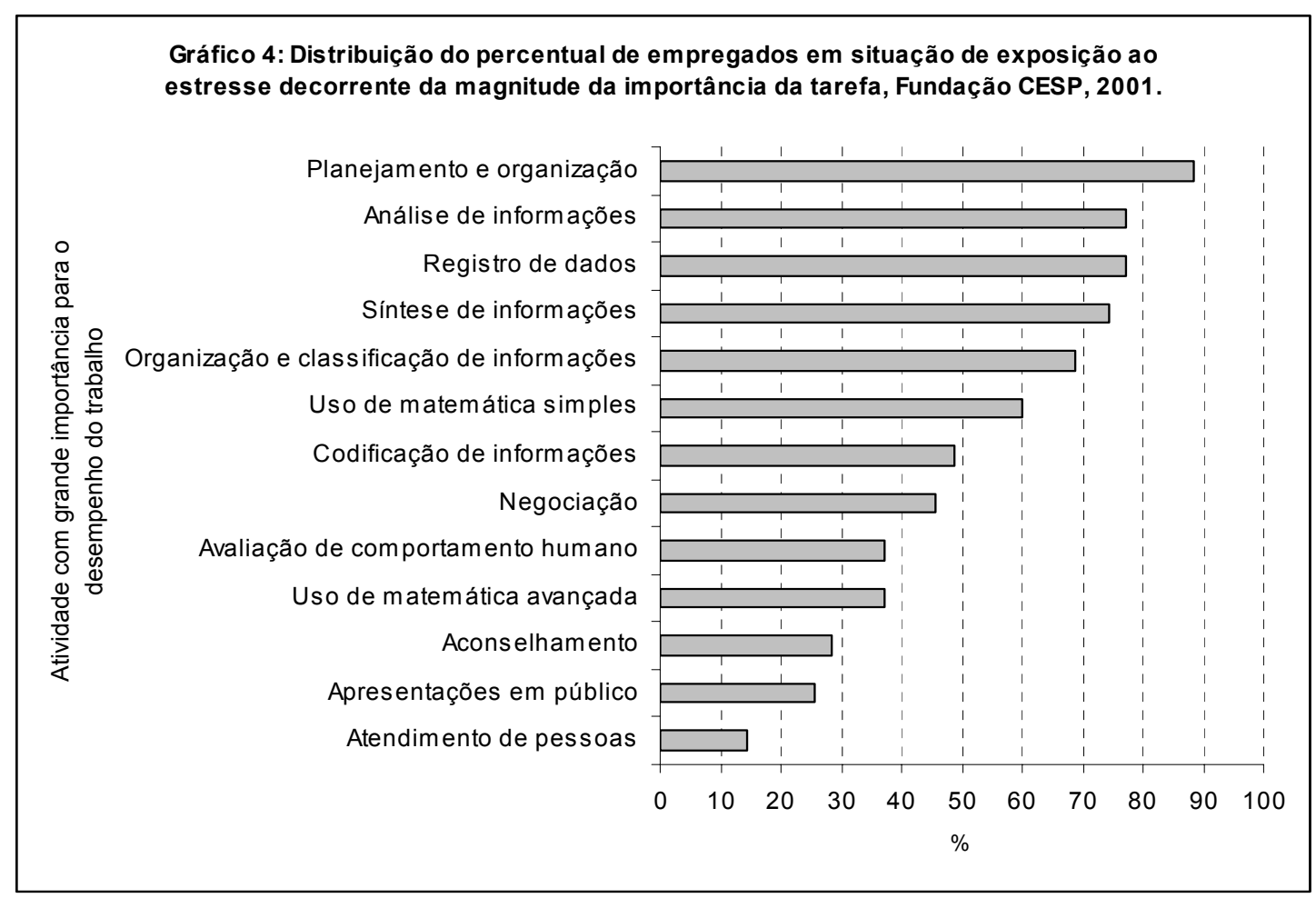




\subsubsection{3 - Análise das exigências:}

\section{- Exigências de percepção:}

As demandas de percepção diziam respeito às demandas de recepção visual de informações, em especial leitura de informações. Os empregados $(100,0 \%)$ consideraram que é alta ou muito alta a acurácia e precisão necessária na recepção de informações.

\section{- Exigências de decisão:}

- Muitos empregados consideraram que tomam decisões de complexidade alta ou extrema $(51,4 \%)$ e/ou que necessitam tomar decisões com urgência alta ou extrema $(62,9 \%)$.

- Foi freqüente o relato de empregados que necessitam de formação profissionalizante ou universitária para o desempenho de suas atividades (45,7\%), ou exigência de treinamento profissional avançado (25,7\%). Também foi freqüente o relato de empregados que consideraram que $o$ recebimento de instruções especiais para ações específicas (42,9\%) tem importância alta ou muito alta para o desempenho de seu trabalho, ou o relato de empregados que consideraram que é necessário tempo de experiência de 1 ano ou mais para o bom desempenho de seu trabalho $(51,4 \%)$.

\section{- Exigências de postura e de movimentação:}

- A maioria dos empregados $(88,6 \%)$ mantinham-se sentados mais que $60 \%$ do seu período de trabalho, não tendo sido observado ou relatado trabalho sentado curvado, em pé, ajoelhado, agachado ou curvado. Porém, em função da inadequação dos mobiliários dos postos de trabalho, com freqüência foram encontradas situações de desvio ou rotação de tronco, esforço estático de antebraço, desvio ou rotação de punhos, hiper-extensão ou hiper-flexão de pescoço, abdução de pernas, bem como dificuldades de livre movimentação de pernas e pés. 
- Um parcela dos empregados (34,3\%) relatou trabalho com os dedos, mãos e antebraço (em especial para digitação) durante $60 \%$ ou mais de seu tempo de trabalho. Não foram relatadas ou observadas ocorrências de movimentos com exigência de esforços musculares ou exigência de aplicação de força em trabalho estático ou ativo de outros segmentos do corpo.

O Gráfico 5 apresenta um resumo da distribuição de empregados em situação de exposição ao estresse decorrente de exigências do trabalho.

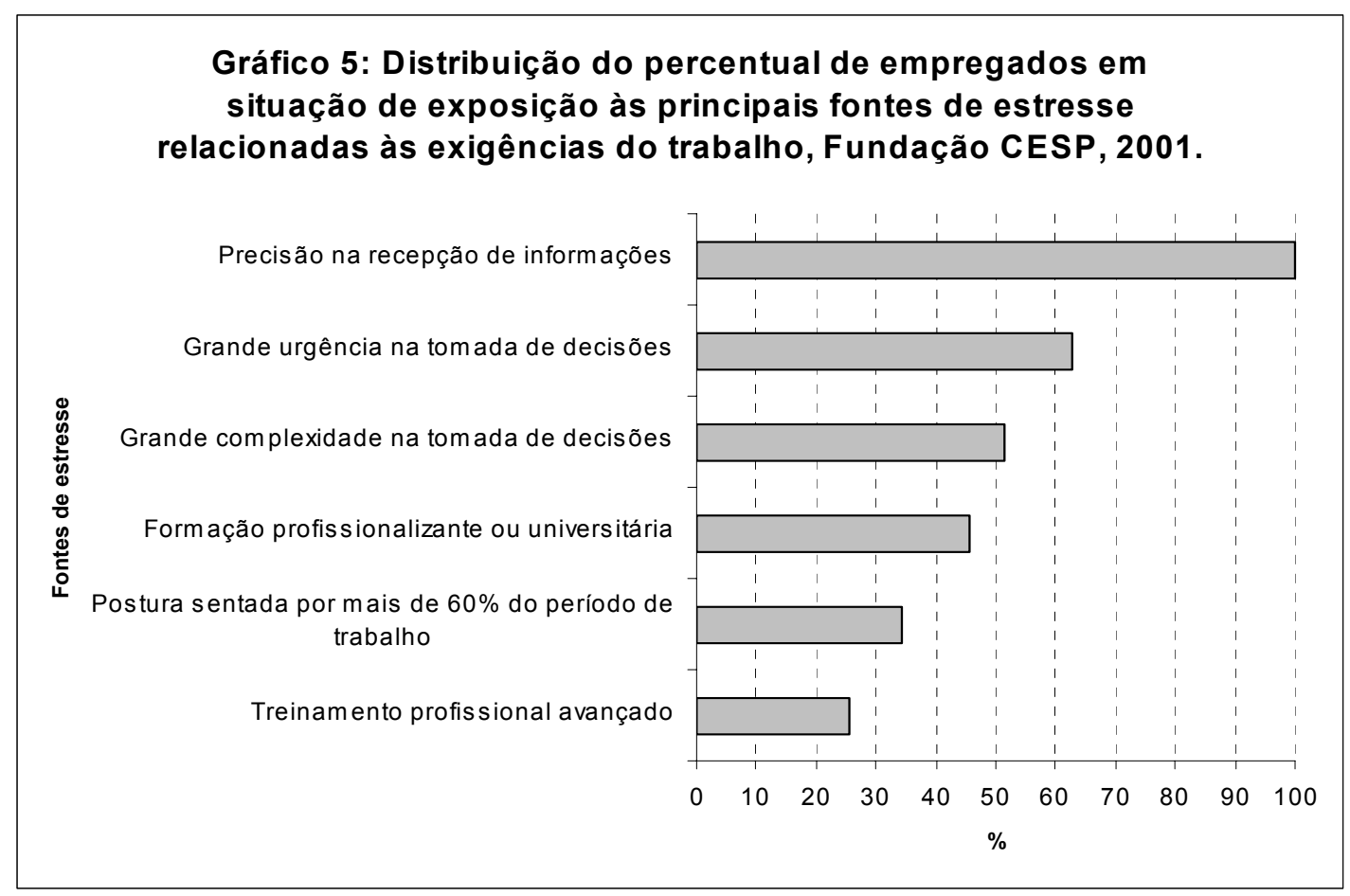




\section{5 - DISCUSSÃO}

Os resultados desta pesquisa foram em grande número e variedade, inclusive sobre questões de naturezas diversas, como as relacionados ao referencial teórico e à metodologia utilizada. Para facilitar a leitura e entendimento, a discussão dos resultados está apresentada por itens temáticos.

\section{1 - TAXA DE RESPOSTA E REPRESENTATIVIDADE DA AMOSTRA}

Um aspecto que merece ser discutido diz respeito à taxa de resposta. Taxa de resposta é o percentual de indivíduos da população de estudo que respondeu ao levantamento, no caso ao questionário (GSA - U.S. General Services Administration - Administração de Serviços Gerais dos EUA 1997). Não há consenso sobre qual seja a taxa ideal de resposta, sendo que por um lado são citados valores em torno de 60,70 ou $75 \%$ de taxa de resposta, e por outro considera-se que qualquer quantidade de "não-respostas" afetaria a acurácia dos resultados (FOLWLER JR. 1990; GSA 1997). De qualquer modo, para se tentar determinar a extensão pela qual a taxa de não-resposta difere da taxa de resposta é recomendada uma análise das perdas (GSA 1997).

Neste estudo a taxa de resposta foi 77,8\%, e a análise das perdas demonstrou que não houve diferenças entre as perdas e a população de estudo, evidenciando uma adesão significativa dos empregados ao estudo.

No caso da entrevista e da análise ergonômica, por se tratar de enfoque exploratório e de enfoque descritivo, foi solicitado 1 voluntário em cada área de trabalho, sendo que 
das 18 áreas existentes surgiram 42 voluntários (14,6\% dos empregados) para a entrevista e 43 voluntários (14,9\% dos empregados) para a análise ergonômica.

Esta adesão não era esperada inicialmente, uma vez que a empresa onde ocorreu a pesquisa estava passando por fase de reestruturação com redução do quadro de pessoal, acrescendo-se o fato de que o pesquisador faz parte deste quadro de pessoal da empresa. Houve a preocupação de que os empregados pudessem sentir que sua participação ou respostas representassem algum tipo de ameaça ou de repercussões não previstas para seu emprego e, em conseqüência, se recusassem a participar ou dessem respostas não sinceras.

Nesse sentido, tanto a adesão dos empregados respondendo ao questionário, como a quantidade de indivíduos que se apresentaram como voluntários para participar da entrevista exploratória e da análise ergonômica do trabalho não confirmaram os receios iniciais de que pudesse ocorrer uma baixa adesão em função da fase pela qual a empresa passava.

Quanto à veracidade das informações fornecidas, nada foi identificado que pudesse levantar dúvidas neste sentido. Pelo contrário, no transcorrer das entrevistas, da aplicação dos questionários, das análises ergonômicas e das devolutivas, os empregados colocaram-se de maneira pessoal e franca, não só no que diz respeito ao trabalho, mas vários deles abordando questões pessoais tanto ligadas ao trabalho como extra-profissionais (familiares, emocionais, de saúde, econômicas, ideológicas e outras).

Ainda discutindo a questão da taxa de resposta, alguns fatores são apontados como relacionados ao aumento desta taxa (FOWLER JR. 1990; GSA 1997; BARUCH 1999), dentre eles, pode-se destacar:

a) o adequado planejamento do processo de coleta de dados, incluindo listagem da população amostral, datas, horários e locais mais adequados, endereçamento correto e forma de administração do questionário; 
b) a negociação e apresentação (inclusive com carta introdutória) da pesquisa. Por exemplo, com apresentação e entrega de um resumo do estudo contemplando objetivos, uso dos resultados, confidencialidade e forma de contato para esclarecimento de dúvidas; orientações sobre a forma de preenchimento do questionário; definição de um período para retorno do questionário; garantia do retorno dos resultados após análise dos dados; formato (visual) do questionário e tempo necessário para sua aplicação;

c) pessoas com melhor nível educacional costumam responder questionários por escrito mais do que pessoas com menor nível de educação;

d) a disponibilidade de tempo e o acesso do pesquisador à população de estudo também são importantes.

CANNELL e KAHN (1966) e BARUCH (1999) apontam ainda, como aspectos importantes na motivação do indivíduo para participar de um estudo:

a) quando o conteúdo do estudo é identificado como relevante para mudanças desejadas;

b) as normas sociais de educação (não recusar um convite);

c) curiosidade;

d) o fato do pesquisador ser percebido como alguém que possa trazer mudanças diretas ou que possa ser um veículo para mudanças desejadas;

e) quando o indivíduo vê a oportunidade de se expressar sobre assuntos que the interessam, mas sobre os quais normalmente não têm esta oportunidade.

Quanto aos fatores relacionados ao planejamento e administração do questionário, buscou-se contemplar todos estes aspectos, iniciando-se pela estratégia de divulgação e acesso junto a todas instâncias hierárquicas da empresa, a escolha e pré-teste dos instrumentos, até o agendamento das atividades, horários e locais adequados às disponibilidades dos empregados, o fornecimento de informações sobre o estudo e sobre os métodos para coleta de dados, bem como a garantia de sigilo e de retorno dos resultados. 
Quanto aos fatores relacionados à motivação, chamou a atenção não só a adesão, mas o interesse manifestado pelos empregados quanto ao estudo, inclusive em conversas informais nos corredores. Especificamente, no transcorrer das entrevistas e das análises ergonômicas quatro aspectos chamaram a atenção como motivadores para a participação:

a) a necessidade de falar sobre questões relacionadas ao trabalho (e até sobre aspectos extra-profissionais) que são fonte de insatisfação e sobre os quase são desejadas mudanças;

b) a possibilidade de falar sobre estas questões com alguém que demonstra interesse no assunto;

c) a possibilidade de que os resultados do estudo possam desencadear mudanças desejadas nas condições de trabalho; e

d) a possibilidade de colaborar de alguma forma para a melhoria das condições de trabalho, ou seja, ser um agente que possa contribuir para estas mudanças.

Tudo isso leva a crer que, quando um estudo relacionado ao trabalho é conduzido de maneira planejada e dentro de parâmetros técnicos, éticos, com efetivo e visível compromisso do pesquisador, e abordando temas relevantes para os trabalhadores, ocorrerá a adesão, participação e envolvimento destes. Isso se dá não só pela possibilidade de ocorrer uma mudança desejada, mas também porque as pessoas desejam colaborar para estas mudanças, e porque a pesquisa tem credibilidade para as pessoas.

\section{2 - ENTREVISTA EXPLORATÓRIA}

O estudo da satisfação no trabalho é complexo em função da variedade de aspectos envolvidos, onde questões sócio-econômicas, do ambiente e da organização do trabalho, dos aspectos psicossociais do trabalho, das características individuais de 
personalidade ou sócio-demográficas interferem e mantêm relacionamentos dinâmicos.

Uma outra dificuldade encontrada no estudo da satisfação no trabalho é a diversidade de teorias relacionadas ao tema, mesmo se carecendo de consistência científica. $\mathrm{O}$ pesquisador encontra dificuldade em identificar um referencial específico sobre o assunto, que possa servir como base para direcionar sua exploração, para definir as estratégias de pesquisa e para explicar os resultados encontrados.

Para BUSSING et. al. (1999), a maioria das teorias sobre satisfação no trabalho não proporciona uma estrutura teórica que ofereça embasamento à verificação de hipóteses relacionadas ao tema.

Para SILVA (1998) os modelos que estudam satisfação no trabalho não têm sido suficientemente consistentes, mas vão se complexificando cada vez mais, mostrando a importância do estudo de novas variáveis e orientando a pesquisa em sentidos não previstos. Isso não devido à emergência de fatos inesperados, mas sim à insuficiência das teorias, à ausência de uma teoria definitiva. Para o autor, situando-se a satisfação no trabalho no campo das intersubjetividades, seria muito difícil, se não impossível, encontrar padrões explicativos universais (SILVA 1998).

Entre as diversas teorias disponíveis, a Teoria de Locke sobre satisfação no trabalho (ver item 1.2.2 - Teorias sobre satisfação no trabalho) foi adotada porque contempla a importância de aspectos psicossociais do trabalho, considera aspectos da subjetividade dos indivíduos (suas emoções e valores), apresenta alguma teorização sobre os efeitos da satisfação no trabalho sobre a saúde dos trabalhadores, e dá suporte ao estudo tanto por meio de método qualitativo como quantitativo.

Essa escolha também busca respaldo em ALBERTO (2000), que considera que, sem ignorar ou menosprezar a importância do contexto sócio-econômico, a relação do homem com o trabalho é um fenômeno de natureza psicossocial. Desta forma, 
estudar a satisfação no trabalho a partir dos aspectos psicossociais do trabalho pode ser um método eficiente para auxiliar na compreensão deste fenômeno.

A escolha da Teoria de Locke foi respaldada a posteriori pelos resultados encontrados na entrevista exploratória, onde a percepção que os empregados têm do conceito de satisfação no trabalho é compatível com o conceito de Locke e com a Teoria de Locke (ver item 1.2.1 - Conceitos e 1.2.2 - Teorias sobre satisfação no trabalho), que considera a satisfação no trabalho como um estado emocional decorrente da avaliação que o indivíduo faz de seu trabalho e de como este trabalho pode permitir o alcance/realização de seus valores.

É oportuno observar que os valores apontados pelos empregados dizem respeito não só às condições materiais que o trabalho permite obter, mas também às condições psicossociais do trabalho (como autonomia, possibilidade de crescimento, responsabilidade, reconhecimento, valorização e outras), e ainda à possibilidade de realizar um trabalho que tenha um valor social / coletivo (agregar valores, ser útil, sentir que o trabalho é importante, contribuir para o crescimento pessoal e coletivo, dentre outros).

Neste sentido, estes achados coincidem com as considerações de ALBERTO (2000) quando diz que, para entender as razões humanas de satisfação/insatisfação, realização/frustração, ajuste/desajuste na relação do homem com o trabalho, é necessário encarar a atividade humana como portadora de um sentido para o homem, onde o caráter ontológico do trabalho parece existir na medida em que essa atividade se dá em um contexto social.

Ainda em relação à entrevista exploratória, os elementos citados como causadores, tanto da satisfação como insatisfação no trabalho puderam ser categorizados de acordo com a classificação de Locke para fatores causais de satisfação no trabalho: trabalho propriamente dito, pagamento, promoção, reconhecimento, condições e ambiente de trabalho, colegas e subordinados, supervisão e gerenciamento, empresa/organização. 
Observou-se que mesmas categorias de elementos receberam valorização diversa, onde a forma como o indivíduo percebe cada aspecto do trabalho pode ser fonte de satisfação ou de insatisfação no trabalho. Por exemplo, o nível de autonomia que o empregado dispõe pode determinar satisfação ou insatisfação de acordo com a forma como o indivíduo avalia a situação.

A adjetivação que os indivíduos atribuem à forma como percebem os elementos do trabalho, podendo considerá-los como fonte de satisfação ou insatisfação, está em acordo com a Teoria de Locke que considera satisfação e insatisfação não como fenômenos distintos, mas como os aspectos opostos de um mesmo fenômeno, onde a presença ou ausência em maior ou menor grau de um dado elemento (por exemplo, nível de autonomia) pode determinar um sentimento mais intenso ou menos intenso de satisfação ou insatisfação.

A entrevista exploratória possibilitou atingir tanto o objetivo de reconhecer o conceito que os trabalhadores que compõem a população de estudo têm sobre satisfação no trabalho e quais os aspectos psicossociais no trabalho que consideram que influenciam a satisfação no trabalho, como o objetivo de verificar se o conceito de satisfação no trabalho e se os aspectos psicossociais no trabalho citados pelos trabalhadores que compõem a população de estudo coincidem com a literatura.

A entrevista exploratória, além de contemplar os objetivos citados, acrescentou outros elementos ao estudo: ela contribuiu para estabelecer um vínculo de confiança e comunicação entre pesquisador e população de estudo, o que veio a facilitar e enriquecer o desenvolvimento das etapas seguintes da pesquisa. Além disso, a entrevista permitiu obter um material com grande riqueza de dados. Estes dados contemplam aspectos do trabalho que vão além dos objetivos, métodos e possibilidades desta pesquisa, mas poderão ser utilizados em outros estudos contribuindo para o aprofundamento do conhecimento das relações entre trabalho e saúde. 


\section{3 - CONFIABILIDADE DOS QUESTIONÁRIOS AUTO- APLICADOS}

Uma outra dificuldade encontrada foi quanto à escolha dos instrumentos e métodos de estudo. Para a pesquisa de aspectos psicossociais podem ser utilizados métodos quantitativos e/ou qualitativos, de acordo com os propósitos do pesquisador (SELLTIZ 1967; GSA 1997).

Para esta pesquisa optou-se pelo método quantitativo, uma vez que ela tem por objetivo o estudo das relações entre satisfação no trabalho e saúde, e as técnicas estatísticas de análise de associações permitem verificar estas relações, tanto entre duas variáveis como entre variáveis múltiplas.

Segundo MARMOT e MADGE (1987), a maior limitação da epidemiologia no estudo de doenças relacionadas ao estresse determinado por fatores psicossociais é inerente à relativa imprecisão da mensuração de dados psicossociais, o que leva à imprecisão na classificação dos indivíduos nas categorias de estudo. Segundo os mesmos autores, esta imprecisão limita a sutileza dos detalhes que podem ser coletados e, portanto, limita a visão que é possível sobre o processo humano envolvido nas relações entre a causa em questão e os resultados mensurados. Buscando controlar esta imprecisão, o levantamento de informações de massa necessita padronizações de mensuração reprodutíveis tanto dos fatores psicossociais como dos aspectos de saúde (MARMOT e MADGE 1987).

Neste sentido, torna-se imprescindível a utilização de instrumentos para coleta de dados que garantam a precisão dos dados obtidos. Assim, buscou-se instrumentos que atendessem os requisitos de confiabilidade e validade (ver anexo IV Propriedades de medida de um questionário). Dois dos instrumentos utilizados - o SF-36-short form e a escala Satisfação no Trabalho do OSI - atendem aos requisitos de validação para a língua portuguesa. O ICT foi traduzido e testado, mas não foi 
validado para a língua portuguesa, configurando uma limitação no uso de seus resultados.

Visando assegurar a confiabilidade da aplicação destes instrumentos na população de estudo, foi verificada sua consistência interna por meio do coeficiente alfa de Cronbach. A escala satisfação no trabalho do OSI e o ICT demonstraram confiabilidade adequada. Quanto ao SF-36, 7 de suas 8 escalas mostraram confiabilidade adequada, sendo que a escala "aspectos sociais" apresentou confiabilidade abaixo do esperado (alfa $=0,67)$.

WARE (2000) relata que, em mais de 25 estudos utilizando o SF-36, as 8 escalas que compõem o instrumento raramente apresentaram confiabilidade menor que o padrão de 0,70 recomendado para medidas usadas em comparações de grupos. SAVONITTI (2000), estudando qualidade de vida em idosos brasileiros institucionalizados, também encontrou confiabilidade satisfatória nas escalas do SF-36, excetuando-se a escala "aspectos sociais" (com alfa $=0,40$ ).

Uma razão para este baixo valor pode ser o pequeno número de itens (apenas dois) que compõem a escala. Toda mensuração pode conter erros, sendo que a maior fonte de erro inerente a um instrumento é o número de itens que o compõem, uma vez que pode haver alguma variabilidade nos escores decorrente do número de itens envolvidos. Assim, quanto maior o número de itens, menor será o erro e melhor será o instrumento (NUNNALLY 1967; PEREIRA 1999).

Segundo PEREIRA (1999), cabe ao pesquisador julgar se o resultado do alfa de Cronbach é bom ou ruim, uma vez que, para este autor, não há um ponto de corte ideal para arbitrar o resultado e, mais importante do que julgá-lo bom ou ruim, é avaliar a complexidade do fenômeno que se pretende medir.

Assim, considerando que (a) "aspectos sociais" é um fenômeno complexo que pode ser influenciado por questões relacionadas ao trabalho, financeiras, culturais e outras que atuam sobre a saúde do indivíduo, e (b) este é um aspecto importante para a 
saúde dos indivíduos, optou-se por não excluir a escala do instrumento e mantê-la na análise dos dados.

\section{4 - PREVALÊNCIAS DE SATISFAÇÃO NO TRABALHO}

Analisando-se a distribuição dos empregados segundo nível de satisfação geral no trabalho verificou-se que ela é normal, com distribuição simétrica dos dados em torno de um valor central, ou seja, a maior proporção dos empregados apresenta níveis intermediários de satisfação no trabalho, e percentuais menores se distribuem nos níveis de maior satisfação e de maior insatisfação (sendo que nesta população não ocorreu insatisfação absoluta, já que os níveis maiores de insatisfação foram no ponto 47 do escore, quando a insatisfação completa está localizada em 22 pontos).

Não há um consenso na literatura sobre a prevalência de satisfação no trabalho que possa ser considerada como padrão ouro (valor de referência). Na Tabela 20, a seguir, pode-se observar que existe uma grande variedade na prevalência de satisfação no trabalho em diferentes estudos realizados em diferentes populações. Isso pode decorrer tanto de diferenças inerentes à situação de trabalho de cada população de estudo, como de variações no método utilizado pelo pesquisador (referencial teórico e características do instrumento utilizado ou, ainda, às diferenças no estabelecimento de pontos de corte em escalas ou em escores para definir o que os autores consideram como indivíduos satisfeitos ou insatisfeitos no trabalho).

FRASER (1983) discutindo a extensão do problema das prevalências de satisfação no trabalho assinala que, de uma forma geral, poucas pessoas se declaram extremamente satisfeitas ou insatisfeitas com seu trabalho, sendo que a maioria demonstra estar razoavelmente satisfeita. Para este autor, o uso destas prevalências como representativas da realidade pode configurar um problema, pois ele considera que a grande maioria dos indivíduos, embora não articule em sua expressão, 
provavelmente está mais ou menos insatisfeita, embora apenas uma minoria verbalize isto, levando a uma prevalência subestimada de insatisfação no trabalho.

Tabela 20: Prevalência de satisfação no trabalho em alguns estudos nacionais e internacionais

\begin{tabular}{|c|c|c|}
\hline Autor / ano & População de estudo & $\begin{array}{l}\text { Prevalência de } \\
\text { satisfação (\%) }\end{array}$ \\
\hline CODA 1986 & $\begin{array}{l}\text { Executivos de empresas de grande porte de São } \\
\text { Paulo }\end{array}$ & 45,0 \\
\hline LICHT 1990 & $\begin{array}{l}\text { Funcionários de escolas superiores, de } 2^{\circ} \text { grau e } \\
\text { de empresas de São Paulo }\end{array}$ & 15,0 \\
\hline PAULA 1990 & $\begin{array}{l}\text { Docentes de instituições de ensino superior em } \\
\text { nutrição no Brasil }\end{array}$ & 16,0 \\
\hline $\begin{array}{l}\text { TOPPINEM e } \\
\text { KALIMO } \\
1995\end{array}$ & $\begin{array}{l}\text { Trabalhadores de área de informática do Instituto } \\
\text { de Saúde Ocupacional da Finlândia }\end{array}$ & 75,0 \\
\hline $\begin{array}{l}\text { KADUSHIN e } \\
\text { KULYS } 1995\end{array}$ & Assistentes sociais de hospitais de Illinois & 28,0 \\
\hline $\begin{array}{l}\text { HAGIHARA } \\
\text { et. al. } 2000\end{array}$ & $\begin{array}{l}\text { Trabalhadores de área administrativa no Japão, } \\
\text { segundo cargo }\end{array}$ & $\begin{array}{l}\text { Variação de } \\
10,0 \text { a } 77,0\end{array}$ \\
\hline
\end{tabular}

BUSSING et. al. (1999) chamam a atenção para o fato de que muitos estudos identificam grandes percentuais de trabalhadores apresentando altos níveis de satisfação mesmo em situações de trabalho adversas com acidentes, condições de trabalho inadequadas, acentuada divisão do trabalho e altos índices de absenteísmo, o que faz considerar a possibilidade de que os resultados acerca dos níveis de satisfação destes estudo sejam obtidos de maneira não adequada, deixando de refletir a realidade. Desta forma, fica reforçada a necessidade discutida anteriormente de utilizar instrumentos e métodos adequados para minimizar estes desvios nos resultados. 
Conforme já discutido, o instrumento utilizado nesta pesquisa demonstrou confiabilidade. Além disso, esse instrumento favoreceu alcançar um dos objetivos desta pesquisa que foi o de identificar os níveis de satisfação no trabalho dos empregados que compõem a população de estudo.

Os aspectos psicossociais do trabalho que aparecem como sendo mais satisfatórios para os empregados foram "relacionamento com outras pessoas da empresa", "conteúdo do trabalho que realiza" e "grau de liberdade e flexibilidade que julga ter no trabalho".

"Relacionamento com outras pessoas da empresa" apareceu como o aspecto do trabalho com maior percentual de empregados satisfeitos. Segundo LOCKE (1976) as relações no trabalho podem ser de dois tipos: funcionais e pessoais. Nas relações funcionais os vínculos entre indivíduos se dão por meio de serviços específicos que as pessoas podem prover entre si, e onde os trabalhadores preferem colegas que colaboram com eles em suas tarefas ou para o alcance de objetivos comuns. Nas relações pessoais os vínculos são as próprias pessoas. Uma relação funcional pode ser mais superficial onde são avaliados aspectos como simpatia, ser amistoso, educado, benevolente ou sincero. Uma relação mais pessoal pode ser mais profunda requerendo a percepção de similaridades fundamentais em atitudes básicas, valores ou filosofia.

A ILO (1984) aponta que a natureza das relações interpessoais no trabalho é relacionada ao estresse no trabalho, onde situações onde ocorrem piores condições de relacionamentos podem desencadear desgaste psicológico, e onde o suporte social de colegas pode ser até mais significativo do que o de chefias. RAMIREZ et. al. (1996), estudando médicos especialistas atuando em hospitais no Reino Unido, identificaram que baixa satisfação com colegas de trabalho, pacientes e com o restante do quadro de pessoal estava associado com esgotamento (burn out), mostrando que aquele aspecto do trabalho pode representar um fator importante para a saúde dos trabalhadores. 
"Conteúdo do trabalho" diz respeito a como os empregados valorizam o trabalho em relação ao interesse, significado, identificação e importância que o trabalhador atribui a este trabalho, e também diz respeito à variedade e oportunidade do uso e/ou aprendizado de habilidades e capacidades, responsabilidades e desafios (LOCKE 1984; EMPLOYMENT E SOCIAL AFFAIRS 1999).

Os resultados deste estudo demonstraram que existe uma satisfação na forma como os indivíduos vêem o significado de seu trabalho e o interesse que ele desperta. SILVA (1998) estudando profissionais administrativos de uma grande empresa do ramo financeiro em Portugal encontrou resultados semelhantes identificando a satisfação com o conteúdo do trabalho que realiza como um dos aspectos que apresentaram maior correlação com a satisfação no trabalho geral.

A satisfação com conteúdo do trabalho parece ter importância especial para a felicidade e bem-estar dos indivíduos. ALBERTO (2000), discutindo a importância dos aspectos psicossociais como determinantes da felicidade no trabalho, salienta que esta felicidade estaria ligada ao sentido do conteúdo no contexto individual e social do trabalhador, ao trabalho que dá razão, que dá significado à existência do homem e à convivência com seu semelhante, e onde, na ausência de sentido compartilhado no trabalho, o indivíduo constrói uma nova espécie de vínculo psicológico (o compromisso com o trabalho), mesmo sem envolvimento ou sem prazer, para justificar inconscientemente sua adaptação às condições de produção a que se vê imposto.

O "grau de liberdade e flexibilidade que julga ter no trabalho" foi o aspecto que apareceu como $3^{\circ}$ em termos de prevalência de maiores níveis de satisfação. Ele remete ao conceito de controle no trabalho de Karasek como sendo o resultante da combinação das possibilidades que o trabalhador tem para tomar decisões sobre o seu trabalho (autonomia) e das possibilidades de uso de suas habilidades (KARASEK e THEORELL 1990). 
ELOVAINIO et. al. (2000), estudando os efeitos de fatores individuais e organizacionais sobre saúde mental e satisfação no trabalho, identificaram o controle no trabalho como fator que exerceu maior importância sobre a variabilidade nos níveis de satisfação no trabalho, onde quanto menor o controle sobre o trabalho, menor é o nível de satisfação.

A satisfação com "liberdade e flexibilidade no trabalho" tem sua importância explicitada quando se consideram os estudos sobre desgaste no trabalho com base no modelo demanda-controle de Karasek, que sustenta que os maiores riscos para a saúde física e mental decorrentes do estresse ocorrem quando os trabalhadores encontram demandas com elevada carga psicológica combinada com baixo nível de controle sobre o trabalho (KARASEK e THEORELL 1990).

Nesta pesquisa, os aspectos psicossociais do trabalho que aparecem como sendo mais insatisfatórios para os empregados foram "salário em relação à expectativa e produtividade", "clima psicológico que predomina na empresa", "oportunidades na carreira" e "oportunidades de atingir aspirações e ambições".

"Salário em relação à experiência e produtividade" foi a principal fonte de insatisfação entre os empregados. Segundo LOCKE (1984), o valor do dinheiro deriva de seu papel como meio de troca onde ele é usado para adquirir outros valores, mas também tem um valor simbólico enquanto uma medida da competência em um mercado de trabalho. Segundo o mesmo autor, empregados querem um sistema de pagamento que seja razoável e eqüitativo, onde o mais amplo valor de interesse é a justiça, o que significa imparcialidade no pagamento entre os diferentes trabalhos na mesma empresa, imparcialidade na concessão de aumento de salário e de méritos, e imparcialidade em relação ao mercado de trabalho. Além disso, mesmo quando o sistema de pagamentos é percebido como justo, as pessoas não vão estar necessariamente satisfeitas, a menos que o pagamento seja suficiente para suprir suas despesas (LOCKE 1984). 
Segundo PERRY (1993) a Teoria da Eqüidade diz que tanto a sub-compensação como a super-compensação são duas formas de iniqüidade que podem causar estresse, onde trabalhadores com salários subestimados podem ter sentimentos de privação ou de estarem sendo roubados, e trabalhadores com salários superestimados podem ter sentimentos de culpa ou de não merecimento. No transcorrer das entrevistas e das análises ergonômicas, surgiram tanto relatos de empregados insatisfeitos com sua remuneração por se considerarem injustiçados, uma vez que ela não seria condizente com sua qualificação educacional e técnica ou com sua experiência profissional, como relatos de empregados que consideraram que sua remuneração está elevada, acima dos parâmetros de mercado, significando uma fonte de preocupação em função do receio de possível substituição por outros profissionais com remuneração inferior.

"Clima psicológico que predomina na empresa" aparece com uma das principais prevalências de empregados insatisfeitos. A empresa onde foi realizado o estudo tem passado por processo de reestruturação que inclui a redução do número de empregados. Nas entrevistas exploratórias foram freqüentes os relatos de empregados declarando-se descontentes com a forma como foi conduzido este processo, com a deficiência nas informações, com a falta de clareza quanto aos rumos da empresa, e também inseguros quanto ao seu futuro na empresa. Curiosamente, os aspectos "comunicação e forma de fluxo de informações", "forma pela qual mudanças e inovações são implementadas" e "grau de segurança que você sente no seu emprego" aparecem com prevalências de indivíduos insatisfeitos menores do que "clima psicológico que predomina na empresa". Porém, estes aspectos podem estar na base da insatisfação quanto ao clima psicológico predominante.

PEPPER e MESSINGER (2000) estudando os impactos da reestruturação e redução do quadro de pessoal sobre a saúde e bem-estar de trabalhadores da Indústria Nuclear Pantex nos Estados Unidos da América identificaram, entre outros achados, que: 
a) trabalhadores de departamentos com elevadas taxas de demissões relataram mais sintomas médicos, pior saúde mental e mais insegurança no emprego que os demais empregados;

b) trabalhadores que sentiram que o processo de demissões foi justo e que a comunicação foi aberta e honesta relataram menos insegurança no emprego;

c) trabalhadores que relataram relações organizacionais melhores tiveram melhor saúde mental, estado de espírito mais elevado e menos estresse; e

d) relatos de cargas de trabalho intensas após as demissões.

RIGOTTO (1998) chama a atenção para funcionários que permanecem numa empresa após "enxugamento" podendo "trazer experiências e sentimentos que questionam a identidade do trabalhador: que valor tenho para a empresa? Em que medida meus esforços estão sendo reconhecidos? Até onde vai o compromisso da empresa conosco?" Tem sido relatada a "síndrome dos sobreviventes" onde trabalhadores que não perderam seus empregos no processo de redução do número de empregados freqüentemente apresentam diminuição do comprometimento, baixo estado de espírito e baixa satisfação no trabalho, bem como sentimentos de culpa por não ter sido demitido, tristeza e preocupação (PEPPER e MESSINGER 2000).

Outro aspecto que pode estar definindo a insatisfação com o clima psicológico predominante na empresa diz respeito à "oportunidades na carreira", que aparece como um dos que apresenta maiores prevalências de indivíduos insatisfeitos.

No caso desta população de estudo, "oportunidades na carreira" se dão por meio da avaliação de desempenho ou por promoções. Segundo LOCKE (1976) a satisfação é vista como uma função da freqüência de promoções em relação ao que é desejado e à importância destas para os valores do indivíduo, onde os padrões de valores dependem de suas aspirações e ambições pessoais.

Isso remete a um dos outros aspectos com maiores prevalências de indivíduos insatisfeitos , que foi "oportunidades para atingir aspirações e ambições” e que diz respeito às possibilidades que o trabalho oferece de alcance dessas aspirações sejam 
quais forem elas (profissionais, pessoais, ideológicas ou outras). No transcorrer das entrevistas e análises ergonômicas ocorreram relatos de insatisfação com salário no que diz respeito à insuficiência do mesmo para possibilitar a aquisição de bens materiais ou a realização de aspirações, tais como comprar uma casa própria ou custear uma faculdade. Também ocorreram relatos de insatisfação quanto à falta de perspectiva em alcançar uma cargo mais elevado, com mais autonomia e valorização.

Segundo LOCKE (1976) as origens do desejo de promoção podem incluir o desejo de crescimento psicológico (possibilitado pelo aumento da responsabilidade), de justiça (se for merecedor da promoção), de salários maiores, e de posição social (para aqueles que baseiam sua auto-imagem naquilo que outros pensam dele).

\section{5 - RELAÇÕES ENTRE SATISFAÇÃO NO TRABALHO E CARACTERÍSTICAS SÓCIO-DEMOGRÁFICAS E FUNCIONAIS}

Nesta pesquisa, em relação às características funcionais, a satisfação no trabalho apareceu associada a cargo e a tempo de empresa.

Quanto ao cargo, empregados com cargo de direção (Diretores, Gerentes e Chefes) apresentam maiores níveis de satisfação no trabalho do que empregados ocupando outros cargos.

RUBIO (1997), estudando o valor de variáveis do contexto do trabalho sobre a satisfação no trabalho, ressalta que algumas características dos cargos ocupados pelos indivíduos e das suas tarefas têm maior relevância do que outras. Entre estas, ele menciona o controle que os indivíduos podem exercer sobre suas condições de trabalho, a integração com o grupo de trabalho, o prestígio profissional na empresa e na sociedade, as responsabilidades assumidas que conferem ao trabalho um valor e 
uma fonte de dignidade, a natureza do trabalho, o salário, as condições e o grau de interesse despertado pelo trabalho.

Nesta população de estudo os cargos de direção são caracterizados potencialmente por autonomia, grande participação na tomada de decisões, grande responsabilidade, salários melhores, tarefas diversificadas e geralmente desafiadoras, reconhecimento e prestígio profissional, podendo conferir o alto nível de satisfação encontrado neste grupo, e que estaria ausente ou presente com menos intensidade nos demais cargos.

Quanto ao tempo de empresa, empregados com menos de 3 anos de empresa apresentam maiores níveis de satisfação que os demais. Esse achado pode ser explicado pela história de reestruturação da empresa e redução do quadro de pessoal. Este processo iniciou-se em 1998, sendo que os empregados com menos de 3 anos de empresa foram admitidos dentro de um período com o processo já iniciado. Os demais empregados passaram por um processo de reestruturação e, como foi discutido anteriormente (ver item 1.1 - Delimitação do problema), estes empregados tiveram mudanças em suas condições de trabalho caracterizadas por aumento do volume de trabalho, intensificação da pressão de prazos, aumento das responsabilidades, insegurança quanto ao seu futuro na empresa. Some-se a isso a possibilidade de ocorrência da "síndrome dos sobreviventes", onde todos estes aspectos podem conduzir a uma queda dos níveis de satisfação.

No que diz respeito às características sócio-demográficas, a satisfação no trabalho não apareceu associada a nenhuma delas.

Existem dados sugerindo um aumento da satisfação no trabalho acompanhando o aumento da idade. MORO (1997), estudando empregados de agências governamentais em Nova Jersey nos Estados Unidos da América, identificou este tipo de associação. Uma explicação seria que as pessoas tornam-se mais satisfeitas e realistas com a vida com o passar dos anos, incluindo satisfação com o trabalho (DIPBLOYE e HOWELL 1994). Porém, diferentemente de outros estudos, nesta população a idade não apareceu associada aos níveis de satisfação no trabalho, 
indicando que esta não é uma característica relevante para a satisfação destes empregados.

Em nosso estudo, a satisfação no trabalho não apareceu associada à variável sexo, e resultado semelhante é encontrado por MORO (1997) estudando empregados de uma agência governamental norte-americana. Os achados relacionando sexo e satisfação não são conclusivos uma vez que existem pesquisas, como as de AHN et. al. (2001), estudando trabalhadores coreanos, ou de KIM (2001), estudando funcionários públicos também coreanos, que identificaram resultados divergentes, onde o primeiro encontrou mulheres com um nível de satisfação no trabalho maior que seus colegas homens, e o segundo encontrou mulheres com menores níveis de satisfação. Estas diferenças nos achados dos diversos estudos sugerem que outras características do contexto de trabalho definem esta associação, embora não possa ser eliminada nos contextos de trabalho onde a ocupação é estreita e historicamente associada a gênero (como no caso da enfermagem), o que não ocorre em nosso estudo.

Conforme discutido anteriormente, o nível salarial aparece como a principal causa de insatisfação entre os empregados, porém não foi identificada uma associação entre faixa de rendimentos e nível de satisfação no trabalho, indicando que esta insatisfação é generalizada e semelhante em todas as categorias salariais nesta população de estudo.

O nível de escolaridade não apareceu associado à satisfação no trabalho, e este achado é semelhante ao de MORO (1997). Porém, na literatura são achados dados divergentes quanto a este aspecto: KIM (2001), estudando funcionários públicos coreanos, não encontrou este tipo de associação; mas PETERSON e DUNNAGAN (1998), em Montana nos Estados Unidos da América, e AHN et. al. (2001), na Coréia, identificaram associações entre satisfação no trabalho e nível educacional, onde trabalhadores com maior nível educacional obtêm empregos que apresentam conteúdo mais satisfatório. 
Os resultados desta nossa pesquisa indicam que os empregados de todos os níveis de escolaridade tem níveis de satisfação no trabalho semelhantes. A insatisfação que ocorre poderia ser devida às seguintes situações: (1) empregados com maior nível de escolaridade estariam insatisfeitos porque estão ocupando cargos incompatíveis com sua qualificação, ou (2) estariam no nível mais alto da carreira sem possibilidade de maior crescimento, ou (3) empregados com menor nível de escolaridade estariam ocupando cargos menos qualificados e com menor salário, ou (4) não teriam possibilidade de ascensão profissional. De fato, todas estas situações foram citadas no transcorrer das entrevistas e análises ergonômicas.

O estado civil não apareceu associado à satisfação no trabalho, indicando que esta não é uma característica importante para a satisfação no trabalho nesta população. Este achado é semelhante ao de MORO (1997) que também não encontrou este tipo de associação. Novamente os dados de literatura são divergentes, onde podem ser citados PETERSON e DUNNAGAN (1998) que identificaram que trabalhadores da Universidade de Montana nos Estados Unidos da América que são casados têm maiores níveis de satisfação no trabalho do que os não casados.

Nesta nossa pesquisa, a ausência de diferenças nos níveis de satisfação no trabalho entre empregados casados e não casados indica que outros aspectos relacionados ao trabalho estão determinando maior impacto na definição dos níveis de satisfação no trabalho do que características ligadas ao estado conjugal.

A divergência dos achados quanto às associações da satisfação no trabalho com características sócio-demográficas e funcionais entre os diversos estudos sinaliza que outras condições do contexto do trabalho podem modificar o impacto de uma dada característica sobre a satisfação. Por exemplo, se uma mulher trabalha em um ambiente onde as condições do trabalho, as possibilidades de carreira e salariais entre homens e mulheres são semelhantes, é provável que ela tenha níveis de satisfação maiores do que uma mulher que trabalha em um ambiente essencialmente masculino com situações de discriminação social. Estas diferenças indicam que, para o estudo da satisfação no trabalho em cada população, é necessário avaliar não só as variáveis 
relacionados ao trabalho, mas também as diferentes características sóciodemográficas e sua relação com a ocupação, conteúdo do trabalho e contexto organizacional.

Neste sentido, mais um dos objetivos desta pesquisa foi alcançado, ou seja, identificar quais as características sócio-demográficas e funcionais que estão associadas à satisfação no trabalho entre os trabalhadores da população de estudo.

\section{6 - RELAÇÕES ENTRE SATISFAÇÃO NO TRABALHO E SAÚDE}

Um dos objetivos desta pesquisa foi verificar se satisfação no trabalho está relacionada à saúde dos trabalhadores que compõem a população de estudo. Este objetivo foi alcançado quando identificou-se associação estatisticamente significativa entre satisfação no trabalho e aspectos da saúde mental e entre satisfação no trabalho e capacidade para o trabalho, e ausência de associação entre satisfação no trabalho e aspectos da saúde física.

\subsection{1 - Satisfação no trabalho e componentes da saúde física e da saúde mental}

A satisfação no trabalho não apareceu associada a nenhum dos aspectos da saúde física estudados (capacidade funcional, aspectos físicos, dor e estado geral de saúde). Esses achados diferem do que diz a literatura revista, que aponta níveis mais altos de satisfação no trabalho associados tanto a melhores condições de saúde física como a menores riscos para ocorrência de problemas de saúde, como fadiga, dificuldades respiratórias, dor de cabeça, problemas digestivos, dores musculares e sintomas 
neurovegetativos (LOCKE 1976; HENNE e LOCKE 1985; ZALEWSKA 1996; ROCHA 1996; PETERSON e DUNNAGAN 1998).

Uma explicação que poderia ser aventada para justificar esta divergência dos resultados desta pesquisa com os dados de literatura é que, como os empregados da população de estudo executam um trabalho que é leve ou moderado do ponto de vista do trabalho físico, existe um risco limitado para ocorrência de agravos à saúde física. Uma outra explicação possível é que estes empregados, por trabalharem em uma empresa de gestão de serviços de saúde, têm fácil acesso a estes serviços, buscando assistência médica nas fases iniciais de manifestação de sintomas físicos, o que favoreceria uma recuperação rápida e evitaria o agravamento dos sintomas. Porém essas possíveis explicações não foram comprovadas, necessitando ser melhor investigadas.

A satisfação no trabalho apareceu associada à saúde mental, e um aspecto relevante é que esta associação apareceu estatisticamente significativa e independente de variáveis sócio-demográficas e funcionais, demonstrando a relevância das relações entre satisfação no trabalho e saúde mental dos trabalhadores.

A saúde mental foi avaliada por meio de 04 das 08 escalas do SF-36 Estas escalas avaliam vitalidade (nível de energia e fadiga), aspectos sociais (limitação em atividades sociais decorrente de problemas de saúde), aspecto emocional (limitações no tipo e na quantidade de trabalho e das atividades de vida diária em conseqüência de problemas emocionais) e saúde mental (ansiedade, depressão, alterações no comportamento e no bem-estar psicológico). O SF-36 é um instrumento para avaliação genérica da saúde e, portanto, estas 4 escalas podem ser consideradas como uma avaliação genérica da condição de saúde mental de acordo com a percepção dos próprios indivíduos, e não um instrumento para diagnóstico de patologias ou distúrbios psicológicos ou emocionais.

CODA (1986) ressalta que alta satisfação no trabalho é importante para a saúde mental do indivíduo na medida em que aquela poderá ter uma extensão de seu efeito 
para a vida particular e, ao contrário, caso ocorra a insatisfação no trabalho, está será acompanhada de desapontamento que permeará a vida particular do indivíduo afetando seu comportamento fora do trabalho. Para ZALEWSKA (1999a, 1999b) satisfação no trabalho é um dos principais componentes para a satisfação geral com a vida e uma estimativa subjetiva de bem-estar.

A associação entre saúde mental e satisfação no trabalho também têm sido assinalada em outros estudos:

a) RAHMAN e SEN (1987), em estudo referente aos efeitos da satisfação no trabalho sobre a saúde de empregados em trabalhos repetitivos em Bangladesh, identificaram que funcionários altamente satisfeitos relataram níveis de saúde mental significativamente maiores e queixas de saúde mínimas quando comparados com trabalhadores com baixa satisfação.

b) O'DRISCOLL e BEEHR (1994), estudando comportamento da chefia e conflitos e ambigüidade de papéis como produtores de efeitos sobre os empregados administrativos dos Estados Unidos da América e da Nova Zelândia, identificaram que a satisfação no trabalho apresentou um efeito mediador importante nessas relações. Os autores consideraram que quando indivíduos encontram incertezas, ambigüidade e conflito de papéis no contexto do trabalho, o principal resultado destas pressões é a insatisfação, e o trabalho é, então, relacionados à outras experiências negativas, entre elas o incremento do desgaste no trabalho. Os autores concluem que esses achado encorajam a continuação dos estudos sobre satisfação no trabalho como um mediador importante entre as reações dos indivíduos às pressões e demandas do trabalho.

c) RAMIREZ et. al. (1996), estudando os efeitos do estresse e da satisfação no trabalho sobre a saúde mental de médicos especialistas de hospitais do Reino Unido, identificaram que satisfação no trabalho estava inversamente associada com exaustão emocional (sentimento de muita exigência emocional), despersonalização (resposta impessoal e sem sentimentos em relação às pessoas) 
e morbidade psiquiátrica (depressão, perda de confiança, distúrbio do sono, e outros sintomas). Os autores também identificaram efeito protetor da satisfação no trabalho sobre a saúde mental. Os aspectos do trabalho apresentando maior contribuição para a satisfação no trabalho foram boas relações interpessoais, valorização e posição profissional, estímulo intelectual, bons recursos e gerenciamento. Os autores consideraram de importância os achados indicando que a satisfação no trabalho protege a saúde mental contra o estresse.

d) ABOUSERIE (1996), investigando fontes de estresse entre o corpo acadêmico de uma universidade no Reino Unido, identificou uma correlação negativa significativa entre estresse e satisfação no trabalho, indicando uma relação inversa entre estes dois fenômenos.

e) ROCHA (1996) contribui para esta discussão ao estudar a relação trabalho-saúde de analistas de sistemas no Estado de São Paulo, ao identificar a satisfação no trabalho como um fator protetor da saúde, aparecendo como fator de diminuição na freqüência de sintomas do "estado nervoso", distúrbios neurovegetativos, alterações do hábito alimentar e problemas digestivos. Neste estudo a satisfação no trabalho também aparece associada negativamente à procura de consulta médica, e como fator de redução da interferência do trabalho na vida familiar e pessoal. Os fatores que aparecem associados à satisfação no trabalho são o aprendizado constante, o controle sobre o processo de trabalho, o sentimento de "ser um artista produzindo uma obra" ao desenhar o sistema (possibilidade de criação), e a percepção de desafio na resolução de problemas.

f) ZALEWSKA (1996) realizou estudos junto a bancários da Polônia buscando verificar a hipótese de que satisfação com a vida depende da satisfação com o trabalho, e que bancários satisfeitos com o trabalho constituem um grupo de risco elevado para ocorrência de problemas de saúde. Seus resultados identificaram que trabalhadores insatisfeitos como o trabalho são menos satisfeitos com todos os aspectos do trabalho examinados (colegas, supervisores, conteúdo do trabalho, condições e organização do trabalho, desenvolvimento e salário) e constituem um 
grupo elevado de risco para ocorrência de problemas de saúde. Trabalhadores insatisfeitos demonstraram ser mais susceptíveis à ansiedade depressiva em situações difíceis, o que provavelmente rebaixaria sua organização das atividades e seu desempenho, e se ressentiam dos efeitos do estresse causado por sobrecarga, apresentando sintomas somáticos (como dores de cabeça, cansaço, corpo tenso, fraqueza muscular e dificuldade para respirar) com mais freqüência do que os trabalhadores satisfeitos.

g) AASLAND et. al. (1997), estudando queixas de saúde e estresse no trabalho em médicos noruegueses, identificaram que o baixo nível de satisfação no trabalho esteve significativamente associado com relato de saúde subjetiva pobre, operacionalizado por meio de alto nível de queixas de saúde subjetivas.

h) PETERSON e DUNNAGAN (1998), estudando empregados da Universidade Estadual de Montana nos Estados Unidos da América, identificaram que pessoas que estão satisfeitas com seus empregos são mais saudáveis tanto física como psicologicamente.

Uma limitação destes estudos, assim como desta nossa pesquisa, é que seu desenho transversal impossibilita o estabelecimento de relação causal entre satisfação no trabalho e saúde mental, uma vez que exposição e evento são observados no mesmo corte temporal.

O que este tipo de estudo oferece é a avaliação das relações por meio das medidas de associação. Estas medidas têm a finalidade de avaliar a co-incidência de uma dada patologia (ou evento relacionado à saúde) na presença de uma condição atribuída hipoteticamente como fator de risco (ALMEIDA FILHO e ROUQUAYROL 1992).

A conecção entre saúde e satisfação no trabalho é difícil de ser estabelecida, porque nem sempre está claro se satisfação produz saúde, saúde produz satisfação, ou se as duas são resultado de algum outro fator (HENNE e LOCKE 1985). Se a direção causal entre estes dois fenômenos já estivesse reconhecida pelas teorias baseadas em 
métodos epidemiológicos, um estudo transversal, como é o caso desta nossa pesquisa, poderia partir deste conhecimento teórico para fazer afirmações sobre as associações identificadas. Porém, esta direção causal entre satisfação no trabalho e saúde ainda não está estabelecida: em revisão bibliográfica realizada no $2^{\circ}$ semestre de 2000 e atualizada no $2^{\circ}$ semestre de 2001, utilizando as bases de dados MEDLINE, SciELO, LILACS, ProBE e DEDALUS, os estudos revistos que foram realizados por método epidemiológico contemplando as relações entre satisfação no trabalho e saúde foram com desenho transversal. Isso demonstra que são necessários estudos longitudinais ou experimentais para investigar do ponto de vista epidemiológico esta causalidade, e que podem, inclusive, ser iniciados a partir de um estudo transversal.

Uma outra limitação dos estudos epidemiológicos, tanto transversais como longitudinais, é que eles não explicam a dinâmica das correlações identificadas. Segundo ALMEIDA FILHO e ROUQUAYROL (1992), o que difere o dado epidemiológico do dado clínico é que o caráter da epidemiologia é eminentemente observacional, onde o olhar sobre a situação de saúde (ou doença) é de natureza externa, por meio da comparação entre sub-grupos de uma dada amostra ou população, com diagnóstico fundamentado em abordagem indutiva e na produção de dados simplificados e padronizados, fornecendo informações genéricas sobre um grande número de indivíduos, e diferindo do dado clínico uma vez que este oferece conhecimento detalhado de cada caso, sendo mais complexo e exaustivo, e tolerando atribuições simbólicas, inclusive com alterações de significado e ambigüidades.

Desta forma, o estudo quantitativo de dados qualitativos permite descrever características de uma população ou amostra, bem como estabelecer associações, riscos e probabilidades entre variáveis. Mas, devido ao seu caráter reducionista, ele não contempla a investigação dos processos que ocorrem na dinâmica das relações observadas, limitando a análise de aspectos sociais ou individuais subjetivos. Desta forma, este tipo de estudo exige a complementação da compreensão dos eventos por meio de outras estratégias, tais como análises qualitativas, estudos de caso ou busca 
de suporte em teorias já estabelecidas, que possibilitem explicar como se dão as trocas e determinações entre indivíduos e variáveis de estudo.

LOCKE (1976), discutindo o uso das análises de associação como estratégia no estudo da satisfação no trabalho, ressalta que uma correlação por si só, não explica nada. Para Locke, embora uma forte correlação estatística ajude a clarificar relações teóricas, não mostra como a alegada causa produz seu efeito, o que seria esperado de uma teoria causal completa e, portanto, esta técnica não exclui outras explicações vindas de outras fontes.

Segundo LESER et. al. (1988) e DEVER (1998), 5 critérios básicos são usados para identificar associações causais:

1) Relação temporal: a causa deve ocorrer antes do efeito.

2) Intensidade: diz respeito à intensidade da associação entre causa e efeito.

3) Consistência: ocorre quando o mesmo tipo de associação aparece consistentemente em estudos diferentes.

4) Especificidade: diz respeito a como uma causa pode levar a um único efeito (alta especificidade) ou a múltiplos efeitos (baixa especificidade).

5) Coerência: um relacionamento supostamente causal deve fazer sentido à luz de fatos conhecidos.

Nesta nossa pesquisa estes critérios ocorreram da seguinte forma:

1) Relação temporal: não pôde ser estabelecida em função do desenho transversal.

2) Intensidade: a análise de regressão mostrou associação estatística significativa entre satisfação no trabalho e os aspectos da saúde mental, e mostrou que esta associação permaneceu independente das características sócio-demográficas e funcionais.

3) Consistência: os diversos estudos citados anteriormente também identificaram associações estatisticamente significativas entre satisfação no trabalho e saúde 
mental, apesar das diferenças nos métodos e instrumentos para coleta e mensuração dos dados utilizados em cada estudo.

4) Especificidade: neste estudo satisfação no trabalho apareceu associada à saúde mental, mas também à capacidade para o trabalho. A satisfação no trabalho também tem sido associada a outros eventos como absenteísmo, produtividade, saúde física e bem-estar subjetivo (LOCKE 1976; PÉREZ-RAMOS 1980, RAHMAN e SEN 1987; ZALEWSKA 1999a, 1999b), indicando que a satisfação no trabalho exerce outros impactos sobre o trabalhador além daqueles relacionados à saúde mental.

5) Coerência: existem teorias, como a Teoria de Locke e a Psicodinâmica do Trabalho de Dejours, que abordam a relação causal entre satisfação no trabalho e saúde mental.

Observando-se estes 5 critérios, fica aparente a existência de evidências sugerindo uma relação causal de um efeito da satisfação no trabalho sobre a saúde mental dos trabalhadores da população de estudo que, entretanto, não pode ser comprovada. Para LESER et. al. (1988), o significado da associação estatística é uma questão de julgamento do pesquisador que ultrapassa qualquer nível de probabilidade. Ou seja, para interpretar o resultado estatístico obtido, o pesquisador deve estabelecer um critério de julgamento baseado no conhecimento teórico já estabelecido. Portanto, para interpretar o significado da associação entre satisfação no trabalho e saúde mental encontrada neste estudo, é necessário considerar o conhecimento já consolidado sobre este tema.

A epidemiologia pode demonstrar a existência ou não das associações entre satisfação no trabalho e saúde, e pode comprovar a direção causal destas associações por meio de estudos longitudinais. Também pode identificar outras variáveis que estejam interferindo nestas associações, bem como avaliar riscos e probabilidades decorrentes das associações e interações destas variáveis. Mas a epidemiologia não pode explicar qual o processo dinâmico que ocorre por trás destas associações e interações. Para a compreensão desses processos é necessário buscar respaldo teórico em outras áreas de conhecimento, por outros métodos (observacionais, 
experimentais, análises de discurso, grupos focais, estudos de caso, ou outros) expliquem como ocorrem estes processo. Segundo ALMEIDA FILHO e ROUQUAYROL (1992), o sucesso da pesquisa em epidemiologia dependerá da construção da pesquisa fundamentada na fronteira ou no bojo do conjunto de conhecimentos teóricos já estruturados e nas realidades factuais, buscando levantar pontos que permaneçam mais ou menos obscuros.

Desta forma, tanto para a formulação de hipóteses como para o estudo das situações de saúde (ou doença), a pesquisa epidemiológica exige, além do uso das técnicas epidemiológicas, a busca de suporte teórico no conhecimento de outras ciências, como a bioestatística, a clínica, a imunologia, a antropologia, a sociologia ou a psicologia (LOCKE 1976; ALMEIDA FILHO e ROUQUAYROL 1992).

$\mathrm{Na}$ tentativa de melhor entendimento de como se dão as relações entre satisfação no trabalho e saúde, de qual a dinâmica que ocorre por trás delas, podem ser buscadas explicações na literatura, como os estudos de natureza qualitativa.

KANTORSKI (1997) aborda o trabalho como categoria central na vida humana, e traduz essa importância por meio de 5 dimensões:

1) o trabalho é o que diferencia o homem da condição animal por meio de uma atividade material transformadora;

2) o homem mantém uma relação de transformação com a natureza que é dotada de finalidade, o que confere um caráter de relacionamento social do homem pelo trabalho;

3) o trabalho significa convivências coletivas, com estágios de divisão social gerando relações sociais;

4) o trabalho é fundamental para a criação da identidade do homem, onde ao trabalhar, o homem se diferencia de outros homens produzindo sua identidade social; e

5) o trabalho é a maneira pela qual o homem se transcende no tempo e no espaço, colocando sua identidade no produto de seu trabalho perenizando-se no tempo e tornando-se sujeito de seu projeto emocional. 
Em resumo, o trabalho é uma das mais importantes maneiras do homem se posicionar como indivíduo único, é algo que complementa e dá sentido a sua vida (LUNARDI FILHO 1997; ALBERTO 2000). Por isso ele é visto como um dos componentes da felicidade humana, onde a felicidade no trabalho é tida como resultante da satisfação plena de necessidades psicossociais, do sentimento de prazer e do sentido de contribuição no exercício da atividade profissional (ALBERTO 2000).

A satisfação no trabalho é identificada como exercendo influência sobre o estado emocional do indivíduo, manifestando-se na forma de alegria decorrente da satisfação, ou na forma de sofrimento decorrente da insatisfação (LOCKE 1969, 1976, 1984). A satisfação com aspectos psicossociais do trabalho é vista como um dos componentes da felicidade no trabalho, e tem sido operacionalizada como um dos aspectos representativos de bem-estar do trabalhador (WARR 1994; PARKER et. al., 1997).

Conforme discutido no item 1.2.2 - Teorias sobre satisfação no trabalho, existem várias teorias que abordam a satisfação no trabalho, seja ocupando-se dela diretamente, seja passando por ela no contexto de outros fenômenos. A Teoria de Locke sobre Satisfação no Trabalho e a Psicodinâmica do Trabalho de Dejours são duas teorias que contemplam as relações entre satisfação no trabalho e saúde, onde satisfação no trabalho está na base da determinação do prazer ou felicidade no trabalho, e insatisfação está na base da determinação do desprazer ou sofrimento no trabalho.

Para LOCKE (1969, 1976, 1984), a satisfação com o trabalho é um estado emocional resultante da avaliação que o indivíduo faz de seu trabalho ou de experiências no seu trabalho em comparação com seus valores de referência, e onde essa emoção se manifesta na forma de alegria (satisfação no trabalho) ou sofrimento (insatisfação no trabalho). LOCKE (1969) assinala que existem três elementos envolvidos neste processo de avaliação: percepção de algum aspecto do trabalho, um padrão de 
valores implícito ou explícito, e um julgamento consciente ou inconsciente entre percepções e valores do indivíduo. Desta forma, os fatores psicossociais no trabalho são centrais na determinação da satisfação no trabalho, não só pela maneira como está estabelecido o ambiente e a organização do trabalho, mas também pela forma como o indivíduo percebe, valoriza e julga estes aspectos.

Locke, baseando-se na concepção de tensão como desencadeador de agravos à saúde, considera que o estado emocional pode ter repercussões físicas e mentais. No âmbito da saúde física, esse sofrimento pode ser fonte de estresse, desencadeando respostas físicas como dificuldade respiratória, dor de cabeça, aumento do colesterol e outras (LOCKE 1969, 1976; HENNE e LOCKE 1985). Para a saúde mental, a insatisfação no trabalho é um estado psicológico desagradável que o indivíduo experimenta como decorrência de um conflito por estar suportando uma situação que preferiria evitar, e que contribui para o aumento do estresse com possíveis conseqüências para a saúde mental como ansiedade, tensão, hostilidade, nervosismo e depressão (LOCKE 1976; HENNE e LOCKE 1985). Porém, o próprio autor questiona a direção causa destes eventos, ressaltando a carência de estudos epidemiológicos que comprovem esta direção (LOCKE 1969; HENNE e LOCKE 1985).

DEJOURS (1994), partindo da análise da psicodinâmica das situações de trabalho, considera que quando o trabalho torna-se fonte de tensão e de desprazer, gerando um aumento da carga psíquica sem possibilidade de alívio desta carga por meio das vias psíquicas, ele dá origem ao sofrimento e à patologia. Quando o trabalho é livremente organizado, ele oferece vias de descarga da energia psíquica tornando-se equilibrante; caso ele não permita a descarga desta energia ocorre aumento da carga psíquica, e o trabalho torna-se fatigante. Para o autor (DEJOURS 1987), a insatisfação no trabalho é uma das formas fundamentais de sofrimento no trabalho, onde esta insatisfação está relacionada ao conteúdo significativo da tarefa.

Se considerarmos que as evidências observadas (e citadas anteriormente) sugerem que as associações encontradas nesta pesquisa são resultado de uma relação causal da satisfação no trabalho sobre a saúde mental dos empregados, torna-se necessário o 
suporte teórico de outras áreas de conhecimento para entender estas relações. Neste sentido, as teorias de Locke e de Dejours podem ser usadas como base para o entendimento dos processos que ocorreram determinando estas relações e configurando os resultados encontrados nesta pesquisa.

Todo este processo de relação entre satisfação no trabalho e saúde, enunciado na literatura científica e sinalizado nesta pesquisa, faz parte do conhecimento do trabalhador que vive as experiências de trabalho, e que consegue explicar estas relações a partir destas experiências:

"Se você tá satisfeito acho que você tem outro ritmo, você trabalha com prazer, você acaba transmitindo, irradiando tudo. Se você está insatisfeito é a mesma coisa, você não consegue ver nada com olho, sabe, com olho positivo (....). Se você tá feliz, trabalha legal, você consegue, você tem prazer pro serviço, você vai embora com prazer. Você não fica carregado."

(Mulher, 34 anos de idade, 14 anos de empresa)

"A pessoa quando tá trabalhando insatisfeita, com certeza ela vai ter dor de cabeça, vai ficar estressada. Dependendo do nível de insatisfação ela pode ficar até depressiva, pode entrar na depressão, mais a parte psicológica. Já uma pessoa satisfeita, por mais serviço que tenha, você faz, você não sente aquele cansaço, aquele peso de vir trabalhar na segunda-feira."

(Mulher, 32 anos de idade, 5 anos de empresa)

\subsection{2 - Satisfação no trabalho e capacidade para o trabalho}

Segundo a ILO (1984), quando as condições psicossociais do trabalho e os fatores humanos estão em equilíbrio, o trabalho promove a satisfação, o aumento da 
capacidade para o trabalho e melhora a condição de saúde. Muitos fatores influenciam a capacidade para o trabalho sendo que alguns deles são o envelhecimento (inclusive envelhecimento funcional), estilo de vida e ambiente de trabalho, criando exigências físicas e mentais para o trabalhador (TUOMI et. al. 1997; BELLUSCI e FISCHER 1999), onde o desempenho no trabalho pode declinar como resultante de demandas físicas excessivas e de aspectos psicossociais no trabalho (POHJONEN 1999).

POHJONEN (1999) discutindo os elementos-chave da capacidade para o trabalho e as maneiras de preservá-los salienta que a capacidade para o trabalho física e psicossocial é uma pré-condição essencial para uma boa condição geral de saúde. O autor considera que, além das condições físicas do ambiente de trabalho, a satisfação no trabalho com aspectos das relações psicossociais também pode afetar a capacidade para o trabalho, citando, entre outras, o planejamento e conteúdo do trabalho, utilização insuficiente das capacidades, variedade no trabalho, retorno (feedback), moral geral no local de trabalho, suporte social recebido dos colegas e capacidade de liderança dos gerenciadores, onde esforços no sentido de corrigir as deficiências quanto a estes aspectos promoverão uma melhoria da capacidade para o trabalho.

Em nosso estudo a satisfação no trabalho apareceu associada à capacidade para o trabalho, e esta associação foi estatisticamente significativa e independente de variáveis sócio-demográficas e funcionais, demonstrando a relevância das relações entre satisfação no trabalho e saúde mental dos trabalhadores.

Este nosso estudo novamente apresenta a limitação no sentido de não poder estabelecer relações causais entre satisfação no trabalho e saúde. Em revisão bibliográfica realizada no $2^{\circ}$ semestre de 2000 e atualizada no $2^{\circ}$ semestre de 2001, utilizando as bases de dados MEDLINE, SciELO, LILACS, ProBE e DEDALUS, não foram identificados estudos explorando as associações entre satisfação e capacidade para o trabalho, indicando que esta é uma área de investigação que deve 
ser desenvolvida em função dos potenciais efeitos da satisfação sobre a capacidade para o trabalho dos indivíduos.

\section{7 - SATISFAÇÃO NO TRABALHO E ORGANIZAÇÃO DO TRABALHO}

A análise ergonômica do trabalho foi utilizada em função de um dos objetivos desta pesquisa, que foi verificar quais aspectos da organização do trabalho podem estar influenciando a satisfação no trabalho dos empregados que compõem a população de estudo. A análise ergonômica do trabalho foi realizada por meio de amostra não probabilística, o que pode acarretar algum viés nos resultados caso a amostra não seja representativa do total dos empregados. A análise de comparação entre o grupo de empregados que participou da análise ergonômica e o que não participou demonstrou que não existem diferenças significativas entre os dois grupos, tanto nos aspectos sócio-demográficos como nos funcionais. Porém estes resultados devem ser considerados com cautela, uma vez que a amostra é não probabilística e existem algumas variáveis com categorias com pequeno número de empregados, fazendo com que estes resultados possam ser devidos ao acaso.

A análise ergonômica do trabalho mostrou que as condições e a organização do trabalho, tanto do grupo de empregados com maior nível de satisfação no trabalho como do grupo com maior nível de insatisfação, tinham como principais as seguintes características: (1) principal objeto de trabalho é abstrato, envolvendo uso de habilidades mentais (atenção, organização, planejamento, aprendizado, síntese, desenvolvimento de estratégias, análise, solução de problemas e outras) por grande parte do tempo de trabalho; (2) instrumentos de trabalho mais utilizados são os relacionados ao armazenamento, transmissão ou manipulação/transformação de informações, sendo o computador o mais significativo; (3) existência de diversificação de tarefas, porém pouca possibilidade de aprendizado e de execução 
de novas atividades; (4) trabalho com exigência de formação educacional qualificada e de experiência anterior; (5) grande responsabilidade por perda de tempo e por valores abstratos; (6) grande parte do tempo de trabalho na posição sentada; e (7) mobiliário e ambiente físico de trabalho apresentando situações não adequadas em termos de biomecânica e de conforto.

O único aspecto onde o grupo de empregados satisfeitos e o grupo de insatisfeitos apresentou diferença significativa foi "freqüência de estresse que pode ter origem em conflitos com padrões sociais", onde o grupo de empregados mais satisfeitos apresentou menor exposição a esta fonte de estresse do que o grupo de empregados mais insatisfeitos. Possíveis explicações para esta diferença podem ser encontradas nos relatos de insatisfação feitos pelos empregados no transcorrer das entrevistas e das análises ergonômicas. Um aspecto relatado como insatisfatório foi o salário insuficiente para custear os estudos, obstruindo a possibilidade de qualificação profissional que possibilite o desenvolvimento de uma carreira interna ou externa à empresa e, por conseqüência, impossibilite uma melhoria da condição financeira e social. Outro aspecto mencionado foi a falta de valorização dos empregados com cargos técnicos ou auxiliares, expresso por meio da falta de reconhecimento tanto pelo trabalho realizado, como pela importância atribuída a este trabalho.

As condições e a organização do trabalho identificadas como sendo caracterizadas por trabalho intelectual, muitas vezes com alta qualificação, exigindo o uso constante de habilidades mentais e da recepção e processamento de informações podem configurar um aumento da carga mental do trabalho. Carga de trabalho mental tem característica tanto quantitativa (volume de trabalho a ser executado) como qualitativa (complexidade do trabalho) (ILO 1984), e significa a carga que atua sobre o sistema nervoso central e que é decorrente das demandas para desempenhar determinada tarefa (LEVI e LUNDE-JENSEN 1996).

Segundo FRASER (1996), o trabalho qualificado e o trabalho intelectual podem levar à fadiga mental decorrente da sobrecarga de trabalho, e esta fadiga pode ser aguda ou crônica. Segundo o autor, a fadiga aguda é a que ocorre após um dia de 
trabalho ou após uma tarefa árdua e que pode levar à exaustão, mas, em geral, não constitui um risco nem leva à doença. Porém, quando ocorre exposição prolongada à sobrecarga mental, horas prolongadas de trabalho, períodos de descanso insuficiente, ou sono inadequado, pode ocorrer a fadiga crônica, que é agravada por condições de trabalho deficientes. A fadiga crônica é uma síndrome difícil de definir, e que pode ser caracterizada por apatia, perda de energia, depressão, irritabilidade, lapsos de julgamento, queda da produtividade e da qualidade do trabalho (FRASER 1996).

Estes aspectos do trabalho identificados como possíveis fontes de aumento da carga mental do trabalho também podem ter um potencial efeito sobre a satisfação no trabalho. Segundo DEJOURS (1987), a insatisfação também pode se dar em relação ao conteúdo ergonômico do trabalho onde aspectos relacionados às condições do posto de trabalho e ambientais podem ser insatisfatórias desencadeando sofrimentos somáticos, alguns com determinismo físico direto, e outros como manifestações de algo que afeta a saúde mental.

$\mathrm{Na}$ presente pesquisa não foram identificadas associações entre condições e organização do trabalho e satisfação no trabalho. Porém, isto não diminui a atenção que deve ser dada a estas condições, tanto pelos seus potenciais efeitos sobre a satisfação no trabalho, como diretamente sobre a saúde dos trabalhadores. 


\section{6 - CONCLUSÕES}

Em relação às hipóteses para investigação neste estudo, as conclusões mais importantes foram que a satisfação no trabalho apareceu significativamente associada à saúde do trabalhador, onde níveis mais elevados de satisfação com aspectos psicossociais do trabalho estavam relacionados com uma melhor condição de saúde mental e de capacidade para o trabalho entre os trabalhadores da população de estudo. Essas associações ocorreram independentes das variáveis sócio-demográficas e funcionais, demonstrando a importância da satisfação no trabalho em relação à saúde dos trabalhadores.

Os aspectos psicossociais do trabalho que apareceram como sendo mais satisfatórios para os empregados foram: relacionamento com outras pessoas da empresa, conteúdo do trabalho que realiza e grau de liberdade e flexibilidade que julga ter no trabalho. Os aspectos psicossociais do trabalho que apareceram como sendo mais insatisfatórios para os empregados foram: salário em relação à expectativa e produtividade, clima psicológico que predomina na empresa, oportunidades na carreira e oportunidades de atingir aspirações e ambições.

As características sócio-demográficas e funcionais que apareceram associadas à satisfação no trabalho entre os trabalhadores da população de estudo foram cargo e tempo de empresa.

As condições e a organização do trabalho da população de estudo são caracterizadas pela realização de trabalho intelectual com uso de habilidades mentais e com recepção e processamento de informação podendo configurar um aumento da carga mental com possibilidade de ocorrência de fadiga mental. A análise ergonômica do trabalho demonstrou ser uma técnica adequada para identificação das características das condições e da organização do trabalho que possam estar acarretando sobrecarga de trabalho. A análise ergonômica dos postos de trabalho não chegou a evidenciar 
diferenças estatisticamente significativas entre os empregados satisfeitos e insatisfeitos, porém isto não diminui a atenção que deve ser dada a estas condições, tanto pelos seus potenciais efeitos sobre a satisfação no trabalho, como diretamente sobre a saúde dos trabalhadores.

Devido a sua complexidade, existe uma série de teorias que buscam explicar a satisfação no trabalho. Este estudo teve como parte de seu referencial teórico a Teoria de Locke. Os resultados indicaram percepções dos empregados quanto aos conceitos e fontes de satisfação e de insatisfação no trabalho compatíveis com os enunciados por Locke.

Ainda devido a sua complexidade, à multiplicidade de teorias existentes e ao seu caráter subjetivo, é necessário rigor metodológico na escolha do referencial teórico e das estratégias de pesquisa, incluindo instrumentos e técnicas para coleta e análise dos dados. Também são necessários cuidados quanto à abordagem, comunicação e entrada no campo de pesquisa, para obtenção da aceitação e adesão dos empregados ao estudo. Neste sentido, as estratégias, métodos e instrumentos utilizados nesta pesquisa mostraram ser adequados aos objetivos propostos.

Uma limitação deste estudo é que, por tratar-se de estudo com desenho transversal, não foi possível estabelecer relações causais entre satisfação e saúde. Para isso são necessários estudos longitudinais. Da mesma forma, para o entendimento de como ocorre a dinâmica destas relações, são úteis os estudos com abordagem qualitativa. 


\section{7 - CONSIDERAÇÕES FINAIS}

Os resultados do estudo demonstraram a significativa relação entre satisfação no trabalho e saúde mental, e entre satisfação no trabalho e capacidade para o trabalho a partir da avaliação de aspectos psicossociais do trabalho, e a importância destes aspectos para a saúde e bem-estar dos empregados.

O trabalho é um modo pelo qual o homem pode se realizar e dar sentido a sua existência, onde a realização de uma atividade que seja satisfatória, que venha ao encontro de seus valores, e que proporcione prazer, aparece associada a uma melhor capacidade para o trabalho e a uma melhor condição de saúde mental.

Assim, a título de considerações para melhorarias na satisfação com o trabalho, saúde mental dos empregados e sua capacidade para o trabalho, sugere-se refletir e avaliar mudanças na concepção e organização do trabalho direcionadas para os aspectos psicossociais do trabalho. Estas considerações compreendem:

- Prévia conceituação, discussão e consolidação internas para direcionar as mudanças.

- Mudanças nas formas de reconhecimento e valorização dos empregados e de seu trabalho: Ex.: treinamento de chefias para o desenvolvimento de habilidades no sentido de reconhecer tanto as exigências do trabalho real como o interesse e os esforços dos empregados ou a qualidade dos serviços realizados; dar conhecimento aos empregados deste reconhecimento, seja por meio de comunicação verbal ou escrita, formal ou informal, pessoal ou coletiva, levando em consideração as formas mais aceitas ou valorizadas pelo grupo de trabalhadores envolvidos; definir incentivos ou recompensar para esforços desenvolvidos e trabalhos realizados, bem como ter claros os critérios de concessão dos mesmos e para que não sejam apenas "pró-forma" ou uma forma de privilégios. 
- Priorizar mudanças que implementem a autonomia e controle exercidos pelos empregados, com aumento da participação individual e coletiva em processos decisórios, e não apenas na forma "cosmética". Ex.: desenvolvimento e avaliação dos impactos psicossociais de grupos de trabalho autônomos; delegação de tarefas associada a treinamento e exigências de trabalho compatíveis; melhorias contínuas nas informações e seus suportes de modo que possam servir como subsídios para tomadas de decisão; suporte das chefias para decisões e condutas adotadas pelos empregados; valorização da discussão e consenso de decisões entre chefias e empregados, bem como promoção do envolvimento dos empregados nas atividades de planejamento e organização, e não só na execução do trabalho. Essas mudanças devem ser acompanhadas de clara definição das competências e responsabilidades, evitando, por exemplo, os conflitos e ambigüidades de papéis e a polivalência com excesso de trabalho ou de pressões.

- Mudanças que implementem o enriquecimento do trabalho e o aumento do nível de habilidades dos empregados a partir do envolvimento dos empregados em todo o processo de trabalho, desde sua concepção até avaliação dos resultados e desde que sejam percebidas como aspecto positivo pelos empregados. Ex.: possibilitar o desenvolvimento de tarefas mais interessantes e complexas, que utilizem os conhecimentos e habilidades que o trabalhador já dispõem e/ou o aprendizado e desenvolvimento de novas habilidades, que signifiquem desafios que venham ao encontro das expectativas dos trabalhadores. Um dos parâmetros de tais mudanças também deve ser o de evitar conflitos e ambigüidades de papéis, e a polivalência com excesso de trabalho ou de pressões.

- Mudanças que implementem claramente, para todos os envolvidos, o desenvolvimento da carreira e a segurança no emprego. Ex.: desenvolvimento e avaliação de plano de carreira; envolvimento dos empregados na definição de critérios de avaliação (de processos, de desempenho, do próprio plano de carreira); plano de treinamentos (sejam internos, sejam via facilitação de acesso a treinamentos ou cursos externos à empresa); possibilitar e valorizar o 
envolvimento em atividades que ofereçam oportunidade de incremento da qualificação dos empregados bem como sua cidadania.

- Mudanças que aumentem os níveis de suporte social. Ex.: treinamento e habilitação de chefias e dos profissionais de Recursos Humanos, Serviço Social e Saúde para oferecer suporte, orientações e encaminhamento aos empregados em questões pessoais e profissionais e para resolução de conflitos.

- Mudanças no fluxo, suporte e qualidade das informações operacionais e organizacionais. Ex.: agilizar a transmissão de informações entre os diversos níveis hierárquicos de forma que as informações cheguem completas e rápidas às pessoas que necessitam delas para realizar seu trabalho; facilitar a comunicação entre pessoas de diferentes níveis hierárquicos; fornecer informações transparentes e claras sobre mudanças que estão ou irão acontecer na empresa, evitando a disseminação de boatos e diminuindo tensões resultantes da incerteza e de informações conflituosas; enfim, pensar a comunicação interna como ferramenta e estratégia gerencial e não apenas para com clientes ou fornecedores.

- Mudanças que implementem um nível de demandas no trabalho adequados às características psico-fisiológicas humanas. Ex.: não utilizar horas-extras como prática para administrar efetivo, contratação de pessoal ou salários; redefinir tarefas, responsabilidades e prioridades com a participação dos trabalhadores.

- Mudanças nas condições do ambiente físico de trabalho: Ex.: adequação das condições do ambiente físico (ruído, temperatura e iluminação) às características psico-fisiológicas humanas, orientando-se, por exemplo, pelas normas técnicas e legislação mais avançada em cada tema; readequação do lay out das áreas e postos de trabalho; readequação do mobiliário e equipamentos (em especial, computadores); facilitar o envolvimento dos empregados na priorização, definição e desenvolvimento dessas mudanças. 
A implementação deste tipo de mudanças deve ser feita com o cuidado de verificar se elas atendem às necessidades, expectativas e desejos dos empregados e se são compatíveis tanto com as características como com as exigências das tarefas. Não respeitadas estas condições, estas mudanças podem facilmente caracterizar apenas um aumento do volume de trabalho, das exigências e responsabilidades no trabalho e dos conflitos inter-pessoais, constituindo novas fontes de sobrecarga para o trabalhador e, portanto, de riscos para a saúde e o bem-estar.

Quaisquer mudanças devem se nortear, portanto, em favorecer aos trabalhadores a escolha e organização mais autônoma possível (no sentido de auto-regulável) de seu trabalho, servindo assim como uma das estratégias para a promoção da satisfação no trabalho e da saúde do trabalhador.

PETERSON e DUNNAGAN (1998) afirmam a validade deste tipo de mudanças quando, estudando o impacto de programas de promoção da saúde no local de trabalho sobre a satisfação no trabalho. Estes autores, por um lado, identificaram que programas - embora sejam percebidos pelos empregados como tendo valor para a melhoria da saúde e bem-estar - não apresentaram impactos sobre a satisfação no trabalho. Por outro lado, os autores identificaram que mudanças na organização do trabalho e melhoria do ambiente psicossocial do trabalho melhoraram substancialmente tanto os impactos sobre a satisfação no trabalho como os resultados na saúde dos empregados.

Como quaisquer mudanças, estas mudanças representam a necessidade de dispêndio financeiro e de tempo, bem como o envolvimento gerencial e dos empregados de todos os níveis hierárquicos da empresa, dos profissionais da área de saúde do trabalho e da área de recursos humanos em todas as suas fases, desde a concepção das mudanças, seu planejamento, organização, implementação, avaliação e acompanhamento.

Evidentemente, este tipo de processo é de longa maturação e duração, com uma implantação gradual, e onde podem ocorrer limitações decorrentes do contexto da 
empresa, que podem ser de caráter econômico, administrativo, de disponibilidade de recursos humanos e de tempo. Neste sentido, as mudanças devem ser feitas a partir de prioridades, e estas prioridades podem ser definidas no sentido de implementar os aspectos psicossociais do trabalho que apareceram como principais fontes de satisfação no trabalho, e de corrigir ou melhorar os aspectos que apareceram como principais fontes de insatisfação no trabalho.

Além de implementar mudanças organizacionais visando satisfação no trabalho e saúde, também são necessários mais estudos, seja por meio de desenho epidemiológico longitudinal ou por meio de método qualitativo, buscando confirmar a direção causal da relação entre satisfação no trabalho e saúde, identificar e conhecer melhor os fatores associados que interferem nesta relação, e caracterizar a dinâmica destas relações, de maneira a auxiliar na compreensão do impacto que o trabalho exerce sobre a saúde do coletivo dos trabalhadores. Desta forma, as estratégias qualitativas e quantitativas não são mutuamente excludentes, ao contrário, o uso conjunto delas enriquece a compreensão deste fenômeno tão complexo.

"Se você não tá fazendo aquilo que você gosta, aí você fica com dor de cabeça, você vem trabalhar mal-humorada, você fica estressada porque você não tá fazendo aquilo que você gosta, então você se torna uma pessoa triste, uma pessoa assim desanimada, e o desânimo o que acontece? O seu corpo vai dar abertura pras doenças, pode vir sei lá uma hipertensão, alguma coisa relacionada com isso, uma enxaqueca, essas doenças novas, asma que agora tão falando que é relacionada com o emocional. Então eu acho que então tem tudo a ver, eu acho que se você está fazendo uma coisa que você goste, então sua saúde ela é muito boa, mas se você tá fazendo uma coisa que não goste a saúde vai então lá embaixo". 


\section{8 - REFERÊNCIAS}

Aasland OG, Olff M, Falkum E, Schweder T, Ursin H. Health complaints and job stress in norwegian physicians: the use of an overlapping questionnaire design. Soc Sci Med. 1997; 45(11):1615-1629.

Abouserie R. Stress, coping strategies and job satisfaction in university academic staff. Educational psychology. 1996; 16(1):49-56.

[Academy] Academy for Health Services Research and Health Policy. Glossary of terms commonly used in health care [document on line]. Washington: Academy; 2002 . Available from:

<URL:http://www.academyhealth.org/publications/glossary.htm> [2002 Mar 22].

Ahn J, Moon S-J, Lee YS. Mismatch and job satisfaction of korean workers. [article on line]. Korean Labor Institute; 2001. Avaiable from: <URL:http://kli.re/english/issuepaper/Mismatch.pdf> [2002 Jan 10].

Alberto LCFR. Os determinantes da felicidade no trabalho: um estudo sobre a diversidade nas trajetórias profissionais de engenheiros. São Paulo; 2000. [Dissertação de Mestrado - Instituto de Psicologia da Universidade de São Paulo].

Alchieri JC. Questões introdutórias sobre medida em psicologia [monografia on line]. São Leopoldo: Centro de Ciências da Saúde da UNISINOS - Universidade do Vale do Rio dos Sinos; 2001. Disponível em: <URL:http://www.saude.unisinos.br/liap/_textos/medidas.pdl> [2002 Fev 18].

Almeida Filho N, Rouquayrol MZ. Introdução à Epidemiologia Moderna. $2^{\mathrm{a}}$ ed. Belo Horizonte: COOPMED; 1992. Metodologia da Pesquisa Epidemiológica; p.79101. 
Almeida MHT. Negociando a reforma: a privatização de empresas públicas no Brasil. Dados Rev Ciênc Sociais. [periódico on line] 1999; 42(3). [60 telas]. Disponível em <URL:http:www.scielo.br/dados> [2001 Ago 20].

Araújo AP. Motivação e satisfação no trabalho: uma pesquisa junto aos empregados de uma instituição bancária, a partir da teoria da motivação e higiene formulada por F. Herzberg. São Paulo; 1985. [Dissertação de Mestrado Faculdade de Economia e Administração da Universidade de São Paulo].

Argyris C. Personalidade e organização: o conflito entre o sistema e o indivíduo. Rio de Janeiro: Renes; 1969. A atitude da Direção e seu impacto sobre os empregados; p.121-157.

Ballone GJ. Percepção e realidade. PsiqWeb: Psiquiatria Geral [artigo on line]. 1999. Disponível em: <URL:http://www.psiqweb.med.br/cursos/percep.html> [2001 Nov 2].

Bardin L. Análise de conteúdo. Lisboa: Edições 70; 1977.

Baruch Y. Response rate in academic studies - a comparative analysis. Human Relations. 1999; 52(4):421-438.

Bailey KD. Methods of social research. $3^{\text {rd }}$ ed.New York: Free Press; 1987. Survey sampling; p.80-103.

Begley TM, Czajka JM. Panel analysis of the moderating effects of commitment on job satisfaction, intent to quit, and health following organizational change. Journal Applied Psychol.ogy 1993; 78(4):552-556.

Bellusci SM. Envelhecimento e condições de trabalho em servidores de uma instituição judiciária - Tribunal Regional Federal da $3^{\text {a }}$ Região, São Paulo. São 
Paulo; 1998. [Dissertação de Mestrado - Faculdade de Saúde Pública da Universidade de São Paulo].

Bellusci SM, Fischer FM. Envelhecimento funcional e condições de trabalho em servidores forenses. Rev Saúde Pública 1999; 33(6):602-609.

Berquó ES, Souza JMP, Gotlieb SLD. Bioestatística. $1^{a}$ ed. São Pualo: EPU, 1987.

Braga GM. Fatores que afetam a satisfação no trabalho na empresa de assistência técnica e extensão rural: Emater; 1978. [Dissertação de mestrado Faculdade de Economia e Administração da Universidade de São Paulo].

Braga VOS, Battistin C, Cabianca AMR, Bertolami A, Oliveira F. A problemática da saúde do trabalhador [artigo on line] 2001. Brasil: estudmed.com. Disponível em: <URL:http://www.estudmed.com/trabalhos/index.htm> [2002 Fev 20].

Brayfield AH, Rothe HF. An index of job satisfaction. Journal Applied Psychology $1951 ; 35(5): 307-311$.

Brief AP, Roberson L. Job attitude organization: an exploratory study. Journal of Applied Social Psychology 1989; 717-727.

Bussing A, Bissels T, Fuchs V, Perrar K.M. A dynamic model of work satisfaction: qualitative approaches. Human Relations. 1999; 52(8):999-1003.

Campbell KN. Adult education: helping adults begin the process of learning. AAOHN J [serial online] 1999; 41(1):31-40. [11 screens] Available from: <URL:http//www.aaohn.org/cemodules/jan99.art.htm> [ 1999 Jul 9].

Cannell CF, Kahn RL. The collection of data by interviewing. In: Festinger L, Katz $\mathrm{D}$, editors. Research methods in the behavioral sciences. New York: Holt, Rinehart and Winston, 1966. P.327-380. 
Cavanagh SJ. Job satisfaction of nursing staff working in hospitals. Journal Advanced Nursing 1992; 17(6):704-11.

[CDC] Centers for Disease Control, World Hearth Organization. Epi Info versão 6.04. Epidemiologia em microcomputadores: um programa para processamento de texto, banco de dados e estatísticas em saúde pública [programa de computador]. Atlanta: Organização Mundial da Saúde; 1986.

Chan KB, Lai G, KO YC, Boey KW. Work stress among six profissional groups: the Singapore experience. Soc Sci Med 2000; 50:1415-1432.

Ciconelli RM. Tradução para o português do questionário de avaliação de qualidade de vida "Medical outcomes study 36 - item short-form health survey (SF-36)" São Paulo; 1997. [Tese de doutorado - Universidade Federal de São Paulo].

Coda R. Satisfação no trabalho e características das políticas de recursos humanos para executivos. São Paulo; 1986. [Tese de Doutorado - Faculdade de Economia e Administração da Universidade de São Paulo].

Cohen F. Measurement of coping. In: Kasl SV, Cooper CL, editors. Stress and Health: issues in research methodology. Great Britain: John Wiley \& Sons; 1987. p.283-305.

Couto HA. Novas perspectivas na abordagem preventiva das LER/DORT. Belo Horizonte: Ergo Ed.; 2000. Objetivos e metodologia; p.101-110.

Cox T, Griffiths A. Psychosocial hazards: assessment issues. In: Proceedings of the International Symposium From Research to Prevention: managing occupational and environmental health hazards; 1995 mar 20-23. Helsinki, Finland. Finnish Institute of Occupational Health; 1995.p46-53. 
Cura MLAD. Satisfação profissional do enfermeiro. Ribeirão Preto; 1994. [Dissertação de mestrado - Escola de Enfermagem de Ribeirão Preto da Universidade de São Paulo].

Dawson-Saunders B, Trapp RG. Basic e clinical biostatistics. $2^{\text {a }}$ ed. Connecticut: Appleton \& Lange; 1994.

Dejours C. Por um novo conceito de saúde. Rev Bras Saúde Ocup 1986; 54(14):711 .

Dejours C. A loucura do trabalho: estudo de psicopatologia do trabalho. Trad. de AI Paraguay e LL Ferreira. 2a ed. São Paulo: Cortez e Oboré; 1987. Que sofrimento?; p.48-62.

Dejours C. A carga psíquica do trabalho. Trad de I Domingues. In: Betiol MIS, coordenador. Psicodinâmica do Trabalho: contribuições da Escola Dejouriana à análise da relação prazer, sofrimento e trabalho. 3ª ed. São Paulo: Atlas; 1994. P21-32.

Dejours C, Abdoucheli E. Itinerário teórico em psicopatologia do trabalho. Trad. de DMR Glina. In: Betiol MIS, coordenador. Psicodinâmica do Trabalho: contribuições da Escola Dejouriana à análise da relação prazer, sofrimento e trabalho. $3^{\text {a }}$ ed. São Paulo: Atlas; 1994. P119-145.

Dejours C. Conferências brasileiras: identidade, reconhecimento e transgressão no trabalho. Trad. Reis ACF. São Paulo: FUNDAP/EAESP-FGV; 1999. Ergonomia e medicina do trabalho: a noção do amor na problemática da saúde; p.85-123.

Dever GEA. A epidemiologia na administração dos serviços de saúde. São Paulo: Biblioteca Pioneira de Administração de Negócios; 1998. Epidemiologia: enfocando a prevenção; p.1-24. 
Dipboye RL, Smith CS, Howell WC. Understanding industrial and organizational psychology: an integrated approach. USA: Harcourt Brace College Publishers; 1994. Job attitudes; p. 147-169.

Doria Filho U. Introdução à bioestatística para simples mortais. São Paulo: Negócio Editora Ltda; 1999.

Elovainio M, Kivimäki M, Steen N, Kalliomäki-Levanto T. Organizational and individual factors affecting mental health and job satisfaction: a multilevel analysis of job control and personality. J Occup Health Psychol 2000; 5(2):269-277.

Employment e Social Affairs. Guidance on work-related stress: spice of life or kiss of death? Luxembourg: European Comunities; 1999. Organizational consequences of stress; p.29-30.

Fayol H. General and industrial management. London: Pitman Publishing; 1971. General principles of management; p.19-42.

Fischer FM, Paraguay AIBB. A ergonomia como instrumento de pesquisa e melhoria das condições de vida e trabalho. In: Fischer FM, Gomes JR, Colacioppo S, organizadores. Tópicos de saúde do trabalhador. São Paulo: HUCITEC; 1989. p.19-71.

Fowler Jr DJ. Survey Research Methods. California:SAGE; 1990. Nonresponse: implementing a sample design; p.45-60.

Franca ACL Indicadores de qualidade de vida no trabalho: esforço empresarial e satisfação dos empregados no ambiente de manufaturas com certificado ISO 9000. São Paulo; 1996. [Tese de Doutorado - Faculdade de Economia e Administração e Contabilidade da Universidade de São Paulo]. 
Fraser TM. Human stress, work and job satisfaction: a critical approach. German: International Labour Office, 1983.

Fraser TM. Work, fatigue, and ergonomics. In: Introduction to industrial ergonomics: a textbook for students and managers. Toronto: Wall and Emerson; 1996.

Fundação CESP. Estrutura organizacional. São Paulo; 2000. [Documento interno].

Fundação CESP. PPRA - Programa de Prevenção de Riscos Ambientais. São Paulo; 2001. [Documento interno].

Giuzi LD. O impacto dos elementos da cultura organizacional na satisfação do trabalhador: validação e aprimoramento de um instrumento de pesquisa. São Paulo; 1993 [Tese de doutorado - Faculdade de Economia e Administração da Universidade de São Paulo].

Groenewegen PP, Hutten JBF. Workload and job satisfaction among general practitioners: a review of the literature. Soc Sci Med 1991; 32(10):1111-1119.

[GSA] U.S. General Services Administration. The survey scoop [article on line] Washington: Office of Information Technology; 1997.

Guillemin F. Cross-cultural adaptation and validation of health status measures. Scand J Rheumatol. 1995; 24:61-63

Guyatt GH, Feeny DH, Patrick DL. Measuring health-related quality of life. Basic Science Review. 1993; 118:622-629.

Hagihara A, Tarumi K, Nobutomo K. Work stressors, drinking with colleagues after work, and job satisfaction among white-collar workers in Japan. Substance Use \& Misuse. 2000; 35(5):737-756. 
Harris RB. Reviewing nursing stress according to a proposed coping-adaption frameork. Adv Nurs Sci 1989; 11(2) 12-28.

Hartman S, Grigsby DW, Crino MD, Chhokar JS. The measurement of job satisfaction by action tendencies. Educational and Psychological Measurement 1986; 46:317-329.

Health Canada. Population Health Approach. Population health: defining health. [document on line] Canada: Health Canada; 2001. Available from: <URL:http://www.hc-sc.gc.ca/hppb/phdd/approach/index.html> [2002 Mar 02].

Henne D, Locke EA. Job dissatisfaction: what are the consequences? Int Journal Psychology 1985; 20:221-240.

Herzberg F. Work and the nature of man. $4^{\text {th }}$ ed. Cleveland: World Publishing; 1971. The Motivation-Hygiene Theory; p.71-91.

Hollmann S, Klimmer F, Schmidt K, Kylian H. Validation of questionnaire for assessing physical work load. Scand J Work Environ Health 1999; 25(2): 105-114.

Hopman WM, Towheed T, Anastassiades T, Tenenhouse A, Poliquim S, Berger C, et. al. Canadian normative data for the SF-36 health survey. CMAJ 2000; 163(3):265-71.

Hoppen N. Um guia para a avaliação de artigos de pesquisa em sistemas de informação. Rev Eletron Administ. [Periódico on line] 1996, 2: (2) Disponível em: <URLhttp://read.ea.ufrgs.br/read03/artigo/guia_a.htm> [2001 fev 26].

Ilmarinen J, Suurnäkki T, Nygård CH, Landau K. Classification of municipal occupations. Scand J Work Environ Health 1991; 17(suppl 1):12-29. 
[ILO] International Labour Office. Psychosocial factors at work: recongnition and control. Report of the Joint ILO/WHO Committee on Occupational Health Ninth Session. Geneva: International Labour Office; 1984.

Judge TA, Locke EA. Effect of dysfunctional thought processes on subjective wellbeing and job satisfaction. Journal Applied Psychology 1993; 78(3):475-490.

Judge AT, Bono JE, Locke EA. Personality and job satisfaction: the mediating role of job characteristics. Journal Applied Psychology 2000; 85(2):237-49.

Kadushin G, Kulys R. Job satisfaction among social work discharge planners. Health and Social Work 1995; 20(3)174-186.

Kalimo R. Psychosocial factors and worker's health: an overview. In: Kalimo R, ElBatawi MA, Cooper CL. Psychosocial factors at work and their relations to health. Geneva: World Health Organization; 1987; p. 3-8.

Kantorski LP. As transformações no mundo do trabalho e a questão da saúde algumas reflexões preliminares. Rev Latinoam Enf 1997; 5(2):5-15.

Karasek R, Theorell T. Healthy work: stress, productivity, and the reconstruction of working life. United States of America: BasicBooks; 1990. The psychosocial work environment; p.31-82.

Kerlinger FN. Foundations of behavioral research. New York: CBS College Publishing; 1986. Reliability. p.404-415.

Kim Y. The determination of public officials' job satisfaction - the case of korean public officials in the cadastral administration. In: International Conference - New technology for a new century. [proceedings on line]. Korea: International Federation of Surveyors; 2001. Avaiable from: 
<URL:http://www.ddl.org.figtree/pub/proceedings/Korea/full/papers/pdg/sessoion12/ kim.pdl> [2001 dez 22].

Klijn TMP. Satisfação no trabalho de mulheres acadêmicas da Universidade de Concepción. Chile; 1998. [Tese de doutorado - Escola de Enfermagem de Ribeirão Preto e Escola de Enfermagem da Universidade de São Paulo].

Korunka C, Vitouch O. Effects of the implementation of information technology on employees' strain and job satisfaction: a context-dependent approach. Work \& Stress 1999; 34(4):341-363.

Lacaz FAC. Saúde dos trabalhadores: cenário e desafios. Cad Saúde Pública 1997; 13 (Supl. 2):07-19.

Landau K, Imhof-Gildein B, Mücke S. On the analysis of sector-related and genderrelated stresses at the workplace - an analysis of the AET data bank. Internat Journal of Industrial Ergonomics 1996; 17:175-186.

Leser W, Barbos V, Baruzzi RG, Ribeiro MBD, Franco LJ. Elementos de epidemiologia geral. São Paulo: Atheneu; 1988. Associações; p.3-6.

Levi L. Stress in Industry. Geneva: International Labour Office, 1984.

Levi L. Definitions and the conceptual aspects of health in relation to work. In: Kalimo R, El-Batawi MA, Cooper CL, editors. Psychosocial factors at work and their relation to the health. Geneva: World Health Organization; 1987. p. 9-14.

Levi L. Psychosocial environmental factors and psychosocially mediated effects of physical environmental factors. Scand J Work Environ Health 1997; 23(3):47-52.

Levi L. The other half of medicine: the concept of psychosocial stress, and its implications for health and the health professions. Forum trends in experimental 
and clinical medicine. Social determinants of health: implications of the health professions. [Article on line] 1998, suppl 4. Available from $<$ URL:http://www.accmed.net/hpi/documenti> [2001 fev 23].

Levi L, Lunde-Jensen P. A model for assessing the costs of stressors at national level: socio-economic costs of work stress in two EU Member States. Ireland: European Foundation for the Improvement of Living and Working Conditions; 1996. Work, stressors, stress and health; p.11-25.

Licht RH. Satisfação, responsabilidade e sentido no trabalho: um estudo preliminar de associação; 1990 [Dissertação de mestrado - Faculdade de Economia e Administração da Universidade de São Paulo].

Lino D, Dias EC. A globalização da economia e os impactos sobre a saúde e segurança dos trabalhadores. [monografia on line]. CUT - Central Única dos Trabalhadores. São Paulo; sd. Disponível em: <URL:http://www.cut.org.br/a60207.htm>. [2000 Ago 30].

Lino MM. Satisfação profissional entre enfermeiras de UTI: adaptação transcultural do Index of Work Satisfaction. São Paulo; 1999. [Dissertação de Mestrado - Escola de Enfermagem da Universidade de São Paulo].

Locke EA. What is job satisfaction? Organiz Behavior Human Performance 1969; 4(4):309-336.

Locke EA. The nature and causes of job satisfaction. In: Dunnette MD, editors. Handbook of industrial and organizational psychology. Chicago: Rand McNally; 1976. p.1297-1349.

Locke EA. Job satisfaction. In: Gruneberg M, Wall T, editors. Social psychology and organizational behaviour. New York: John Wiley \& Sons; 1984. p. 93-117. 
Locke EA, Whiting RL. Sources os satisfaction and dissatisfaction among solid waste management employees. Journal Applied Psychology 1974; 59(2):145-156.

Lu L, Shiau C, Cooper CL. Occupational stress in clinical nurses. Counselling Psychology Quarterly. 1997; 10(1):39-50.

Lunnardi Filho WD. Prazer e sofrimento no trabalho: contribuições à organização do processo do trabalho da enfermagem. Rev Bras Enferm. 1997; 50(1):77-92.

Lundberg O, Manderbacka K. Assessing reliability of a measure of self-rated health. Scand J Soc Med 1996; 24(3):218-224.

Lynn MR. Reliability estimates: use and disuse. In: Downs FS, editor. Readings in research methodology. $2^{\text {nd }}$ ed. Philadelphia:Lippincott; 1999. P.236-238.

Marmot MG, Madge N. An epidemiological perspective on stress and health. In: Kasl SV, Cooper CL (editors). Stress and Health: Issues in research methodology. Great Britain: John Wiley \& Sons; 1987. P.3-26.

Maslow AH. Motivation and personality. $2^{\text {nd }}$ ed. New York: Harper \& Row; 1970. A theory of human motivation; p.35-58.

Mayo E. Problemas humanos de uma civilización industrial. Trad. de AM Elquera. Buenos Aires: Galatea Nueva Visión; 1959.

McEwen BS. Protective and damaging effects of stress mediators. N Engl j med 1998; 338(3):171-178.

McGregor D. Os aspectos humanos da empresa. $2^{\text {a }}$ ed. Lisboa: Livraria Clássica; sd. 
Mendes R. Patologia do trabalho. $1^{\text {a }}$ ed. Atheneu: Rio de Janeiro; 1999. Aspectos históricos da patologia do trabalho; p.3-31.

Mendes R, Dias EC. Da medicina do trabalho à saúde do trabalhador. Rev Saúde Pública 1991; 25(5):341-349.

Menezes PR. Validade e confiabilidade das escalas de avaliação psiquiátrica. Rev Psiq Clinica. [Periódico on line] 1998, 25:(5 - $\mathrm{n}^{\mathrm{o}}$ esp.). Disponível em: <URL:http://www.hcnet.usp.br/ipq/revista/r255/conc255b.htm> [2001 fev 26].

Microsoft Inc. Word for Windows [Computer program]. Version 97. Washington: Microsoft Inc.; 1998a.

Microsoft Inc. Excell for Windows [Computer program]. Version 97. Washington: Microsoft Inc.; 1998b.

Minayo-Gomez C, Thedim-Costa SMF. A construção do campo da saúde do trabalhador: percurso e dilemas. Cad. Saúde Pública 1997; 13 (Supl. 2):21-31.

Ministério da Saúde. Anais da $8^{\text {a }}$ Conferência Nacional de Saúde. Brasília (DF); 1987.

Ministério da Saúde. Programa de saúde do idoso: dados estatísticos sobre os idsoso: o envelhecimento populacional brasileiro e as transformações na sociedade. [Documento on line] 1999a. Disponível em <URL:http://saude.gov.br/programas/idoso/programa.htm> [2001 Set 21].

Ministério da Saúde. Doenças ocupacionais e acidentes de trabalho [Documento on line] 1999b. Disponível em: <URL:http://saude.gov.br/programas/Trabalhador> [2001 Fev 21]. 
Ministério da Saúde. Portaria n 1339/GM, de 18.11.99 Instituí a Lista de Doenças relacionadas ao Trabalho, a ser adotada como referência dos agravos originados no processo de trabalho no Sistema Único de Saúde, para uso clínico e epidemiológico, constante no Anexo I desta Portaria. Diário Oficial da União, Brasília, 19 nov. 1999. Seção I, p.21. [Legislação on line] 1999c. Disponível em: $<$ URL:http://www.cvs.saude.gov.br/dowload.asp?tipo=zip\&arquivo=99pgm1339.zip $>$ [2002 Fev 21].

Ministério do Trabalho e do Emprego. Portaria 3214/78, de 08.06.1978: aprova as Normas Regulamentadoras - NR - do Capítulo V, Título II, da Consolidação das Leis do Trabalho, relativas a Segurança e Medicina do Trabalho. Site do Ministério do Trabalho e do Emprego. Disponível em: <URL:http://www.mtb.gov.br/Temas/SegSau/Legislacao/Normas/Default.asp>[2001 Dez 12].

Moraes LFR, Pereira LZ, Velosos HM, Silva AAR. O diagnóstico do estresse ocupacional em gerentes do setor de prestação de seviços em Belo Horizonte. In: XXII ENANPAD - Encontro Nacional dos Programas de Pós-Graduação em Administração; 1998; Foz do Iguaçu.

Moreno CRC. Critérios cronobiológicos na adaptação ao trabalho em turnos alternantes: validação de um instrumento de medida, 1993. [Dissertação de Mestrado - Faculdade de Saúde Pública da Universidade de São Paulo].

Moro FBP. Investigação do efeito de características individuais na organização: uma abordagem sistêmica. Florianópis; 1997. [ Tese de Doutorado - Universidade Federal de Santa Catarina]. Disponível em: <URL:http://www.eps.ufsc.br/teses97/moro/index.html\#R> [2002 jan 12].

[NIOSH] National Institute for Occupational Safety and Health. Work-related musculoskeletal disorders and psychosocial factors. In: Bernard BP editor. Musculoskeletal disorders and workplace factors: a critical review of 
epidemiologic evidence for work-related musculoskeletal disorders of the neck, upper extremity, and low back. [document on line] $2^{\text {nd }}$ ed. Cincinnati: NIOSH; 1997. Available from: <URL:http://www.cdc.gov/niosh/ergosci1.html> [2001 Mar 30].

Nunnally FC. Psychometric Theory. USA: McGraw Hill; 1967. Assessment of reliability. p. 206-235.

O’Driscoll MP, Beehr TA. Supervisor behaviours, role estressors and uncertainty as predictors of personel outcomes for subordinates. Journal Organizational Behaviour 1994; 15:141-155.

O'Driscoll MP, Beehr TA. Moderating effects of perceived control and need for clarity on the relationship between role estressors and employee affective reactions. Journal Science Psychology 2000; 140(2):151-9.

[OMS] Organizatión Mundial de la Salud. Promoción de la salud: glosario. Health Promotion, noncommunicable disease prevention and surveillance (HPS) [document on line] $1998 . \quad$ Available from: <URL:http://www.who.int/hpr/docs/glossary.html> [2001 Abr 05].

Paraguay, AIBB. Ergonomia. Carga de Trabalho. Fadiga Mental. Rev Bras Saúde Ocup 1987; 59(15):39-43.

Parker SK, CN, WTD. The work characteristics and employe well-being within a context of strategic downsizing. Journal Occup Health Psychol. 1997; 2(4):289303.

Parkes KR. Personality and coping as moderators of work stress process: models, methods and measures. Work stress 1994; 8(2):110-129. 
Pasquali L. Princípios de elaboração de escalas psicológicas. Rev Psiq Clínica. [Periódico on line] 1998, 25:(5 - $\mathrm{n}^{\mathrm{o}}$ esp.). Disponível em: <URL:http://www.hcnet.usp.br/ipq/r255/conc255a.htm> [2001 fev 26].

Paula NM. Levantamento dos fatores de satisfação e insatisfação no trabalho vivenciados pelos docentes de alguns cursos de graduação em nutrição no Brasil. São Paulo; 1990. [Dissertação de Mestrado - Faculdade de Administração do Hospital São Camilo].

Pepper LD, Messinger $M$. The health effects downsizing in the nuclear industry:Pantex [research on line]. Boston: National Institute of Occupational Safety and Health (NIOSH); 2000. Avaible form <URL:http://www.cdc.gov/niosh/pdfs/2001-133g16-4.pdf). [2001 jan 12].

Pereira JCR. Análise de dados qualitativos: estratégias metodológicas para as ciências da saúde humanas e sociais. São Paulo: EDUSP, 1999.

Pérez-Ramos J. Satisfação no trabalho: metas e tendências. Assis; 1980. [ Tese de Livre-docência - Instituto de Psicologia de Assis da Universidade Estadual Júlio de Mesquita Filho].

Pérez-Ramos J. Motivação no trabalho: abordagens teóricas. Psicol. USP 1990; $1(2): 127-140$.

Perry LS. Effects of inequity on job satisfaction and self-evaluation in a national sample of african-american workers. Journal Soc Psychol. 1993; 133(4), 565-573.

Peterson M, Dunnagan T. Analysis of a worksite health promotion program's impact on job satisfaction. J Occup Environ Med 1998; 40(11):973-979.

Peurala M. MWA as a part of occupational health services: review for 1995-1998.

Newsletter Finnish Institute [serial on line] 1999; (special issue). Available from: 
<URL:http://www.occuphealth.fi/ttl/tedotus/tyoterv/199/engl/review06.htm> Out 28].

Pohojonen T. Key components of wok ability and how to maintain them. Newsletter of the Finnish Institute. 1999; Special Issue.

Prado JR (coord.) Iniciação à administração: preceitos básicos. São Paulo: Papelivros; 1985. Os precursores da administração; p.13-34.

Pratt LI, Barling J. Differing between daily events, acute and chronic stressors: a framework and its implications. In: Hurrell Jr. JJ, Murphy LR, Sauter SL, Cooper CL. Occupational stress: issues and developments in research. Great Britan: Taylor \& Francis; 1988. P.41-53.

Rahman M, Sen AK. Effect of job satisfaction on stress, performance and health in self-paced repetitive work. Int Arch Occup Environ Health. 1987; 59:115-121.

Ramirez AJ, Graham J, Richards MA, Cull A, Gregory WM. Mental health of hospital consultants: the effects of stress and satisfaction at work. Lancet 1996; 347:724-728.

Rapôso ALQRS, Matos MMS. Globalização, sociedade civil e Estado: humanização e reequilíbrio para uma gestão descentralizada e auto-regulada. Rev Desenvolv Meio Ambiente. [Periódico on line] sd: [12 telas]. Disponível em <URL:http://www.uol.com.br/cultvox/revistas/prodema/prodema4.dpf> [2001 Out $10]$.

Rigotto RM. Saúde dos trabalhadores e meio ambiente em tempos de globalização e reestruturação produtiva. Rev Bras Saúde Ocup 1998; 93/94(25):9-20.

Robertson IT, Cooper CL, Williams J. The validity of the occupational stress indicator. Work \& Stress 1990; 4(1):29-39. 
Rocha LE. Estresse ocupacional em profissionais de processamento de dados: condições de trabalho e repercussões na vida e saúde dos analistas de sistemas. São Paulo; 1996. [Tese de Doutorado - Faculdade de Medicina da Universidade de São Paulo].

Rohmert W, Landau K. A New technique for job analysis. London: Taylor \& Francis; 1983.

Rubio JAP. Motivacion y satisfaccion laboral: retrospectiva sobre sus formas de analisis. Revista Española de Investigaciones Sociologicas. 197; 80:133-167.

Russel CJ, Bobko P. Moderated regression analysis and Likert scales: too coarse for comfort. Journal Applied Psychology 1992; 77(3):336-342.

San Martín MI, Camporro AM, Guerra AV, Rosa CA, Teijido MR, Ocaña JMG, Ulloa OP. Satisfacción laboral de los profesionales de atención primaria del área 10 del insalud de Madrid. Rev Esp Salud Publica 2000; 74 (2):139-147.

Savonitti BHRA. Qualidade de vida dos idosos institucionalizados. São Paulo; 2000. [Dissertação de Mestrado - Escola de Enfermagem da Universidade de São Paulo].

[SEADE] Fundação Sistema Estadual de Análise de Dados. Guia de investimentos e geração de empregos: energia elétrica. [Artigo on line]. Disponível em URL: <URL:http://www.seade.gov.br/negocios/snpor_03.html> [09 Jan 2001].

Seligmann-Silva E. Desgaste mental no trabalho dominado. São Paulo: Cortez Editora; 1994a. Psicopatologia da Recessão; p.253-293.

Seligmann-Silva E. Introdução: da psicopatologia à psicodinâmica do trabalho: marcos de um percurso. In: Betiol MIS, coordenador. Psicodinâmica do Trabalho: 
contribuições da Escola Dejouriana à análise da relação prazer, sofrimento e trabalho. 3a ed. São Paulo: Atlas; 1994b. p13-19.

Selltiz C, Jahoda M, Deutsch M, CooK SW. Métodos de pesquisa nas relações sociais. $2^{\text {a }}$ ed. São Paulo: Herder/EDUSP; 1967. Planejamento de pesquisa. p.57-90.

Serrano ROL. O setor elétrico e sua inserção num cenário globalizado; 1999 [Monografia de Pós Graduação - MBA em Energia Elétrica - Instituto de Economia da Universidade Federal do Rio de Janeiro]. [Monografia on line]. Disponível em: $<$ URL:http://www.eletrobras.gov.br/mostra_arquivo.asp?id=http://www.eletrobras.g ov.br/downloads/EM_Biblioteca/monografia_ricardo_versao2.pdf\&tipo=biblioteca_ publicacoes $>$ [2000 Set 06].

Siefert K, Jayaratne S, Chess WA. Job satisfaction, burnout, and turnover in health care social workers. Health Soc Work 1991; 16(3):193-202.

Silva RB. Para uma análise da satisfação no trabalho. Sociologia: Problemas e Práticas. 1998; 26:149-178.

Silva AMAPN, Martinez TLR, Almeida M. Associações entre dislipidemia, estresse, padrão de comportamento coronariano tipo A (perfil A), ansiedade e psicodinâmica vocal. Importância dessas associações como fatores de risco da doença arterial coronariana. In: Paiva LM, Silva AMAPN. Medicina Psicossocial $3^{\text {a }}$ ed. São Paulo: Artes Médicas; 1994. P. 642-662.

Sneed J, Herman CM. Influence of job characteristics and organizational commitment on job satisfaction of hospital foodservice employees. J Am Diet Assoc 1990; 90(8):1072-1076.

Spini D, Vollenwyder $\mathrm{N}$, d'Epinay CJL. Is well-being subject to an adaptive process in old age? [Poster on line] Gerontological Society of America Annual 
Meeting; 1999 nov 19-23; San Francisco: Gerontological Society of America. Available from <URL:http://www.unige.ch/CIG/gsa99dsnv.htm> [2001 out 20].

SPSS Inc. SPSS 10.0 for Windows [Computer program]. Chicago: SPSS Inc.; 1999.

Spurgeon A, Gompertz D, Harrington JM. Modifiers of non-especific symptoms in occupational and environmental syndromes. Occup health med 1996; 53:361-366.

Steuer RS. Satisfação no trabalho, conflito e ambigüidade de papéis: estudo junto às enfermeiras de Maternidade Escola do Município de São Paulo. São Paulo; 1989 [Dissertação de mestrado - Faculdade de Saúde Pública da Universidade de São Paulo].

Sutherland VJ, Cooper CL. Sources of work. In: Hurrell Jr. JJ, Murphy LR, Sauter SL, Cooper CL. Occupational stress: issues and developments in research. Great Britan: Taylor \& Francis; 1988. p.3-40.

Swan JA, Moraes LFR, Cooper CL. Developing the occupational stress indicator (OSI) for use in Brazil: a report on the reliability and validity of the translated OSI. Stress Medicine 1993; 9:247-253.

Tanaka OU, Melo C. Avaliação de Programas de Saúde do Adolescente: um modo de fazer [livro on line]. São Paulo: EDUSP; 2001. Coleta e análise de dados. Disponível em:

URL:http://bireme.br/bvs/adolesc/P/textocompleto/adolescente/capitulo/cap03.htm> [2001 Out 23].

Taylor FW. Princípios da Administração Científica. 8a ed. São Paulo: Atlas;1995.

Theorell T. How to deal with stress in organizations? - a health perspective on theory and practice. Scand J Work Environ Health 1999; 25 (6, special issue): 616-624. 
Toppinen S, Kalimo R. Work demands, job satisfaction and burnout in computer professionals. In: Proceedings of the International Symposium from Research to Prevention: managing occupational and environmental health hazards; 1995 mar 20-23. Helsinki; 1995. p.93-95.

Tuomi K, Ilmarinen J, Jahkola A, Katajarinne L, Tulkki A. Índice de capacidade para o trabalho. Trad. de Fischer FM. Helsinki: Instituto de Saúde Ocupacional, 1997.

Vander AJ, Sherman JH, Luciano DS. Fisiologia humana. $4^{\mathrm{a}}$ ed. São Paulo: McGraw-Hill; 1981. Mecanismos de defesa do organismo: imunologia, substâncias estranhas, estresse e envelhecimento; p.607-649.

Vingård E, Theorell T. To measure psychosocial factors in working life. In: Work Life 2000 [article on line]1998 aug 24-26; Copenhagen: National Institute for $\begin{array}{llll}\text { Working } & \text { Life; } & 2000 & \text { Available }\end{array}$ from:<URL:http://www.niwl.se/wl2000/workshops/workshop5/description_em.asp> [2002 Mar 31].

Vroom VH. Work and motivation. New York: John Wiley \& Sons; 1967.

Ware JE. SF-36 Health Survey Update. SPINE. 2000; 25(24):3130-3139.

Ware JE, Kosinski M. Interpreting SF-36 Summary Health Measures: a response [article on line]. Boston: Medical Outcomes Trust; 2001. Available from: <URL:http:www.sf36.com/news/index.shtml?sid=1064> [2001 Dez 15].

Warr P. A conceptual framework for the study of work and mental health. Work Stress. 1994; 8(2):84-97.

Wright TA, Cropanzano R. Psychological well-being and job satisfaction as predictors of job performance. J Occup Health Psychol 2000; 5(1):84-94. 
Wünsch Filho V. Perfis epidemiológicos dos trabalhadores brasileiros. São Paulo; 2001. [Apostila da Disciplina Epidemiologia dos agravos à saúde relacionados ao trabalho, do Departamento de Epidemiologia da Faculdade de Saúde Pública da USP].

Zalewska AM. Health promotion among bank workers: who is primarily in need of health promotion and what types of promoting activities they necessitate. In: Juczynski Z, Oginska-Bulik N, editors. Health Promotion: A Psychosocial Perspective. Poland: Universiy of Lódz Press; 1996. p. 135-143.

Zalewska AM. Achievement and social relations values as conditions of the importance of work aspects and job satisfaction. Int J Occup Saf Ergon 1999a; 5(3):395-416.

Zalewska AM. Job satisfaction and importance of work aspects related to predominant values and reactivity. Int J Occup Saf Ergon 1999b; 5(4):485-511. 
8 - ANEXOS 


\section{ANEXO I - ORGANOGRAMA DA EMPRESA}

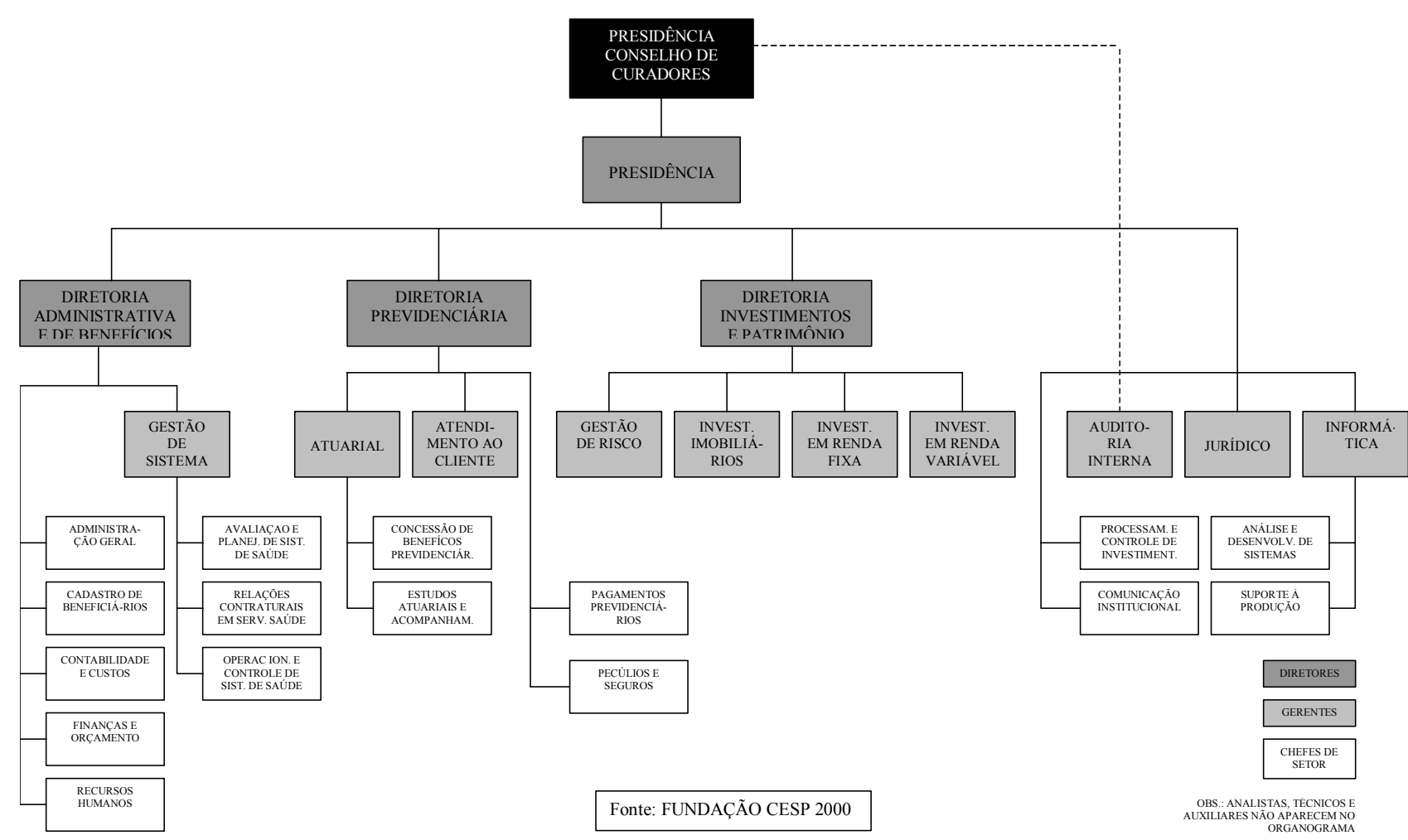




\section{ANEXO II - COMPETÊNCIAS DAS ÁREAS DE TRABALHO}

$\mathrm{Na}$ Fundação CESP existem 4 diretorias, 10 divisões e 16 setores, alguns com pequeno número de funcionários e com chefias em comum. Visando facilitar a compreensão e otimizar a análise dos dados, foi realizado agrupamento sob a denominação "áreas de trabalho" considerando semelhanças nas atribuições e liderança sob a mesma chefia/gerência. Esta descrição das principais competências (devido ao grande número, nem todas as competências de todas as áreas foram elencadas) foi elaborada com base na estrutura organizacional da empresa (FUNDAÇÃO CESP 2000) e em consulta aos empregados das áreas.

- Administração geral: planejar, controlar e realizar as compras e contratações de serviços administrativos. Executar todas as atividades relativas a instalações, móveis e equipamentos de escritórios, telefonia e eletricidade. Administrar os serviços de estacionamento e de veículos da empresa. Controlar a recepção e expedição de correspondências e periódicos da empresa. Administrar e operacionalizar serviços de microfilmagem, reprodução de cópias e arquivo inativo. Administrar a utilização de passagens aéreas, hotéis e transporte para empregados em situações a serviço da empresa.

- Atendimento ao Cliente: planejar, propor e coordenar a execução das políticas de atendimento aos associados. Executar as atividades de atendimento aos associados, seja por meio de atendimento pessoal, por correspondência ou por central de tele-atendimento. Diagnosticar, analisar, propor alternativas e implementar processos de trabalho, bem como buscar a excelência do atendimento em conjunto com outras áreas da empresa.

- Atuarial: gerenciar a concessão dos benefícios previdenciários, bem como a aplicação dos regulamentos dos planos previdenciários. Coordenar a análise do desempenho financeiro e atuarial dos planos previdenciários e de pecúlio por morte, propondo e acompanhando medidas necessárias ao equilíbrio dos planos de custeio. Coordenar as atividades relativas à contagem de tempo de serviço 
executada por empresa especializada, para concessão de aposentadorias. Proceder à análise, cálculo e concessão dos benefícios previdenciários. Analisar, interpretar e aplicar a legislação previdenciária bem como as alterações regulamentares dos planos. Elaborar estudos atuariais, informações e relatórios dos planos previdenciários. Elaborar os cálculos e avaliar as reservas técnicas dos benefícios concedidos e a conceder dos planos previdenciários para contabilização mensal. Controlar as contas de aposentadorias e Fundo Previdenciário dos participantes.

- Auditoria interna: desenvolver trabalhos de auditoria interna nos sistemas administrativos, contábeis e operacionais, convencionais ou computadorizados, assim como avaliar os dispositivos de controle. Verificar a observância às políticas e legislação em vigor, detectando os desvios de sua aplicação, em qualquer órgão da empresa. Elaborar relatório contendo descrição dos problemas apurados, comentando-os e sugerindo medidas corretivas.

- Cadastro de beneficiários: administrar a base de dados do cadastro de associados da empresa, mediante implantação, acompanhamento e controle de informações recebidas. Operacionalizar e controlar as inclusões, alterações e exclusões de participantes nos planos de saúde. Controlar a emissão, orientar a distribuição e recolhimento das carteiras de identificação de beneficiários da empresa. Conceder autorizações para acesso às informações do cadastro e acompanhar as operações realizadas pelos usuários.

- Comunicação institucional: desenvolver e manter as atividades relacionadas a difundir informações referentes aos produtos da empresa. Atender a imprensa externa. Vender espaço para propaganda em publicações internas nas quais existam possibilidades de veiculação, dentro de critérios fixados pela Diretoria. Criar e produzir material gráfico para público interno e externo.

- Contabilidade e custos: responder pelas atividades de contabilidade da empresa, mantendo o registro contábil e o arquivo documental de todos os atos e fatos da 
administração da empresa, bem como aplicar a normatização, observando as exigências legais. Contabilizar e conciliar todos os valores gerados pelas áreas. Analisar e validar a correta destinação dos recebimentos e pagamentos efetuados pelo setor de finanças e orçamento, solicitando as providências cabíveis. Elaborar e distribuir os balancetes e balanços exigidos pelo Poder Público, bem como as análises econômico-financeiras, relatórios contábeis e gerenciais que retratem as operações realizadas pela empresa. Controlar e orientar a atividade contábil, tributária e fiscal da empresa.

- Diretoria: nesta categoria estão compreendidas a Presidência da empresa e as três Diretorias e têm como competências gerais: gerenciar a empresa dentro dos limites estatutários; liderar e coordenar o processo de planejamento estratégico; representar a empresa ativa, passiva, judicial e extrajudicialmente, observadas as disposições do estatuto; supervisionar a administração da empresa, gerir as diversas áreas da empresa; gerenciar a aplicação dos ativos e responder pelas aplicações do patrimônio da empresa, bem como das reservas previdenciárias; gerenciar os planos previdenciários, seguros e serviços de atendimento aos clientes; responder pela análise do desempenho e equilíbrio financeiro e atuarial dos planos previdenciários, seguros e pecúlio; responder pela celebração de contratos de serviços e suprimentos no âmbito da entidade; responder pela gestão de recursos humanos da empresa, pela administração do cadastro de beneficiários e pelos serviços da administração geral; responder pela gestão de sistemas de saúde.

- Finanças e orçamento: gerenciar as operações de contas a receber e a pagar da empresa. Administrar a concessão e recebimento de empréstimo pessoal. Responder pela elaboração dos orçamentos econômico e financeiro dos programas subvencionados e dos recursos próprios da empresa. Elaborar, em conjunto com as demais áreas da empresa, o orçamento anual e trienal. Controlar a execução orçamentária. Apropriar os custos das áreas e programas da empresa. 
- Gestão de sistemas de saúde: administrar os programas de benefícios em saúde, visando a adequação técnica e financeira. Promover a gestão do sistema de saúde visando contribuir para a melhoria da qualidade de vida dos associados e para a boa gestão dos negócios da empresa. Promover a integralização e interação das áreas de saúde curativa, ocupacional, preventiva e educativa. Promover o uso racional dos benefícios em saúde. Acompanhar a evolução e tendências do mercado no segmento saúde, objetivando manter a competitividade do sistema de serviço oferecido.

- Informática: desenvolver, especificar, implantar e manter sistemas de informação. Prestar apoio técnico e orientações aos usuários quanto aos sistemas de informação. Definir, elaborar e documentar programas, bem como realizar testes de rotinas e de integração de sistemas. Estabelecer normas básicas para documentação de sistemas e aplicações, bem como critérios de acesso e segurança de dados. Identificar, analisar, definir e desenvolver documentação, utilitários e aplicações que atendam às necessidades das diversas áreas da empresa. Administrar a rede de microinformática as empresa. Administrar as atividades desenvolvidas pelos prestadores de serviços relacionados à área. Administrar os recursos de informática da empresa, orientando e controlando a utilização dos equipamentos pelos usuários. Gerenciar, desenvolver, coordenar, executar o processo de substituição, modernização e adequação de tecnologia e sistemas em informação da empresa.

- Investimentos e patrimônio: engloba a gestão de risco e os investimentos em renda fixa, renda variável e imobiliários. Elaborar o cenário macroeconômico que servirá de referência para definição das políticas de investimentos da empresa. Elaborar a análise de risco de crédito de instituições financeiras, de papéis privados e de mercado de carteiras de renda fixa e variável.

- Jurídico: coordenar a condução dos assuntos jurídicos da empresa junto a órgãos externos, inclusive no que diz respeito à alterações de normas que regem as atividades da empresa. Defender direitos e interesses da empresa. Informar ou 
orientar as diversas áreas da empresa no que tange a aspectos jurídicos. Elaborar, analisar, revisar e aprovar contratos, convênios e demais documentos que envolvam interesses da empresa.

- Operacionalização e controle de sistemas de saúde: elaborar, divulgar e controlar os cronogramas de processamentos, pagamentos e cobranças dos programas de saúde. Operacionalizar o sistema de credenciamento, abrangendo recebimento e conferência do faturamento, controle de digitação, acompanhamento do processamento, análise de inconsistências, pagamento aos recursos de saúde e controles respectivos. Operacionalizar o sistema de glosas e ajustes. Administrar contratos e efetuar as cobranças e pagamentos. Operacionalizar o sistema de reembolso nas situações cabíveis, abrangendo recebimento, conferência e codificação das solicitações de reembolso, acompanhamento de processamento, análise de inconsistências, créditos e controles.

- Processamento e controle de investimentos: desenvolver atividades de controle e avaliação de rentabilidade dos investimento. Controlar aplicações e recebimentos dos investimentos da empresa. Acompanhar a rentabilidade, liquidez e aspectos legais das aplicações realizadas. Processar a contabilização e a liquidação dos investimentos, bem como elaborar o fluxo de caixa dos investimentos. Desenvolver mecanismos que permitam mensurar a aderência do processo de investimentos em relação à legislação, regulamento, política e parâmetros aprovados pela Diretoria.

- Pagamentos previdenciários, pecúlio e seguros: administrar a folha de pagamento dos planos previdenciários. Controlar a concessão dos benefícios, seus reajustes e manutenções. Analisar e interpretar a legislação previdenciária, tributária e trabalhista relativa à folha de pagamentos. Coordenar as atividades de divulgação, acompanhamento de repasses, liquidação de sinistro, gerenciamento de tabelas e manutenção dos planos de pecúlios e dos programas de seguridade. Acompanhar, avaliar e propor alterações nos regulamentos dos 
planos de pecúlios e seguridade. Elaborar relatórios gerenciais sobre os programas de seguridade e planos de pecúlio.

- Relações contratuais em serviços de saúde: contratar e administrar os serviços médico-hospitalares, odontológicos e correlatos. Avaliar e acompanhar o desenvolvimento dos contratos. Realizar estudos sobre tabelas de serviços e propor base de contratação ou reajuste para os serviços credenciados. Manter atualizado o cadastro de recursos credenciados. Autorizar a realização de atendimento em saúde especiais. Adquirir materiais de órtese e prótese de alto custo para utilização em procedimentos cirúrgicos.

- Recursos humanos: prover e administrar uma política de recursos humanos. Administrar e operacionalizar as atividades de registro e documentação de pessoal e rotinas pertinentes à folha de pagamentos. Desenvolver estudos referentes ao plano de cargos, salários e benefícios. Analisar e implantar alterações decorrentes de acordos sindicais e de exigências legais. Subsidiar e acompanhar o andamento de processos trabalhistas. Propiciar a capacitação e aperfeiçoamento profissional dos empregados da empresa. Planejar, programar e executar as atividades de treinamento e desenvolvimento do quadro de pessoal da empresa. Realizar trabalhos de recrutamento e seleção de pessoal. Acompanhar/coordenar os trabalhos desenvolvidos pela medicina e segurança do trabalho. 


\section{ANEXO III}

\section{ROTEIRO PARA ENTREVISTA EXPLORATÓRIA}

- Apresentação do pesquisador

- Orientação sobre finalidade da pesquisa

- Orientação sobre finalidade da entrevista

- Orientação sobre finalidade do termo de consentimento e solicitação de assinatura do termo de consentimento

- Solicitação de consentimento para gravação da entrevista

- Realização das perguntas:

1 - O que é satisfação no trabalho para você?

2 - Pensando no seu trabalho, quais são as coisas/aspectos que você considerada importantes para você se sentir satisfeito no seu trabalho?

3 - Pensando no seu trabalho, quais são as coisas/aspectos que você considerada importantes para você se sentir insatisfeito no seu trabalho? 


\section{ANEXO 4 - PROPRIEDADES DE MEDIDA DE UM QUESTIONÁRIO}

O uso de dados quantitativos para análise de aspectos subjetivos tem uma de suas questões principais centradas no erro de medida. Para ALCHIERI (2001) o erro está presente em todas as mensurações e é inerente à medida. Neste sentido, erro significa a falha em coletar os dados com precisão (BAILEY 1987), e pode ser devido à forma como o instrumento foi estruturado.

Quando um questionário é construído com base em conceitos ou hipóteses ambíguos ou mal formulados, ou com uma definição operacional pobre destes conceitos, ou ainda com uma redação falha ou duvidosa, então o erro pode ser grande e o estudo utilizando este questionário pode não ser confiável (BAILEY 1987).

Para avaliar o erro inerente a um instrumento, devem ser verificadas as propriedades de medidas do instrumento, ou seja, sua confiabilidade e validade. Caso o instrumento seja construído em uma língua e posteriormente traduzido para ser utilizado em outra língua, ele deve passar por um processo de adaptação transcultural.

\section{- Confiabilidade:}

É a consistência nos escores obtidos por meio de um instrumento de mensuração, ou seja, é a extensão pela qual os diversos itens do instrumento medem um determinado conceito e estão correlacionados entre si (KERLINGER 1986; BAILEY 1987; GSA 1997).

Segundo KERLINGER (1986), a preocupação com a confiabilidade nos instrumentos utilizados vem da dependência existente em relação à mensuração dos dados, e ao fato de que instrumentos usados para obtenção de dados com 
componente psicológico oferecem erros no processo de mensuração, onde a dimensão, tamanho ou grau do erro é definida pela confiabilidade.

A baixa confiabilidade de um instrumento pode ser devida tanto à falta de clareza na definição do conceito que o instrumento está avaliando como à forma como as questões estão redigidas, podendo fazer com que diferentes pessoas entendam as questões de maneiras diversas (BAILEY 1987)

Para verificar a confiabilidade de um instrumento por meio de sua consistência interna, a medida mais utilizada é o Coeficiente Alpha de Cronbach (NUNNALLY 1967; PEREIRA 1999). Este coeficiente analisa as correlações entre os itens que compõe o questionário (LINO 1999).

Segundo LYNN (1999), a confiabilidade de um instrumento pode ser afetada tanto pela abrangência da variável que está sendo medida como pelas condições sob as quais a mensuração está sendo conduzida. Desta forma, a confiabilidade pode variar de acordo com a população ou amostra e com as condições sob as quais a mensuração está sendo realizada e, portanto, a confiabilidade deve ser avaliada a cada nova utilização do instrumento (LYNN 1999).

\section{- Validade:}

Validade refere-se à utilidade do instrumento, isto é, se ele está realmente mensurando aquilo que se deseja mensurar (KERLINGER 1986; HOPPEN et. al. 1996; MENEZES 1998).

Para validação de um instrumento, três aspectos de validade podem ser avaliados preferencialmente: validade de conteúdo, validade de critério e validade de construto (KERLINGER 1986; MENEZES 1998): 


\section{- Validade de conteúdo:}

Avalia a representatividade ou adequação do conteúdo do instrumento de medida, ou seja, avalia se a medida representa aquilo que se quer medir, se abrange os diferentes aspectos do seu objeto, e se não contém elementos que possam ser atribuídos a outros objetos de estudo (KERLINGER 1986; HOPPEN et. al. 1996; MENEZES 1998). Essa avaliação consiste essencialmente em um julgamento, onde juizes, que devem ser peritos no objeto de estudo, vão ajuizar se os itens que compõem o questionário são representativos do que se quer medir (KERLINGER 1986; PASQUALI 1998).

\section{- Validade de critério:}

É realizada por meio da comparação dos resultados do instrumento com uma ou mais variáveis externas ou critérios, conhecidos ou considerados como representativos do atributo em estudo (KERLINGER 1986). Neste tipo de validação, a maior dificuldade é a obtenção de um critério de comparação que possa ser considerado como válido para mensurar aspectos subjetivos (KERLINGER 1986). A validade de critério é estimada estatisticamente, e um instrumento é válido quando seus resultados correspondem aqueles do(s) critério(s) padrão(ões) (GUYATT et. al. 1993; MENEZES 1998).

\section{- Validade de construto:}

Estabelece a ligação entre a teoria (nível conceitual) e as medidas (nível operacional), consistindo em testes estatísticos que verificam a relação entre conceitos teóricos e variáveis a serem medidas (HOPPEN et. al. 1996; MENEZES 1998). O instrumento deve correlacionar-se com outras variáveis correlatas, outras medidas do mesmo construto (validade convergente), mas não deve correlacionar-se com variáveis referentes à medidas de construtos diferentes (validade discriminante) (ROBERTSON et. al. 1990; GSA 1997).

Para alguns autores como KERLINGER (1986) e BAILEY (1987), este é o tipo de validade mais significativo porque liga as práticas e idéias psicométricas às idéias teóricas referentes ao construto que está sendo avaliado. 


\section{- Adaptação transcultural:}

Compreende tanto a adaptação do instrumento como a sua validação na língua alvo.

- Adaptação transcultural:

Consiste na tradução do instrumento, compreendendo as seguintes etapas (GUILLEMIN 1995; CICONELLI 1997):

a) tradução: produção de diversas traduções por tradutores da língua nativa e da língua alvo;

b) versão da tradução para o idioma original (back-translation): produção de versões do instrumento traduzido para a língua nativa original;

c) revisão por um comitê: um comitê multidisciplinar, incluindo especialistas, bilingües e leigos, compara a versão de origem e a final, buscando garantir que esta seja compreensiva e tenha equivalência transcultural (semântica, idiomática, experimental e conceitual);

d) pré-teste: aplicação do instrumento para verificar sua equivalência e avaliar erros e desvios na tradução;

e) ponderação de escores: adaptação da ponderação de escores para o contexto cultural, caso isso seja relevante.

- Validação transcultural:

Consiste na demonstração das propriedades de medida de um instrumento (confiabilidade e validade) em um contexto cultural específico (GUILLEMIN 1995; CICONELLI 1999). 


\section{ANEXO V - QUESTIONÁRIO 1}

\section{IDENTIFICAÇÃO}

Este questionário será utilizado como parte de uma pesquisa sobre as relações entre satisfação no trabalho e saúde.

Por favor, responda cuidadosamente todas as questões não deixando nenhuma em branco.

Havendo dúvidas ou necessidade de mais informações sinta-se à vontade para buscar maiores esclarecimentos junto à responsável pela pesquisa, Maria Carmen Martinez, pelo telefone 0000-0000 ou pessoalmente no $\mathrm{X}^{\mathrm{o}}$ andar da Xxxxxxxxx.

Código de controle

Setor de trabalho:

Cargo atual:

Tempo na empresa:

Sexo: F( ) M( ) Idade:

Escolaridade:

$1^{\mathrm{o}}$ grau incompleto (não concluiu a $8^{\mathrm{a}}$ série)

$1^{\mathrm{o}}$ grau completo (concluiu $8^{\mathrm{a}}$ série

$2^{\circ}$ grau incompleto (não terminou o curso colegial ou técnico)

$2^{\circ}$ grau completo (concluiu o $3^{\circ}$ ano do colegial ou técnico)

$3^{\circ}$ grau incompleto (iniciou faculdade mas não ( ) terminou)

$3^{\circ}$ grau completo (concluiu a faculdade)

Pós-graduação incompleta (iniciou mestrado ou ( ) doutorado mas não concluiu)

Pós-graduação completa (concluiu mestrado ou ( ) doutorado)
Estado civil:

Solteiro (a)

Casado (a) ou com companheira (o) ............. ( )

Separado (a) ou

divorciado (a).................. ( )

Viúvo (a) ......................... ( ) 


\section{ANEXO VI - QUESTIONÁRIO 2 \\ Escala Satisfação no Trabalho do OSI - Occupational Stress Indicator}

Instrumento elaborado por Cooper (ROBERTSON et. al. 1990), traduzido e validado para o português por Swan, Moraes e Cooper (SWAN et. al. 1993). Versão em português da escala Satisfação no Trabalho disponível em Couto (2000)

Esta parte do questionário fornecerá dados que possibilitarão caracterizar a satisfação com o trabalho de uma forma geral e a satisfação com aspectos específicos do trabalho.

Por favor, dê sua opinião honesta e responda todas as questões.

Em cada uma das próximas questões, assinale a alternativa que mais se aproxima do seu sentimento em relação ao aspecto do trabalho em questão. Responda fazendo um círculo em torno do número em cada questão, de acordo com a seguinte escala:

6 - enorme satisfação

5 - muita satisfação

4 - alguma satisfação

3 - alguma insatisfação

2 - muita insatisfação

1 - enorme insatisfação

\section{Como você se sente em relação ao seu trabalho?}

\begin{tabular}{|l|l|l|l|l|l|l|l|}
\hline 1. $\begin{array}{l}\text { Comunicação e forma de fluxo de informações na } \\
\text { empresa em que você trabalha }\end{array}$ & $\mathbf{6}$ & $\mathbf{5}$ & $\mathbf{4}$ & $\mathbf{3}$ & $\mathbf{2}$ & $\mathbf{1}$ \\
\hline $\begin{array}{l}\text { 2. Seu relacionamento com outras pessoas na empresa em } \\
\text { que trabalha }\end{array}$ & $\mathbf{6}$ & $\mathbf{5}$ & $\mathbf{4}$ & $\mathbf{3}$ & $\mathbf{2}$ & $\mathbf{1}$ \\
\hline $\begin{array}{l}\text { O sentimento que você tem a respeito de como seus } \\
\text { esforços são avaliados }\end{array}$ & $\mathbf{6}$ & $\mathbf{5}$ & $\mathbf{4}$ & $\mathbf{3}$ & $\mathbf{2}$ & $\mathbf{1}$ \\
\hline 4. O conteúdo do trabalho que você faz & $\mathbf{6}$ & $\mathbf{5}$ & $\mathbf{4}$ & $\mathbf{3}$ & $\mathbf{2}$ & $\mathbf{1}$ \\
\hline 5. O grau em que você se sente motivado por seu trabalho & $\mathbf{6}$ & $\mathbf{5}$ & $\mathbf{4}$ & $\mathbf{3}$ & $\mathbf{2}$ & $\mathbf{1}$ \\
\hline 6. Oportunidades pessoais em sua carreira atual & $\mathbf{6}$ & $\mathbf{5}$ & $\mathbf{4}$ & $\mathbf{3}$ & $\mathbf{2}$ & $\mathbf{1}$ \\
\hline 7. O grau de segurança no seu emprego atual & 6 & $\mathbf{5}$ & $\mathbf{4}$ & $\mathbf{3}$ & $\mathbf{2}$ & $\mathbf{1}$ \\
\hline
\end{tabular}




\begin{tabular}{|c|c|c|c|c|c|c|}
\hline $\begin{array}{l}\text { 8. A extensão em que você se identifica com a imagem } \\
\text { externa ou realizações de sua empresa }\end{array}$ & 6 & 5 & 4 & 3 & 2 & 1 \\
\hline 9. O estilo de supervisão que seus superiores usam & 6 & 5 & 4 & 3 & 2 & 1 \\
\hline $\begin{array}{l}\text { 10. A forma pela qual mudanças e inovações são } \\
\text { implementadas }\end{array}$ & 6 & 5 & 4 & 3 & 2 & 1 \\
\hline 11. O tipo de tarefa e o trabalho em que você é cobrado & 6 & 5 & 4 & 3 & 2 & 1 \\
\hline $\begin{array}{l}\text { 12. O grau em que você sente que você pode crescer e se } \\
\text { desenvolver em seu trabalho }\end{array}$ & 6 & 5 & 4 & 3 & 2 & 1 \\
\hline 13. A forma pela qual os conflitos são resolvidos & 6 & 5 & 4 & 3 & 2 & 1 \\
\hline $\begin{array}{l}\text { 14. As oportunidades que seu trabalho lhe oferece no } \\
\text { sentido de você atingir suas aspirações e ambições }\end{array}$ & 6 & 5 & 4 & 3 & 2 & 1 \\
\hline 15. O seu grau de participação em decisões importantes & 6 & 5 & 4 & 3 & 2 & 1 \\
\hline $\begin{array}{l}\text { 16. O grau em que a organização absorve as } \\
\text { potencialidades que você julga ter }\end{array}$ & 6 & 5 & 4 & 3 & 2 & 1 \\
\hline $\begin{array}{l}\text { 17. O grau de flexibilidade e de liberdade que você julga } \\
\text { ter em seu trabalho }\end{array}$ & 6 & 5 & 4 & 3 & 2 & 1 \\
\hline $\begin{array}{l}\text { 18. O clima psicológico que predomina na empresa em que } \\
\text { você trabalha }\end{array}$ & 6 & 5 & 4 & 3 & 2 & 1 \\
\hline $\begin{array}{l}\text { 19. Seu salário em relação à sua experiência e à } \\
\text { responsabilidade que tem }\end{array}$ & 6 & 5 & 4 & 3 & 2 & 1 \\
\hline $\begin{array}{l}\text { 20. A estrutura organizacional da empresa em que você } \\
\text { trabalha }\end{array}$ & 6 & 5 & 4 & 3 & 2 & 1 \\
\hline 21. O volume de trabalho que você tem para desenvolver & 6 & 5 & 4 & 3 & 2 & 1 \\
\hline $\begin{array}{l}\text { 22. O grau em que você julga estar desenvolvendo suas } \\
\text { potencialidades na empresa em que trabalha }\end{array}$ & 6 & 5 & 4 & 3 & 2 & 1 \\
\hline
\end{tabular}




\title{
ANEXO VII - QUESTIONÁRIO 3
}

\section{SF 36 - Versão em português do Medical Outcomes Study 36 - Item short form health survey}

\begin{abstract}
Este questionário vem sendo utilizado em vários países do mundo desde 1991, tendo sido traduzido e validado para o português em 1997 por Rozana Mesquita Ciconelli em tese para obtenção do título de doutor em medicina pela Universidade Federal de São Paulo.
\end{abstract}

Instruções: Esta parte da pesquisa questiona você sobre sua saúde. Estas informações nos manterão informados de como você se sente e quão bem você é capaz de fazer suas atividades de vida diária. Responda cada questão marcando a resposta como indicado. Caso você esteja inseguro em como responder, por favor tente responder o melhor que puder.

1. Em geral, você diria que sua saúde é:

(circule uma)

2.

Excelente

Muito boa

Boa

Ruim

Muito ruim

2. Comparada a um ano atrás, como você classificaria sua saúde em geral, agora?

Muito melhor agora do que a um ano atrás

Um pouco melhor agora do que a um ano atrás

Quase a mesma de um ano atrás

Um pouco pior agora do que há um ano atrás 
3. Os seguintes itens são sobre atividades que você poderia fazer atualmente durante um dia comum. Devido a sua saúde, você tem dificuldade para fazer essas atividades? Neste caso, quanto?

\begin{tabular}{|c|c|c|c|}
\hline Atividades & $\begin{array}{l}\text { Sim. } \\
\text { Dificulta } \\
\text { muito }\end{array}$ & $\begin{array}{l}\text { Sim. } \\
\text { Dificulta } \\
\text { um pouco }\end{array}$ & $\begin{array}{l}\text { Não. Não } \\
\text { dificulta de } \\
\text { modo algum }\end{array}$ \\
\hline $\begin{array}{l}\text { a) Atividades vigorosas, que exigem muito esforço, } \\
\text { tais como correr, levantar objetos pesados, } \\
\text { participar em esportes árduos }\end{array}$ & 1 & 2 & 3 \\
\hline $\begin{array}{l}\text { b) Atividades moderadas, tais como mover uma } \\
\text { mesa, passar aspirador de pó, jogar bola, varrer a } \\
\text { casa }\end{array}$ & 1 & 2 & 3 \\
\hline c) Levantar ou carregar mantimentos & 1 & 2 & 3 \\
\hline d) Subir vários lances de escada & 1 & 2 & 3 \\
\hline e) Subir um lance de escada & 1 & 2 & 3 \\
\hline f) Curvar-se, ajoelhar-se ou dobrar-se & 1 & 2 & 3 \\
\hline g) Andar mais de 1 quilômetro & 1 & 2 & 3 \\
\hline h) Andar vários quarteirões & 1 & 2 & 3 \\
\hline i) Andar um quarteirão & 1 & 2 & 3 \\
\hline Tomar banho ou vestir-se & 1 & 2 & 3 \\
\hline
\end{tabular}


4. Durante as últimas 4 semanas, você teve algum dos seguintes problemas com o seu trabalho ou com alguma atividade diária regular, como conseqüência de sua saúde física?

(circule uma em cada linha)

\begin{tabular}{|c|c|c|}
\hline & Sim & Não \\
\hline $\begin{array}{l}\text { a) Você diminuiu a quantidade de tempo que se dedicava ao } \\
\text { seu trabalho ou a outras atividades? }\end{array}$ & 1 & 2 \\
\hline b) Realizou menos tarefas do que você gostaria? & 1 & 2 \\
\hline $\begin{array}{l}\text { c) Esteve limitado no seu tipo de trabalho ou em outras } \\
\text { atividades? }\end{array}$ & 1 & 2 \\
\hline $\begin{array}{l}\text { d) Teve dificuldade de fazer seu trabalho ou outras atividades } \\
\text { (p.ex.: necessitou de um esforço extra)? }\end{array}$ & 1 & 2 \\
\hline
\end{tabular}

5. Durante as últimas 4 semanas, você teve algum dos seguintes problemas com o seu trabalho ou outra atividade regular diária, como conseqüência de algum problema emocional (como sentir-se deprimido ou ansioso)?

(circule uma em cada linha)

\begin{tabular}{|c|c|c|}
\hline & Sim & Não \\
\hline $\begin{array}{l}\text { a) Você diminuiu a quantidade de tempo que dedicava ao seu } \\
\text { trabalho ou a outras atividades? }\end{array}$ & 1 & 2 \\
\hline b) Realizou menos tarefas do que você gostaria? & 1 & 2 \\
\hline $\begin{array}{l}\text { c) Não trabalhou ou não fez qualquer das atividades com tanto } \\
\text { cuidado como geralmente faz? }\end{array}$ & 1 & 2 \\
\hline
\end{tabular}


6. Durante as últimas 4 semanas, de que maneira sua saúde física ou problemas emocionais interferiram nas suas atividades sociais normais, em relação a família, vizinhos, amigos ou em grupo?

(circule uma)

De forma nenhuma 1

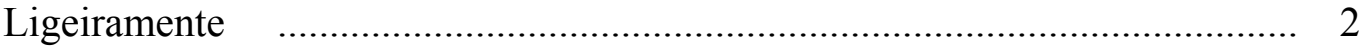

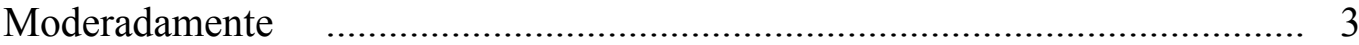

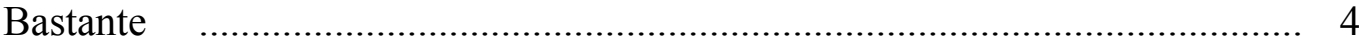

Extremamente

7. Quanta dor no corpo você teve durante as últimas 4 semanas? (circule uma) Nenhuma

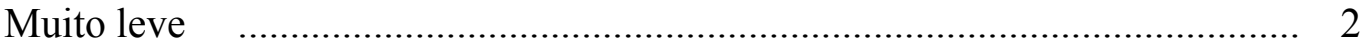

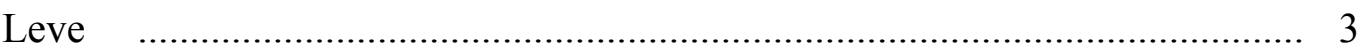

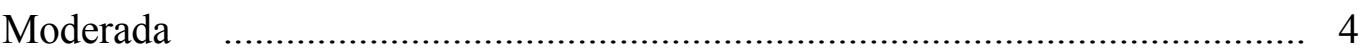

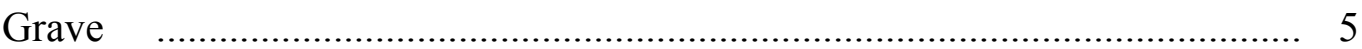

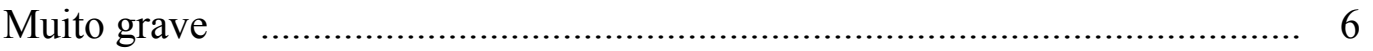

8. Durante as últimas 4 semanas, quanto a dor interferiu com o seu trabalho normal (incluindo tanto o trabalho fora de casa como dentro de casa)?

(circule uma)

De maneira alguma 1

Um pouco

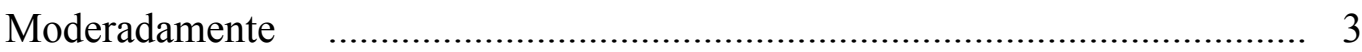

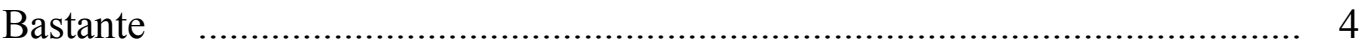

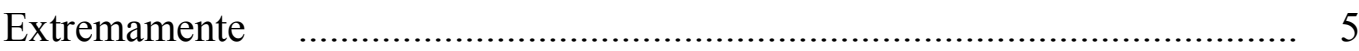


9. Estas questões são sobre como você se sente e como tudo tem acontecido com você durante as últimas 4 semanas. Para cada questão, por favor dê uma resposta que mais se aproxime da maneira como você se sente. Em relação as últimas 4 semanas.

(circule um número para cada linha)

\begin{tabular}{|c|c|c|c|c|c|c|}
\hline & $\begin{array}{l}\text { Todo } \\
\text { tempo }\end{array}$ & $\begin{array}{c}\text { A maior } \\
\text { parte do } \\
\text { tempo }\end{array}$ & $\begin{array}{l}\text { Uma boa } \\
\text { parte to } \\
\text { tempo }\end{array}$ & $\begin{array}{c}\text { Alguma } \\
\text { parte do } \\
\text { tempo }\end{array}$ & $\begin{array}{l}\text { Uma } \\
\text { pequena } \\
\text { parte do } \\
\text { tempo }\end{array}$ & Nunca \\
\hline $\begin{array}{l}\text { a) Quanto tempo você tem se } \\
\text { sentido cheio de vigor, cheio } \\
\text { de vontade, cheio de força? }\end{array}$ & 1 & 2 & 3 & 4 & 5 & 6 \\
\hline $\begin{array}{l}\text { b) Quanto tempo você tem se } \\
\text { sentido uma pessoa muito } \\
\text { nervosa? }\end{array}$ & 1 & 2 & 3 & 4 & 5 & 6 \\
\hline $\begin{array}{l}\text { c) Quanto tempo você tem se } \\
\text { sentido tão deprimido que } \\
\text { nada pode animá-lo? }\end{array}$ & 1 & 2 & 3 & 4 & 5 & 6 \\
\hline $\begin{array}{l}\text { d) Quanto tempo você tem se } \\
\text { sentido calmo ou tranqüilo? }\end{array}$ & 1 & 2 & 3 & 4 & 5 & 6 \\
\hline $\begin{array}{l}\text { e) Quanto tempo você tem se } \\
\text { sentido com muita energia? }\end{array}$ & 1 & 2 & 3 & 4 & 5 & 6 \\
\hline $\begin{array}{l}\text { f) Quanto tempo você tem se } \\
\text { sentido desanimado } \\
\text { abatido? }\end{array}$ & 1 & 2 & 3 & 4 & 5 & 6 \\
\hline $\begin{array}{l}\text { g) Quanto tempo você tem se } \\
\text { sentido esgotado? }\end{array}$ & 1 & 2 & 3 & 4 & 5 & 6 \\
\hline $\begin{array}{l}\text { h) Quanto tempo você tem se } \\
\text { sentido uma pessoa feliz? }\end{array}$ & 1 & 2 & 3 & 4 & 5 & 6 \\
\hline $\begin{array}{l}\text { i) Quanto tempo você tem se } \\
\text { sentido cansado? }\end{array}$ & 1 & 2 & 3 & 4 & 5 & 6 \\
\hline
\end{tabular}


10. Durante as últimas 4 semanas, quanto do seu tempo a sua saúde física ou problemas emocionais interferiram com as suas atividades sociais (como visitar amigos, parentes, etc.)?

(circule uma)

Todo o tempo

A maior parte do tempo

2

Alguma parte do tempo

3

Uma pequena parte do tempo

4

Nenhuma parte do tempo

5

11. o quanto verdadeiro ou falso é cada uma das afirmações para você?

(circule um número em cada linha)

\begin{tabular}{l|c|c|c|c|c}
\hline & $\begin{array}{c}\text { Definitiva- } \\
\text { mente } \\
\text { verdadeira }\end{array}$ & $\begin{array}{c}\text { A maioria } \\
\text { das vezes } \\
\text { verdadeira }\end{array}$ & Não sei & $\begin{array}{c}\text { A maioria } \\
\text { das vezes } \\
\text { falsa }\end{array}$ & $\begin{array}{c}\text { Definitiva- } \\
\text { mente falsa }\end{array}$ \\
\hline a) $\begin{array}{l}\text { Eu costumo adoecer } \\
\text { um pouco mais } \\
\text { facilmente que as } \\
\text { outras pessoas }\end{array}$ & 1 & 2 & 3 & 4 & 5 \\
\hline b) Eu sou tão saudável \\
$\begin{array}{l}\text { quanto qualquer pessoa } \\
\text { que eu conheço }\end{array}$
\end{tabular}




\section{ANEXO VIII - QUESTIONÁRIO 4}

\section{ÍNDICE DE CAPACIDADE PARA O TRABALHO}

Esse questionário foi elaborado pelo Instituto de Saúde Ocupacional da Finlândia, Helsinki; traduzido e adaptado por pesquisadores das seguintes instituições: Faculdade de Saúde Pública da Universidade de São Paulo: Departamento de Saúde Ambiental e Centro de Estudos e Pesquisas sobre o Envelhecimento; Universidade Federal de São Carlos: Departamento de Enfermagem; Fundação Oswaldo Cruz - Escola Nacional de Saúde Pública: Centro de Estudos em Saúde do Trabalhador e Ecologia Humana.

Por favor, responda cuidadosamente a todas as questões, assinalando a alternativa que você acha que melhor reflete a sua. Não deixe nenhuma questão sem responder.

Suponha que a sua melhor capacidade para o trabalho tem um valor igual a 10 pontos.

Assinale com um $X$ um número na escala de zero a dez, quantos pontos você daria para a sua capacidade de trabalho atual.

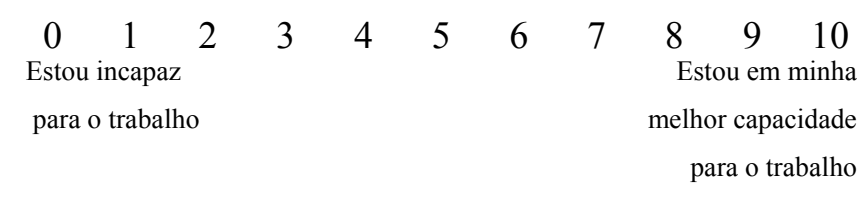

Como você classificaria sua capacidade atual para o trabalho em relação às exigências físicas do seu trabalho? (Por exemplo, fazer esforço físico com partes do corpo)

Muito boa

Boa

Moderada

Baixa

Muito baixa

Como você classificaria sua capacidade atual para $o$ trabalho em relação às exigências mentais do seu trabalho? (Por exemplo, interpretar fatos, resolver problemas, decidir a melhor forma de fazer?

Muito boa

Boa

Moderada

Baixa

Muito baixa 
Na sua opinião quais das lesões por acidentes ou Doenças citadas abaixo você possui atualmente. Marque também aquelas que foram confirmadas pelo médico.

01.Lesão nas costas Em minha Diagnóstico

02.Lesão nos braços/mãos

03.Lesão nas pernas/pés

04.Lesão em outras partes do corpo

Onde? Que tipo de lesão ?

05. Doença na parte superior das costas ou da região do pescoço, com dores freqüentes

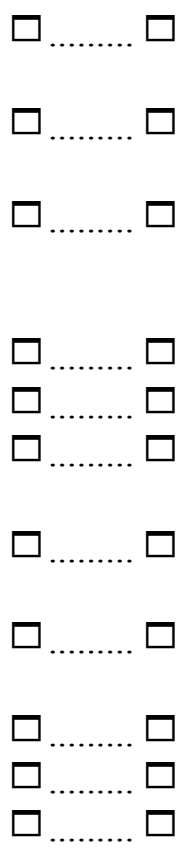

06. Doença na parte inferior das costas com dores freqüentes

07. Dor nas costas que se irradia para a perna (ciática)

08. Doença músculo-esquelética afetando os membros (braços e pernas) com dores freqüentes

09. Artrite reumatóide

10. Outra doença músculo-esquelética... Qual?

11. Hipertensão arterial (pressão alta) ...

12. Doença coronariana, dor no peito durante exercício (angina pectoris)..

13. Infarto do miocárdio, trombose coronariana

14. Insuficiência cardíaca

15. Outra doença cardiovascular? Qual?

16. Infecções repetidas no trato respiratório (incluindo amigdalite, sinusite aguda, bronquite aguda)

17.Bronquite crônica

18. Sinusite crônica

19.Asma

20.Enfisema

21. Tuberculose pulmonar

22. Outra doença respiratória Qual?

23. Distúrbio emocional severo (ex.: depressão severa)

24. Distúrbio emocional leve (ex.: depressão leve, tensão, ansiedade, insônia)

25. Problema ou diminuição na audição
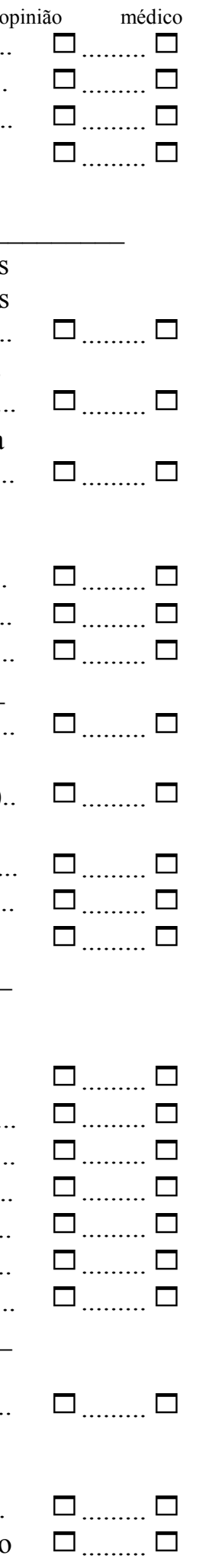

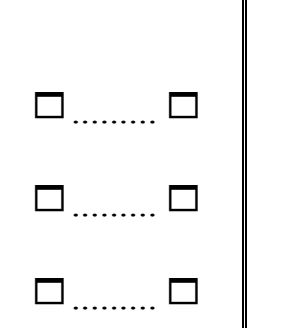
34. Outra doença digestiva Qual?
35. Infecção das vias urinárias

26. Doença ou lesão da visão (não)

Em minha Diagnóstico opinião médico assinale se apenas usa óculos e/ou lentes de contato de cgrau)

27.Doença neurológica (acidente vascular cerebral ou "derrame", neuralgia, enxaqueca, epilepsia ....

28. Outra doença neurológia ou dos orgãos dos sentidos Qual?

29.Pedras ou doença da vesícula biliar 30.Doença do pâncreas ou do fígado .. 31. Úlcera gástrica ou duodenal

32. Gastrite ou irritação duodenal ....... 33. Colite ou irritação do colon

36. Doença dos rins

37. Doença nos genitais e aparelho reprodutor (ex.: problemas nas trompas ou próstata)

38. Outra doença geniturinária

39. Alergia, eczema

40. Outra erupção Qual?

41. Outra doença da pele Qual?

42. Tumor benigno

43. Tumor maligno (câncer) Onde?

44. Obesidade

45. Diabetes

46.Bócio ou outra doença da tiróide....

47. Outra doença endócrina ou metabólica.

Qual?

48. Anemia.

49. Outra doença no sangue

50. Defeito de nascimento Qual?

51. Outro problema ou doença Qual?
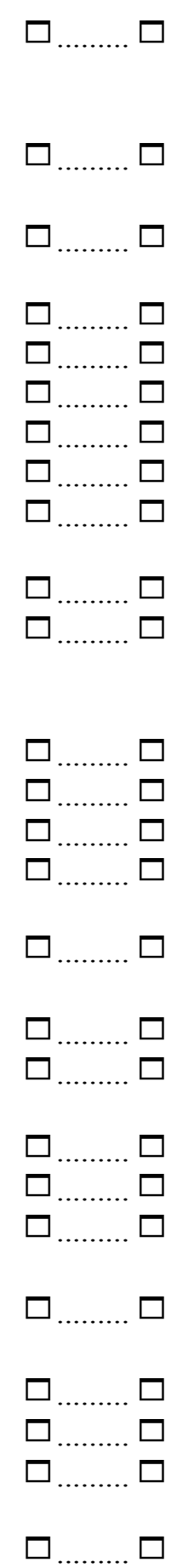
Sua lesão ou doença é um impedimento para seu trabalho atual? (Você pode marcar mais de uma resposta nesta pergunta)

Não há impedimento/

Eu não tenho doenças

Eu sou capaz de fazer meu trabalho, mas ele me causa alguns sintomas

Algumas vezes preciso diminuir meu ritmo de trabalho ou mudar meus métodos de trabalho

Freqüentemente preciso diminuir meu ritmo de trabalho ou mudar meus métodos de trabalho.

Por causa de minha doença sinto-me capaz de trabalhar apenas em tempo parcial

Na minha opinião estou totalmente incapacitado para trabalhar

Quantos dias inteiros você esteve fora do trabalho devido a problemas de saúde, consulta médica ou para fazer exame durante os últimos 12 meses?

Nenhum

Até 9 dias

De 10 a 24 dias

De 25 a 99 dias

De 100 a 365 dias

Considerando sua saúde, você acha que será capaz de daqui a 2 anos fazer seu trabalho atual? É improvável.

Não estou muito certo

Bastante provável
Recentemente você tem conseguido apreciar suas atividades diárias?

Sempre

Quase sempre

Às vezes

Raramente

Nunca

Recentemente você tem se sentido ativo e alerta?

Sempre

Quase sempre

Às vezes

Raramente

Nunca

Recentemente você tem se sentido cheio de esperança para o futuro?

Continuamente

Quase sempre.

Às vezes

Raramente

Nunca 


\section{ANEXO IX - GLOSSÁRIO DE TERMOS ESTATÍSTICOS}

Amostra não probabilística: neste tipo de amostra não é conhecida a probabilidade pela qual um indivíduo é escolhido do universo de estudo para compor a amostra. Tem como desvantagem não assegurar que a amostra seja representativa de uma grande população. A amostra probabilística acidental ou por conveniência é aquela na qual o pesquisador considera os casos que aparecem (SELLTIZ 1967; BAILEY 1987)

Coeficiente Alpha de Cronbach é a fórmula básica para determinar a confiabilidade baseada na consistência interna (NUNNALLY 1967). A consistência interna indica o quão fortemente os itens de um instrumento estão relacionados a cada um dos outros itens (DAWSON-SAUNDERS e TRAPP 1994). O Alpha de Cronbach é baseado na correlação entre os itens, trabalhando as covariâncias e variâncias internas das medidas (PEREIRA 1999; SPSS 1999). O valor do Alpha de Cronbach é dado em um escore que varia de 0,0 a 1,0, onde quanto mais próximo de 1,0, maior a consistência do instrumento (DAWSON-SAUNDERS e TRAPP 1994).

Coeficiente de Correlação de Spearman: este coeficiente é usado para descrever a relação entre duas variáveis ordinais (ou uma ordinal e outra numérica) com distribuição não normal, onde os valores de cada variável são ordenados do menor para o maior e o coeficiente de correlação é computado sobre essas ordenações (SPSS 1999). O resultado pode variar $-1 \mathrm{a}+1$, quando o valor está próximo da unidade indica perfeita correlação entre as ordenações dos valores, e valores negativos indicam que esta correlação é inversa (DAWSON-SAUNDERS e TRAPP 1994). 
Distribuição normal: é a distribuição simétrica dos dados ao redor do ponto central, onde média, mediana e moda têm valores iguais, $68 \%$ da população está incluída entre 1 desvio padrão, 95,5\% da população está incluída entre 2 desvios padrão e 99,7\% da população está incluída entre 3 desvios padrão (DORIA FILHO 1999).

Estudo experimental: é aquele onde trabalha-se comparando dois grupos formados aleatoriamente, sendo que no grupo chamado experimental é feita uma intervenção que consiste na aplicação ou supressão do fator suspeito, visando a obtenção do efeito correspondente (ALMEIDA FILHO e ROUQUAYROL 1992).

Estudo longitudinal: é o estudo epidemiológico no qual causa e efeito são considerados em momentos históricos sucessivos e, por isso, permitem identificação da direção causal (ALMEIDA FILHO e ROUQUAYROL 1992)

Estudo transversal: é o estudo epidemiológico no qual fator e efeito são observados num mesmo momento histórico. Este tipo de estudo é usado para testas hipóteses de associação, sem definir seu caráter etiológico, devido à simultaneidade da ocorrência da informação sobre o sintoma/doença e fator associado (ALMEIDA FILHO e ROUQUAYROL 1992)

Kolmogorov-Smirnov: o teste de Kolmogorov-Smirnov é realizado para verificar se uma amostra têm distribuição normal ou não, e seu resultado é baseado sobre a maior diferença absoluta entre a distribuição cumulativa teórica e a observada (SPSS 1999).

Kruskal-Wallis: este teste não-paramétrico verifica se diversas amostras independentes são da mesma população, e é baseado na análise da ordenação dos valores observados (SPSS 1999; DAWSON-SAUNDERS e TRAPP 1994).

Mann-Whitney: é um teste não paramétrico equivalente ao teste t. Testa se duas amostras independentes são da mesma população, e é baseado no cálculo de locação dos valores em postos (ranks) e não como os valores reais (DORIA FILHO 1999; SPSS 1999). 
Nível de significância estatística: dá a probabilidade de rejeitar incorretamente a hipótese nula quando ela é verdadeira (DAWSON-SAUNDERS e TRAPP 1994):

Hipótese nula:

Ho: média de $\mathrm{X}_{1}=$ média de $\mathrm{X}_{2}$

Hipótese alternativa:
Ha: média de $\mathrm{X}_{1} \neq$ média de $\mathrm{X}_{2}$

Qui-quadrado é um teste de significância estatística aplicado a dados qualitativos, e que pode ser usado para testar se as proporções encontradas no grupo estudado diferem das esperadas na população total (DORIA FILHO 1999; BERQUÓ et.at. 1987))

Teste exato de Fischer: este teste é usado como uma alternativa ao Qui-quadrado para examinar associações quando o tamanho da amostra é pequeno $(n<20)$ ou quando uma casela da tabela tem freqüência esperada menor que 5 (DAWSONSAUNDERS e TRAPP 1994; SPSS 1999). "Ele calcula a probabilidade de que a tabela de contingência usada tenha sido obtida por acaso e, para tanto, sem mudar os totais das colunas e linhas, ele constrói todas as tabelas possíveis" (DORIA FILHO 1999).

Teste post hoc: pode determinar quais as médias que diferem, demonstrando quais as categorias da variável que determinam as diferenças significativas (SPSS 1999).

Teste t: este teste é usado para comparar as médias de duas variáveis quantitativas contínuas com distribuição normal (DORIA FILHO 1999; SPSS 1999)

Variância: é a medida da dispersão dos valores de uma variável em torno da média (SPSS 1999) 


\section{ANEXO X - ROTEIRO PARA ANÁLISE ERGONÔMICA DO}

\section{TRABALHO}

Tradução do roteiro para aplicação do método AET - Análise Ergonômica do Trabalho de ROHMERT e LANDAU (1983), disponível em BELLUSCI (1998).

\section{INTRODUÇÃO À APLICAÇÃO DOS CÓDIGOS DE CLASSIFICAÇÃo}

As características do trabalho analisadas com o AET são avaliadas como meio de padronizar códigos de classificação destinados a obter informações comparáveis sobre o trabalho, em período relativamente curto.

Códigos com múltiplos níveis são usados para avaliar a extensão do stress - Códigos de Significância (S), Exclusividade (E), Duração (D) e Freqüência do stress. Código único e múltiplos níveis são usados em nível de escala nominal para classificar as condições do design do trabalho.

Ao classificar uma característica se usa somente o código correspondente a ela.

O uso do código Significância mostra a importância de um aspecto da produção do trabalho em relação a outros.

O código Exclusivo é relacionado com uma questão específica. Ele torna possível a classificação de um fator não adequado ao código padrão. São duas variantes neste código:

a) Código de classificação (escala de classificação nominal) - Múltiplas propriedades em relação a um instrumento de trabalho são verificadas, sendo que a mais importante precisa ser selecionada.

b) B) Código de esforço relacionado (escala de nível numérico) - É usado para descrever o esforço associado com o stress no trabalho da pessoa. O código é graduado de 0 a 5 , que indicam o aumento do esforço.

O código Duração é baseado em um período de oito horas. Seja qual for o período de trabalho real, ele será assumido como se fosse de oito horas e a proporção do tempo gasto com cada tarefa será convertido para uma proporção de tempo. A intenção é possibilitar a comparação do conteúdo do trabalho mesmo com diferentes períodos de tempo de trabalho. 
O código Freqüência é usado para relatar a freqüência com que cada elemento do trabalho ocorre quando outros fatores do trabalho são descritos.

O código Alternativa pergunta somente sobre a presença de um fator específico. A característica em questão se aplica ao trabalho?

\section{F - FREQÜÊNCIA}

0 - Não se aplica

1 - Muito pouco freqüente

2 - Pouco freqüente

3 - Médio

4 - Freqüente

5 - Muito freqüente

\section{S - SIGNIFICÂNCIA}

0 - Não se aplica

1 - Muito pouca

2 - Pouca

3 - Médio

4 - Alta

5 - Muito alta

A - ALTERNATIVA (presença)

0 - Não se aplica

1 - Se aplica

D - DURAÇÃO

0 - Não se aplica (muito pouco freqüente)

1 - Menos de 10\% (50 min) do período de trabalho

2 - Menos de 30\% (160 min) do período de trabalho - 2h40 min

3 - Entre 30\% (160 $\mathrm{min}$ ) e 60\% (320 $\mathrm{min}$ ) do período de trabalho - 5h20 min

4 - Mais do que 60\% (320 $\mathrm{min}$ ) do período de trabalho - 5h20 min

5 - Contínuo durante todo o período de trabalho $-8 \mathrm{~h}$ 
A parte A, composta por 143 questões aborda o homem e o sistema de trabalho, ou seja, os objetos, instrumentos e o ambiente de trabalho.

A parte B analisa, através de 31 quesitos, a tarefa relacionada a objetos materiais de trabalho, ao processamento de informações e planejamento, a outras pessoas e ao número e freqüência de repetição de tarefas.

A parte $\mathrm{C}$ coleta dados, através de 42 itens, para análise das exigências do trabalho no que diz respeito a recepção de informação, decisões, estresse devido a posição e movimentação no trabalho.

\title{
ROTEIRO PARA ANÁLISE DO TRABALHO (AET)
}

\author{
A - ANÁLISE DO TRABALHO \\ A - 1 - OBJETOS DE TRABALHO
}

Durante que proporção do tempo o trabalhador desempenha tarefas envolvendo:

1 D Objetos de trabalho?

2 D Materiais de trabalho sólidos?

3 D Líquidos?

4 D Gases?

5 D Material de trabalho frágil?

6 D Material de trabalho flexível/elástico?

7 D Material de trabalho plástico?

8 D Material de trabalho extremamente sujo?

9 D Material de trabalho extremamente oleoso?

10 D Material de trabalho extremamente afiado

11 D Material de trabalho delicado e riscável?

12 D Material de trabalho facilmente deformável ou dobrável?

13 D Material de trabalho frágil ou rasgável?

14 D Trabalho com grânulos?

15 D Trabalho com material entrelaçado?

16 D Trabalho com objetos semelhantes a folha/lâmina? 
17 D Trabalho com partes planas ou blocos?

18 D Trabalho com barras ou rolos?

19 D Material de trabalho pequeno ou muito pequeno, manipulável com os dedos?

20 D Material de trabalho de tamanho médio, manipulável com as mãos?

21 D Material de trabalho grande ou muito grande, manipulável com as mãos, braços ou com o corpo todo ou por meio de equipamento manual?

22 D Material de trabalho de baixo peso, com menos de um quilo, manipulável com os dedos ou mãos?

23 D Material de trabalho de peso médio, de um a dez quilos, manipulável com as mãos?

24 D Material de trabalho com mais de dez quilos, manipulável por uma pessoa sem o auxílio de equipamento?

25 D Material de trabalho explosivo?

26 D Material de trabalho inflável?

27 D Material de trabalho cáustico ou intoxicante?

28 D Material de trabalho radioativo?

29 D Material de trabalho irritante da pele ou de mucosas?

30 D Material de trabalho que causa outros riscos à saúde?

31 D Indique a proporção de tempo durante o qual o controle de energia é o mais importante trabalho requerido do trabalhador.

32 D Indique a proporção de tempo durante o qual o trabalho do trabalhador envolve habilidades mentais.

33 D Indique a proporção de tempo durante o qual o trabalho do trabalhador ocupase diretamente com vidas humanas, animais ou plantas vivas como o mais importante objeto de trabalho.

\section{A - 2 - EQUIPAMENTOS DE TRABALHO}

$34 \mathrm{~S}$ Uso de instrumento de trabalho estacionário para produção, modelagem e remodelagem de material

$35 \mathrm{~S}$ Uso de instrumento de trabalho estacionário para separar, abrandar e limpar o material 
$36 \mathrm{~S}$ Uso de instrumento de trabalho estacionário para combinar, ligar, revestir e transformar materiais

37 S Uso de instrumento de trabalho manualmente operável para a transformação de materiais

$38 \mathrm{~S}$ Uso de instrumento de trabalho dirigíveis para transformação de materiais

$39 \mathrm{~S}$ Uso de instrumento de trabalho móvel para modelar ou remodelar materiais

40 S Uso de instrumento de trabalho móvel para separar, abrandar e limpar e cortar materiais

$41 \mathrm{~S}$ Uso de instrumento de trabalho móvel para unir e revestir materiais

42 S Uso de instrumento de trabalho para transformação de energia

43 S Uso de instrumento de trabalho estacionário para transformação de informação

$44 \mathrm{~S}$ Instrumento de trabalho usado para organizar

$45 \mathrm{~S}$ Uso de instrumentos de trabalho fixos ou móveis tendo como objeto de trabalho seres humanos, animais ou plantas vivas

$46 \mathrm{~S}$ Uso de transportadores contínuos

$47 \mathrm{~S}$ Uso de guindaste ou máquinas elevatórias

$48 \mathrm{~S}$ Uso de equipamento móvel manualmente operado

49 S Condução e operação de facilidades de transporte motorizadas

50 S Condução e operação de outras facilidades motorizadas móveis

$51 \mathrm{~S}$ Uso de outros equipamentos de trabalho

$52 \mathrm{~S}$ Uso de elementos de controle acionáveis com os dedos

$53 \mathrm{~S}$ Uso de controles manualmente acionáveis

$54 \mathrm{~S}$ Uso de controles acionáveis com os pés

55 F Acionamento de chaves/interruptores de serviço com uma ou duas possibilidades

56 F Acionamento de chaves/interruptores de serviço com três ou mais possibilidades

57 F Uso de teclados

$58 \mathrm{~F}$ Uso de elementos de controle para ajustamento contínuo

59 F Uso de dispositivos de medição

$60 \mathrm{~S}$ Uso de outros instrumentos para reconhecimento do estado

$61 \mathrm{~S}$ Uso de auxiliares técnicos para ajudar os órgãos sensoriais 
62 E Cadeira de trabalho

1 assento totalmente ajustável

2 assento não ajustável

3 banquinho

4 suporte

5 sem assento

63 E Descanso para os pés

0 ajustável

2,5 não ajustável

$5 \mathrm{sem}$

64 E Mesa de trabalho

0 ajustável em altura e ângulo de posição

1 não ajustável

5 sem

65 E Descanso de braços

0 ajustável

2,5 não ajustável

$5 \mathrm{sem}$

66 E Número de pessoas trabalhando no espaço do escritório

0 não se aplica

1 local de trabalho para um

2 local de trabalho para dois

3 local de trabalho para três a seis

4 local de trabalho para sete a trinta

5 local de trabalho para mais de trinta

67 E Número de pessoas trabalhando na oficina ou armazém

0 não se aplica

1 local de trabalho para um

2 local de trabalho para dois

3 local de trabalho para três a seis

4 local de trabalho para sete a trinta

5 local de trabalho para mais de trinta 
68 E Tamanho da sala de trabalho (metro quadrado)

0 não se aplica

1 menos que doze

2 doze a trinta

3 trinta e um a noventa

4 noventa e um a quatrocentos e cinqüenta metros

5 mais de quatrocentos e cinqüenta metros

69 E Outros locais de trabalho

0 não se aplica

1 definido, local de trabalho móvel dentro de uma planta ou oficina

2 definido, local de trabalho móvel fora da planta

3 indefinido, local de trabalho móvel dentro da planta

4 indefinido, local de trabalho móvel fora da planta

5 definidos, locais de trabalho múltiplos

\section{A - 3 AMBIENTE DE TRABALHO}

70 E Efeitos desfavoráveis da iluminação

Extensão do estresse

Duração do estresse

Proporção de oito horas de trabalho

$$
1 / 10<\mathrm{t} \leq 1 / 3 \quad 1 / 3<\mathrm{t} \leq 2 / 3 \quad \mathrm{t}>2 / 3
$$

Iluminação adequada sem contrastes 0

desfavoráveis

Iluminação quase adequada, com possível

1

2

ocorrência de efeitos desfavoráveis

Iluminação inadequada 
71 E Condições climáticas desfavoráveis

$$
\begin{aligned}
& \text { Duração do estresse } \\
& \text { Proporção de oito horas de trabalho } \\
& 1 / 10<t \leq 1 / 3 \quad 1 / 3<t \leq 2 / 3 \quad t>2 / 3
\end{aligned}
$$

Os fatores climáticos individuais (temperatura do ar, umidade, fluxo de ar, calor radiante) estão totalmente adaptados à dureza do trabalho e às vestimentas necessárias, permitindo o trabalho sobre condições desfavoráveis

A adaptação dos elementos climáticos individuais, dureza do trabalho e necessidade de vestimentas varia apenas desprezivelmente de um valor termal neutro

12

A adaptação dos elementos climáticos individuais, dureza do trabalho e roupas necessárias variam significativamente de um valor termal neutro

$$
\begin{array}{llll}
2 & 3 & 4
\end{array}
$$

Considerando a dureza do trabalho a ser analisado e as roupas necessárias, as condições climáticas da sala estão perto do limite de tolerância superior

72 E Vibrações mecânicas (do corpo todo ou das extremidades superiores)

Extensão do estresse

Proporção de oito horas de trabalho

$$
1 / 10<t \leq 1 / 3 \quad 1 / 3<t \leq 2 / 3 \quad t>2 / 3
$$

Sem vibração

Vibrações com pequenas amplitudes e de baixas freqüências além da freqüência natural dos órgãos internos (4 a 8 Hz influêncial vertical ou 1 a 2 Hz influência horizontal)

$\begin{array}{llll} & 1 & 2 & 3 \\ \text { Vibração de aceleração média } & 2 & 3 & 4\end{array}$

Vibração de aceleração extrema de freqüência perto das freqüências naturais dos órgãos internos (vibração do corpo todo, vibração na posição sentada sem qualquer absorção pelas juntas) 
73 E Ruído

Extensão do estresse

$$
\begin{aligned}
& \text { Duração do estresse } \\
& \text { Proporção de oito horas de trabalho } \\
& 1 / 10<\mathrm{t} \leq 1 / 3 \quad 1 / 3<\mathrm{t} \leq 2 / 3 \quad \mathrm{t}>2 / 3
\end{aligned}
$$

Intensidade do som, freqüência e duração do estresse pelo ruído sem efeito significativo

0

Nível de pressão sonora significativamente abaixo do nível sonoro admissível

1

2

3

Nível de pressão sonora alcança o nível sonoro admissível

2

3

4

Nível de pressão sonora acima do valor admitido

3

4

74 D Baixa ou alta pressão

75 D Substâncias químicas, gases, poeiras

76 D Inconveniências devido a odores ruins

$77 \mathrm{D}$ Ambiente de trabalho sujo ou molhado

78 D Influências atmosféricas (tempo que trabalha ao ar livre)

79 D Impedimento por roupas de proteção e/ou equipamentos de proteção

80 D Perigos no trabalho

0 não se aplica

1 muito pequeno

2 pequeno

3 médio

4 grande

5 extremo

81 D Ocorrência de doenças ocupacionais

0 não se aplica

1 muito pequeno

2 pequeno

3 médio

4 grande

5 extremo 
82 A Regularidade das horas de trabalho

83 E Sistemas de turnos

1 um único turno de trabalho

2 trabalho em dois turnos

3 trabalho em três turnos

4 outro sistema de turnos

84 A Trabalho noturno (ao menos metade do tempo de trabalho é das 22 às 6 horas)

85 E Sistema de turnos alternantes

0 não se aplica

1 mensalmente ou mais infrequentemente

2 mais que uma vez por mês

3 semanalmente

4 mais que uma vez por semana

5 diariamente

86 A Sistema de turno contínuo incluindo finais de semana

87 A Continuidade do trabalho (sem mudanças o ano todo)

88 E Horário de início pela manhã

0 não se aplica

1 depois de $8 \mathrm{~h}$

2 depois das $7 \mathrm{~h}$ e até as $8 \mathrm{~h}$

3 depois das $6 \mathrm{~h}$ e até as $7 \mathrm{~h}$

4 depois das $5 \mathrm{~h}$ e até as $6 \mathrm{~h}$

$55 \mathrm{~h}$ ou mais cedo

89 E Horário de término a tarde/noite

0 não se aplica

1 até as $16 \mathrm{~h}$

2 depois das $16 \mathrm{~h}$ e até as $18 \mathrm{~h}$

3 depois das $18 \mathrm{~h}$ e até as $20 \mathrm{~h}$

4 depois das $20 \mathrm{~h}$ e até as $22 \mathrm{~h}$

5 depois das $22 \mathrm{~h}$

90 A Horário de trabalho flexível

91 E Tempo adicional de horas regulares de trabalho (horas extras por semana) 
0 não se aplica

1 máximo de 2 horas

2 mais de 2 e máximo de 4 horas

3 mais de 4 e máximo até 6 horas

4 mais de 6 e máximo de 9 horas

5 mais de 9 horas

92 E Número total de horas semanais de trabalho (sem horas extras)

1 até 21 horas

2 mais de 21 até 25 horas

3 mais de 25 até 30 horas

4 mais de 30 até 40 horas

5 mais de 40 horas

93 E Número de pausas longas (maior ou igual a 5 minutos)

0 Não se aplica

1 sem pausa (por ex., trabalho em tempo parcial)

2 uma

3 duas

4 mais que duas

94 E Duração total do tempo de pausa (se variar conforme o turno, usar a de maior duração)

1 mais que 90 minutos

261 a 90 minutos

331 a 60 minutos

416 a 30 minutos

515 minutos ou menos

95 E Paradas obrigatórias devido a interferência de tempo

0 não se aplica

11 a 2 por 8 horas de trabalho

2 de 3 a 8 por 8 horas de trabalho

3 de 1 a 6 por hora

4 de 7 a 12 por hora

5 mais de 12 por hora 
96 E Duração total da parada obrigatória devido ao tempo de parada da máquina 0 não se aplica

15 minutos por 8 horas de turno

26 a 15 minutos por 8 horas de turno

316 a 30 minutos por 8 horas de turno

431 a 60 minutos por 8 horas de turno

97 E Seqüências de operações

0 não se aplica

1 sistemas de trabalho similares são agrupados juntos num mesmo local

2 trabalho segue o princípio de fluxo (os sistemas individuais de trabalho são arranjados de acordo com o processo de trabalho)

3 trabalho com controle automático de seqüência de operações

4 trabalho segue outros princípios de produção

98 A Trabalho individual (realizado por uma só pessoa)

99 A Lugar de trabalho único (as tarefas de trabalho estão relacionadas a um único local de trabalho)

100 E Estrutura de trabalho

1 muito pouca estrutura restringindo (free-lance)

2 pouca estrutura restringindo (cientista)]

3 estrutura restritiva média (professor, trabalho administrativo)

4 estrutura restritiva forte (seqüência amplamente pré-determinada de tarefas)

5 estrutura restritiva muito forte ( seqüência precisamente pré-determinada de tarefas)

101 E Número total de empregados sob responsabilidade do trabalhador (direta e indiretamente)

0 não se aplica

110 ou menos empregados

211 a 50 empregados

351 a 250 empregados

4251 a 750 empregados

5751 ou mais empregados 
102 E Número de supervisores subordinados ao trabalhador pelos quais ele é responsável e aos quais ele tem autoridade para dar instruções

0 não se aplica

11 ou 2 supervisores

23 ou 4 supervisores

35 ou 6 supervisores

47 ou 8 supervisores

59 ou mais supervisores

103 E Exercendo autoridade sobre pessoas que não tenham funções gerenciais

0 não se aplica

11 a 4 empregados

25 a 8 empregados

39 a 12 empregados

413 a 16 empregados

517 ou mais empregados

104 A Exercendo função de assistente (atuando como conselheiro técnico, não dá instruções mas tem responsabilidade direta)

105 S Responsabilidade e autoridade instrucional através de pessoas não empregadas pela organização empregadora

106 E Tipo de instrução dada ao trabalhador

0 nenhuma instrução em relação à tarefa é necessária porque o nível de complexidade do trabalho é muito pequeno e o trabalho é muito repetitivo

1 instrução precisa sobre a tarefa é dada previamente à execução da tarefa

2 instruções precisas sobre a tarefa e instruções gerais à sua execução são dadas previamente à execução da tarefa

3 são dadas instruções exclusivamente sobre as tarefas (o modo do trabalho a ser executado é deixado para o trabalhador)

4 muito pouca instrução de tarefa é dada

5 sem instruções de tarefa 
$107 \mathrm{E}$ Teste de qualidade do produto ou trabalho feito (classifique o tipo de teste de qualidade feito)

0 não se aplica

1 o trabalhador pode influenciar a qualidade do produto mas não é feito teste/avaliação

2 o próprio trabalhador checa o resultado

3 o resultado é checado dentro do grupo ou departamento dos colegas do trabalhador

4 a execução da tarefa e o resultado são completamente controlados ou checados por um supervisor no departamento

5 o resultado é checado por alguém de fora do departamento do trabalhador

108 E Tipo de função gerencial do trabalhador

0 não se aplica

1 gerenciamento direto

2 supervisão direta

3 dirige e coordena vários grupos de trabalho cada um com seu próprio líder

4 gerencia uma parte substancial da organização

5 gerencia uma organização inteira

109 E Extensão da responsabilidade por acidentes

0 não se aplica

1 muito restrita

2 restrita

3 média

4 significante

5 muito significante

110 E Responsabilidade pela prevenção de danos a materiais e deterioração na qualidade

0 não se aplica

1 muito restrita

2 restrita

3 média

4 alta 
5 muito alta

111 E Responsabilidade por perda de tempo

0 não se aplica

1 muito restrita

2 restrita

3 média

4 alta

5 muito alta

112 E Responsabilidade por valores abstratos

0 não se aplica

1 muito restrita

2 restrita

3 média

4 alta

5 extrema

113 F Contato com pessoas no maior ou mais alto grau gerencial

114 F Contato com pessoas no nível gerencial subordinado

$115 \mathrm{~F}$ Contato com grupo de supervisores subordinados

$116 \mathrm{~F}$ Contato com pessoas que não tem função gerencial

117 F Conflitos que podem se originar da posição do empregado na organização

118 F Conflitos que podem se originar de contato com pessoas não empregadas na organização

$119 \mathrm{~F}$ Estresse que pode ter origem em conflito do empregado com padrões sociais

120 A Remuneração por estatuto

121 A Remuneração por acordo industrial

122 A Remuneração por acordo entre a representação dos trabalhadores e o empregador

123 A Remuneração por contrato individual de trabalho

124 A Classificação pelo nível educacional do empregado

125 A Classificação pelas exigências do trabalho

126 A Classificação por mérito

127 A Outros métodos de classificação 
128 E Pagamento de promoções e salários

0 não se aplica

1 diariamente

2 semanalmente

3 mensalmente

4 anualmente

5 outras forma de pagamento (ex.: comissão paga irregularmente)

129 A Avaliação sumária do trabalho

130 A Avaliação analítica do trabalho

131 E Número de grupos de salários

0 sem grupos

1 até 3 grupos

2 de 4 a 7 grupos

3 de 8 a 11 grupos

4 de 12 a 15 grupos

5 mais de 15 grupos

132 E Remuneração por anos de idade

0 sem gradação por idade

1 máximo alcançado para a idade de 20 anos

2 máximo alcançado para a idade entre 21 e 30 anos

3 máximo alcançado para a idade entre 31 e 40 anos

4 máximo alcançado para a idade entre41 e 50 anos

5 máximo alcançado após os 50 anos de idade

133 E Remuneração por tempo de serviço na empresa

0 sem gradação por tempo de serviço

1 máximo alcançado após 1 a 5 anos de serviço

2 máximo alcançado após 6 a 10 anos de serviço

3 máximo alcançado após 11 a 15 anos de serviço

4 máximo alcançado após 16 a 20 anos de serviço

5 máximo alcançado após mais que 21 anos de serviço

134 A Remuneração por outros métodos de gradação

135 A Trabalho por produção 
136 A Remuneração segundo a quantia de trabalho por unidade de tempo

137 A Remuneração segundo esquema de fator único

138 A Remuneração segundo esquema multifatorial

139 A Outros métodos de remuneração baseados no mérito

140 A Remuneração com avaliação sistemática de mérito

141 A Compensações financeiras dadas por trabalho em turno, trabalho aos sábados, domingos e feriados e horas extras

142 A Benefícios dados por condições de trabalho ruins

143 A Extras voluntários (subsídios para despesas de viagens, etc.)

B - ANÁLISE DA TAREFA

Tarefas principalmente relacionadas a objetos materiais de trabalho

$144 \mathrm{~S}$ Ajuste e preparo do objeto de trabalho

$145 \mathrm{~S}$ Transporte

146 S Inserção

147 S Processamento (manual ou por meio de ferramentas)

148 S Ajuste, montagem e medição

149 S Operação e controle de máquinas e equipamentos

$150 \mathrm{~S}$ Montagem e desmontagem de peças por uso das mãos ou de ferramentas

151 S Organização de objetos de trabalho

152 S Alimentação e retirada de objetos e materiais de trabalho

$153 \mathrm{~S}$ Desempenho de operações manuais simples

154 S Avaliação de qualidade, valor e condição

$155 \mathrm{~S}$ Checagem da qualidade ou quantidade de objetos de acordo com padrões definidos

156 S Monitoragem, observação contínua de máquinas, etc.

Tarefas relacionadas principalmente ao processamento de informações e planejamento

157 S Planejamento e organização

158 S Codificação e decodificação de informação

159 S Transcrição da informação

160 S Organização e classificação 
161 S Combinação de informação (inclui síntese e integração de dados)

162 S Análise de informação ou de dado

163 S Contagem (simples soma de processos e eventos)

164 S Utilização de matemática

Tarefas relacionadas principalmente a outras pessoas

165 S Apresentação em público

$166 \mathrm{~S}$ Avaliação do comportamento humano

167 S Assistência, atendimento, cuidado

$168 \mathrm{~S}$ Entretenimento

$169 \mathrm{~S}$ Aconselhamento

170 S Negociação

171 S Instrução e treinamento

172 S Entrevista

173 E Número de operações dentro das tarefas gerais

11 a 3 operações

24 a 6 operações

37 a 9 operações

410 a 12 operações

5 mais de 12 operações

174 E Tempo do ciclo da operação relacionada à tarefa primária

0 não se aplica (sem repetição existente ou visível)

1 tempo de mais de 45 minutos

2 tempo de ciclo de 45 a 5 minutos

3 tempo de ciclo de 5 a 2 minutos

4 tempo de ciclo de 2 a 1 minutos

5 tempo de ciclo de menos de 1 minuto

C - ANÁLISE DAS EXIGÊNCIAS DO TRABALHO

Dimensões da percepção: recepção visual da informação

$175 \mathrm{~S}$ Estrutura e padrões

176 S Cores

177 S Tamanho e forma 
178 S Posição

179 S Quantidade e número

$180 \mathrm{~S}$ Velocidade de montagem dos objetos

Recepção da informação via senso de audição

181 S Padrões de som

182 S Diferentes sons e vibrações

183 S Audição direcionada

Recepção da informação via senso de toque e termossensores da pele

184 S Maciez e dureza

$185 \mathrm{~S}$ Aspereza e maciez

186 S Estímulo climático

Recepção da informação via senso de olfato ou senso gustativo

187 S Quão significante é a informação que entra via senso de olfato ou senso gustativo

Entrada de informação proprioceptiva

188 S Quão significante é a recepção de um estímulo interno

189 A Julgamento absoluto da informação que entra sem uso de amostras ou escalas comparáveis

190 A Julgamento relativo da informação que entra com uso de amostras ou escalas comparáveis

191 E Acurácia requerida e precisão da informação que entra

1 muito pequena

2 pequena

3 média

4 alta

5 extrema

192 E Complexidade da decisão

1 muito pequena

2 pequena

3 média

4 alta

5 extrema 
193 E Urgência de decisão

1 muito pequena

2 pequena

3 média

4 alta

5 extrema

194 E Educação geral (não adaptável as categorias utilizadas para a realidade brasileira)

195 E Educação profissional

0 não se aplica (suficiente treinamento de 14 dias)

1 treinamento de até 1 ano e 6 meses

2 aprendizagem completa (trabalhador experimentado)

3 diploma de escola técnica

4 diploma de escola profissional

5 educação universitária

196 E Experiência profissional requerida para execução do trabalho

0 não se aplica

11 mês ou menos

2 mais que 1 mês e até 6 meses

3 mais que 6 meses e até 1 anos

4 mais que 1 ano e até 3 anos

5 mais que 3 anos

197 E Conhecimento de línguas estrangeiras

0 não se aplica

1 conhecimento muito pequeno

2 conhecimento pequeno

3 conhecimento médio

4 conhecimento extensivo

5 conhecimento muito extensivo

198 S Exigência de um treinamento profissional avançado

199 S Conhecimento de instruções especiais para a ação

200 D Posição de trabalho sentado, normal 
201 D Posição de trabalho sentado, curvado

202 D Posição de trabalho em pé, normal

203 D Posição de trabalho ajoelhado, agachado, ou levantando curvado

204 D Posição de trabalho consiste em levantar-se consideravelmente curvado

205 D Dedos, mãos e antebraço (trabalho muscular sem apoiar o peso do corpo, apertar e reter objetos, digitação)

206 D Braço, ombro e costas (trabalho muscular sem apoiar o peso do corpo: carregar, abraçar e levantar objetos, operar britadeira)

207 D Pernas e pés (trabalho muscular com suporte do peso do corpo, como operar máquinas por meio de pedais)

208 D Uso de ambos os braço com suporte dos músculos da parte superior do corpo

209 D Uso de ambas as perna com apoio dos músculos da pelve

210 D Uso do sistema dedos-mãos (inclui o uso de ambas as mãos)

211 D Uso do sistema mãos-braços (inclui o uso de ambos os braços com apoio dos músculos da parte superior das costas)

212 D Usos do sistema pés-pernas (inclui o uso de ambas as pernas)

213 D Aplicação de força para trabalho estático

0 não de aplica

1 muito pequena

2 pequena

3 média

4 alta

5 muito alta

214 E Aplicação de força para trabalho dinâmico pesado

0 não de aplica

1 muito pequena

2 pequena

3 média

4 alta

5 muito alta 
215 E Aplicação de força para trabalho ativo leve

0 não de aplica

1 muito pequena

2 pequena

3 média

4 alta

5 muito alta

216 E Freqüência de movimentos para trabalho ativo leve

0 não de aplica

1 muito pequena

2 pequena

3 média

4 alta

5 muito alta 


\section{ANEXO XI - TERMO DE CONSENTIMENTO}

Declaro que eu, , concordo em participar voluntariamente de uma ou mais etapas da pesquisa científica sobre satisfação e saúde no trabalho, pesquisa esta que tem como objetivo estudar como a satisfação no trabalho pode colaborar para a saúde dos trabalhadores, e que vem sendo realizada sob responsabilidade de MARIA CARMEN MARTINEZ, mestranda da Faculdade de Saúde Pública da Universidade de São Paulo.

Estou ciente de que os meus resultados pessoais são confidenciais e que serão utilizados somente para fins de pesquisa. Autorizo a divulgação do resultado individual somente para minha pessoa e o resultado coletivo para divulgação pública.

Estou ciente, também, que tenho liberdade de opção para participar ou não da pesquisa, e que posso a qualquer momento abandonar o estudo, sem qualquer prejuízo pessoal ou do trabalho.

Assinatura

São Paulo, de de 2001. 


\section{ANEXO XII - CRONOGRAMA DE TRABALHO}

\begin{tabular}{|c|c|c|c|c|c|c|c|}
\hline ATIVIDADE & $\begin{array}{c}\text { Jan/ } \\
01\end{array}$ & $\begin{array}{c}\text { Fev/ } \\
01\end{array}$ & $\begin{array}{c}\text { Mar/ } \\
01\end{array}$ & $\begin{array}{c}\text { Abr/ } \\
01\end{array}$ & $\begin{array}{c}\text { Mai/ } \\
01\end{array}$ & $\begin{array}{c}\text { Jun/ } \\
\text { 01 }\end{array}$ & $\begin{array}{c}\mathrm{Jul} / \\
\mathbf{0 1}\end{array}$ \\
\hline $\begin{array}{l}\text { Definição das estratégias para coleta e } \\
\text { análise de dados }\end{array}$ & & & & & & & \\
\hline $\begin{array}{l}\text { Entrega do projeto de pesquisa à } \\
\text { Comissão de Ética e Comissão da Pós- } \\
\text { Graduação }\end{array}$ & & & & $\bullet$ & & & \\
\hline Atualização da revisão bibliográfica & & & & $\bullet \bullet$ & & & \\
\hline Organização do banco de dados & & & & trat & & & \\
\hline $\begin{array}{l}\text { Apresentação do projeto de pesquisa à } \\
\text { Gerência da Divisão Saúde }\end{array}$ & - & & & & & & \\
\hline $\begin{array}{l}\text { Apresentação do projeto de pesquisa à } \\
\text { Diretoria da Empresa }\end{array}$ & & & & & & & \\
\hline $\begin{array}{l}\text { Apresentação do projeto de pesquisa às } \\
\text { Chefias da empresa }\end{array}$ & & & & & & & \\
\hline Realização dos pré-testes & & & & & $\bullet$ & & \\
\hline $\begin{array}{l}\text { Apresentação do projeto de pesquisa aos } \\
\text { empregados e aplicação do questionário }\end{array}$ & & & & & & & \\
\hline ATIVIDADE & $\begin{array}{c}\text { Ago/ } \\
01\end{array}$ & $\begin{array}{c}\text { Set/ } \\
01\end{array}$ & $\begin{array}{c}\text { Out/ } \\
\text { 01 }\end{array}$ & $\begin{array}{c}\text { Nov/ } \\
01\end{array}$ & $\begin{array}{c}\text { Dez/ } \\
01\end{array}$ & $\begin{array}{c}\text { Jan/ } \\
\mathbf{0 2}\end{array}$ & $\begin{array}{c}\text { Fev/ } \\
02\end{array}$ \\
\hline Atualização da revisão bibliográfica & $\bullet \bullet$ & & $\bullet$ & & & & \\
\hline Realização das entrevistas & $\bullet \bullet \bullet$ & & & & & & \\
\hline Realização das análises ergonômicas & $\bullet \bullet \bullet \bullet$ & $\bullet \bullet \bullet$ & $\bullet \bullet \bullet \bullet$ & $\bullet$ & & & \\
\hline Digitação dos dados & $\bullet \bullet \bullet \bullet$ & & & $\bullet \bullet$ & & & \\
\hline Análise dos dados & $\bullet \bullet \bullet$ & $\bullet$ & 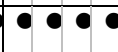 & $\bullet \bullet$ & & & \\
\hline $\begin{array}{l}\text { Devolução dos resultados individuais } \\
\text { dos questionários aos empregados }\end{array}$ & & & & & • & & \\
\hline $\begin{array}{l}\text { Devolução dos resultados coletivos à } \\
\text { Diretoria da empresa }\end{array}$ & & & & & & & $\bullet$ \\
\hline $\begin{array}{l}\text { Devolução dos resultados coletivos às } \\
\text { Chefias }\end{array}$ & & & & & & & $\bullet$ \\
\hline $\begin{array}{l}\text { Devolução dos resultados coletivos aos } \\
\text { empregados }\end{array}$ & & & & & & & \\
\hline $\begin{array}{l}\text { Elaboração da discussão, redação do } \\
\text { texto final }\end{array}$ & & & & & & & - \\
\hline
\end{tabular}




\section{ANEXO XIII - DISTRIBUIÇÃO DOS NÍVEIS DE SATISFAÇÃO NO TRABALHO}

Distribuição do número e porcentagem de empregados segundo nível da satisfação e aspecto do trabalho, Fundação CESP, 2001.

\begin{tabular}{|c|c|c|c|c|c|c|c|c|c|c|c|c|c|c|}
\hline \multirow{3}{*}{$\begin{array}{c}\text { Aspecto do } \\
\text { trabalho }\end{array}$} & \multicolumn{14}{|c|}{ Nível de satisfação } \\
\hline & \multicolumn{2}{|c|}{$\begin{array}{c}\text { Enorme } \\
\text { insatisfação }\end{array}$} & \multicolumn{2}{|c|}{$\begin{array}{c}\text { Muita } \\
\text { insatisfação }\end{array}$} & \multicolumn{2}{|c|}{$\begin{array}{c}\text { Alguma } \\
\text { insatisfação }\end{array}$} & \multicolumn{2}{|c|}{$\begin{array}{c}\text { Alguma } \\
\text { satisfação }\end{array}$} & \multicolumn{2}{|c|}{$\begin{array}{c}\text { Muita } \\
\text { satisfação }\end{array}$} & \multicolumn{2}{|c|}{$\begin{array}{c}\text { Enorme } \\
\text { satisfação }\end{array}$} & \multicolumn{2}{|c|}{ Total } \\
\hline & $\mathbf{N}^{\mathbf{o}}$ & $\%$ & $\mathbf{N}^{\mathbf{o}}$ & $\%$ & $\mathbf{N}^{\circ}$ & $\%$ & $\mathbf{N}^{\circ}$ & $\%$ & $\mathbf{N}^{\circ}$ & $\%$ & $\mathbf{N}^{\mathbf{o}}$ & $\%$ & $\mathbf{N}^{0}$ & $\%$ \\
\hline Comunicação & 1 & 0,4 & 14 & 6,3 & 66 & 29,5 & 105 & 46,9 & 33 & 14,7 & 5 & 2,2 & 224 & $\overline{100,0}$ \\
\hline Relacionamento & - & - & - & - & 9 & 4,0 & 49 & 21,9 & 130 & 58,0 & 36 & 16,1 & 224 & 100,0 \\
\hline Avaliação & 7 & 3,1 & 11 & 4,9 & 46 & 20,5 & 84 & 37,5 & 65 & 29,0 & 11 & 4,9 & 224 & 100,0 \\
\hline Conteúdo & - & - & 2 & 0,9 & 20 & 8,9 & 58 & 25,9 & 115 & 51,3 & 29 & 12,9 & 224 & 100,0 \\
\hline Motivação & 2 & 0,9 & 7 & 3,1 & 25 & 11,2 & 89 & 39,7 & 74 & 33,0 & 27 & 12,1 & 224 & 100,0 \\
\hline Carreira & 10 & 4,5 & 28 & 12,5 & 59 & 26,3 & 74 & 33,0 & 38 & 17,0 & 15 & 6,7 & 224 & 100,0 \\
\hline Segurança & 8 & 3,6 & 11 & 4,9 & 56 & 25,0 & 81 & 36,2 & 62 & 27,7 & 6 & 2,7 & 224 & 100,0 \\
\hline Imagem & - & - & 6 & 2,7 & 19 & 8,5 & 102 & 45,5 & 82 & 36,6 & 15 & 6,7 & 224 & 100,0 \\
\hline Supervisão & 6 & 2,7 & 10 & 4,5 & 42 & 18,8 & 75 & 33,5 & 72 & 32,1 & 19 & 8,5 & 224 & 100,0 \\
\hline Mudança & 2 & 0,9 & 15 & 6,7 & 73 & 32,6 & 92 & 41,1 & 34 & 15,2 & 8 & 3,6 & 224 & 100,0 \\
\hline Tarefas & - & - & 9 & 4,0 & 28 & 12,5 & 99 & 44,2 & 76 & 33,9 & 12 & 5,4 & 224 & 100,0 \\
\hline Crescimento & 6 & 2,7 & 19 & 8,5 & 42 & 18,8 & 72 & 32,1 & 61 & 27,2 & 24 & 10,7 & 224 & 100,0 \\
\hline Conflitos & - & - & 12 & 5,4 & 69 & 30,8 & 95 & 42,4 & 42 & 18,8 & 6 & 2,7 & 224 & 100,0 \\
\hline Aspirações & 8 & 3,6 & 24 & 10,7 & 55 & 24,6 & 78 & 34,8 & 48 & 21,4 & 11 & 4,9 & 224 & 100,0 \\
\hline Decisões & 9 & 4,0 & 19 & 8,5 & 72 & 32,1 & 77 & 34,4 & 35 & 15,6 & 12 & 5,4 & 224 & 100,0 \\
\hline Potencialidades & 7 & 3,1 & 16 & 7,1 & 54 & 24,1 & 96 & 42,9 & 45 & 20,1 & 6 & 2,7 & 224 & 100,0 \\
\hline Flexibilidade & - & - & 6 & 2,7 & 26 & 11,6 & 78 & 34,8 & 91 & 40,6 & 23 & 10,3 & 224 & 100,0 \\
\hline Clima & 13 & 5,8 & 25 & 11,2 & 67 & 29,9 & 80 & 35,7 & 27 & 12,1 & 12 & 5,4 & 224 & 100,0 \\
\hline Salário & 15 & 6,7 & 31 & 13,8 & 56 & 25,0 & 61 & 27,2 & 50 & 22,3 & 11 & 4,9 & 224 & 100,0 \\
\hline Estrutura & 5 & 2,2 & 15 & 6,7 & 59 & 26,3 & 84 & 37,5 & 55 & 24,6 & 6 & 2,7 & 224 & 100,0 \\
\hline Volume & - & - & 14 & 6,3 & 43 & 19,2 & 82 & 36,6 & 72 & 32,1 & 13 & 5,8 & 224 & 100,0 \\
\hline Desenvolvimento & 2 & 0,9 & 10 & 4,5 & 34 & 15,2 & 96 & 42,9 & 70 & 31,3 & 12 & 5,4 & 224 & 100,0 \\
\hline
\end{tabular}




\section{ANEXO XIV - TESTE DE NORMALIDADE DAS VARIÁVEIS}

Teste de normalidade das variáveis quantitativas contínuas por meio do teste de Kolmogorov-Smirnov, Fundação CESP, 2001.

\begin{tabular}{lc}
\hline \multicolumn{1}{c}{ Variável } & p \\
\hline Idade & 0,500 \\
Satisfação no trabalho & $0,518^{*}$ \\
Capacidade funcional & 0,000 \\
Aspectos físicos & 0,000 \\
Dor & 0,002 \\
Estado de saúde geral & 0,001 \\
& 0,007 \\
Aspectos sociais & 0,000 \\
Aspectos emocionais & 0,000 \\
Saúde mental & 0,001 \\
Índice de capacidade para o trabalho & 0,001
\end{tabular}

* $\mathrm{p}>0,05$ : distribuição normal 


\title{
ANEXO XV - RESUMO DA DISTRIBUIÇÃO DOS RESULTADOS DA ANÁLISE ERGONÔMICA DO TRABALHO
}

\author{
Percentual de indivíduos em situação de pior exposição às fontes de estresse
}

\begin{tabular}{|c|c|c|c|c|}
\hline Item analisado & $\begin{array}{c}\text { Insati- } \\
\text { feitos }\end{array}$ & $\begin{array}{l}\text { Satis- } \\
\text { feitos }\end{array}$ & Total & $\mathbf{p}$ \\
\hline \multicolumn{5}{|l|}{1 - Análise do sistema de trabalho } \\
\hline $\begin{array}{l}\text { Grande duração de tempo (mais que } 60 \% \text { do período de trabalho) } \\
\text { utilizando habilidades mentais }\end{array}$ & 83,3 & 82,6 & 83,3 & $0,64^{\mathrm{F}}$ \\
\hline $\begin{array}{l}\text { Grande duração de tempo (mais que } 60 \% \text { do período de trabalho) } \\
\text { ocupando-se diretamente com vidas humanas }\end{array}$ & 11,1 & 5,9 & 8,6 & $0,52^{\mathrm{F}}$ \\
\hline \multicolumn{5}{|l|}{1.2 - Equipamentos } \\
\hline $\begin{array}{l}\text { Grande importância no uso de instrumentos estacionários para } \\
\text { transformação da informação (em especial computador) }\end{array}$ & 100,0 & 94,1 & 97,2 & $0,48^{\mathrm{F}}$ \\
\hline $\begin{array}{l}\text { Grande importância no uso de instrumentos para organização } \\
\text { (telefone, papel, caneta, fotocopiadoras, e outros) }\end{array}$ & 66,7 & 76,4 & 71,5 & $0,39^{\mathrm{F}}$ \\
\hline Freqüência alta no uso de teclados & 83,4 & 58,8 & 71,4 & $0,10^{\mathrm{F}}$ \\
\hline Cadeira de trabalho não ajustável & -- & 5,9 & 2,9 & $0,48^{\mathrm{F}}-$ \\
\hline Mesa de trabalho não ajustável & 94,4 & 94,1 & 94,3 & $0,74^{\mathrm{F}}$ \\
\hline Ausência de descanso para os braços & 66,7 & 58,8 & 62,9 & 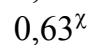 \\
\hline Grande número de pessoas trabalhando no mesmo espaço físico & 88,9 & 64,7 & 77,1 & $0,10^{\mathrm{F}}$ \\
\hline $\begin{array}{l}\text { Outros locais de trabalho fora da planta da empresa (múltiplos e/ou } \\
\text { indefinidos) }\end{array}$ & 11,2 & 23,5 & 17,1 & $0,30^{\mathrm{F}}$ \\
\hline \multicolumn{5}{|l|}{$\begin{array}{l}1.3 \text { - Ambiente de trabalho (físico, organizacional e } \\
\text { remuneração) }\end{array}$} \\
\hline Exposição prolongada e/ou intensa à iluminação desfavorável & -- & -- & -- & \\
\hline $\begin{array}{l}\text { Exposição prolongada e/ou intensa à condições climáticas } \\
\text { desfavoráveis }\end{array}$ & -- & -- & -- & \\
\hline Exposição prolongada e/ou intensa à ruído & -- & -- & -- & \\
\hline Trabalho em turnos & -- & -- & -- & \\
\hline Horário de início do trabalho após $7 \mathrm{~h} 00$ & 100,0 & 100,0 & 100,0 & \\
\hline Horário de término do trabalho após $20 \mathrm{~h} 00$ & 100,0 & 100,0 & 100,0 & \\
\hline Acima de 6 horas extras semanais & 27,8 & 41,2 & 34,3 & 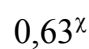 \\
\hline $\begin{array}{l}\text { Número de horas semanais de trabalho (sem horas extras) entre } 30 \\
\text { e } 40 \text { horas }\end{array}$ & 94,4 & 94,1 & 94,3 & $0,74^{\mathrm{F}}$ \\
\hline $\begin{array}{l}\text { Menos que } 2 \text { pausas longas (cinco minutos ou mais) por dia } \\
\text { (excluído horário de almoço) }\end{array}$ & 33,4 & 41,2 & 37,1 & $0,63^{x}$ \\
\hline Pausa para almoço inferior a 60 minutos & 5,6 & 5,9 & 5,7 & $0,74^{\mathrm{F}}$ \\
\hline Seqüência de operações com controle automático ou fluxo rígido & -- & -- & -- & \\
\hline Estrutura de trabalho restritiva forte ou muito forte & 11,1 & 11,8 & 11,4 & $0,67^{\mathrm{F}}$ \\
\hline Responsabilidade por grande número de empregados (50 ou mais) & -- & 11,8 & 5,7 & $0,23^{\mathrm{F}}$ \\
\hline Responsabilidade por 7 ou mais pessoas com nível de chefia & -- & 5,9 & 2,9 & $0,23^{\mathrm{F}}$ \\
\hline Exercendo função de assessoria técnica & 27,8 & 35,3 & 31,4 & 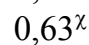 \\
\hline $\begin{array}{l}\text { Responsabilidade significativa sobre pessoas não empregadas da } \\
\text { empresa }\end{array}$ & 5,6 & 17,6 & 11,5 & $0,28^{\mathrm{F}}$ \\
\hline $\begin{array}{l}\text { Recebimento de instruções precisas sobre a tarefa e a forma como } \\
\text { deve ser executada }\end{array}$ & 22,2 & 23,5 & 22,9 & $0,62^{\mathrm{F}}$ \\
\hline Controle de qualidade formal sobre o trabalho & 22,2 & 23,6 & 22,8 & $0,62^{\mathrm{F}}$ \\
\hline
\end{tabular}

$F=$ teste de associação pelo teste exato de Fischer

$\chi=$ teste de associação pelo $\chi^{2}$ 


\begin{tabular}{|c|c|c|c|c|}
\hline Item analisado & $\begin{array}{l}\text { Insati- } \\
\text { feitos }\end{array}$ & $\begin{array}{l}\text { Satis- } \\
\text { feitos }\end{array}$ & Total & $\mathbf{p}$ \\
\hline Exercendo função gerencial sobre parte substancial da empresa & -- & 11,8 & 5,7 & $0,23^{\mathrm{F}}$ \\
\hline Responsabilidade significativa sobre acidentes & -- & 11,8 & 5,7 & $0,23^{\mathrm{F}}$ \\
\hline Responsabilidade significativa sobre danos materiais & -- & 11,8 & 5,7 & $0,23^{\mathrm{F}}$ \\
\hline Responsabilidade significativa sobre perda de tempo & 55,5 & 52,9 & 54,3 & $0,88^{x}$ \\
\hline Responsabilidade significativa sobre valores abstratos & 66,6 & 82,3 & 74,3 & $0,25^{\mathrm{F}}$ \\
\hline $\begin{array}{l}\text { Freqüência alta de contato com pessoas de alto nível gerencial } \\
\text { (Diretoria) }\end{array}$ & 5,6 & 23,5 & 14,3 & $0,15^{\mathrm{F}}$ \\
\hline $\begin{array}{l}\text { Freqüência alta de contato com pessoas de nível gerencial } \\
\text { intermediário (Gerentes) }\end{array}$ & 22,2 & 41,2 & 31,4 & $0,23^{x}$ \\
\hline $\begin{array}{l}\text { Freqüência alta de contato com pessoas de nível de nível gerencial } \\
\text { menor (Supervisão / Chefia) }\end{array}$ & 66,7 & 64,7 & 65,7 & $0,90^{x}$ \\
\hline Freqüência alta de contato com pessoas sem nível gerencial & 100,0 & 87,3 & 91,4 & $0,10^{\mathrm{F}}$ \\
\hline $\begin{array}{l}\text { Freqüência significativa de potencial de conflito na relação com } \\
\text { pessoas da empresa }\end{array}$ & 22,2 & 11,8 & 17,1 & $0,36^{\mathrm{F}}$ \\
\hline $\begin{array}{l}\text { Freqüência significativa de potencial de conflito no relacionamento } \\
\text { com pessoas não empregadas da empresa }\end{array}$ & 38,9 & 23,5 & 25,7 & $0,54^{\mathrm{F}}$ \\
\hline $\begin{array}{l}\text { Freqüência de estresse que pode ter origem em conflitos com } \\
\text { padrões sociais }\end{array}$ & 38,9 & 5,9 & 22,8 & $0,02^{\mathrm{F}}$ \\
\hline Classificação salarial de acordo com nível educacional & 83,3 & 82,4 & 82,9 & $0,64^{\mathrm{F}}$ \\
\hline Classificação/promoção salarial por mérito (avaliação anual) & 100,0 & 100,0 & 100,0 & \\
\hline Remuneração inferior a 12 salários mínimos & 50,0 & 64,7 & 57,1 & $0,34^{x}$ \\
\hline \multicolumn{5}{|l|}{2 - Análise da tarefa } \\
\hline 2.1- Análise relacionada ao objeto de trabalho material & -- & -- & -- & \\
\hline \multicolumn{5}{|l|}{2.2 - Análise relaciona ao objeto de trabalho abstrato } \\
\hline Significância alta ou muito alta uso de planejamento e organização & 88,8 & 88,2 & 88,5 & $0,67^{\mathrm{F}}$ \\
\hline Significância alta ou muito alta uso de codificação de informações & 50,0 & 47,1 & 48,6 & $0,86^{\chi}$ \\
\hline Significância alta ou muito alta uso de transcrição de informações & 77,8 & 76,5 & 77,1 & $0,62^{\mathrm{F}}$ \\
\hline $\begin{array}{l}\text { Significância alta ou muito alta uso de organização e classificação } \\
\text { de informações }\end{array}$ & 72,3 & 64,7 & 68,6 & $0,63^{x}$ \\
\hline $\begin{array}{l}\text { Significância alta ou muito alta uso de combinação e síntese de } \\
\text { informações }\end{array}$ & 72,2 & 76,5 & 74,3 & $0,54^{\mathrm{F}}$ \\
\hline Significância alta ou muito alta uso de análise de informações & 83,3 & 70,6 & 77,2 & $0,31^{\mathrm{F}}$ \\
\hline $\begin{array}{l}\text { Significância alta ou muito alta uso de matemática simples } \\
\text { (contagem) }\end{array}$ & 50,0 & 70,6 & 60,0 & $0,21^{x}$ \\
\hline $\begin{array}{l}\text { Significância alta ou muito alta uso de matemática avançada } \\
\text { (estatística ou financeira) }\end{array}$ & 44,4 & 29,4 & 37,1 & $0,36^{x}$ \\
\hline \multicolumn{5}{|l|}{2.3 - Tarefas relacionadas à pessoas } \\
\hline Importância significativa na realização de apresentação em público & 16,7 & 35,2 & 25,7 & $0,19^{\mathrm{F}}$ \\
\hline Importância significativa na avaliação do comportamento humano & 33,4 & 41,2 & 37,2 & $0,63^{x}$ \\
\hline Importância significativa na assistência, atendimento e cuidado & 16,7 & 11,8 & 14,3 & $0,52^{\mathrm{F}}$ \\
\hline Importância significativa no aconselhamento & 27,8 & 29,4 & 28,5 & $0,60^{\mathrm{F}}$ \\
\hline Importância significativa na negociação & 44,5 & 47,1 & 45,7 & $0,88^{x}$ \\
\hline Importância significativa na instrução e treinamento & 11,1 & 23,5 & 17,2 & $0,30^{\mathrm{F}}$ \\
\hline Importância significativa na realização de entrevistas & 5,6 & 17,7 & 11,5 & $0,28^{\mathrm{F}}$ \\
\hline
\end{tabular}

$F=$ teste de associação pelo teste exato de Fischer

$\chi=$ teste de associação pelo $\chi^{2}$ 


\begin{tabular}{l}
\hline Item analisado \\
\hline \hline 3 - Análise das demandas
\end{tabular}

\section{1 - Demandas de percepção}

Grande acurácia e precisão requeridas na informação que entra

\section{2-Demandas de decisão}

Grande complexidade na tomada de decisão

Grande urgência na tomada de decisão

Necessidade de nível educacional profissionalizante ou universitário

Experiência profissional anterior requerida com duração de um ano ou mais

Conhecimento extensivo de línguas estrangeiras

Exigência de um treinamento profissional avançado

Importância significativa de conhecimento de instruções especiais para ação

\section{3 - Demandas de postura / atividade}

Grande parte do tempo de trabalho ( $60 \%$ ou mais) em posição sentada normal

Grande parte do tempo de trabalho ( $60 \%$ ou mais) realizando esforço muscular de dedos, mãos e antebraço (em especial, digitação)

Grande parte do tempo de trabalho ( $60 \%$ ou mais) realizando trabalho muscular com braço, ombro e costas
Insati- Satis- Total p

feitos feitos

$100,0 \quad 100,0 \quad 100,0$

$61,1 \quad 41,2 \quad 51,4 \quad 0,17^{x}$

$72,2 \quad 52,9 \quad 62,9 \quad 0,46^{x}$

$50,0 \quad 41,2 \quad 45,7 \quad 0,60^{x}$

$38,9 \quad 64,7 \quad 51,4 \quad 0,13^{x}$

$\begin{array}{llll}-- & 5,9 & 2,9 & 0,48^{\mathrm{F}}\end{array}$

$\begin{array}{llll}22,2 & 29,4 & 25,7 & 0,46^{\mathrm{F}}\end{array}$

$44,5 \quad 41,1 \quad 42,9 \quad 0,85^{x}$

$94,4 \quad 82,4 \quad 88,6 \quad 0,28^{\mathrm{F}}$

$38,9 \quad 29,4 \quad 34,3 \quad 0,55^{x}$

$11,2 \quad 11,8 \quad 11,5 \quad 0,65^{\mathrm{F}}$

$F=$ teste de associação pelo teste exato de Fischer

$\chi=$ teste de associação pelo $\chi^{2}$ 